VILNIUS GEDIMINAS TECHNICAL UNIVERSITY

Andrius ČEPONIS

\title{
RESEARCH OF PIEZOELECTRIC ENERGY HARVESTING SYSTEMS BASED ON CANTILEVERS WITH IRREGULAR CROSS-SECTIONS
}

DOCTORAL DISSERTATION

TECHNOLOGICAL SCIENCES,

MECHANICAL ENGINEERING (09T)

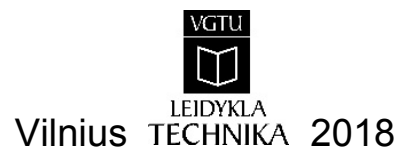


Doctoral dissertation was prepared at Vilnius Gediminas Technical University in 2014-2018.

\section{Supervisor}

Prof. Dr Dalius MAŽEIKA (Vilnius Gediminas Technical University,

Mechanical Engineering - 09T).

The Dissertation Defense Council of Scientific Field of Mechanical Engineering of Vilnius Gediminas Technical University:

\section{Chairman}

Prof. Dr Vytautas TURLA (Vilnius Gediminas Technical University, Mechanical Engineering - 09T).

Members:

Prof. Dr Mindaugas JUREVIČIUS (Vilnius Gediminas Technical University, Mechanical Engineering - 09T),

Assoc. Prof. Dr Artūras KILIKEVIČIUS (Vilnius Gediminas Technical University, Mechanical Engineering - 09T),

Prof. Dr Habil. Vytautas OSTAŠEVIČIUS (Kaunas University of Technology, Mechanical Engineering - 09T),

Dr Jens TWIEFEL (Leibniz University Hannover, Germany, Mechanical Engineering - 09T).

The dissertation will be defended at the public meeting of the Dissertation Defence Council of Mechanical Engineering in the Senate Hall of Vilnius Gediminas Technical University at 10 a. m. on 15 November 2018.

Address: Sauletekio al. 11, LT-10223 Vilnius, Lithuania.

Tel.: +370 5274 4956; fax +370 5270 0112; e-mail: doktor@vgtu.lt

A notification on the intend defending of the dissertation was send on 12 October 2018.

A copy of the doctoral dissertation is available for review at VGTU repository http://dspace.vgtu.lt and at the Library of Vilnius Gediminas Technical University (Saulètekio al. 14, LT-10223 Vilnius, Lithuania).

VGTU leidyklos TECHNIKA 047-M mokslo literatūros knyga

ISBN 978-609-476-137-9

(C) VGTU leidykla TECHNIKA, 2018

(C) Andrius Čeponis, 2018

andrius.ceponis@vgtu.lt 
VILNIAUS GEDIMINO TECHNIKOS UNIVERSITETAS

Andrius ČEPONIS

\section{GEMBINIŲ PJEZOELEKTRINIŲ \\ ENERGIJOS SURINKIMO SISTEMŲ SU NETAISYKLINGAIS SKERSPJŪVIAIS TYRIMAS}

DAKTARO DISERTACIJA

TECHNOLOGIJOS MOKSLAI, MECHANIKOS INŽINERIJA (09T)

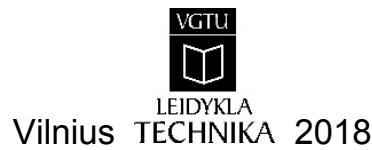


Disertacija rengta 2014-2018 metais Vilniaus Gedimino technikos universitete.

\section{Vadovas}

prof. dr. Dalius MAŽEIKA (Vilniaus Gedimino technikos universitetas, mechanikos inžinerija - 09T).

Vilniaus Gedimino technikos universiteto Mechanikos inžinerijos mokslo krypties disertacijos gynimo taryba:

\section{Pirmininkas}

prof. dr. Vytautas TURLA (Vilniaus Gedimino technikos universitetas, mechanikos inžinerija - 09T).

\section{Nariai:}

prof. dr. Mindaugas JUREVIČIUS (Vilniaus Gedimino technikos universitetas, mechanikos inžinerija - 09T),

doc. dr. Artūras KILIKEVIČIUS (Vilniaus Gedimino technikos universitetas, mechanikos inžinerija - 09T),

prof. habil. dr. Vytautas OSTAŠEVIČIUS (Kauno technologijos universitetas, mechanikos inžinerija - 09T),

dr. Jens TWIEFEL (Hanoverio Leibnico universitetas, Vokietija, mechanikos inžinerija - 09T).

Disertacija bus ginama viešame Mechanikos inžinerijos mokslo krypties disertacijos gynimo tarybos posėdyje $2018 \mathrm{~m}$. lapkričio $15 \mathrm{~d}$. 10 val. Vilniaus Gedimino technikos universiteto senato posèdžiu salèje.

Adresas: Saulètekio al. 11, LT-10223 Vilnius, Lietuva.

Tel.: (8 5) 274 4956; faksas (8 5) 270 0112; el. paštas doktor@vgtu.lt

Pranešimai apie numatomą ginti disertaciją išsiųsti $2018 \mathrm{~m}$. spalio $12 \mathrm{~d}$.

Disertaciją galima peržiūrèti VGTU talpykloje http://dspace.vgtu.lt ir Vilniaus Gedimino technikos universiteto bibliotekoje (Saulètekio al. 14, LT-10223 Vilnius, Lietuva). 


\section{Abstract}

A dissertation analyses the problems of increasing an output power of piezoelectric energy harvesters based on single cantilever and cantilever arrays.

The main aim of dissertation is to propose a method to increase an output energy density and power density of piezoelectric layer of cantilever type energy harvester by introducing irregular cross section of the cantilever and rigidly composed cantilevers in cantilever arrays.

The dissertation covers a review of the most relevant scientific literature, numerical and experimental investigations of piezoelectric energy harvesters based on cantilevers with different irregular cross-sections and cantilever arrays based on rigidly composed cantilevers.

The dissertation consist of introduction, three chapters, general conclusions, references, list of scientific publications published by the author of the topic of dissertation and three appendixes. The introduction covers problem relevance, formulation of the goals and objectives, introduces novelty of the dissertation and overviews the dissertation structure.

The first chapter describes background and motivation of mechanical vibrations energy harvesting, an overviews the main mechanical vibrations energy harvesting technologies and their operation principles.

The second chapter is related to numerical and experimental investigations of piezoelectric energy harvesters based on rectangular and trapezoidal cantilevers with irregular cross-sections. The cross-sections of cantilevers were modified by rectangular, cylindrical and trapezoidal gaps. Electrical and mechanical characteristics of the piezoelectric cantilevers were analysed while different shape gaps were used.

The third chapter presents numerical and experimental investigations of polygon type piezoelectric energy harvesters. Three different designs of the cantilever arrays introduced and investigated i. e. rectangular, saw-tooth and polygon type. The investigation reveals influence of rigidly composed cantilevers and irregular cross-sections to electrical and mechanical characteristics of the energy harvesting systems.

Seven scientific articles, related to the topic of the dissertation were published: 4 papers were published in journals with citation index and included to Clarivate Analytics Web of Science database, 1 paper was published in conference material book indexed in Clarivate Analytics Web of Science "Conference Proceedings" database, 2 papers were published in the journals included in other databases. The results of the dissertation were presented at 5 international conferences. 


\section{Reziumè}

Disertacijoje pateikiama pjezoelektrinių energijos surinkimo sistemų pagrịstų gembèmis ir gembių masyvais galios ir energijos didinimo problemas.

Pagrindinis disertacijos tikslas pasiūlyti pjezoelektrinių gembiu ir gembių masyvų pagrịstų susietomis gembèmis išejimo energijos tankio ir galios tankio didinimo metodus.

Disertacijoje pateikta mokslinès literatūros analizè, pristatyti skaitiniai ir eksperimentiniai, pjezoelektrinių gembių su netaisyklingais skerspjūviais ir pjezoelektrinių gembių masyvų pagristų standžiai susietomis gembèmis, tyrimai.

Disertaciją sudaro, ịvadas, trys skyriai, bendrosios išvados, naudotos literatūros ir autoriaus publikacijų disertacijos tema sąrašai ir trys priedai. Ivade apibrěžiamas problemos aktualumas, formuluojami tikslas ir uždaviniai, ịvardijamas disertacijos naujumas, apžvelgiama disertacijos struktūra ir disertacijos autoriaus publikacijos bei pranešimai konferencijose.

Pirmame skyriuje, remiantis moksline literatūra, aprašomi mechaninių vibracijų energijos surinkimo technologijų fundamentalūs pagrindai ir šių technologijų taikymo principai. Aprašomos pagrindinès mechaninių vibracijų energijos technologijomis pagrịstų keitiklių veikimo principai.

Antrame skyriuje pristatomi skaitinių ir eksperimentinių, pjezoelektrinių energijos surinkimo sistemų pagrịstų stačiakampèmis ir trapecinèmis gembėmis su netaisyklingais skerspjūviais, tyrimų rezultatai. Gembių skerspjūviai modifikuoti stačiakampėmis, cilindrinėmis ir trapecinėmis išpjovomis. Analizuojamos elektrinès ir mechaninès charakteristikos kai keitiklių skerspjūvis yra modifikuotas skirtingos formos išpjovomis.

Trečiame skyriuje pristatomi daugiakampių masyvų pagrịstų standžiai susietomis gembèmis skaitiniai ir eksperimentiniai tyrimai. Tyrimai apima triju skirtingų formų gembių masyvus t. y. stačiakampess, pjūklo ir daugiakampio formų. Tyrimų rezultatai atkleidžia standžiai susietų gembių ir netaisyklingos formos skerspjūvių įtaką elektrinèms ir mechaninėms šių energijos keitiklių charakteristikoms.

Disertacijos tema publikuoti 7 moksliniai straipsniai: 4 straipsniai publikuoti žurnaluose turinčiuose citavimo indeksą ir ịtrauktuose ị Clarivate Analytics Web of Science duomenų bazes, 1 straipsnis publikuotas leidinyje ịtrauktame ị Clarivate Analytics Web of Science "Conference Proceedings" duomenų bazę, 2 straipsniai publikuoti žurnaluose ịtrauktuose ị kitas duomenų bazes. Rezultatai, gauti rengiant disertaciją, pristatyti penkiose tarptautinėse konferencijose. 


\section{Notations}

\section{Symbols}

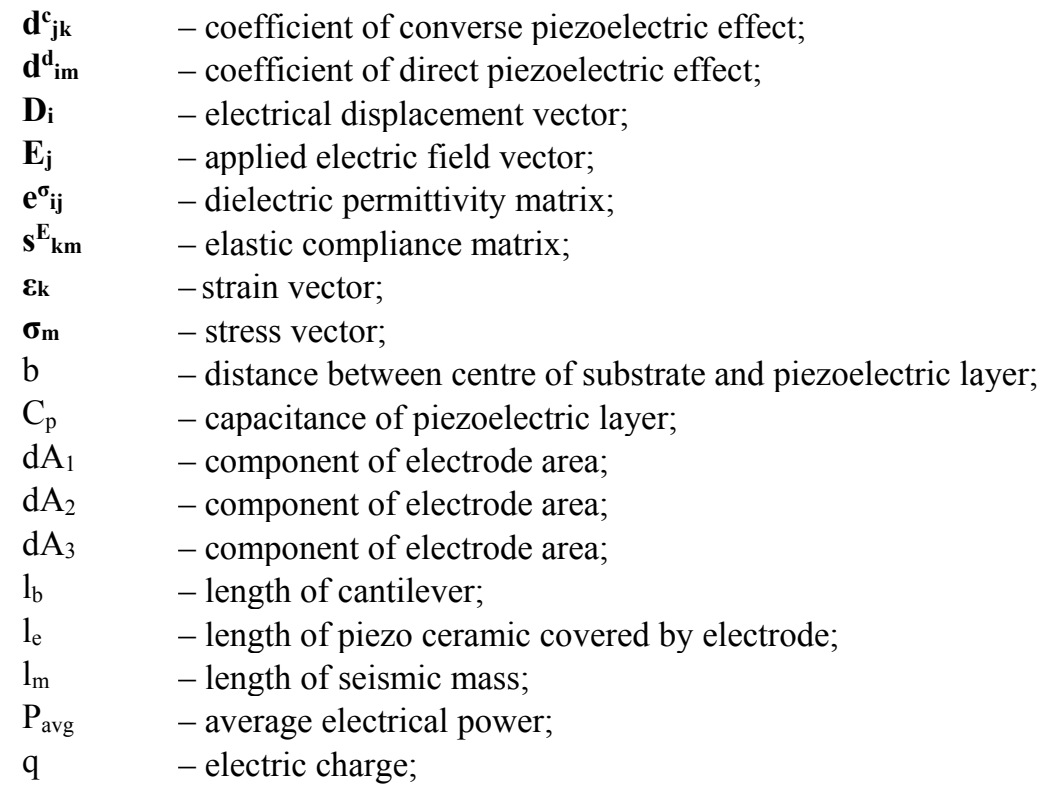




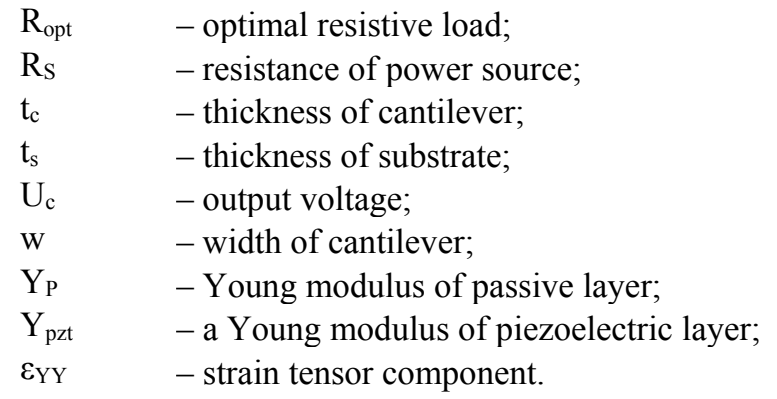

\section{Abbreviations}

EH - energy harvesting;

EMF - electromotive force;

FEM - finite element model;

MEMS - microelectromechanical system;

PVDF - polyvinylidene fluoride;

PZT - lead zirconate titanate;

WED - wireless electronic devices. 


\section{Contents}

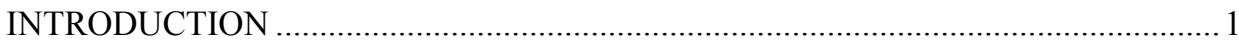

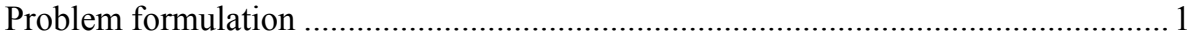

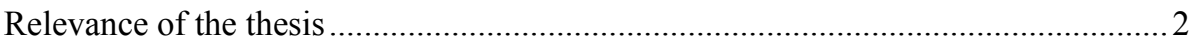

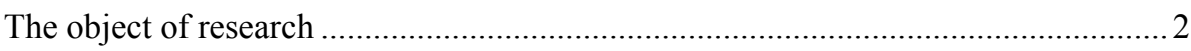

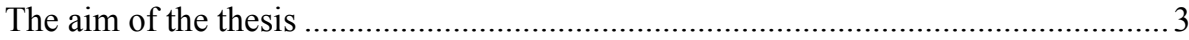

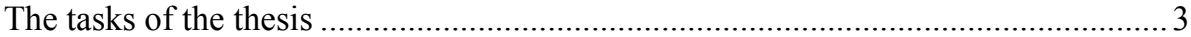

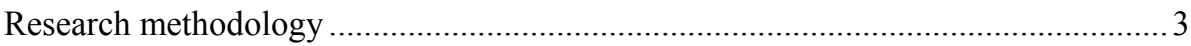

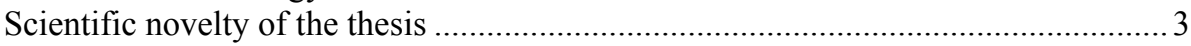

Practical value of the research findings ................................................................ 4

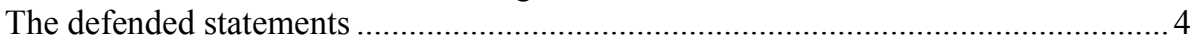

Approval of the research findings ........................................................................ 4

Structure of the dissertation................................................................................ 5

Acknowledgment …………………………………........................................ 5

1. A SURVEY OF ENERGY HARVESTING FROM

MECHANICAL VIBRATIONS .........................................................................

1.1. A concept of energy harvesting from mechanical vibrations .............................. 7

1.1.1. Energy harvesting of mechanical vibrations using

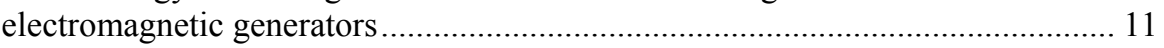

1.1.2. Energy harvesting of mechanical vibrations using

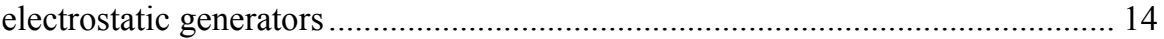

1.1.3. Energy harvesting of mechanical vibrations using piezoelectric generators ................................................................................. 16 
1.2. Piezoelectric energy harvesters: operation principle and designs......................20

1.2.1. Mathematical model of direct and converse piezoelectric effect................. 20

1.2.2. Mathematical model of cantilever type piezoelectric energy harvester....... 23

1.2.3. Cantilever based piezoelectric energy harvesters ................................... 28

1.2.3. Piezoelectric energy harvesters with frequency tuning option ................... 30

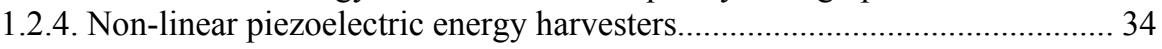

1.2.5. Multi-frequency piezoelectric energy harvesters.................................... 36

1.3. Conclusions of chapter 1 and formulating tasks for the dissertation .................. 40

2. CANTILEVER TYPE PIEZOELECTRIC ENERGY HARVESTERS WITH IRREGULAR CROSS-SECTIONS

2.1. Background of irregular cross-section designs.............................................. 41

2.2. Investigation of rectangular piezoelectric cantilevers with

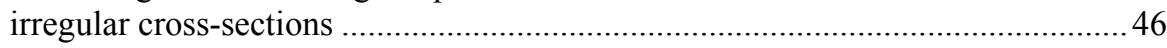

2.2.1. Designs of rectangular piezoelectric cantilevers with

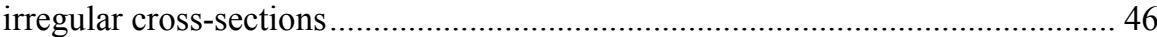

2.2.2. Numerical investigation of rectangular piezoelectric cantilevers with

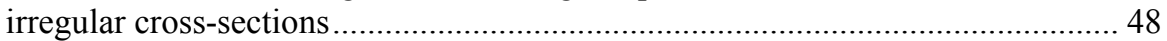

2.2.3. Experimental investigation of rectangular cantilevers with

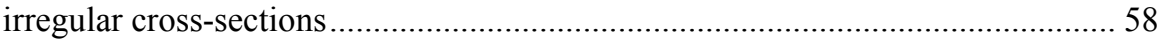

2.3. Investigation of trapezoidal piezoelectric cantilevers with

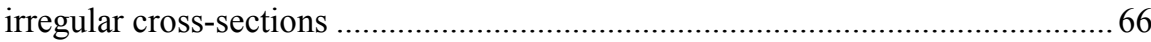

2.3.1. Designs of trapezoidal piezoelectric cantilevers with irregular crosssections

2.3.2. Numerical investigation of trapezoidal cantilevers with irregular cross-sections

2.3.3. Experimental investigation of trapezoidal cantilevers with

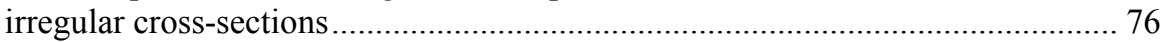

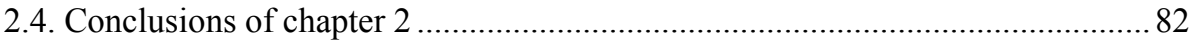

3. PIEZOELECTRIC MULTI-FREQUENCY ENERGY HARVESTERS BASED ON LINKED CANTILEVER ARRAYS ........................................................... 83

3.1. A Square type piezoelectric cantilever array for multi-frequency energy

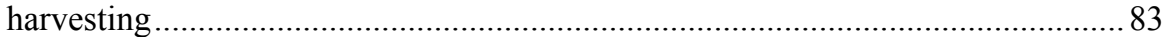

3.1.1. Design of the square type multi-frequency cantilever array ...................... 84

3.1.2. Numerical investigation of the square type multi-frequency

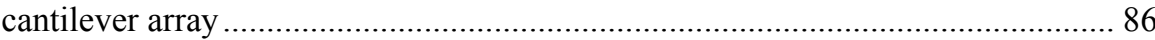

3.1.3. Experimental investigation of the square type multi-frequency

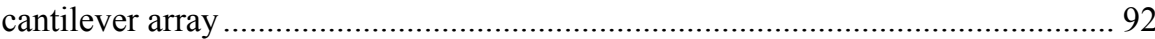

3.2. A piezoelectric saw-tooth cantilever array for multi-frequency energy harvesting

3.2.1. Design of the piezoelectric saw-tooth multi-frequency cantilever array.

3.2.2. Numerical investigation of the piezoelectric saw-tooth multi-frequency cantilever array 
3.2.3. Experimental investigation of the piezoelectric saw-tooth multi-frequency

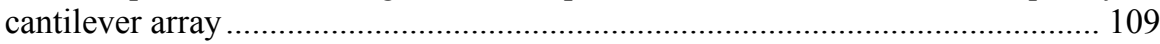

3.3. A piezoelectric polygon shape multi-frequency cantilever array ...................... 114

3.3.1. Design of the piezoelectric polygon shaped multi-frequency

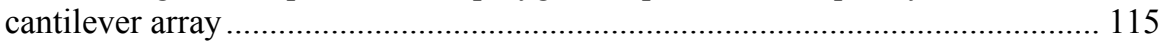

3.3.2. Numerical investigation of the piezoelectric polygon shaped multi-frequency cantilever array ..................................................................... 116

3.3.3. Experimental investigation of the piezoelectric polygon shaped multi-frequency cantilever array .................................................................. 123

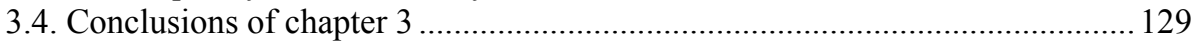

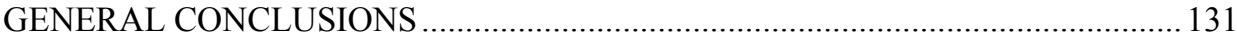

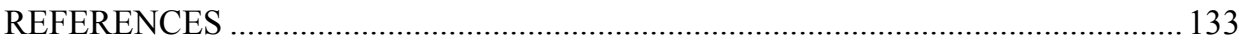

LIST OF SCIENTIFIC PUBLICATIONS BY THE AUTHOR ON THE TOPIC OF

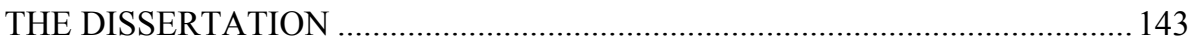

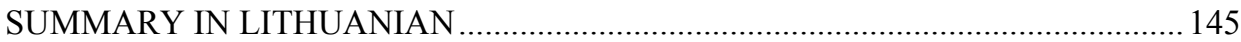

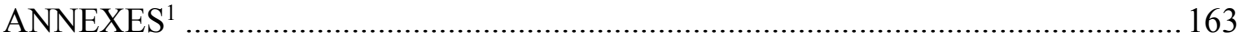

Annex A.The author's declaration of conscientiousness ...................................... 164

Annex B. Agreements of co-authors to provide published materials in the dissertation

Annex C. Copies of scientific publications published by the author on the topic

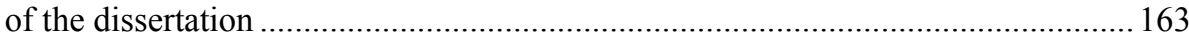

${ }^{1}$ The annexes are supplied in the enclosed compact disc 



\section{Introduction}

\section{Problem formulation}

Wireless sensors, autonomous electronic systems and modern health monitoring devices take huge part in nowadays life. Usually, such low power devices are employed to follow and control numerous physical parameters, store data and wirelessly transfer it. Therefore, a numerous application areas of wireless low power systems can be found. However, the main demerit of these systems is autonomous power supply implemented using conventional electro-chemical batteries. These type of batteries have short operation time, high service costs and are unfriendly to environment. Therefore, alternative power supply systems must be used. One of the most promising technology is mechanical vibrations energy harvesting based on piezoelectric transducers. Usually, this type of energy harvesting systems are made as different piezoelectric cantilevers. An effective usage of piezoelectric layer bonded to cantilever is the key factor defining characteristics of output power and energy densities for piezoelectric energy harvesters. In order to increase values of these characteristics, bending strain inducted in the cantilevers must be increased.

Conventional cantilever with regular cross-section has linearly decreasing strain function along the cantilever length that is the maximum strain value is obtained at the clamped end while the free end is unstrained. 
Such bending strain distribution along piezoelectric cantilever cause of low energy and power densities.

Single cantilever is able to provide an output power only at one excitation frequency. Therefore, multi-frequency piezoelectric energy harvesters, composed as cantilever arrays are used. However, the most of cantilever arrays suffer from low power and energy densities due to inefficient operation of whole system during variation of excitation frequency. Usually, only one cantilever of array operates at the highest efficiency at particular excitation frequency while the others are almost useless.

The dissertation focuses on investigations related to efficient exploitation of piezoelectric layer employed at energy harvesters based on single cantilever as well as cantilever arrays.

\section{Relevance of the thesis}

Development of a novel power supply technologies based on piezoelectric mechanical vibrations energy harvesting, can extend application areas of wireless and low power electronic systems. The piezoelectric mechanical vibrations energy harvesters are able to provide lifetime energy supply for various electronic devices. However, based on overview of the most recent researches it can be noticed that investigations, related to effective exploitation of piezoelectric layer, are highly relevant.

For nowadays, cantilever based energy harvesters are the most popular design for energy harvesting system. On the other hand, these energy harvesters suffers from inefficient usage of piezoelectric layer. Inefficient usage of piezoelectric layer is caused by uneven bending strain and it distribution characteristics. Therefore, investigations related to efficient usage of piezoelectric layer have notable scientific importance. Much deeper and extensive investigation in this area could have positive influence to electrical characteristics of piezoelectric energy harvesters as well as application of this mechanical vibrations energy harvesting technology.

\section{The object of research}

The object of this research is cantilever based piezoelectric energy harvesting systems. 


\section{The aim of the thesis}

The goal of the thesis is to propose design improvements for cantilever and polygon type piezoelectric energy harvesters in order to increase output power and energy densities.

\section{The tasks of the thesis}

In order to achieve the aim of the thesis, the following tasks have to be performed:

1. To review state of the art related to mechanical vibrations energy harvesting technologies focusing on piezoelectric type energy harvesting systems.

2. To propose a method for increasing output power and energy densities of piezoelectric cantilever and cantilever arrays by introducing irregular shape of cross sections and polygon type structures of linked cantilevers.

3. To investigate piezoelectric energy harvesters, based on cantilevers with irregular shape of cross section, to perform numerical and experimental studies, and evaluate their electrical characteristics.

4. Numerically and experimentally investigate mechanical and electrical characteristics of polygon type piezoelectric energy harvesters based on rigidly linked cantilevers.

\section{Research methodology}

The research methodology involves methods of comparative and literature analysis in order to investigate object of the research and review the state of art.

Theoretical studies of piezoelectric cantilevers and cantilever arrays were based on vibration theory and statistical methods. Numerical models were built and analysed by Comsol Multiphysics, LTspice, Origin and SolidWorks software.

The methods of experimental research have been used to validate results obtained numerically. Measurements of mechanical and electric characteristics of the prototypes were performed employing Polytec OFV 056 scanning vibrometer, Polytec PSV 500 3D scanning vibrometer, Keyence LK-G155 laser displacement sensor, Yokogawa DLM2000 mixed signal oscilloscope hardware.

\section{Scientific novelty of the thesis}

The scientific novelty of this research is specified as follows: 
1. Irregular cross-section design allows to increase electric energy and power densities of piezoelectric energy harvesters. Introduced irregular shapes of cross-sections allow to increase bending strains and to make more even bending strains distribution along cantilever.

2. Cantilevers rigidly composed to polygon shape arrays increases density of resonance frequencies in narrow frequency range, increase bending strain of cantilevers and provides higher electric power and energy densities.

\section{Practical value of the research findings}

Proposed irregular cross-section designs can be widely used to improve all types of piezoelectric energy harvesters based on single cantilevers as well as cantilever arrays. Moreover, polygon type cantilever arrays can be applied to develop new types of piezoelectric multi-frequency energy harvesters as well as to improve design of existing energy harvesters.

\section{The defended statements}

1. Irregular cross-section of piezoelectric cantilever passive layer ensures more even bending strain distribution along the length of the cantilever and increases output power and energy densities of piezoelectric layer more than 3.14 times compare to the conventional piezoelectric cantilever.

2. Cantilever arrays composed as indissoluble polygon type structure provide higher natural frequencies density at narrow frequency range and ensures higher values of total bending strain at the whole structure.

\section{Approval of the research findings}

Seven papers were published on the topic of the dissertation: 4 papers are published in journals with citation index and included to Clarivate Analytics Web of Science databases (Čeponis 2017a, 2017b, 2018a, 2018b), 1 paper was published in conference materials included to Clarivate Analytics Web of Science "Conference Proceedings" database (Čeponis, 2016), 2 papers are published in journals included to other databases (Čeponis, 2015, 2017c).

The author has made 5 presentations at 5 scientific conferences: 
1. International Conference "Mechanika-2016", Investigation of cantilever beam for piezoelectric energy harvesting. Kaunas, Lithuania.

2. The $12^{\text {th }}$ International Conference Mechatronic Systems and Materials, Investigation of trapezoidal cantilever beam for piezoelectric energy. Bialystok, Poland.

3. The $4^{\text {th }}$ International Academic Conference for Graduates, Investigation of piezoelectric cantilevers with improved energy harvesting efficiency. Nanjing, China.

4. The $13^{\text {th }}$ International Conference Mechatronic Systems and Materials, Multi-frequency piezoelectric energy harvester based on rhomb type cantilever array. Vilnius, Lithuania.

5. The $5^{\text {th }}$ International Academic Conference for Graduates, Multi-frequency piezoelectric energy harvester based on saw-tooth shape cantilever array. Nanjing, China.

\section{Structure of the dissertation}

The dissertation consist of the introduction, three chapters and general conclusions, the list of references and the list of publications published by the author on the topic of the dissertation and annexes.

Volume of the work is 132 pages excluding annexes, the text consist of 102 pictures, 47 numbered equations and 10 tables were used. 109 literature sources were referenced during preparation of the doctoral dissertation.

\section{Acknowledgment}

I would like to express my sincere gratitude to my scientific supervisor Prof. Dr Dalius Mažeika for the continuous support of my Ph.D studies, related research and perpetration of this thesis, for his patience, motivation, and immense knowledge. Prof. Dr Dalius Mažeika advices and mentoring motivated to move on and do not stop at achieved results. I could not have imagined having a better advisor and mentor. 



\section{1}

\section{A survey of energy harvesting from mechanical vibrations}

This chapter surveys technologies of energy harvesting from mechanical vibrations using electromagnetic, electrostatic and piezoelectric systems. Also, detail overview of piezoelectric energy harvesters are provided including design, mechanical and electrical characteristics of the most recent developed piezoelectric energy harvesting devices. On basis of survey presented in this chapter the main objective and tasks of the thesis were formulated. The survey presented in this chapter is based on papers Čeponis and Mažeika 2015, Čeponis et al. 2017 and Čeponis et al. 2018.

\subsection{A concept of energy harvesting from mechanical vibrations}

During the last decade, wireless, wearable and low power electronic systems have been develop extensively. An application of wireless electronic devices (WED) covers numerous fields of science, industry, engineering and daily life. In most cases, WED are powered by conventional electro-chemical batteries. Usage of the 
batteries causes short lifetime of the system, expensive maintenance cost and pollution of environment (Elvin and Erturk, 2013). Electro-chemical batteries can be changed by alternative energy sources as for example energy harvesting $(\mathrm{EH})$ systems. EH is a technique that captures, harvests, or scavenges a variety of unused ambient energy sources (e. g., solar, thermal, vibration, and wind) and converts the harvested energy into electrical energy to recharge the batteries or drive load directly. Compare to large-scale EH power stations with fixed location (solar farms, wind farms) portable EH systems harvest low scale energy (of the order of miliJoules). One of the advantages of the portable EH systems is that it can be easy installed in different, locations, configured and used as energy supply system for WED (Tan, 2012; Anton and Sodano, 2007).

Ambient energy sources are easily accessible in the environment and there is no need to make efforts to create these energy sources. As for example: in order to create electrical energy in conventional way we are burning fossil or timber based fuels (Priya and Inman, 2009; Thomas and et al. 2006). On the other hand, instead of conventional ways of electrical energy production we can harvest energy from environment. The main energy sources and EH technologies are given in Fig. 1.1.

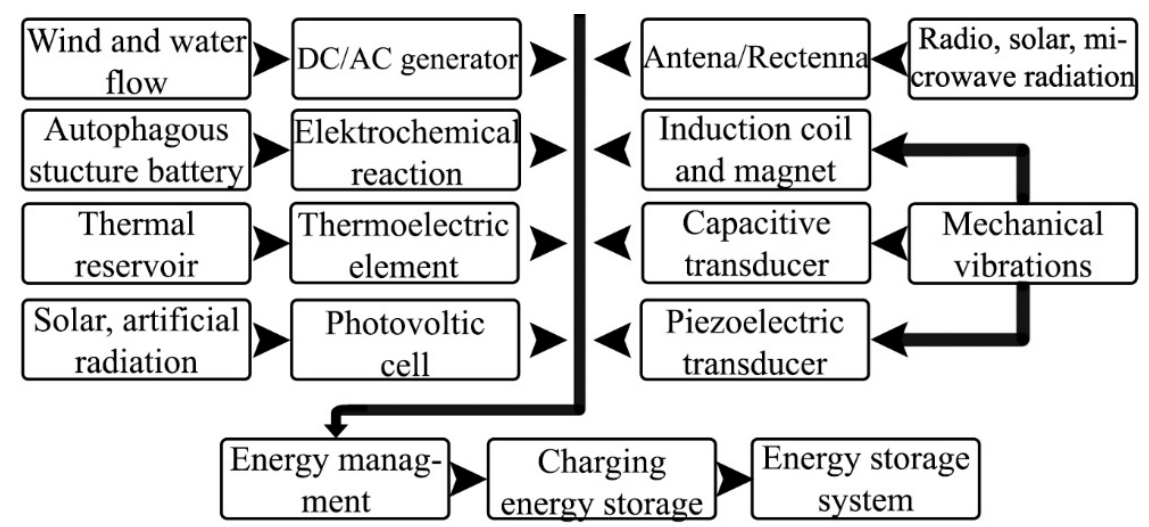

Fig. 1.1. Energy sources and energy harvesting systems (Thomas and et al. 2006)

All energy sources are listed in Fig. 1.1 are can be used for electrical energy production. However, technologies for energy harvesting are different and have some disadvantages. Wind and water flow, solar and artificial radiation energies can be harvester efficiency only at fixed location and high scale power plats. Thermal energy can be harvested from reservoir or bore with fixed locations. These disadvantages makes these EH technologies unsuitable to power WED systems, because of high scale or fixed EH systems locations. On the other hand, radio, 
solar, microwave radiation have no demand on fixed EH location. These energy sources can be harvested with mobile systems. However, in most cases, energy orbits are very low and can not provide suitable energy feed for WED systems. Hence, EH from mechanical vibrations are the most suitable to power low power systems. Firstly, EH devices are portable, small scale and has high power densities. In addition, these systems are able operate at different environments filled by mechanical vibrations. On basis of this we can conclude that EH of mechanical vibrations is the most universal and suitable for WED systems compare to other technologies (Thomas and et al. 2006).

Energy of mechanical vibrations is produced by mechanically vibrating devices such as cars, machine-tools, human and etc. This kind of energy can be harvested by using magnetic induction, capacitance induction or piezoelectricity. One of the advantage of mechanical vibrations energy is that it provides a possibility to be harvested without strict requirements of mounting location (Ahmed and et al. 2012).

For nowadays, harvesting of mechanical vibrations energy can provide permanent, low cost, lifetime, battery less power supply for WED. Moreover, EH technologies are environmentally friendly i. e. these technologies does not creates wastes during energy conversion process (Priya and Inman, 2009). Energy of mechanical vibrations harvested using three main EH technologies, that are based on energy conversion principles: electromagnetic, electrostatic and piezoelectric (Roundy and et al. 2004). The general block diagram, which represents energy harvesting flow chart given in Fig. 1.2.

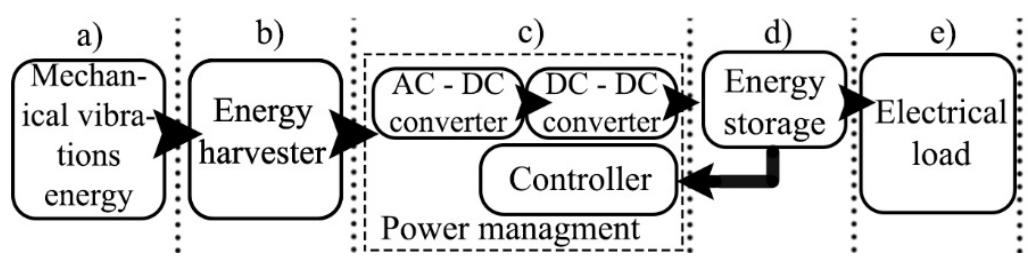

Fig. 1.2. General flow chart of energy harvester unit (Tan, 2012)

The EH of mechanical vibrations consist of five main components: source of the mechanical vibrations, transducer, converter, energy storage device and electrical load (Fig. 1.2). A body that is in periodic or non-periodic motion produces mechanical energy. Energy harvester is a transducer that converts energy of mechanical vibrations into electrical energy (Fig. 1.2 b). The power management circuit converts harvested electrical energy from its primary form into DC type (Fig. 1.2 c). Energy storage device (capacitor, battery and etc.) stores energy for 
further usage (Fig. 1.2 d). The electrical load can be WED as for instance wireless sensor, low power electronic device, low power transmitters and etc. (Fig. 1.2 e).

The flow chart given in Fig. 1.2 represents general operation principle of energy harvesting system. Fig. 1.1 shows that energy of mechanical vibrations can be harvested by systems with different energy conversion principles. In order to compare different EH systems, derivative power density units must be used. Such comparison is necessary to indicate the most suitable energy conversion principle for specific case. The power density represents output power ratio to harvester's active material volume. Such comparison could be made in order to indicate EH systems performance and possible power output (Roundy and et al. 2004).

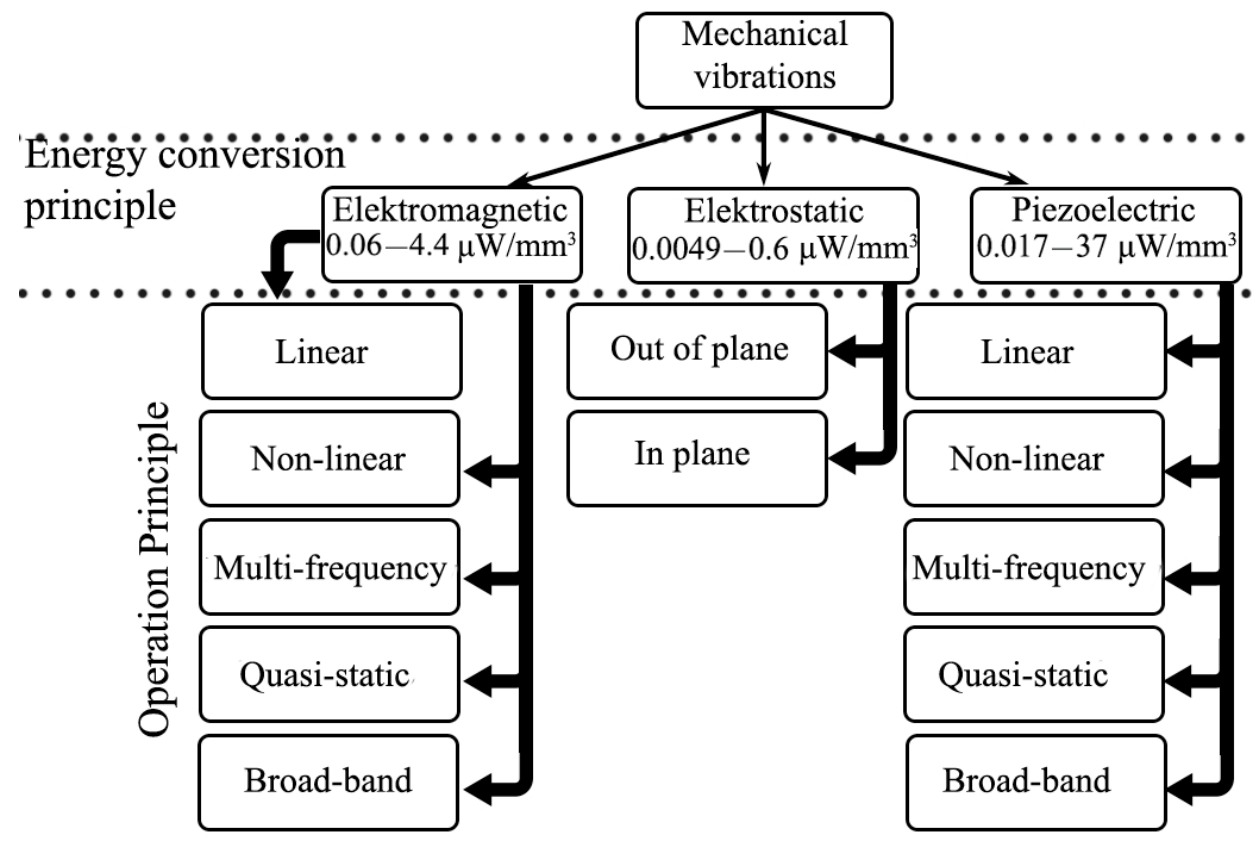

Fig. 1.3. Classification of mechanical vibration energy conversion principles and energy harvesters operation principles (Kazmierski and Beeby, 2011; Priya and Inman, 2009; Elvin and Erturk, 2013)

Operation principles of electromagnetic and piezoelectric energy harvesters is similar. Linear energy harvesters provides suitable energy feed only at resonance with host. Therefore, if frequency of host vibrations fluctuates, these energy harvesters has low or very low output power. Non-linear energy harvesters can be used instead of linear in order to improve frequency response characteristics of the system. However, effective frequency band is very narrow. Therefore, if frequency of host vibrations fluctuates in wide range, these energy harvester also 
becomes less effective. Multi-frequency energy harvesters, in most cases, are based on several linear harvesters composed to one system. Resonant frequencies of each EH systems part are located close to each other and covers much wider frequency band compare to non-linear energy harvester. Quasi-static energy harvesters operates in off resonance mode and generates stable but low output power. These energy harvesters are much stable compare to others.

Energy harvesters based on electrostatic energy conversion principle operates in different way as well and it is very difficult compare these devices to electromagnetic and piezoelectric (Kazmierski and Beeby, 2011). In addition, power density of energy harvester directly related to impedance of electrical load. Impedance matching between energy harvester and the electrical load is necessary to maximize the efficiency of energy harvesters (Hehm and Manoli, 2015).

It can be concluded that the main principle of mechanical vibrations energy harvesting is to convert kinetic energy of mechanical vibrations into electrical energy and to store it or supply it to electric device. Energy of mechanical vibrations can be harvested applying different energy conversion principles and using different operation principle of the harvester. The WED powered by EH systems able to operate in different environments filled by mechanical vibration energy (Priya and Inman, 2009).

\subsubsection{Energy harvesting of mechanical vibrations using electromagnetic generators}

Michael Faraday discovered electromagnetic induction in 1831. For nowadays, it is used to generate electric energy in different scales. Faraday's law of electromagnetic induction states that electrical current induces in any closed circuit when the magnetic flux moves through a surface bounded by the conductor changes. This applies whether the field itself changes in strength or the conductor moved through it. Therefore, it can be concluded that electromagnetic generators are based on coils and permanent magnets. These components are the main parts of electromagnetic generator. If permanent magnet or coil is fixed to the frame and is in motion, then electrical energy is generated. The relative displacement caused by movement makes the transduction mechanism to work and generate electrical energy. The induced voltage, also known as an electromotive force (EMF), across the coil is proportional to the strength of the magnetic field, the velocity of the relative motion and the number of turns of the coil. Electromagnetic generator is characterized by high output current and low voltage (Kazmierski and Beeby, 2011).

Majority of electromagnetic generators are based on rotational or linear movement of wind and hydroelectric turbines, steam turbines and etc. to smaller scale applications like generators to recharge automotive batteries and etc. The 
electromagnetic generators also used to harvest low power energy i. e. form micro to milli watts using both rotational and linear devices. Therefore, employment of these generators in harvesting of mechanical vibrations energy is possible as well (Priya and Inman, 2009).

The electromagnetic mechanical vibrations energy harvesters can be classified in three groups i. e. linear, non-linear and multi-frequency harvesters. Electromagnetic energy harvesters have simple design. Moreover, there is a possibility to combine electromagnetic, piezoelectric and electrostatic energy conversion principles into one device and to obtain hybrid type energy harvester (Hehm and Manoli, 2015).

The most common operating principle of electromagnetic energy harvesters is linear The highest efficiency of liner energy harvester can be obtained when it operates at particular excitation frequency. It means that harvester will generate the highest output power if resonant frequency of the harvester matches with the vibration frequency of the host. Reports related to linear electromagnetic energy harvesters are published by Amirtharajah and et al. (1998), El-Hami and et al. (2001), von Buren and Troster (2006), Beeby and et al. (2007) and Chae and et al. (2017) fully represents operation principle of these systems.

Moreover, numerous designs of linear electromagnetic energy harvesters adopted for microelectronic and microelectromechanical systems (MEMS) shows that this type of energy harvesters is suitable for micro-scale electronic systems and devices (Seree and et al. 2006; Wang and et al. 2009; Jiang and et al. 2011; Han and et al. 2014b; Saleem and et al. 2017). However, this type of energy harvesters have limits in scaling due to usage of coils (Harb, 2011).

Linear electromagnetic energy harvesters able to generate much higher energy scales in order to ensure energy feed for the systems with higher energy demands. For this purpose, linear electromagnetic energy absorbers and electromagnetic pendulum systems. can be used (Zou and et al. 2010; Gonzalez-Buelga and et al, 2015; Satpute and et al. 2017, Ding and et al. 2016; Lee and Chung, 2016; Yurchenko and Alevras, 2018).

In most cases, linear electromagnetic energy harvesters are second order spring-mass systems. Taking into account that electrical characteristics of the discussed energy harvesters directly related to the relative displacement i. e. velocity between coil and permanent magnet, it can conclude that the highest electrical outputs will be achieve at the resonant frequency of the system. In order to obtain the best electrical performance of linear electromagnetic energy harvester, the excitation frequency must coincidence with resonant frequency of energy harvester. This is main disadvantage of the harvester and it reduce application field of such type of energy harvesters. 
Non-linear electromagnetic energy harvesters provide possibility to harvest mechanical vibrations energy in wider frequency spectrum. Therefore, it is possible to exploit this feature to maximize the harvestable energy where the host vibration frequency changes in time (Cammarano and et al. 2011). Hence, non-linear operation of harvester ensures more effective mechanical vibration energy harvesting at wider frequency spectrum. As a result, it leads to more adaptive characteristics of electromagnetic energy harvesters. There are different research of non-linear electromagnetic energy harvesters performed by Cammarano and et al. (2011), Bradai and et al. (2015) and Khan and et .al. (2014). The most authors concluded that implementation of non-linear behaviour of electromagnetic energy harvesters gives possibility ensure stable and much efficient broadband energy harvesting. Non-linear operation principle solves the main disadvantage of linear energy harvester. However, effective frequency range for energy harvesting can vary from few to several herz (Harne and et al. 2013; Cattone and et al. 2014, Trigona and et al. 2011; Zhu and Beeby, 2013). Therefore, non-linear electromagnetic energy harvesters are effective only when excitation frequency varies in small frequency range. If excitation frequency has large fluctuations, then the power generated by linear and non-liner energy harvesters decreases rapidly (Sari and et al. 2008).

Narrow effective frequency range can be extended by using active and passive frequency tuning (Wischke and et al. 2010; Vullers and et al. 2010; Asai and et al. 2017). However, frequency tuning technologies have the following disadvantages i. e. frequency tuning must be performed manually or frequency tuning system must be powered by external power supply (Podder and et al. 2017). On the other hand, multi-frequency operation principle gives possibility to bypass these disadvantages. Such operation principle ensures efficient energy harvesting at several discrete frequencies that are located close to each other (Wei and Jing, 2017).

For nowadays, several different designs of electromagnetic multi-frequency energy harvesters were introduced. In most cases, these energy harvesters are based on cantilever arrays (Sari and et al. 2008) or cantilevers with several resonant frequencies, that are close to each other (Yang and et al. 2009). Liu and et al. (2013) also proposed circular suspension structure as multi-frequency harvester. Multi-frequency energy harvesters have several different designs which have wide spectrum of applications (Mallick and et al. 2017; Chiu and et al. 2016; Han and et al. 2014a ). However, the main similarity of these harvesters is several resonant frequencies at narrow frequency range. Such, frequency response characteristics are obtained by composing several linear energy harvesters to one $\mathrm{EH}$ system. 

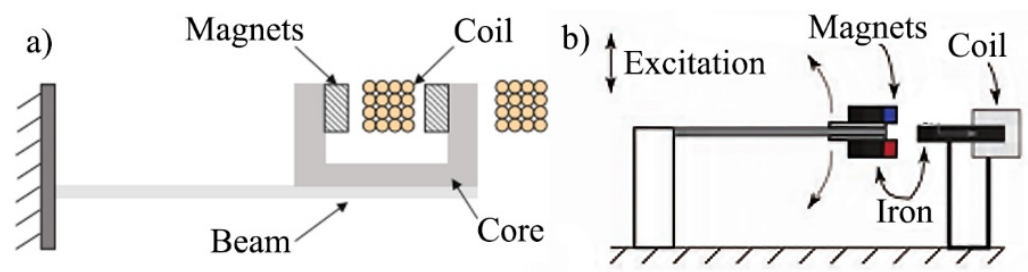

c)

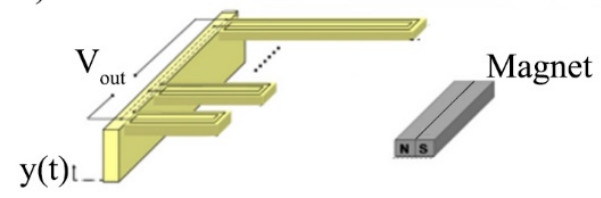

Fig. 1.4. Electromagnetic energy harvesters: a) linear (Priya and Inman, 2009); b) non-linear (Cammarano and et al. 2011); c) multi-frequency

(Sari and et al. 2008)

Fig. 1.4 a shows conventional design of electromagnetic energy harvester with single resonance frequency. Fig. $1.4 \mathrm{~b}$ represents the simplest design of nonlinear electromagnetic energy harvester and Fig. $1.4 \mathrm{c}$ shows the design of multifrequency energy harvester based on several linear harvesters composed to one system.

Multi-frequency energy harvesters provide possibility to bypass disadvantages of linear and non-liner energy harvesters and can be used for different vibration hosts without any additional adjustment (Wei and Jin, 2017). Therefore, it can be concluded that multi-frequency operation principle can ensure stable energy feed during frequency varying excitation (Roundy and et al. 2005).

Energy harvesting of mechanical vibrations based on electromagnetic conversion principle is able to provide high current at low excitation frequencies. On the other hand, on basis of electromagnetic induction theory can be said that electromagnetic energy harvesters will suffer from interference with external magnetic fields and low efficiency at high excitation frequencies.

\subsubsection{Energy harvesting of mechanical vibrations using electrostatic generators}

Energy conversion of mechanical vibrations at electrostatic energy harvesters is based on capacitor electrodes (or electrode fingers) of variable capacitor. Air, vacuum, or an insulating dielectric material separates these electrodes. Typically, a dielectric material used to both increase the harvested energy and to prevent short circuit between capacitor plates (Elvin and Erturk, 2013). Therefore, the main component of electrostatic energy harvester is the variable capacitor. Capacitor is 
charged by external power supply. It creates charges of equal absolute value but opposite sign on electrodes of capacitor. The charge is stored in the capacitor while battery is disconnected (Beeby and et al. 2007).

In general, operation of electrostatic energy harvester is based on charging electrodes of capacitor. The charge value depends on input voltage. The charge on electrodes generates electrostatic force that is the main parameter of energy conversion mechanism. Resistance of electrostatic force to the mechanical motion of the electrode can be defined as an effective work has done by harvester. Therefore, effective work performed by energy harvester defines as difference between input mechanical energy and generated electrical energy (Basset and et al. 2016).

Electrostatic energy harvesters can be classified into two groups considering to electrode configuration and motion type of the harvester i. e. in plane operation (overlapping electrodes) and out of plane operation (gap closing) (Tao and et al. 2014).

Numerous designs of electrostatic harvesters based on in plane operation are presented. Electrostatic energy harvester with overlapping electrodes and vapour insulation layer was reported by Seo and et al. (2015), turbine based electrostatic energy harvester was reported by Feng and et al. (2017) (Fig. 1.5 a) and with nonlinear parylene springs and high-performance electret material based on fluorinated polymer reported by Matsumoto et al. (2011). However, electrostatic energy harvesters based on in plane operation principle are not very useful because of the need of big mounting space and electrodes with large area (Koga and et al. 2017; Truong and et al. 2017).

On the other hand, out of plane (gap closing principle) operation principle of electrostatic energy harvester gives possibility to concentrate much higher electrodes surface in notably lower volume. Out of plane harvesters ensure higher capacitance density compare to in plane harvesters and have larger output power of the whole energy harvesting system (Basset and et al. 2016).

Numerous implementations of electrostatic energy harvesters based on in plane operation principle can be found. As for example, electrostatic energy harvester based on fixed-fixed ends cantilever reported by Mahmoud and et al. (2017), comb based electrostatic energy harvester reported by Koga and et al. (2017) (Fig. 1.5 b) or energy harvester for MEMS with non-linear effect inducted by electrostatic forces combined with mechanical stoppers reported by Tao and et al. (2015).

It can be concluded that operation principle of electrostatic energy harvester is based on resistance of electrostatic forces to mechanical motion of the electrodes. This phenomena is named as electrostatic induction. However, power density of electrostatic energy harvester can be improved only by increasing capacitance. Insulation material is very important parameter of these energy harvesting systems therefore numerous research reports of electrostatic energy harvesters 
with different insulation materials can be found (Ma and Zhang, 2017; Siang and et al. 2017).
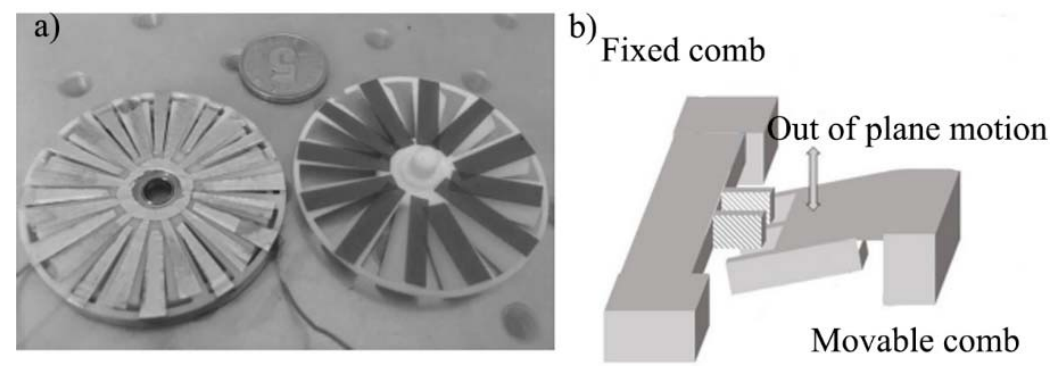

Fig. 1.5. Electrostatic energy harvesters: a) based on in plane operation principle (Feng and et al. 2017); b) based on out of plane operation principle (Koga and et al. 2017)

In general, electrostatic energy harvesters generates relativity low output power, compare to electromagnetic and piezoelectric harvesters (Basset and et al. 2016). Moreover, operation of electrostatic energy harvester is based on usage of external electric supply systems and this disadvantage makes these type of harvesters not so applicable as electromagnetic or piezoelectric (Siang and et al. 2017; Jeong and et al. 2017). On the other hand, electrostatic energy harvesters can be adapted to micro scale electronic systems due to low mounting volume and highly scalable design. These advantages gives possibility to combine electrostatic energy harvesters with extra low power systems and to use them where mounting space is limited (Kaur and et al. 2015; Jia and et al. 2013).

\subsubsection{Energy harvesting of mechanical vibrations using piezoelectric generators}

Piezoelectricity was discovered and described in late 1880. The brothers Pierre and Jacques Curie were conducted experiments on various crystals and noticed that group of natural crystals like tourmaline, quartz, topaz, cane sugar and Rochelle salt exhibits surfaces charges changes while they are affected by external mechanical stress. Latter, direct piezoelectric effect was described as follows: mechanical stress or strain externally inducted at a poled element with non-centrosymmetric structure changes the dipole moment associated with that element and as a result voltage or charge displacement is created (Priya and Inman, 2009).

For nowadays, a direct piezoelectric effect is used to convert mechanical stress or strain to electrical signal or electrical energy (Bai and et al. 2018). In most recent literature it can be found a numerous designs of piezoelectric energy harvesters based on different type of cantilevers i. e. cantilevers with non-linear 
behaviour, cantilevers that operates as multi-frequency systems and etc. (Ostaševičius and et al. 2015a; Kazmierski and Beeby, 2011). However, during last several years, numerous investigation were conducted on piezoelectric cantilevers with different geometrical shapes and configurations in order to obtain high output power, current and voltage densities. Unfortunately, the main disadvantage of the cantilever remained i. e. the highest electrical characteristics can be achieved only at one excitation frequency.

In order to increase efficiency of piezoelectric energy harvesters based on cantilevers, the geometry and dimensions of the harvesters must be carefully designed. It must be done in order to obtain exact matching of resonant frequency of cantilever and frequency of host vibrations (Roundy and et al. 2004). In most cases, vibration frequency of the host is unstable because of the different operation conditions (Zhu and et al. 2010). Therefore, exact excitation frequency of the harvester is unknown in advance. So, energy harvester with fixed resonant frequency is unable to achieve the highest power output during fluctuation of excitation frequency. Cantilever based energy harvester must be improved by a resonance frequency tuning system in order to improve its possibility to operate at different excitation frequencies (Ahmed and et al. 2012). Based on investigations of Roundy and Zhang (2005), the resonant frequency of energy harvester can be tuned by two principles i. e. passively and actively. Unfortunately, active frequency tuning has demand on additional power supply. In general, the level of the harvested energy is much lower that is needed to power on frequency tuning system (Zhu and et al. 2010). Therefore, active frequency tuning methods will be not analysed.

Passive resonance tuning methods are classified as mechanical and magnetic. Frequency tuning can be implemented in two ways i. e. manually or as self-tuning system (Elvin and Erturk, 2013). Manual resonance tuning is based on theory of vibrations i. e. resonance of the system can be tuned by changing mass value or stiffness of the system. Therefore, manual frequency tuning is difficult to perform during systems operation (Cheng and et al. 2017).

Magnetic field based resonance tuning uses magnetic force to change stiffness of energy harvesting system. It can be noticed that the stiffness tuning is more practical and has more options compare to the changing of mass value. In addition, non-linear principle of stiffness changes can provide high benefits for broadband energy harvesting. The non-linear energy harvesters can be divided to two groups i. e. non-linear stiffness harvesters and non-linear piezoelectric coupling harvesters. The non-linear piezoelectric energy harvesters can be based on several main configurations i. e. mono-stable, bi-stable, and with mechanical stoppers (Elvin and Erturk, 2013; Twiefel and Westermann, 2013).

Mono-stable configuration of energy harvester can tune resonance curve to the right or left and provide broadband energy harvesting. Unfortunately, mono- 
stable operation of energy harvesters has limitation for their practical application. Piezoelectric energy harvester based on mono-stable configuration can operate only with a slow and known frequency varying function (Erturk and et al. 2009a). Moreover, a mono-stable mechanism must be implemented to perturb and drive the energy harvesting system at high-energy orbits while it operates in a low energy branch (Elvin and Erturk, 2013).

Bi-stable configuration of piezoelectric energy harvesters is based on largescale oscillations inducted by periodic or stochastic forces. If piezoelectric energy harvesting system periodically forced by low or high force with relevant perturbation the harvester is able to provide high-orbit energy outputs (Twiefel and Westermann, 2013). Therefore, such energy harvester are able to overcome traditional cantilever based energy harvesting systems over a wide bandwidth. Moreover, energy harvesting system, which is stochastically excited, shows noticeable higher electrical performance. It caused by accurately designed distance between magnets used in energy harvesting system (Tang and Yang, 2012). Performance of bi-stable energy harvester can be improved by induction of stochastic resonance. For this case, system must be properly forced to periodically change of the potential barrier and as a result, the large-amplitude transition between two stable states will be observed (Elvin and Erturk, 2013).

Also, mechanical stoppers can be used for non-linear energy harvesting. If energy harvester with mechanical stoppers is excited by harmonic vibrations it increases the bandwidth of the harvester during excitation frequency changes. Moreover, the same bandwidth obtained during frequency decreases. Unfortunately, during decreasing of excitation frequency the energy harvester modified by mechanical stoppers exhibits much lower power performance compare to the harvester without mechanical stoppers (Chen and et al. 2017). Performance of energy harvester with stoppers is controlled by stopper height and offset distance from fixed end of the cantilever. Hence, if application field of harvesters has known probability density function, a location of the stoppers must be adjusted to frequency increasing. In order to get the maximum performance of energy harvesting system with mechanical stoppers, the height of stoppers must be set as high as possible. It causes the minimal damping and improves electrical performance of the system. Therefore, it is possible to increase performance of energy harvester with stoppers when harmonic excitation is at upsweep or random excitation scenarios. However, harvesters with such configuration suffers from noise, fatigue and mechanical wear at the contact point (Elvin and Erturk, 2013).

Self-tuning method is based on capability of energy harvesting system to change it resonant frequency according to the function of excitation frequency without using any additional interference (Zhu and et al. 2010). 
Multi-frequency operation principle of piezoelectric energy harvester is used for wideband energy harvesting and can assign to alternative solution of non-linear operation principle. In most cases, multi-frequency operation principle has more advantages than non-linear operation or energy harvesting systems with frequency tuning. Energy harvesters based on multi-frequency operation principle is magnetic field free, have no demand on mechanical stoppers and has no demand of external power supply or operator intervention. In general, multi-frequency energy harvesters efficiently operate at several discrete resonance frequencies in narrow frequency band (Tang and Yang, 2012).

Multi-frequency piezoelectric energy harvesting can be achieved by employing several resonant frequencies of a single cantilever or to use array of different cantilevers that have different resonant frequencies and are integrated to one energy harvesting system. In most cases, multi-frequency piezoelectric energy harvesters operate at the first or the second out-of-plane bending vibration mode. These vibration modes have the highest strain/stress values and electrical output power. Moreover, multi-frequency energy harvesting does not require manual or self-tuning mechanisms (Tan, 2012). Multi-frequency energy harvester have much simpler construction and can be easily implemented in micro-electro-mechanical (MEMS) systems (Ahmed and et al. 2012). However, some disadvantages must be taken to into account i. e. vibration modes of multi-frequency energy harvesters can be far away from each other therefore application field of such harvester can be complicated (Kazmierski and Beeby, 2011). Also, it must be pointed that multi-frequency piezoelectric energy harvester effectively operate at discrete frequencies. Moreover, usage of such harvesters is based on cantilever array configuration and leads to low power density. In addition, multi-frequency energy harvesters requires complex interface circuits in order to prevent charge cancelation, which occurs during harvesters operation at different phases of vibration modes. Also interface circuits must have different matching loads for each cantilever and vibration mode (Hehn amd Manoli; 2015).

As a conclusion it can be mentioned that energy harvesting of mechanical vibrations using piezoelectric systems are well scalable and suitable for MEMS implementations. It has the following features as simple design, small manufacturing cost, high power density. Such advantages of the piezoelectric energy harvesters make them highly desirable compare to electromagnetic and electrostatic systems. However, piezoelectric energy harvesters suffers from non-uniform bending strain distribution along the cantilever length.

The next section will cover a detail overview of piezoelectric energy harvesters based on linear, non-linear and multi-frequency operation principles. Piezoelectric energy harvesters with different design and operating principles will be analysed indicating advantages and disadvantages of the harvesters. 


\subsection{Piezoelectric energy harvesters: operation principle and designs}

This section gives an overview on direct and converse piezoelectric effect and mathematical model of piezoelectric energy harvester based on cantilever. Also, the section surveys state of the art of the most recent piezoelectric energy harvesters designs and operation principles.

\subsubsection{Mathematical model of direct and converse piezoelectric effect}

Brothers Pierre and Jacques Curie performed the first theoretical and experimental demonstration of piezoelectric effect in 1880 . The demonstrations revealed connectivity between a crystallographic structure and a macroscopic piezoelectric phenomenon in specially prepared crystals made of tourmaline, quartz, topaz, cane sugar and Rochelle salt. The scientists proved that electrical charge is inducted on the surface of crystal while it affected by mechanical strain (Priya and Inman, 2009).

For nowadays, piezoelectrisity is described and standardized by IEEE Standard 176-1987 (ANSI/IEEE Std. 176-1987, 1987). The constitutive equations of piezoelectric materials can be written as follows:

$$
\begin{aligned}
& D_{i}=e_{i j}^{\sigma} E_{j}+d_{i m}^{d} \sigma_{m} ; \\
& \varepsilon_{k}=d_{j k}^{c} E_{j}+s_{k m}^{E} \sigma_{m} .
\end{aligned}
$$

here vector $\boldsymbol{D}_{\boldsymbol{i}}$ represents electrical displacement; $\boldsymbol{\varepsilon}_{\boldsymbol{k}}$ is strain vector; $\boldsymbol{E}_{\boldsymbol{j}}$ is the applied electric field vector; $\boldsymbol{\sigma}_{\boldsymbol{m}}$ is the stress vector; $\mathbf{e}^{\sigma}{ }_{i j}$ is the dielectric permittivity matrix; $d^{c}{ }_{j k}$ and $d^{d}{ }_{i m}$ are piezoelectric coefficients for converse and direct piezoelectric effect, respectively; $\boldsymbol{s}_{\boldsymbol{k} \boldsymbol{m}}$ is the elastic compliance matrix.

Eq. (1.1) and Eq. (1.2) can be written in matrix form as given in Eq. (1.3) (ANSI/IEEE Std. 176-1987, 1987).

$$
\left[\begin{array}{c}
D_{i} \\
\varepsilon_{k}
\end{array}\right]=\left[\begin{array}{ll}
e_{i j}^{\sigma} & d_{i m}^{d} \\
d_{j k}^{c} & s_{k m}^{E}
\end{array}\right]\left[\begin{array}{c}
E_{j} \\
\sigma_{m}
\end{array}\right] .
$$

The piezoelectric coefficient $\boldsymbol{d}^{c}{ }_{\boldsymbol{j} k}$ defines strain per unit of electrical field and $\boldsymbol{d}^{\boldsymbol{d}}{ }_{\boldsymbol{i} \boldsymbol{m}}$ defines electrical displacement per unit of mechanical stress. The superscripts $c$ and $d$ added to indicate difference between converse and direct piezoelectric effect. The superscripts $\sigma$ and $E$ indicates that dielectric permittivity and elastic 
compliance matrixes of the material are measured at constant stress and constant electric field respectively (Sirohi and Chopra, 2000).

Piezoelectric coefficient $\boldsymbol{d}^{c} \boldsymbol{j}$ is shown below (ANSI/IEEE Std. 176-1987, 1987)

$$
\mathbf{d}_{\mathbf{j k}}^{\mathbf{c}}=\left[\begin{array}{ccc}
0 & 0 & d_{31} \\
0 & 0 & d_{32} \\
0 & 0 & d_{33} \\
0 & d_{24} & 0 \\
d_{15} & 0 & 0 \\
0 & 0 & 0
\end{array}\right],
$$

here the coefficients $d_{31}, d_{32}$ and $d_{33}$ relates to the normal strain in the 1,2 and 3 directions respectively to a field along the poling direction, $E_{3}$. The coefficients $d_{15}$ and $d_{24}$ relate the shear strain in the 1-3 plane to the field $E_{1}$ and shear strain in the 2-3 plane to the $E_{1}$ field, respectively (Sirohi and Chopra, 2000).

The compliance matrix is defined as (ANSI/IEEE Std. 176-1987, 1987)

$$
\mathbf{s}_{\mathbf{k m}}^{\mathbf{E}}=\left[\begin{array}{cccccc}
S_{11} & S_{12} & S_{13} & 0 & 0 & 0 \\
S_{12} & S_{22} & S_{23} & 0 & 0 & 0 \\
S_{13} & S_{23} & S_{33} & 0 & 0 & 0 \\
0 & 0 & 0 & S_{44} & 0 & 0 \\
0 & 0 & 0 & 0 & S_{55} & 0 \\
0 & 0 & 0 & 0 & 0 & S_{66}
\end{array}\right] .
$$

The permittivity matrix can be expressed as follows

$$
\mathbf{e}_{\mathrm{ij}}^{\boldsymbol{\sigma}}=\left[\begin{array}{ccc}
e_{11}^{\sigma} & 0 & 0 \\
0 & e_{22}^{\sigma} & 0 \\
0 & 0 & e_{33}^{\sigma}
\end{array}\right] .
$$

The stress vector represented below

$$
\boldsymbol{\sigma}_{\mathbf{m}}=\left[\begin{array}{l}
\sigma_{1} \\
\sigma_{2} \\
\sigma_{3} \\
\sigma_{4} \\
\sigma_{5} \\
\sigma_{6}
\end{array}\right]=\left[\begin{array}{l}
\sigma_{11} \\
\sigma_{22} \\
\sigma_{33} \\
\sigma_{23} \\
\sigma_{31} \\
\sigma_{12}
\end{array}\right] .
$$


Eq. (1.2) describes converse piezoelectric effect and that is used for designing actuators. On the other hand, direct piezoelectric effect described by Eq. (1.1) represents mechanical stress conversion to electrical charge. Therefore, piezoelectric material affected by stress field generates electrical charge. Assuming that external electrical field on the piezoelectric material is equal to 0 then Eq. (1.1) becomes (Sirohi and Chopra, 2000).

$$
\left[\begin{array}{l}
D_{1} \\
D_{2} \\
D_{3}
\end{array}\right]=\left[\begin{array}{cccccc}
0 & 0 & 0 & 0 & d_{15} & 0 \\
0 & 0 & 0 & d_{24} & 0 & 0 \\
d_{31} & d_{32} & d_{33} & 0 & 0 & 0
\end{array}\right]\left[\begin{array}{c}
\sigma_{1} \\
\sigma_{2} \\
\sigma_{3} \\
\sigma_{4} \\
\sigma_{5} \\
\sigma_{6}
\end{array}\right] .
$$

Eq. (1.8) shows that electrical displacement vector $\boldsymbol{D}_{\boldsymbol{i}}$ is inducted by stress vector $\boldsymbol{\sigma}_{\boldsymbol{m}}$ that is applied to piezoelectric material with $\boldsymbol{d}^{\boldsymbol{d}}{ }_{\boldsymbol{i} \boldsymbol{m}}$ piezoelectric coefficient. In general, Eq. (1.8) shows principle of mechanical stress conversion to electric displacement by piezoelectric material. This principle is basis of mechanical energy conversion in piezoelectric energy harvesters.

Electrical displacement vector $\boldsymbol{D}_{\boldsymbol{i}}$ is directly related to electric charge generated by piezoelectric material. Eq. (1.9) shows dependence of electric charge from area of electrodes.

$$
q=\iint\left[\begin{array}{lll}
D_{1} & D_{2} & D_{3}
\end{array}\right]\left[\begin{array}{l}
d A_{1} \\
d A_{2} \\
d A_{3}
\end{array}\right] .
$$

here $d A_{1}, d A_{2}, d A_{3}$, are the components of electrode area in the $2-3,1-3$, and $1-2$ planes respectively. Also, it must be pointed that electric displacement vector is normal to electrode area $d A$. The charge $q$ and the voltage $U_{c}$ depends on capacitance of piezoelectric material and have the following relation (Sirohi and Chopra, 2000).

$$
U_{c}=\frac{q}{C_{p}} .
$$

Piezoelectric energy harvesters are composite systems and consist of piezoelectric layer named as active layer and metal layer named as passive layer. This kind of composite structure allows use brittle piezoelectric material at high stresses and strains. The next section gives basic mathematical model of piezoelectric energy harvester based on composite cantilever. 


\subsubsection{Mathematical model of cantilever type piezoelectric energy harvester}

The energy harvester consists of multi-layered cantilever and tip mass rigidly attached to the free end of the cantilever. The cantilever is composed of one metal layer and one piezoelectric layer. The piezoelectric sheet is glued on the top side of the metal layer and is connected to an electrical load resistance. Piezoelectric harvester is utilizing $d_{31}$ mode of the piezoelectric effect. Energy harvester is subjected to the base excitation, as shown in Fig. 1.6. Transverse displacement in $z$ direction at any point $x$ along the beam axis is denoted by $w(x, t)$ and is a sum of displacement of the base and transverse displacement of the cantilever relative to the base. The size parameter of the investigated beam is illustrated in Fig. 1.6.

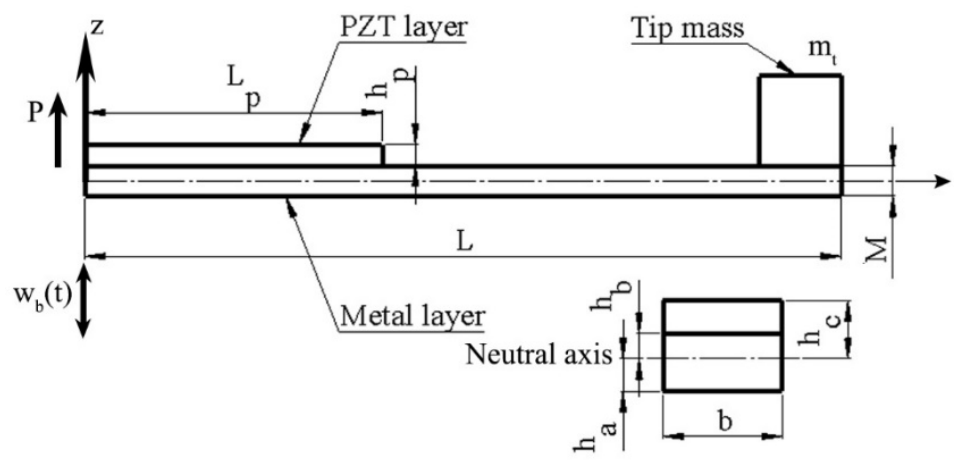

Fig. 1.6. Schematics of piezoelectric cantilever

Length of the metal and PZT layers are denoted as $L$ and $L p$ respectively. The corresponding heights are $h_{m}$ and $h_{p}, b$ is the width of the cantilever. $h_{a}$ and $h_{b}$ are the bottom and top position of the metal layer with respect to the neutral axis, $h_{a}$ is the top position of the piezoelectric sheet with respect to neutral axis.

The governing equation of motion of the cantilever that is subjected to base excitation is obtained by using the Euler-Bernoulli beam assumptions that yield: (Erturk and Inman, 2008)

$$
\frac{\partial^{2} M(x, t)}{\partial x^{2}}+C_{s} I \frac{\partial^{5} w_{r}(x, t)}{\partial^{4} x \partial t}+m \frac{\partial^{2} w_{r}(x, t)}{\partial t^{2}}=-\left(m+m_{t} \delta(x-L) \frac{\partial^{2} w_{b}(t)}{\partial t^{2}} .\right.
$$

Where $w_{r}(x, t)$ is the transverse displacement of the cantilever relative to the base, $M(x, t)$ is the internal bending moment of the cantilever, $C_{s}$ is the strain damping coefficient, $I$ is the equivalent area moment of inertia, $m$ is the equivalent mass per unit length of the cantilever, $m_{t}$ is the tip mass, $\delta(x)$ is Dirac function. Here: 


$$
m=\frac{m_{m} L+m_{p} L}{L} .
$$

The base displacement $w_{b}(x, t)$ can be written as:

$$
w_{b}(x, t)=z_{0} \sin \left(2 \pi f_{b} t+\varphi\right) .
$$

Where $z_{0}$ is the amplitude of the base displacement and $f_{b}$ is the excitation frequency and $\varphi$ is phase. The internal bending moment term in Eq. (1.11) is the first moment of axial strain over the cross-section: (Yan and et. al., 2014)

$$
M(x, t)=-\int_{h_{a}}^{h_{b}} \sigma_{m} b(x) z d z-\int_{h_{b}}^{h_{c}} \sigma_{p} b(x) z d z .
$$

Where $b(x)$ is the width, $h_{a}$ and $h_{b}$ are the bottom and top position of the metal layer with respect to the neutral axis, $h_{a}$ is the top position of the piezoelectric sheet with respect to neutral axis. Furthermore, $\sigma_{m}$ and $\sigma_{p}$ are the axial stress components in the metal layer and the piezo ceramic layer, respectively ( $\mathrm{x}$ is the axial direction), and they are given by the following constitutive relations: (Erturk and Inman, 2008)

$$
\begin{gathered}
\sigma_{m}=Y \varepsilon_{m} . \\
\sigma_{p}=C_{11}^{E} \varepsilon_{p}-e_{31} E_{z} .
\end{gathered}
$$

Where $Y$ is the elastic modulus (i. e. Young's modulus) of the metal layer, $\varepsilon$ is the strain along the $x$ direction, $C_{11}$ is the element of elastic modulus of the piezo ceramic layer at constant electric field (it will be denoted as $E_{p}$ in the further equations), $e_{31}$ is the effective piezoelectric stress constant and $E_{z}$ is the electric field component in z-direction (i. e. the poling direction). Based on the plane-stress assumption for a transversely isotropic thin piezo ceramic beam (about the $\mathrm{z}$ direction), the elastic modulus component of the piezo ceramic can be expressed:

$$
C_{11}^{E}=\frac{1}{S_{11}^{E}}=E_{p} .
$$

Where $S_{11}$ is the elastic compliance at constant electric field. Furthermore, based on the same assumption, $e_{31}$ can be given in terms of the more commonly used piezoelectric strain constant $d_{31}$ as:

$$
e_{31}=\frac{d_{31}}{S_{11}^{E}}
$$


The strain along the $\mathrm{x}$ direction of the cantilever at a certain thickness $\mathrm{z}$ from the neutral axis of the symmetric composite beam is simply proportional to the curvature of the cantilever:

$$
\varepsilon(x, z, t)=-z \frac{\partial^{2} w_{r}(x, t)}{\partial x^{2}} .
$$

The electric field component $E$ can be expressed in terms of the respective voltage:

$$
E=\frac{U}{h_{p}} .
$$

Substituting Eq. (1.15-1.20) into Eq. (1.14), the following expression of the internal bending moment will be obtained: (Yan and et. al., 2014)

$$
\begin{aligned}
& M(x, t)=-\int_{h_{a}}^{h_{b}} Y(-z) \frac{\partial^{2} w_{r}(x, t)}{\partial x^{2}} \cdot b(x) \cdot z d z- \\
& -\left[\int_{h_{b}}^{h_{c}} E_{p}(-z) \frac{\partial^{2} w_{r}(x, t)}{\partial x^{2}} \cdot b(x) \cdot z d z-\int_{h_{b}}^{h_{a}} \frac{U}{h_{p}} \cdot e_{31} \cdot b(x) \cdot z d z\right]=\left.Y b(x) \frac{\partial^{2} w_{r}(x, t)}{\partial x^{2}} \frac{z^{3}}{3}\right|_{h_{a}} ^{h_{b}}+ \\
& +E_{p} b(x) \frac{\partial^{2} w_{r}(x, t)}{\partial x^{2}}+\left.z^{3}\right|_{h_{b}} ^{h_{c}}+\left.\frac{U}{h_{p}} e_{31} b(x) \frac{z^{2}}{2}\right|_{h_{b}} ^{h_{c}}=Y b(x) \frac{\partial^{2} w_{r}(x, t)}{\partial x^{2}}\left(\frac{h_{b}^{3}-h_{a}^{3}}{3}\right)+ \\
& +E_{p} b(x) \frac{\partial^{2} w_{r}(x, t)}{\partial x^{2}}\left(\frac{h_{c}^{3}-h_{b}^{3}}{3}\right)+\frac{U}{h_{p}} e_{31} b(x)\left(\frac{h_{c}^{2}-h_{b}^{2}}{2}\right) .
\end{aligned}
$$

Before substituting Eq. (1.21) into Eq. (1.11), the electrical term must be multiplied by $[d \delta(x) / d x-d \delta(x-L) / d x]$. Also, some definitions can be made to simplify the expression of internal bending moment: (Yan and et. al., 2014)

$$
\begin{gathered}
Y I=b(x)\left[Y\left(\frac{h_{b}^{3}-h_{a}^{3}}{3}\right)+E_{p}\left(\frac{h_{c}^{3}-h_{b}^{3}}{3}\right)\right] . \\
\vartheta=\frac{e_{31} b(x)}{h_{p}} \cdot\left(\frac{h_{c}^{2}-h_{b}^{2}}{2}\right) .
\end{gathered}
$$

$\vartheta$ is a coupling term. Finally $M(x, t)$ is obtained as follows:

$$
M(x, t)=Y I \frac{\partial^{2} w_{r}(x, t)}{\partial x^{2}}+\vartheta \cdot U(t)\left[\frac{d \delta(x)}{d x}-\frac{d \delta(x-L)}{d x}\right] .
$$

Substituting Eq. (1.24) into Eq. (1.11), the coupled cantilever equation can be obtained as follows: (Yan and et. al., 2014) 


$$
\begin{aligned}
& Y I \frac{\partial^{4} w_{r}(x, t)}{\partial x^{4}}+C_{s} I \frac{\partial^{5} w_{r}(x, t)}{\partial^{4} x \partial t}+m \frac{\partial^{5 \backslash 2} w_{r}(x, t)}{\partial t^{2}}+\vartheta \cdot U(t) \\
& \cdot\left[\frac{d \delta(x)}{d x}-\frac{d \delta(z-L)}{d x}\right]=-\left(m+m_{t} \cdot \delta(x-l)\right) \frac{\partial^{2} w_{b}(t)}{\partial^{2} t}
\end{aligned}
$$

The mass per unit length term $m$ has the following expression:

$$
\mathrm{m}=\mathrm{b}_{\mathrm{p}} \rho_{p} h_{p}+b_{m} \rho_{m} h_{m} .
$$

Where $\rho_{p}$ and $\rho_{m}$ are the mass densities of the piezo ceramic and the metal, respectively. The Galerkin method can be used for transverse displacement of the cantilever and can be written as follows: (Erturk and Inman, 2008)

$$
w_{r}(x, t)=\sum_{i=0}^{n} \Phi_{i}(x) q_{i}(t)
$$

Where $\Phi_{i}(x)$ is the mode shape of the cantilever beam and $q_{i}(t)$ is the modal coordinates of the $i$-th vibration mode. The mode shapes are calculated as:

$$
\Phi_{i}(x)=A_{i} \sin \beta_{i} x+\beta_{i} \cos \beta_{i} x+C_{i} \sinh \beta_{i}+D_{i} \cosh \beta_{i} x .
$$

Where the relation between $\beta$ and $w$ is as follows:

$$
w_{i}=\beta_{i}^{2} \sqrt{\frac{Y I}{m L^{4}}} .
$$

Substituting Eq. (1.25) into Eq. (1.27) and making simplification, the following expression can be obtained:

$$
\ddot{q}(t)+2 \xi_{i} w_{i} \dot{q}_{i}(t)+w_{i}^{2} q_{i}(t)+\chi_{i} \cdot U(t)=f(i) .
$$

Where $\xi_{i}$ is mechanical damping coefficient $w_{i}$ is natural frequency of the cantilever, $\chi$ is piezoelectric coupling term of the harvester which is given by:

$$
\chi_{i}=-\vartheta \Phi_{i}\left(L_{p}\right) .
$$

The external force can be expressed as: (Yan and et. al., 2014)

$$
f_{i}=-\left(m+m_{t}\right) \cdot \frac{d^{2} w_{b}}{d t^{2}} \int_{0}^{1} \Phi_{i} d x
$$

Let's analyze electrical dynamics of a single layer piezoelectric cantilever (Fig. 1.6) under bending vibrations. Consider that the electrodes of a single layer are connected to a resistive load. Based on electromechanical coupling effect coming from constitutive relation the electric displacement along $\mathrm{z}$ axis can be written as follows:

$$
D=e_{31} \cdot \varepsilon_{p}+\epsilon_{33} \cdot E
$$


Where $D$ is the electric displacement component in z-direction $\epsilon_{33}$ is the permittivity component at constant strain with the plane-stress assumption for a cantilever. The electric current output can be obtained from the Gauss's law:

$$
\frac{d}{d t}\left(\int_{A} D \cdot n d A\right)=\frac{U(t)}{R} .
$$

where $n$ is the normal vector to the plane of the piezo ceramic layer and electrode plane, respectively. Eq. (1.34) can be rewritten as follows:

$$
D=e_{31} \cdot(-z) \frac{\partial^{2} w_{r}(x, t)}{\partial x^{2}}+\epsilon_{33} E .
$$

By substituting Eq. (1.34) into Eq. (1.35), the governing equation of the strainvoltage relation is obtained:

$$
\frac{\varepsilon_{p} \cdot b \cdot L_{p}}{h_{p}} \cdot \frac{d U(t)}{d t}+\frac{U(t)}{R}=-e_{31} h_{p c} \cdot b \int_{0}^{L} \frac{\partial^{3} w_{r}(x, t)}{\partial x^{2} \partial t} d x .
$$

Where $b, h_{p}$ and $L$ are the width, thickness and the length of the piezoceramic layer, respectively, and $h_{p c}$ is the distance between the neutral axis and the center of the piezoceramic layer that can be calculated as follows:

$$
h_{p c}=\left(\frac{h_{m}+h_{p}}{2}\right) \text {. }
$$

Substituting Eq. (1.27) into Eq. (1.36) and applying Kirchhoff laws, we obtain the following equation:

$$
C_{p} \frac{d U(t)}{d t}+\frac{U(t)}{R}-\sum \chi_{i} \dot{q}(t)=0 .
$$

Where $R$ is the resistance and $C_{p}$ is the internal capacitance of the harvester, which can be written as:

$$
C_{p}=\frac{\in_{33} b L_{p}}{h_{p}} .
$$

Identification of the above terms has an important use for modelling of bimorph piezoelectric energy harvester. 


\subsubsection{Cantilever based piezoelectric energy harvesters}

For nowadays, cantilever based piezoelectric energy harvesters are the most frequently used devices for vibration energy harvesting. However, these type of harvesters suffers from several disadvantages such as narrow frequency band, uneven strain distribution along the length of the cantilever and low electrical output characteristics. Therefore, investigations with goal to find a solution of aforementioned problems are performed.

Goldschmidtboeing and Woias (2008) conducted analytical and experimental investigations on optimal design of piezoelectric cantilever for single excitation frequency. The goal of investigation was to examine efficiency and maximum tolerable excitation amplitude for the piezoelectric cantilevers with rectangular and triangle geometrical shape. The photos of investigated piezoelectric cantilevers are given in Fig. 1.8.

a)

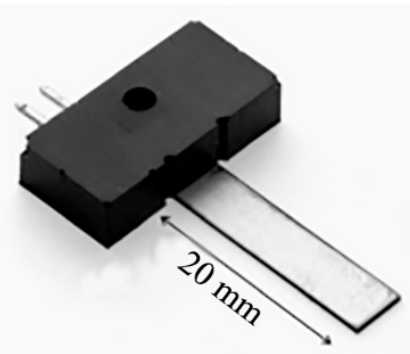

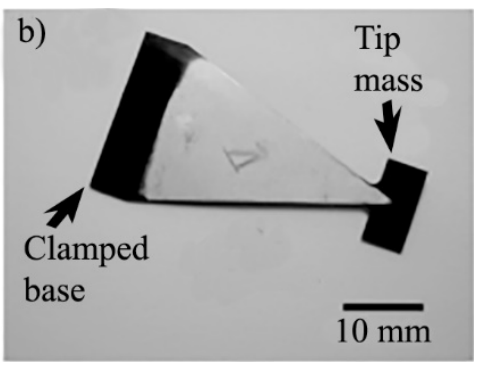

Fig. 1.8. Piezoelectric cantilevers for energy harvesting: a) rectangular; b) triangle (Goldschmidtboeing and Woias, 2008)

Based on results of analytical and experimental investigations, authors concluded that the shape has only a little influence on the efficiency, but can have strong influence on vibration amplitude and respectively to the output power. In addition, authors highlighted that the optimal design of the harvester must has a triangular shape. It was concluded that in order to optimize the maximum tolerable excitation amplitude, the tip mass must be increased (Goldschmidtboeing and Woias, 2008).

Jin and et al. (2017) investigated influence of different shapes of piezoelectric cantilevers on their electrical characteristics. Authors studied three different shapes of piezoelectric cantilevers i. e. truncated triangular, trapezoidal and rectangular shapes. Analytical models of vibrations and electrical characteristics of piezoelectric cantilevers with arbitrary shapes were used for this study. Moreover, experimental investigations of three different prototypes were conducted in order to confirm theoretical results. The prototypes of investigated harvesters are shown 
in Fig. 1.8. Based on theoretical and experimental investigations the authors concluded that the total charges on the electrodes surface are hardly affected by the shapes in width of the cantilever. The shape and width of piezoelectric harvester make impact to the capacitance of the piezoelectric layer and open circuit output voltage. When width of the free end of cantilever is decreasing, then resonant frequency is decreasing as well and the peak value of open circuit voltage will be higher. Therefore harvested power at the optimal load will be increased (Jin and et al. 2017).

Muthalif and Nordin (2015) conducted analytical, numerical and experimental investigations of piezoelectric cantilevers used for vibration energy harvesting with different shapes. The focus of the investigation was to indicate optimal shape of piezoelectric cantilever for the both single harmonic and broadband vibrations. Euler-Bernoulli beam theory employed in order to derive equations of motion of cantilevers. FEM software used to simulate cantilevers and experimental investigations performed in order to confirm obtained results. The view of investigated cantilevers is given in Fig. 1.10.

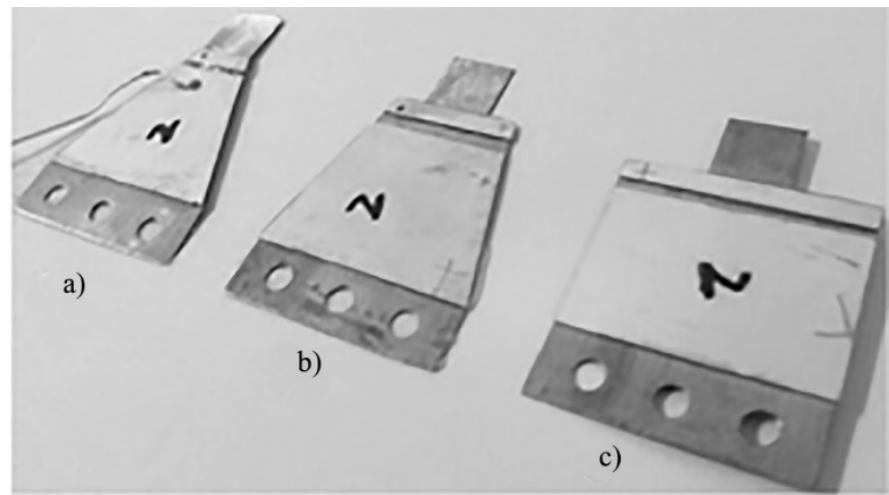

Fig. 1.9. Piezoelectric cantilevers with different shape for energy harvesting:

a) truncated triangular; b) trapezoidal; c) rectangular (Jin and et al. 2017)

The authors noticed that cantilever with triangular shape exhibits much higher output voltage compare to cantilevers with rectangular shape. The utilization of comb-shaped cantilever structure showed that it is possible to increase number of natural frequencies of the system within the desired frequency range. Moreover, analysis of bending strain distribution in piezoelectric cantilevers showed that cantilevers with triangle shape have more uniform bending strain distribution under the same load. 

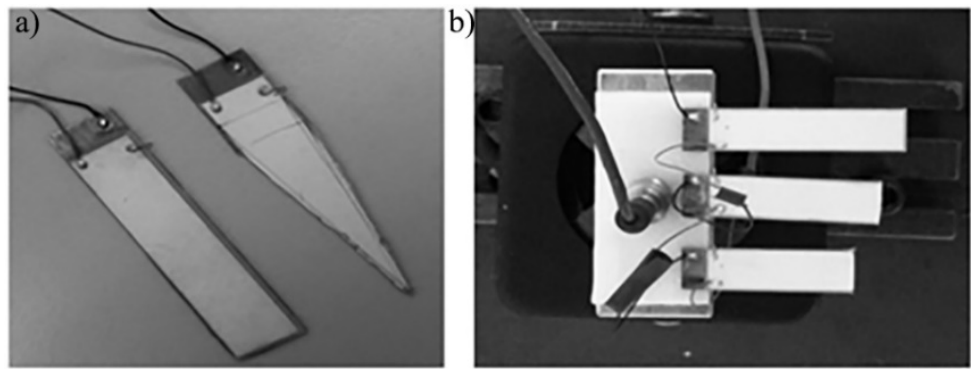

Fig. 1.10. Cantilevers for piezoelectric energy harvesting: a) rectangular and triangular cantilevers; b) comb-shaped array based on cantilevers (Muthalif and Nordin, 2015)

The authors concluded that triangular shape based cantilever exhibits twice higher average bending strain compare to the rectangular cantilever. Therefore, due to this phenomenon, the voltage output generated by truncated cantilevers will also be much higher compare to rectangular (Muthalif and Nordin, 2015).

It can be found numerous reports on investigations related to optimization and application of different shapes and vibration modes of piezoelectric cantilevers which can be used for energy harvesting (Thein and et al. 2016; Hosseini and Hamedi, 2015; Mohamed and et al. 2016; Žižys and et al. 2015; Ostaševičius and et al. 2015). Moreover, numerous models were developed in order to predict mechanical and electrical characteristics of cantilevers with different shapes (Erturk and Inman, 2008; Erturk and Inman, 2009; Deitl and et al. 2010). However, regardless of extensive investigations, the main disadvantage of energy harvester based on single piezoelectric cantilever is still remaining i. e. single cantilever based energy harvester operates with highest efficiency only while natural frequency of the cantilever matches excitation frequency of the host and energy harvesting system is in resonance with host. Unfortunately, if mismatch occurs between natural and excitation frequencies, efficiency and electrical characteristics of cantilever decreases dramatically and energy harvesting systems becomes useless (Kazmierski and Beeby, 2011).

\subsubsection{Piezoelectric energy harvesters with frequency tuning option}

In most cases, resonant frequency of energy harvester when it achieve highest efficiency is not changing. However, there are solutions how to adjust resonant frequency of the harvester to the frequency of host vibrations. Resonant frequency tuning methods provides a possibility to adjust resonant frequency of piezoelectric energy harvester to the needed value by changing stiffness or mass of the harvester. 
Morris and et al. (2008) reported on piezoelectric energy harvester based on polyvinylidene fluoride (PVDF) membrane with tuneable resonant frequency. The resonant frequency of the proposed energy harvester can be tuned by an adjustable link that symmetrically pre-tensions both PVDF sheets. The tuning of resonant frequency can be made by changing the length of the rigid coupling element (Morris and et al. 2008). Cross-section view of the proposed energy harvester is given in Fig. 1.11.

Based on results of numerical and experimental investigations authors concluded that piezoelectric energy harvester with extensional resonant tuning mode is able to change resonant frequency with respect to preloading force. Moreover, experimental study of the prototype energy harvester confirmed that frequency can be adjusted at the range over $150 \mathrm{~Hz}$. Also, such design can be implemented with different geometrical parameters and cover different ranges of excitation frequencies (Morris and et al. 2008).

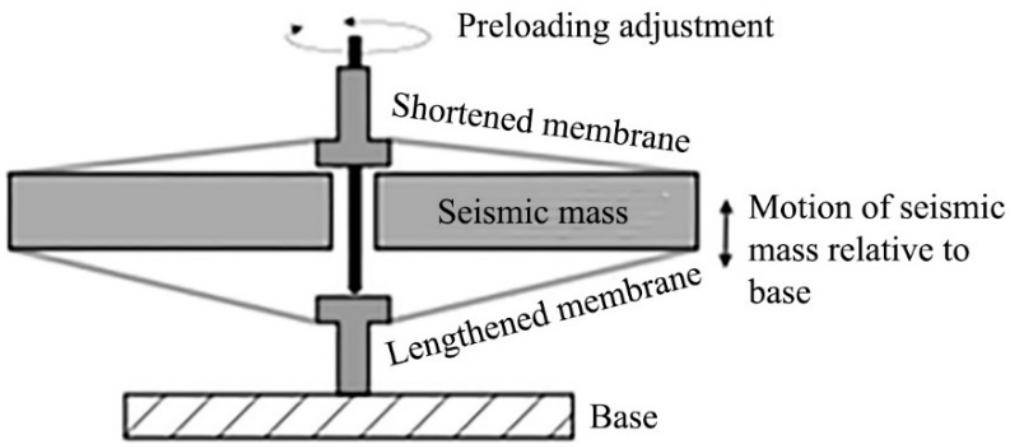

Fig. 1.11. Cross-section view of the energy harvester with tuneable resonant frequency (Morris and et al. 2008)

Challa and et al. (2008) introduced piezoelectric energy harvester with magnetic forces employed to tune resonant frequency. Magnetic forces are employed to change the stiffness of the piezoelectric energy harvester. Such interaction of piezoelectric energy harvester and external magnetic forces enables to increase or decrease the stiffness of the device and by this way alter the natural frequency of the piezoelectric energy harvester. Schematic view of the harvester is given in Fig. 1.12.

Performed numerical and experimental investigations of the proposed frequency tuning technique revealed that effective operation frequency can be 
changed by $\pm 40 \%$ from the native resonant frequency. During altering of the resonant frequency a power of $240-280 \mu \mathrm{W}$ can be obtained over the frequency range of 22-32 Hz (Challa and et al. 2008).
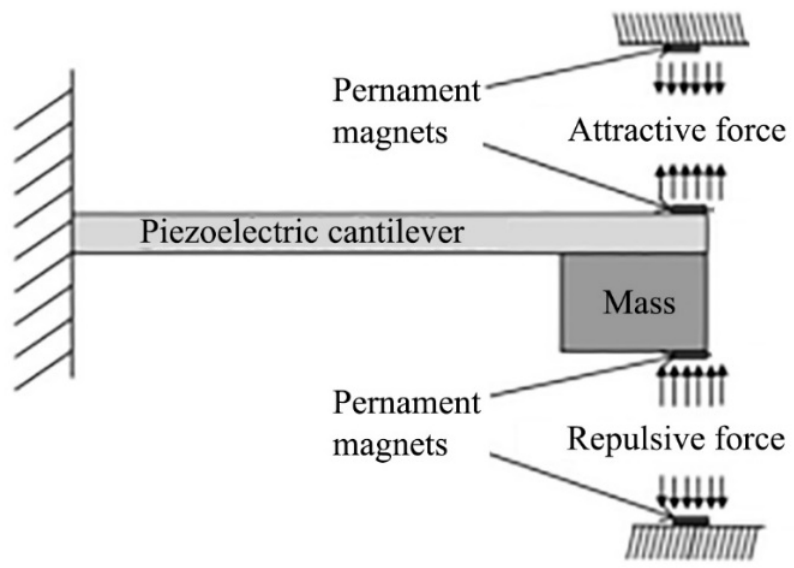

Fig. 1.12. Schematic view of piezoelectric energy harvester with magnetic resonant frequency tuning (Challa and et al. 2008)

Aboulfotoh and et al. (2017) reported on self-tuning piezoelectric energy harvester based on clamped-clamped cantilever with a slider. The proposed design of harvester consist of cantilever and slider that is placed on the cantilever. The cantilever rigidly fixed to supporting frame. There is a small gap between slider and cantilever that allows slider to move freely along the cantilever. Schematic view of the harvester given in Fig. 1.13.

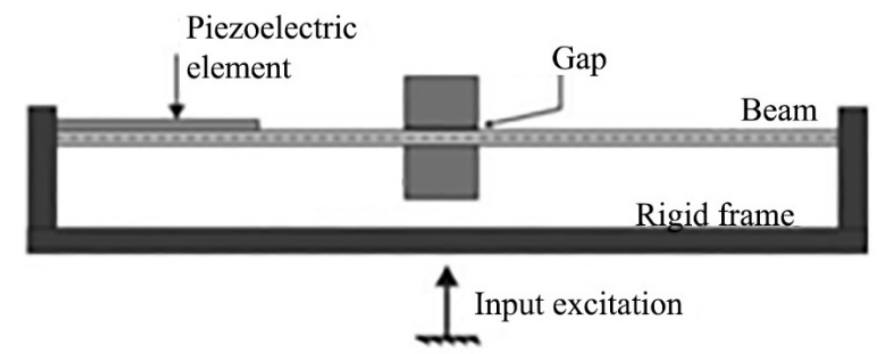

Fig. 1.13. Schematic view of self-tuning energy harvester (Aboulfotoh and et al. 2017)

Based on results of investigation authors concluded that proposed energy harvester is able to operate at a large bandwidth of excitation frequencies i. e. from 
$135 \mathrm{~Hz}$ to $165 \mathrm{~Hz}$. Self-tuning was achieved by sliders motion to the node position of excited deformation mode. Such behaviour of the slider leads to significant increment in the vibration amplitude as well as increment in output voltage level (Aboulfotoh and et al. 2017).

$\mathrm{Gu}$ and Livermore (2012) reported on piezoelectric energy harvester for rotation applications with passive resonant frequency self-tuning. The proposed energy harvester consist of rigid piezoelectric cantilever which is placed near a flexible driving cantilever with a seismic mass i. e. steel ball at the end of driving cantilever. The resonant frequency of the flexible driving cantilever is affected by the centrifugal forces. Thereby rotation affects the stiffness of the driving cantilever and by this way the resonant frequency of the overall harvesting system. The schematic view of energy harvester is given in Fig. 1.14.

Passive resonant frequency tuning occurs because resonant frequency of flexible cantilever directly depends on centrifugal force generated by rotation of whole system. The tension in piezoelectric cantilever is also inducted. On the other hand, stiffness is much higher and dominates over inducted axial tensioning effects. Dynamic centrifugal force is directly acts to natural frequency of piezoelectric cantilever during systems motion (Gu and Livermore, 2012).

Frequency tuning methods are able to provide possibility to adapt resonant frequencies of piezoelectric energy harvesters to frequencies of host vibration and by this way to achieve effective energy harvesting at broad frequency range.

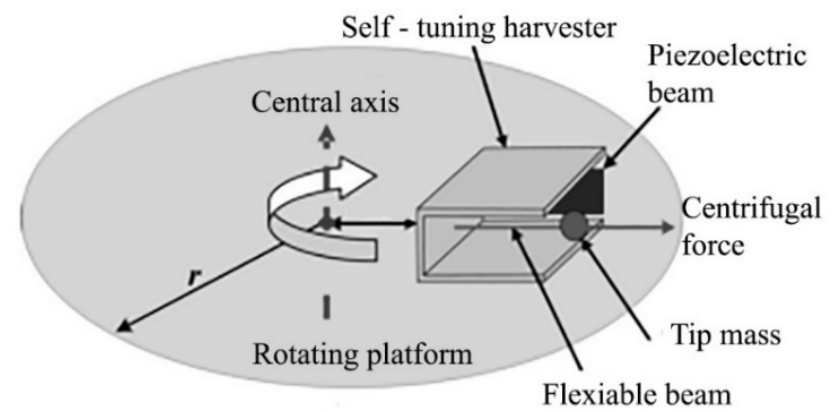

Fig. 1.14. Piezoelectric energy harvester for rotation applications with resonant frequency self-tuning configuration (Gu and Livermore, 2012)

Liu and et al. (2016) reported two-degree-of-freedom (2-DOF) cantilever based piezoelectric energy harvester with mechanical stopper for broadband energy harvesting. The proposed 2-DOF piecewise linear energy harvester consist of main piezoelectric cantilever for energy conversion and driving cantilever with mechanical stopper. Schematics of the proposed design given in Fig. 1.15. 


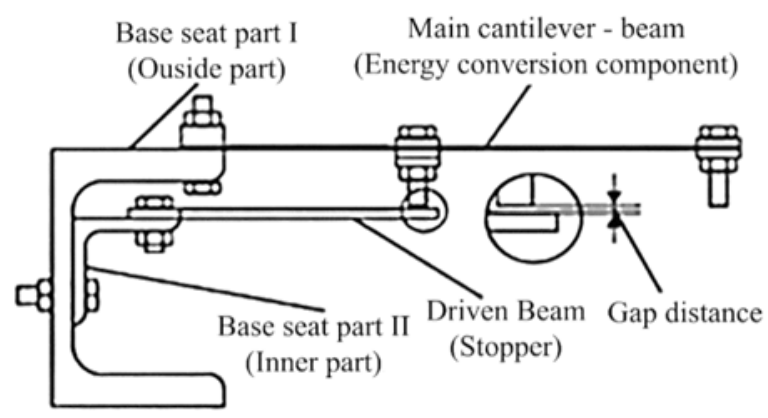

Fig. 1.15. 2-DOF piezoelectric energy harvester with mechanical stopper (Liu and et al. 2016)

Therefore, if vibrations of the host is appropriately high then the active cantilever starts vibrate and the mass placed in the middle of the system moves down over the gap distance. It creates impact to driven cantilever and as a result cantilever starts to vibrate for a shot time together with the active cantilever. Hence, the driven cantilever acts as mechanical stopper and ensures stiffness changes at the active cantilever and as a result changes resonance frequency (Liu and et al. 2016). The authors concluded that proposed design of the harvester provides frequency bandwidth of $7.4 \mathrm{~Hz}$ which is 5.2 times higher compare to the conventional 2-DOF linear energy harvester. Moreover, the maximum electrical power at the first and the second resonant frequencies can reach up to $429 \mu \mathrm{W}$ and $411 \mu \mathrm{W}$ respectively (Liu and et al. 2016).

Resonant frequency tuning based on mechanical methods were intensively investigated. It can be noticed that these methods are able to provide large frequency tuning range (Kazmierski and Beeby, 2011). However, mechanical methods for resonant frequency tuning have main disadvantage: these systems are depended on manual adjustment like pre-deflection, preload or gravity centre of seismic mass. Moreover, operation of energy harvester must be interrupted (Elvin and Erturk, 2013). Frequency tuning methods based on magnetic forces are able to provide moderate resonant frequency adjustment bandwidth (Leng and et al. 2017). However, this method is suitable only for scenarios where small frequency changes occur. Moreover, the usage of magnetic forces to tune resonant frequency increase the complexity of system design (Elvin and Erturk, 2013).

\subsubsection{Non-linear piezoelectric energy harvesters}

Non-linear behaviour obtained thru magnetic field influence to structural stiffness is able to provide resonant frequency tuning of energy harvester. However, this principle ensures efficient operation of the harvester at narrow frequency range. 


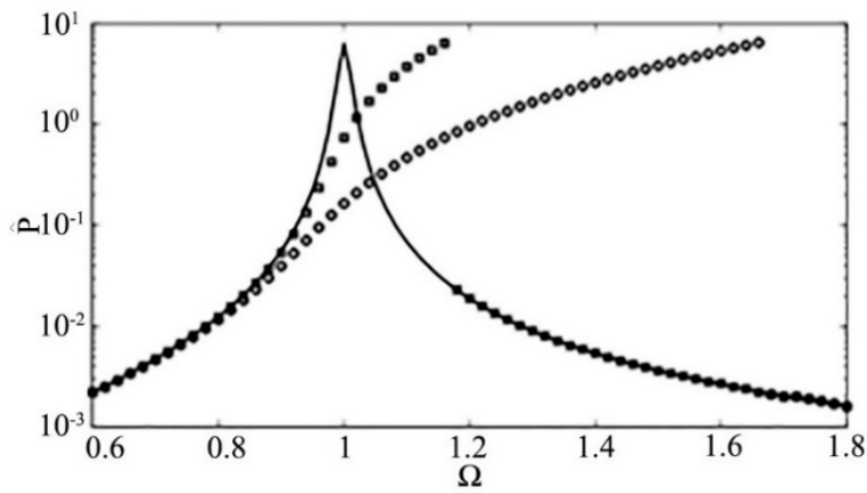

Fig. 1.16. Non-dimensional power of energy harvest with different non-linearity with damping ratio $\zeta=0.01$ and excitation amplitude 0.5 . Solid line-linear energy harvesting system; Squares and circles-harvesting system with different hardening conditions (Ramlan and et al. 2010)

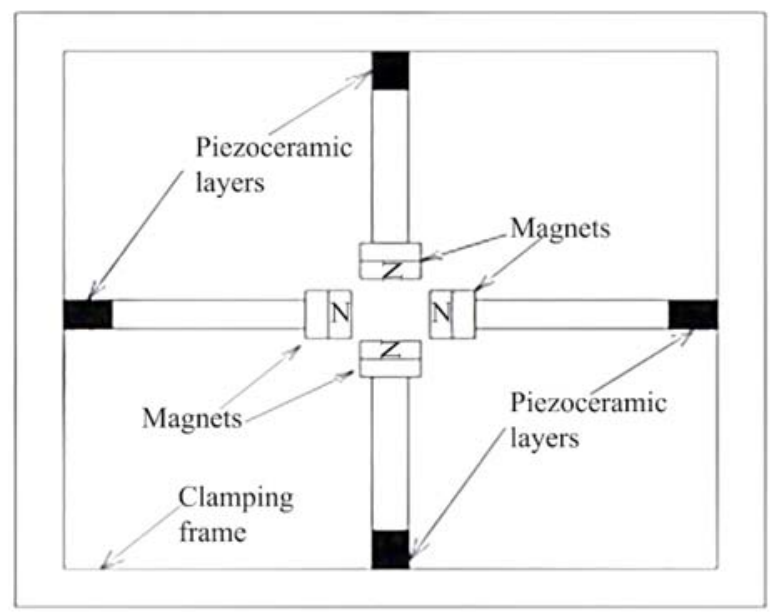

Fig. 1.17. Double bi-stable energy harvester (Wang, J. and Wang Z., 2017)

Ramlan and et al. (2010) studied non-linear mono-stable energy harvester with stiffness increasing mechanism. Employed numerical and analytical models revealed that energy harvester with stiffness increasing mechanism provides the same energy output as conventional energy harvester. Moreover, level of nonlinearity has no influence to the electrical performance of energy harvester.

However, according to graph given in Fig. 1.16 it can be noticed that monostable energy harvesting system with stiffness increasing mechanism has much 
larger bandwidth. Significant power can be harvested in this frequency range due to the shift of the resonant frequency (Ramlan and et al. 2010).

Wang, J. and Wang, Z. (2017) reported a double bi-stable piezoelectric energy harvester for energy harvesting from random vibrations. The goal of investigation was to improve energy harvesting at weak excitation amplitudes and pull down potential barrier thru bi-stable energy harvesting technique. The proposed design consist of four cantilevers with permanent magnets attached to free ends of cantilevers. Each magnet has three forces of magnetic repulsion and these forces serves for decreasing the potential barrier of the harvester. Schematic of the energy harvester design is shown in Fig. 1.17.

Based on results of analytical and experimental investigation, the authors concluded that double bi-stable piezoelectric energy harvester is able to overcome potential barrier at much lower excitation amplitude compare to single cantilever based energy harvester. The results obtained at the highest studied excitation amplitude showed that double bi-stable energy harvester vibration and output voltage amplitudes are much higher compare to single bi-stable energy harvester (Wang, J. and Wang, Z., 2017).

It can be found numerous implementations of non-linear piezoelectric energy harvesters based on mono-stable (Daqaq, 2012; Tao and et al. 2018), bi-stable (Wang and Liao, 2016; Paula and et al. 2015) mechanical stoppers (Twiefel and Westermann, 2013; Zhao and Yang, 2018). Introduction of non-linearity to piezoelectric energy harvesters can provide solution for the main disadvantage of energy harvesters i. e. narrow effective frequency response characteristics. Moreover, it can be found investigations on tri-stable (Zhu and et al. 2017), multi-stable (Harris and et al. 2017), hybrid (Yang and Towfighian, 2017) employment of multiple non-linear techniques (Wang and et al. 2017). Unfortunately, non-linarites can provide bandwidth of piezoelectric energy harvesters only from several hertz to ten of hertz (Elvin and Erturk, 2013). Therefore, if changes of excitation frequency is much wider then non-linear piezoelectric energy harvesters are not able to provide suitable energy supply in predefined frequency range. Hence, this problem can be solved by multi-frequency piezoelectric energy harvesters that will be overviewed in the next section.

\subsubsection{Multi-frequency piezoelectric energy harvesters}

In most cases, multi-frequency energy harvester are based on several cantilevers composed to cantilever array. Cantilevers composed in cantilever array have individual resonant frequencies. Such structural configuration provides possibility to obtain several discrete resonance peaks at narrow frequency range. Discrete resonances peaks are located close to each other and covers wider frequency range compare to non-linear energy harvesters. 
Zhou and et al. (2012a) reported on multi-frequency double cantilever for piezoelectric multi-frequency energy harvesting. The primary cantilever was used as dynamic magnifier and the secondary one was used as multi-frequency energy harvester. In general, the proposed concept is a dynamic magnifier with dual mass damper with tuning, where an intermediate mass inserted between the vibrating base and the harvester in order to amplify the vibrations in the harvester. The results of modal analysis of proposed multi-frequency energy harvester is given in Fig. 1.18.

Based on results of analytical, numerical and experimental investigations, the authors concluded that all vibration modes could be tuned for desired frequency spectrum by tuning dimensions of the both cantilevers and weights of seismic masses. Moreover, experimental investigation revealed that proposed concept of energy harvester is able to harvest 25.5 times more energy. Usage of such concept provides 10-1000 times higher output energy (Zhou and et al. 2012a).

Tadesse and et al. (2009) investigated hybrid multi-frequency energy harvester based on piezoelectric and electromagnetic energy conversion methods. Target of investigation was to employ the first and the second bending modes of cantilever for multi-frequency energy harvesting. The proposed design of energy harvester consist of tapered cantilever with three piezoelectric patches bonded on both sides of it.

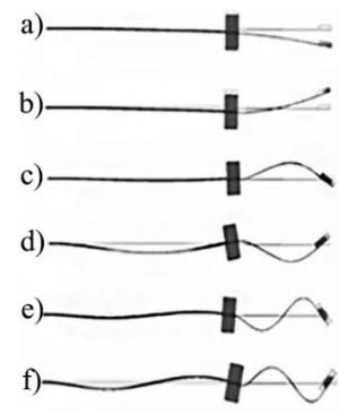

g)

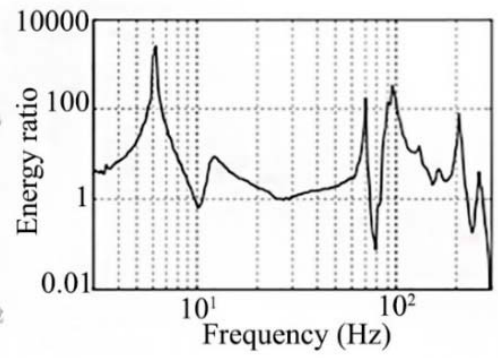

Fig. 1.18. First six mode shapes of harvester and output energy ratio: a) $1^{\text {st }}$ mode; b) $2^{\text {nd }}$ mode; c) $3^{\text {th }}$ mode; d) $4^{\text {th }}$ mode; e) $5^{\text {th }}$ mode; f) $6^{\text {th }}$ mode; g) ratio of harvested energy (in proportion to square of voltage) using the multi-frequency energy harvester over the traditional single cantilever beam-type harvester (Zhou and et al. 2012a)

Usage of tapered cantilever allows obtaining almost constant area moment of inertia and as a result, the cantilever becomes more sensitive to low excitation amplitudes. Also, stationary inductive coil was fixed at the housing of energy harvester hereby that tip mass of cantilever was concentric with the coil. Schematics of proposed energy harvester is given in Fig. 1.19. 


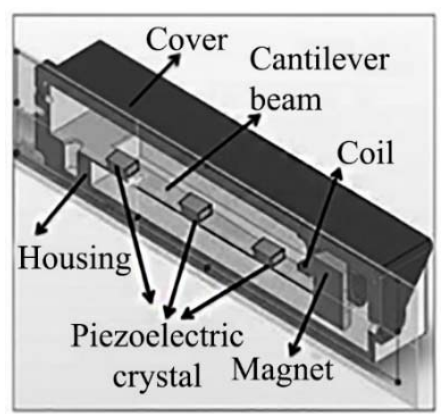

Fig. 1.19. Hybrid multi-frequency energy harvester (Tadesse and et al. 2009)

Advantages of such design are as follows: during systems excitation by constant low frequency the output energy based on electromagnetic part of the system. However, if excitation frequency is high, the piezoelectric part of the system becomes the main energy source. Such combination of electromagnetic and piezoelectric vibration energy conversion mechanisms leads to significally increased of output energy from one device over a wide operating frequency range (Tadesse and et al. 2009).

Authors concluded that combining of two energy conversion methods into the one platform allows to improve functionality of the system over a wide frequency range. Prototype of proposed energy harvester showed output power of $0.25 \mathrm{~W}$ and $0.25 \mathrm{~mW}$ from electromagnetic and piezoelectric parts, respectively. Considering to small size of the energy harvesting system that is $25 \times 30 \times 125 \mathrm{~mm}^{3}$ it can be noticed that authors achieved very high output characteristics (Tadesse and et al. 2009).

Ferrari and et al. (2008) reported on piezoelectric cantilever array based on three identical cantilevers with different weight of seismic masses. Usage of different seismic masses weights gives opportunity to cover wide frequency range thru difference in resonance frequencies and by this way obtain multi-frequency energy harvesting. Moreover, number of cantilevers can be increased in order to cover much wider frequency range. The schematic of multi-frequency energy harvester given in Fig. 1.20.

Unfortunately, the proposed design has main disadvantage i. e. during system operation at frequency sweep or at random frequency excitation at the highest efficiency operates only one cantilever while others are almost useless due to mismatch in resonant frequencies. So, power density of such system is much lower compare to other designs.

However, proposed design can be minimized for MEMS and to cover much wider frequency range compare to other multi-frequency or non-linear broad banding methods (Ferrari and et al. 2008). 


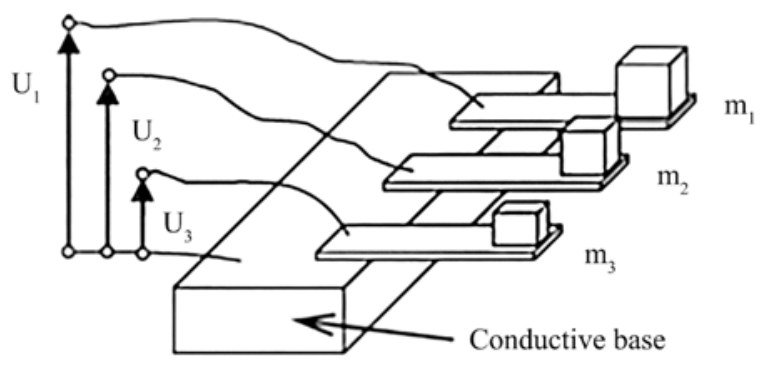

Fig. 1.20. Schematics of multi-frequency cantilever array: $U_{1}, U_{2}, U_{3}$ is output voltages; $\mathrm{m}_{1}, \mathrm{~m}_{2}, \mathrm{~m}_{3}$ is seismic masses (Ferrari and et al. 2008).

Kok and et al. (2011) studied two different designs of piezoelectric multifrequency cantilever arrays. The authors used thick lead zirconate titanate (PZT) film as main material for the energy harvesting systems. The first design consisted of six cantilevers with constant width and different lengths. The second design consisted of five cantilevers with constant length but different widths. In both cases height of cantilever was constant. In general, such implementations shows possibility to change geometrical parameters of cantilever arrays in order to change effective frequency range. The photo of prototypes is given in Fig. 1.21.

The authors concluded that array with different lengths of cantilevers is able to cover frequency range of $220-520 \mathrm{~Hz}$ with maximum output voltage of $0.78 \mathrm{~V}$, while array configuration with different widths is able to cover frequency range of 200-600 Hz with output voltage peak of $0.62 \mathrm{~V}$ (Kok and et al. 2011).
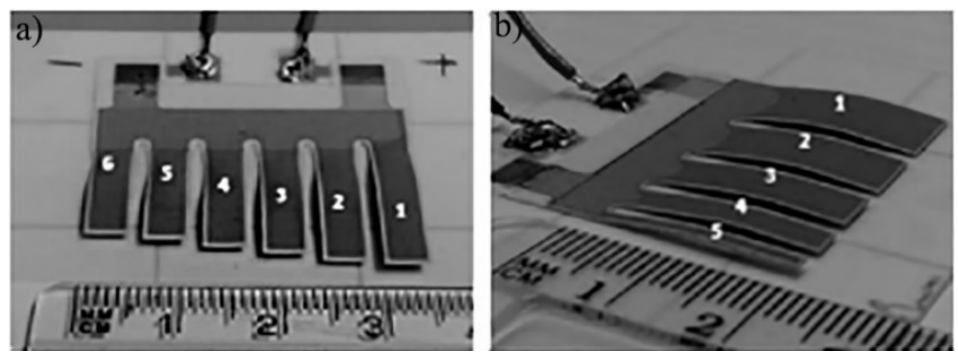

Fig. 1.21. Multi-frequency piezoelectric energy harvester based on cantilever arrays:

a) with different length of cantilevers; b) with different width of cantilevers

(Kok and et al. 2011)

Numerous implementations of multi-frequency energy harvesters are proposed till now. For example multi-frequency energy harvesters with double mass (Qu and et al. 2011), fractal-inspired (Castagnetti, 2016), two degree of freedom 
(2-DOF) (Wu and et al. 2012) or multiple degree of DOF (Xiao and et al. 2016), zigzag shaped (Lee and et al. 2018; Zhou and et al. 2017b) and etc. Extensive investigations and reported results shows that multi-frequency energy harvesters have huge potential. However, the main disadvantage of multi-frequency energy harvesters is still remaining-low power density at different frequencies or random excitation frequencies.

\subsection{Conclusions of chapter 1 and formulating tasks for the dissertation}

1. The review of literature related to energy harvesting systems shows that various energy harvesting technologies are used. However, piezoelectric energy harvesting systems are most suitable for practical implementations, because of the simple design, high scalability and magnetic field free. Also, it does not require external power supply. On the other hand, there still lacking solutions for more effective usage of piezoelectric layer.

2. Piezoelectric energy harvesters based on cantilevers need more deep research on non-uniform bending strain distribution along the length of the cantilever. The most of research was done analysing rectangular, trapezoidal and triangle shapes of the cantilever. However, research on bending strain distribution of cantilevers with modifications cross-section is performed insufficiently.

3. Piezoelectric multi-frequency energy harvesters based on cantilever arrays suffers from low power and energy densities. It mainly caused because of only single cantilever operates efficiently at resonant frequency while the rest cantilevers generate very low electrical output.

Based on the conclusions, the following tasks are formulated to achieve the aim:

1. To propose a method for increasing electric output power density and energy density of piezoelectric cantilever and cantilever arrays through irregular shape of cross sections and polygon type structures based on linked cantilevers.

2. To investigate piezoelectric energy harvesters based on cantilevers with irregular shape of cross-section, to perform numerical and experimental study and asses their electrical characteristics.

3. Numerically and experimentally investigate mechanical and electrical characteristics of polygon type piezoelectric energy harvesters based on rigidly composed cantilevers and to evaluate their efficiency. 


\section{2}

\section{Cantilever type piezoelectric energy harvesters with irregular cross-sections}

This chapter shows numerical and experimental investigations of piezoelectric cantilevers with irregular cross-sections used for mechanical vibrations energy harvesting. Firstly, the chapter covers motivation and idea of irregular cross-sections. The second part of the chapter summarize numerical and experimental investigations performed on rectangular and trapezoidal piezoelectric cantilevers with cross-section modified by rectangular, cylindrical and trapezoidal gaps.

The results presented in this chapter are published in two papers (Čeponis et al. 2017, Čeponis et al. 2018).

\subsection{Background of irregular cross-section designs}

Usually, mechanical vibrations energy harvesting systems are based on piezoelectric cantilevers. In general, cantilevers vibrates at the first fundamental frequency and the first out of plane bending mode. It leads that the highest bending strain value is obtained at the fixed end of cantilever while at the free end strain is equal to 0 . Bending strain distribution function along the length of cantilever is 
almost constant. However, based on Eq. (1.36) output voltage of energy harvester depends on definite integral of bending strain function. It means that function of bending strain must be constant at piezo ceramic layer in order to increase output voltage.

In order to obtain constant bending strain distribution and increase output voltage, modifications of cross-section shape were proposed. The modifications of cross-section geometrical parameters allow to reduce area moment of inertia and as a result to increases bending strain value at modified section.

It can be found that area moment of inertia strongly depends on thickness of passive layer and active layer. In this work the main focus is on passive layer cross-section modifications. Possibility modify active layer was neglected due to technologically difficult processing of the material. Therefore, reduction of metal layer provides decreased area moment of inertia and as can be found strain relationship between strain and area moment of inertia is inversely proportional. Hence, reduction of area moment of inertia can be obtained by reduction of metal layer thickness at whole system. It will lead to improved bending strain values. On the other hand, bending strain distribution function ant piezoelectric layer will be the same as at system before reduction. Therefore, proposed modifications based on periodical gaps not only improves bending strain but also will ensure almost constant bending strain distribution in piezoelectric layer. The modifications of cross sections made by rectangular, cylindrical and trapezoidal gaps. The gaps placed with same periodity regardless of theirs geometrical shapes. Moreover, cantilever with conventional rectangular cross-section investigated as well, in order to obtain reference data for comparison of the results. The schematics of cross-sections are shown in Fig. 2.2.

The shapes of gaps designed in order to obtain the highest reduction of area moment of inertia. The geometrical parameters of the gaps is almost the same, it done in order to obtain possibility compare value of bending strain obtained at with different gaps. Therefore, cross-sections designed with same geometrical parameters and boundary conditions. Length $L$, height $H$ and width of the crosssection were $10 \mathrm{~mm}, 1 \mathrm{~mm}$ and $5 \mathrm{~mm}$, respectively.
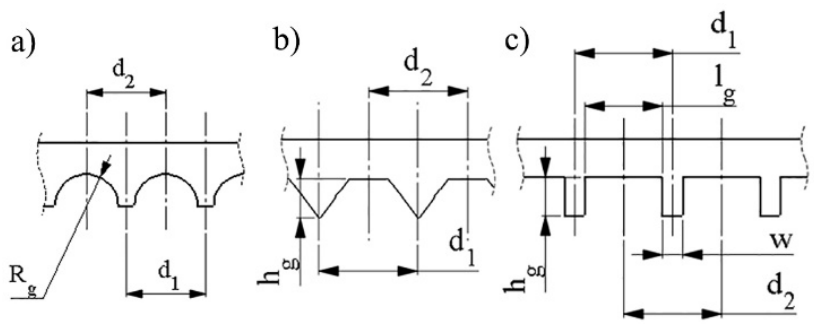

Fig. 2.1. Geometrical parameters of the gaps used for modification of cross-sections:

a) cylindrical gaps; b) trapezoidal gaps; c) rectangular gaps 
a)

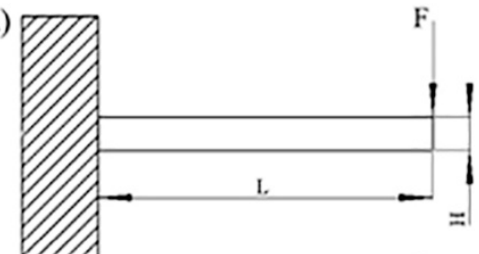

c)

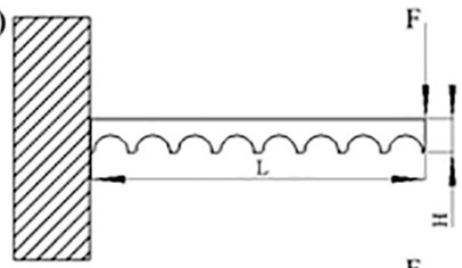

b)

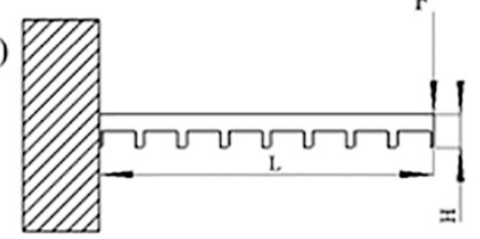

d)

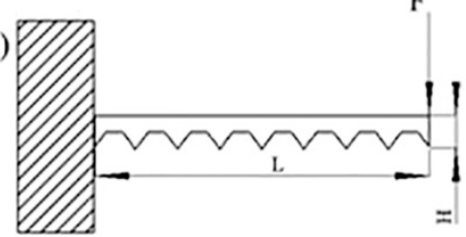

Fig. 2.2. Schematics of investigated cross-sections configurations: a) without cross-section modifications; b) cross-section modified by rectangular gaps; c) cross-section modified by cylindrical gaps; d) cross-section modified by trapezoidal gaps

Table 2.1. Geometrical parameters of the gaps used for cross-sections modifications

\begin{tabular}{|l|l|l|}
\hline Parameter & Value & Comments \\
\hline $\mathrm{d}_{1}=\mathrm{d}_{2}$ & $1.26 \mathrm{H}$ & The periodicity of gaps \\
\hline $\mathrm{R}_{\mathrm{g}}=\mathrm{h}_{\mathrm{g}}$ & $0.5 \mathrm{H}$ & $\begin{array}{l}\text { The radius and height of } \\
\text { gaps }\end{array}$ \\
\hline $\mathrm{l}_{\mathrm{g}}$ & $\mathrm{H}$ & $\begin{array}{l}\text { The length of rectangular } \\
\text { gap }\end{array}$ \\
\hline $\mathrm{w}$ & $0.26 \mathrm{H}$ & $\begin{array}{l}\text { The distance between rec- } \\
\text { tangular gaps }\end{array}$ \\
\hline
\end{tabular}

All geometrical parameters of the gaps related to the height $\mathrm{H}$ of the cross sections. Motivation of this interaction based on direct relationship between area moment of inertia and height of the cross-section. Also, periodicity between gaps $d_{1}$ and $d_{2}$ were influenced by need to protect brittle piezo ceramic from possible cracks during dynamic and static loads applied to cantilevers.

Therefore, numerical investigation of samples was performed. The samples were modelled with strict respect to geometrical parameters represented in Table 2.1. One end of all samples fixed rigidly. Static load $F$ applied to each tip. Load force value was constant for all cases i. e. $0.1 \mathrm{~N}$. Schematics of samples is given in Fig. 2.3.

However, considering to the same geometric parameters of the gaps differences between cantilevers occurs. In order to indicate the differences, weigh of modified cantilevers calculated considering to condition that the cantilevers are 
made from beryllium bronze $\mathrm{C} 17200$. The mass of cantilevers modified by cylindrical, rectangular and trapezoidal gaps are $0.283 \mathrm{~g}, 0.265 \mathrm{~g}, 0.270 \mathrm{~g}$, respectively. According to these values, we can conclude that the highest difference between masses does not exceed $13 \mathrm{mg}$ or $4.59 \%$. Therefore, investigation of bending strain distribution, comparison of strain values and predictions of possible outputs are comparable.

Numerical investigation based on stationary study performed with Comsol 5.2 software in order to indicate bending strain distribution, average bending strain value and deflection of the modified cantilevers under same conditions. Geometrical parameters and boundary conditions were set as given in Fig. 2.3 and Table 2.1. Strain tensor component $\varepsilon_{Y Y}$ and tip displacement in $z$ direction chosen as critical parameters for this investigation. The strain tensor $\varepsilon_{Y Y}$ represents bending deformations that directly related to output voltage of piezoelectric cantilever. The probe line for bending strain component was placed on top surface of samples. Obtained strain characteristics and strain distribution visualisation given at Fig. 2.4.

Fig. 2.3 shows bending strain characteristics at sample with regular crosssection. As can be noticed, the highest bending strain value is located near fixed end of cantilever while the lowest at free end.

On the other hand, cantilevers with modified cross sections have noticeably higher bending strain distribution. The distribution fluctuates over length of sample. The fluctuations of bending strain based on cross section thickness and on value of area moment at particular point of cross section. In order to compare the results, the mean value of bending strains with standard deviation were calculated. as well as deflection of the tip of every sample. The results of comparison are given in Fig. 2.4.

Analysis of Fig. 2.5 revealed that the highest bending strain tensors component $\varepsilon_{Y Y}$ value obtained at cross section with rectangular gaps. Compare to regular cross section design bending strain value is higher more than 3.7 times. Also, can be noticed that deviation for this case has the highest value as well. Considering to possible practical implementation of cross-section modifications by rectangular gaps is the most suitable.

The second highest strain value was obtained at cantilever modified by trapezoidal gaps. Compare to regular cross section design, average strain value is higher more that 3.15 times and differences in average bending strain value is only $4.98 \%$. Fig. 2.5 also represents deflection of samples under same loading conditions. Analysis of the results showed that the highest tip deflection is obtained when cantilevers cross-section modifications are made by rectangular gaps and is $4.5 \mu \mathrm{m}$. This value is 6.82 times higher compare to cantilever with regular cross section design. The second highest tip deflection is obtained at cantilever modified 
by trapezoidal gaps. The displacement of tip reached $3.6 \mu \mathrm{m}$. This value is 5.45 times higher compare to cantilever with regular cross-section.
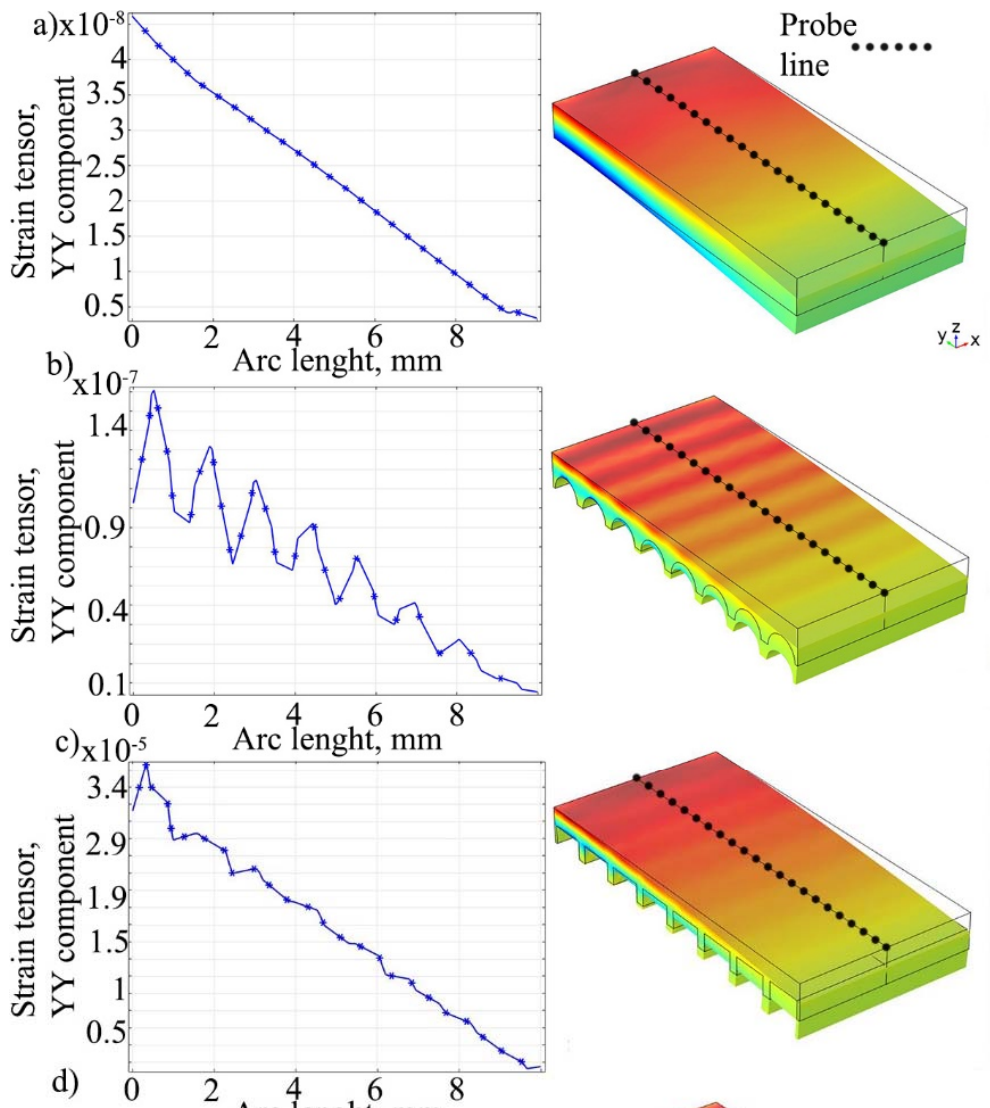

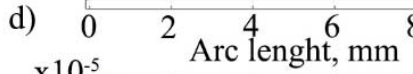
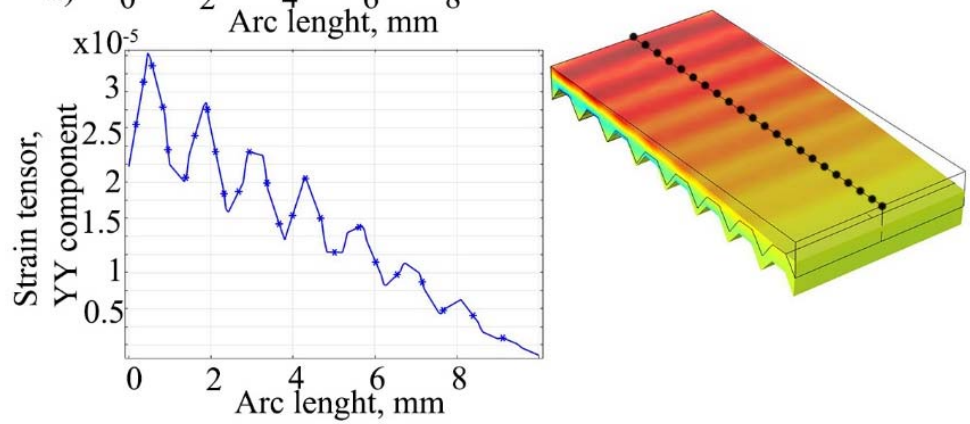

Fig. 2.3. Bending strain characteristics: a) regular cross-section design; b) cross-section modified by cylindrical gaps; c) cross-section modified by rectangular gaps;

d) cross-section modified by trapezoidal gaps 

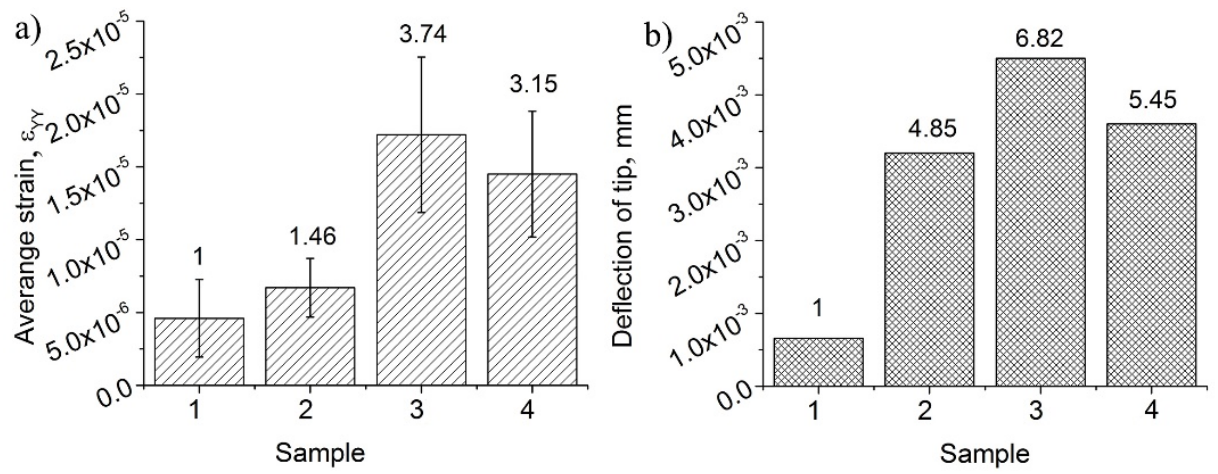

Fig. 2.4. Average strain and tip deflection characteristics:

a) average strain characteristics; b) tip deflection characteristics; 1 - regular cross-section design; 2 - cross-section modified by cylindrical gaps; 3 - cross-section modified by rectangular gaps; 4 - cross-section modified by trapezoidal gaps

Therefore, on basis of results can be concluded that modifications of cross sections can provide much higher bending strain values across cantilever. In addition, deflections of modified cantilevers will be increased as well.

\subsection{Investigation of rectangular piezoelectric cantilevers with irregular cross-sections}

This section provides results of numerical and experimental investigation of rectangular cantilevers with irregular cross sections. Three different cross sections investigated. Modified profiles of cross sections reduce stiffness of cantilevers and ensures gain in bending strain and strain distribution across piezo ceramic layer. Therefore, modifications of cross sections improve electrical characteristics of rectangular piezoelectric cantilevers.

\subsubsection{Designs of rectangular piezoelectric cantilevers with irregular cross-sections}

Geometrical parameters of presented piezoelectric cantilevers are the same as well as materials and weight of seismic mass is $8.71 \mathrm{~g}$. However, difference is crosssection profile under piezo ceramic layer can be observed. The profiles based on numerical investigation discussed in section 2.1. Hence, it was noticed that output voltage depends on bending strain function inducted in piezo ceramic layer. Moreover, it was indicated that bending strain function at piezoelectric cantilever is 
directly proportional to area moment of inertia in passive layer under piezo ceramic layer. Therefore, reduction of passive layer thickness will cause a lower value of area moment of inertia and larger bending strain value at piezoelectric cantilever. So, modifications of cross-section must be investigated in order to verify these presumptions.

Periodical gaps with cylindrical, rectangular and trapezoidal shapes introduced for this purpose. Such shapes of the gaps chosen with the aim to reduce value of the area moment of inertia. Geometrical parameters of the gaps are based on numerical investigation presented in section 2.1. The gaps placed under piezo ceramic layers. Moreover, the regular cantilever designed for the reference and comparison purposes. The schemes of the cross section designs and geometrical parameters of the cantilevers given in Fig. 2.6 and Table 2.2.

Table 2.2. Geometrical parameters of the cantilevers

\begin{tabular}{|l|l|l|}
\hline Parameter & Value, $\mathrm{mm}$ & Description \\
\hline $\mathrm{w}$ & 5 & Widths of the cantilevers \\
\hline$t_{\mathrm{s}}$ & 1 & Thickness of the cantilevers \\
\hline $\mathrm{t}_{\mathrm{c}}$ & 0.5 & Thickness of the piezo ceramic layer \\
\hline$l_{\mathrm{e}}$ & 30 & Length of the piezo ceramic layer \\
\hline $\mathrm{l}_{\mathrm{b}}$ & 50 & Length of the cantilever \\
\hline $1_{\mathrm{m}}$ & 10 & Length of the seismic mass \\
\hline $1_{\text {cir }}$ & 29 & Length of modified cross section \\
\hline $1_{\text {rec }}$ & 28.5 & Length of modified cross section \\
\hline$l_{\text {hex }}$ & 29.5 & Length of modified cross section \\
\hline
\end{tabular}

a)

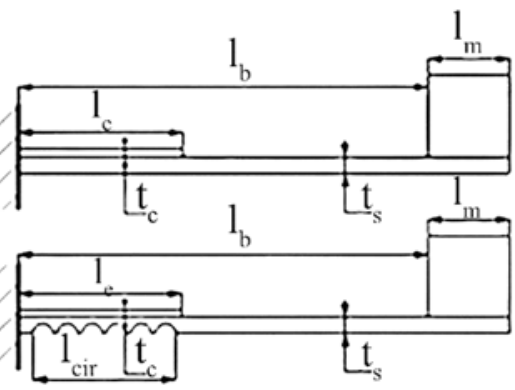

c)

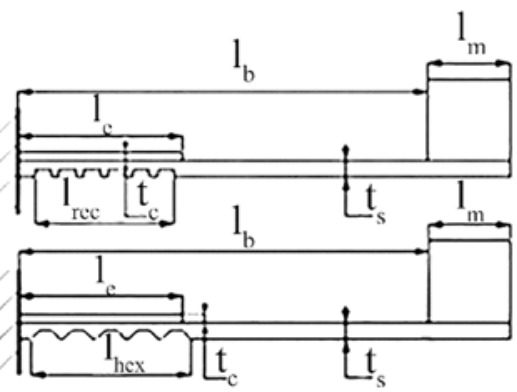

Fig. 2.5. Schematics of the cantilevers with irregular cross sections: a) conventional design of the cross-section; b) cross-section modified by cylindrical gaps; c) cross-section modified by rectangular gaps; d) cross section modified by trapezoidal gaps 


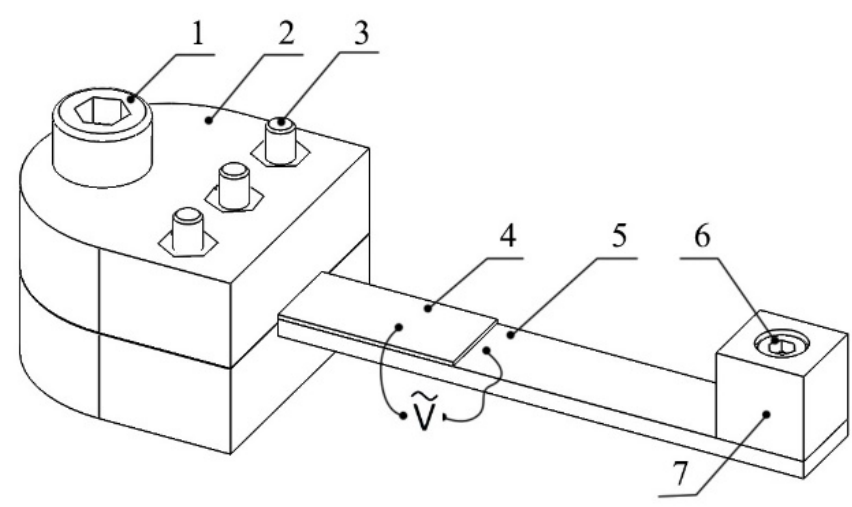

Fig. 2.6. Principle scheme of piezoelectric energy harvesting system: 1 - clamping bolt of the whole structure; 2 - plastic support frame; 3 - clamping bolts for cantilever; 4 - piezo ceramic layer; 5 - cantilever; 6 - clamping bolt for the seismic mass; 7 - seismic mass

Principle scheme of the piezoelectric energy harvesting system based on proposed cantilevers shown in Fig. 2.6. The energy harvesting system consists of rectangular cantilever with piezo ceramic layer, which glued on the top surface of the cantilever. The seismic mass attached to the tip of cantilever by bolt. The plastic clamping frame with three bolts used to clamp the cantilever at the one end and to fix whole energy harvesting system to the host.

\subsubsection{Numerical investigation of rectangular piezoelectric cantilevers with irregular cross-sections}

Numerical investigation of the cantilevers with irregular cross section performed. The aim of investigation was to analyse and assess mechanical and electrical characteristics of the proposed piezoelectric cantilevers and to compare results to the conventional case. Modal analysis of each cantilever performed. Natural frequencies and modal shapes obtained. Frequency response analysis performed in order to obtain mechanical and electrical characteristics of the piezoelectric cantilevers. Finite element models (FEM) built by Comsol Multiphysics 5.2 software. Properties of the materials and boundary conditions used for the models given in Table 2.3 and Fig. 2.7.

Acceleration of the host was set to $0.5 \mathrm{~m} / \mathrm{s}^{2}$, the gravity force was included in the models as well. Resistive loads connected in parallel to the piezo ceramic layer. The approximate optimal resistive load value calculated by Eq. (2.1). 


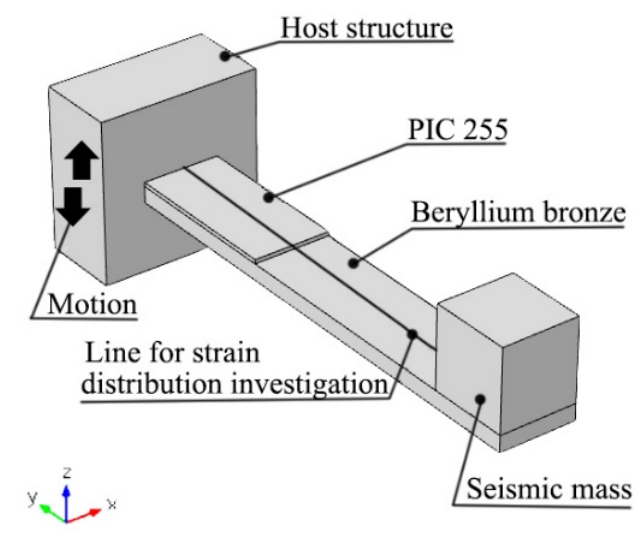

Fig. 2.7. Numerical model of the cantilever

$$
R_{o p t}=\frac{t_{c}}{w l_{e} \varepsilon_{33} \omega_{n}}=\frac{1}{\omega_{n} C_{p}} .
$$

Here, $t_{c}$ is the thickness of piezo ceramic layer, $w$ is width of piezo ceramic layer, $l_{e}$ is length of piezo ceramic layer, $\varepsilon_{33}$ the dielectric constant, $\omega_{n}$ natural frequency of piezoelectric cantilever, $C_{p}$ is the capacitance of piezo ceramic layer. The capacitance of the piezo ceramic layer can be calculated as simplified parallel plate capacitor.

The optimal resistive loads were calculated in order to maximize power transfer from energy source to electrical load (Table 2.4). A key factor of the optimal resistance load is match to the resistance of the source. As a result, amount of power delivered to the load is the same as the power dissipated in the source. So, when both resistances matches, average power could be expressed as follows:

$$
P_{a v g}=\frac{1}{2} \frac{U^{2} R_{o p t}}{\left(R_{S}+R_{o p t}\right)^{2}} .
$$

Here $U$ is peak voltage; $R_{S}$ is resistance of the power source.

Modal analysis of piezoelectric cantilevers performed in order to indicate natural frequency of the first, out-of plane, bending mode for all cantilevers. The results of modal analysis given in Table 2.5. Obtained results revealed that natural frequencies of piezoelectric cantilevers are within interval 25-600 Hz. This frequency spectrum falls to the most common ambient vibrations frequency range (Kazmierski and Beeby, 2011).

Frequency domain study of cantilevers performed in order to analyse bending strain and it distribution characteristic. The numerical investigations of electrical 
characteristics as output voltage, output current and average output power performed as well.

Table 2.3. Material properties

\begin{tabular}{|l|l|l|}
\hline Material properties & $\begin{array}{l}\text { Beryllium bronze, } \\
\text { C17200 }\end{array}$ & Piezo ceramic PIC255 \\
\hline Density, $\mathrm{kg} / \mathrm{m}^{3}$ & 8360 & 7800 \\
\hline Young's modulus, $\mathrm{N} / \mathrm{m}^{2}$ & $10^{10}$ & - \\
\hline Poisson's ratio & 0.34 & - \\
\hline $\begin{array}{l}\text { Isotropic structural loss } \\
\text { factor }\end{array}$ & 0.02 & 0.015 \\
\hline Relative permittivity & - & $\begin{array}{l}\text { In the polarization direction } \\
\varepsilon_{33}{ }^{\mathrm{T}} / \varepsilon_{0}=1200 \\
\text { Perpendicular to polarity } \varepsilon_{11}{ }^{\mathrm{T}} / \varepsilon_{0} \\
=1500\end{array}$ \\
\hline $\begin{array}{l}\text { Elastic stiffness coefficient } \\
\mathrm{c}_{33} \mathrm{D}, \mathrm{N} / \mathrm{m}^{2}\end{array}$ & - & $16.6 \cdot 10^{10}$ \\
\hline $\begin{array}{l}\text { Dielectric loss factor-tan, } \\
\delta \cdot 10^{-3}\end{array}$ & - & 20 \\
\hline Coupling factor, $\mathrm{k}_{31}$ & - & 0.35 \\
\hline $\begin{array}{l}\text { Piezoelectric voltage } \\
\text { coefficient } \mathrm{g}_{31} \cdot 10^{-3}, \mathrm{mV} / \mathrm{N}\end{array}$ & - & -11.3 \\
\hline
\end{tabular}

Table 2.4. Values of the optimal resistive

\begin{tabular}{|l|l|}
\hline Cantilever & Value, $\mathrm{M} \Omega$ \\
\hline Conventional & 1.415 \\
\hline Modified by cylindrical gaps & 3.675 \\
\hline Modified by rectangular gaps & 3.042 \\
\hline Modified by trapezoidal gaps & 3.694 \\
\hline
\end{tabular}

Table 2.5. Natural frequencies of piezoelectric cantilevers

\begin{tabular}{|l|l|}
\hline Type of piezoelectric cantilever & Natural frequency, $\mathrm{Hz}$ \\
\hline Conventional cantilever & 205.32 \\
\hline Cantilever with cylindrical gaps & 105.07 \\
\hline Cantilever with rectangular gaps & 116.07 \\
\hline Cantilever with trapezoidal gaps & 123.16 \\
\hline
\end{tabular}


Analysed frequency ranges stated with strict respect to the results of the modal analysis. Bending strain and it distribution characteristics analysed in the centre of each cantilever as shown in Fig. 2.7. The strain probe placed on the surface of the piezo ceramic layer and whole cantilever in order to obtain the strain characteristics along the length of piezoelectric cantilever.

The subject of evaluation was bending strain tensor component $\varepsilon_{\mathrm{YY}}$. The $\varepsilon_{\mathrm{YY}}$ strain tensor is one of the parameters, which determinates electrical characteristics of the cantilevers, which operates at bending modes. The results of numerical investigations given in Fig. 2.8 and Fig. 2.9.

Analysis of the graph (Fig. 2.8 a) showed that bending strain distribution at the conventional cantilever constantly decreasing from the fixed to free end. It can be noticed, that graph has rupture at $30 \mathrm{~mm}$. It was caused by sudden change in the thickness of piezoelectric cantilever. Additional shear deformations occur due to differences in the thickness. The highest bending strain value at the conventional piezoelectric cantilever obtained at frequency $205 \mathrm{~Hz}$. Maximum bending strain $\varepsilon_{Y Y}$ value equal to $1.5 \cdot 10^{-3}$. The difference between bending strain value at the fixed and free end of the piezoelectric cantilever is $33.41 \%$. Hence, it can be concluded that bending strain at piezo ceramic is distributed non-uniformly and as a result, piezo ceramic layer is employed inefficiently.

Analysis of the Fig. 2.8 b, showed that bending strain characteristics at cantilever with cylindrical gaps has peaks. Such behaviour of bending strain characteristic caused by periodically changes in area moment of inertia. It can be noticed that thickness of the cantilever is one of key parameters that determinates value of the area moment of inertia as well as distribution function of it.

Therefore, value and distribution function of area moment of inertia have direct influence to bending strain and it distribution. So, a function of area moment of inertia was obtained by the periodic cylindrical gaps and as a result the highest strain value was obtained at $105 \mathrm{~Hz}$. Maximum strain $\varepsilon_{Y Y}$ value was equal to $9 \cdot 10^{-3}$. The difference between bending strain value at the fixed and free end of the cantilever is $22.25 \%$. The results shows that maximum strain value increased approximately 6 times and bending strain distribution improved more than $12 \%$ compare to the conventional piezoelectric cantilever.

Fig. 2.9 a, shows that bending strain and it distribution characteristic at the cantilever with rectangular gaps has similar strain characteristics to case with cylindrical gaps. Periodic bending strain peaks caused by modifications made to the cross section. 


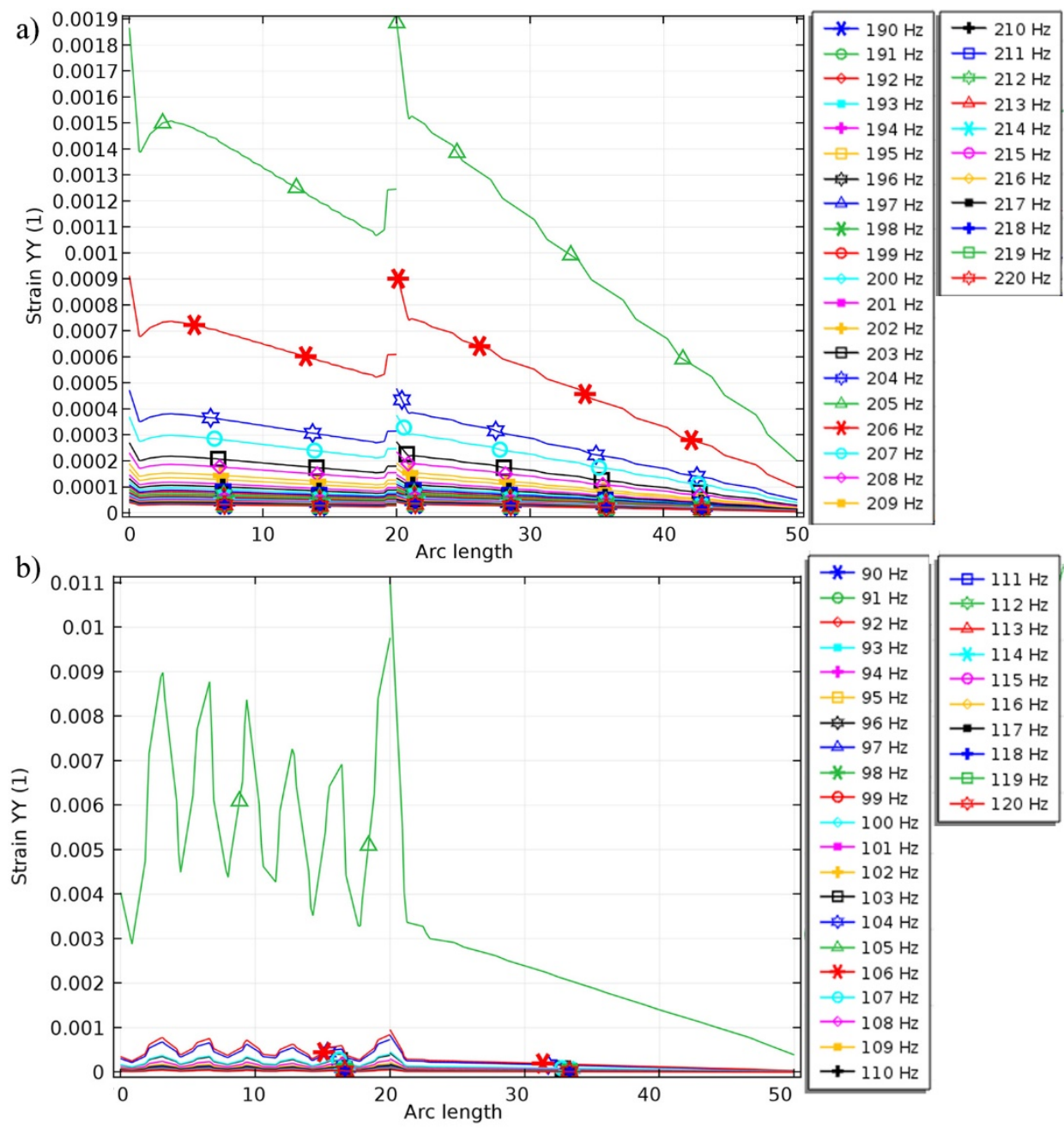

Fig. 2.8. Bending strain characteristics at conventional cantilever and cantilever modified by cylindrical gaps: a) conventional cantilever; b) cantilever modified by cylindrical gaps

The highest bending strain value obtained at $116 \mathrm{~Hz}$ and it is equal to $1.4 \cdot 10^{-3}$. The difference between bending strain values at the fixed and free end of the piezoelectric cantilever is $28.57 \%$. It can be noticed that the highest bending strain value is slightly lower compare to the conventional piezoelectric cantilever. 


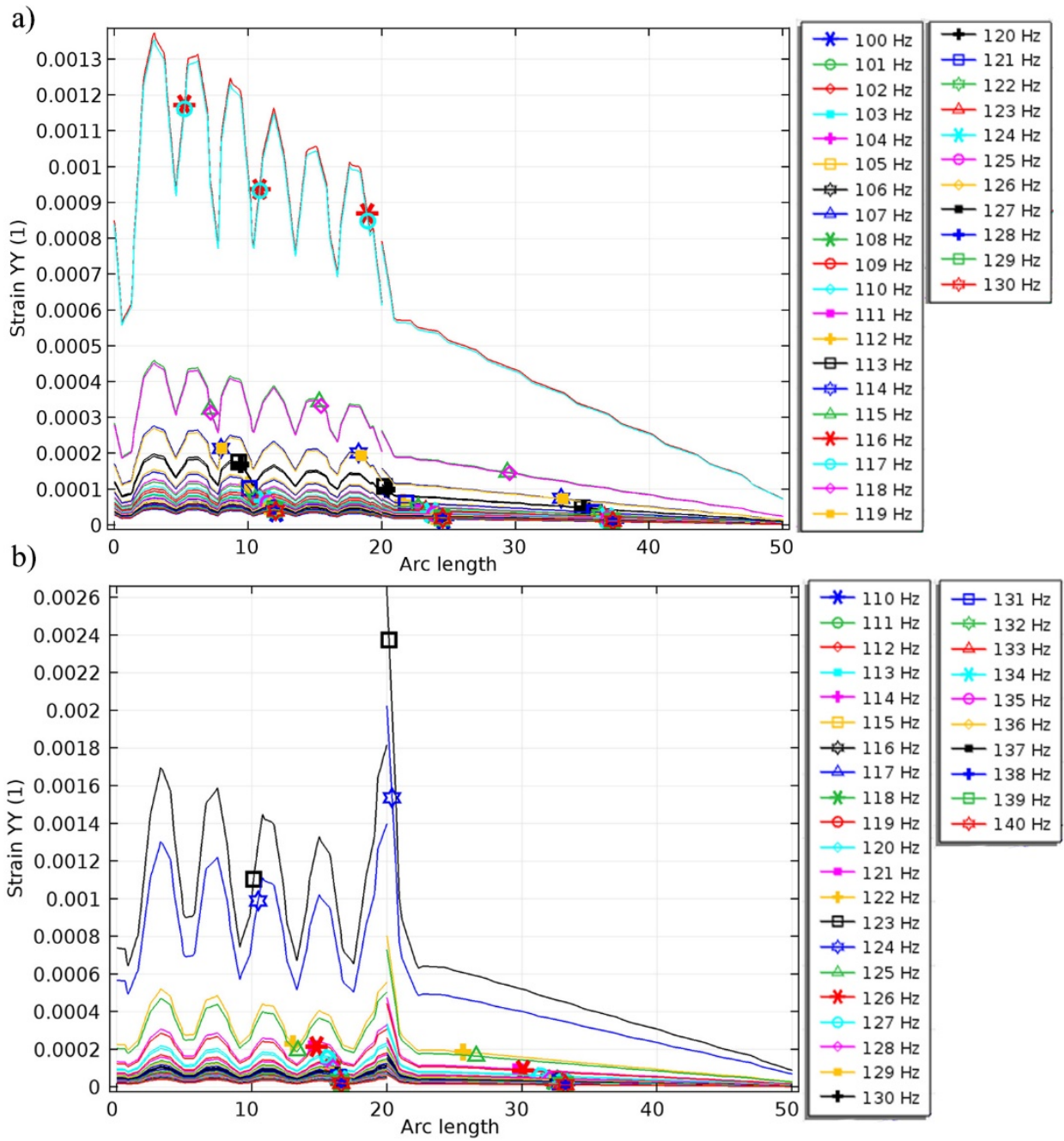

Fig. 2.9. Bending strain characteristics of cantilevers modified by rectangular and trapezoidal gaps: a) cantilever modified by rectangular gaps; b) cantilever modified by trapezoidal gaps

On the other hand, bending strain distribution has better characteristic compare to the conventional cantilever. It caused by geometry of the gaps i. e. at the corners of the gaps additional shear deformations were inducted and by this way strain $\varepsilon_{Y Y}$ distribution was improved. According to this can be concluded that bending strain distribution was improved more than $10 \%$. Such characteristic will 
ensure improved usage of piezo ceramic layer compare to the conventional piezoelectric cantilever.

Results of the numerical investigation given in Fig. 2.9 b represents bending strain and strain distribution characteristic at the piezoelectric cantilever with trapezoidal gaps. Non-uniform bending strain characteristic with periodic strain peaks can be observed in this case as well. The highest bending strain value occurred at frequency $123 \mathrm{~Hz}$ with maximum value equal to $1.75 \cdot 10^{-3}$. The difference between bending strain values at the fixed and free end of the cantilever is $20.87 \%$. It can be noticed that the highest bending strain value obtained in this case is slightly higher compare to the conventional piezoelectric cantilever. Moreover, bending strain distribution was improved more than $12 \%$ compare to the conventional piezoelectric cantilever. In order to indicate piezoelectric cantilever with the best bending strain characteristics the comparison of average $\varepsilon_{Y Y}$ strain performed. The results of comparison given in Fig. 2.10.

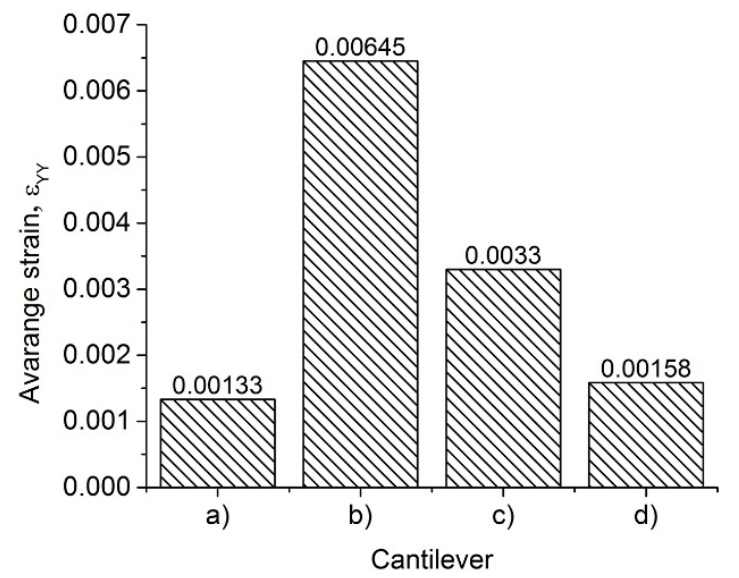

Fig. 2.10. Comparison of average bending strain component $\varepsilon_{Y Y}$ : a) conventional cantilever, b) cantilever with cylindrical gaps; c) cantilever with rectangular gaps; d) cantilever with trapezoidal gaps per didelis

According to the results given in Fig. 2.10 become obvious that the best bending strain characteristic has piezoelectric cantilever with the cylindrical gaps. An average strain at the piezoelectric cantilever with cylindrical gaps is 4.8 times higher compare to the conventional piezoelectric cantilever. On basis of these results can be concluded that cylindrical gaps have noticeable influence to the bending strain characteristics. The numerical investigations of electrical characteristics performed as well. The optimal resistance loads (Table 2.4) were connect in parallel with piezo ceramic layer. 

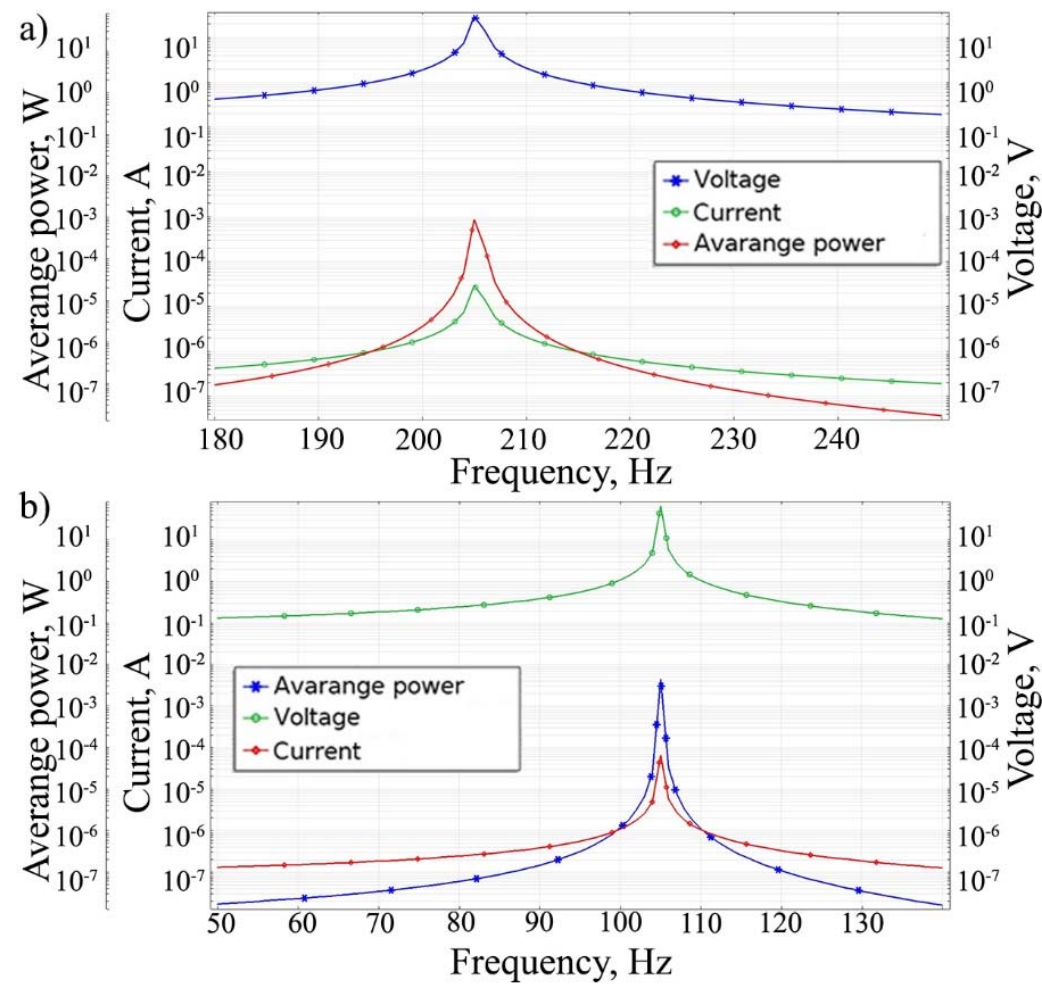

Fig. 2.11. Electrical characteristics of the piezoelectric cantilevers: a) conventional cantilever; b) cantilever with cylindrical gaps

The results of numerical investigations given in Fig. 2.11 and Fig. 2.12.

The electrical characteristics of conventional piezoelectric cantilever given in Fig. 2.11 a. Analysis of the graph revealed that the highest values of the electrical characteristics obtained while the cantilevers base excitation frequency was $205 \mathrm{~Hz}$. Therefore, output voltage on the resistive load reached $15.5 \mathrm{~V}$, current at the resistance load was equal to $16.1 \mu \mathrm{A}$. An average power was equal to $0.22 \mathrm{~mW}$. Obtained values will be used as a reference data for further comparison of the piezoelectric cantilevers.

The electrical characteristics of the piezoelectric cantilever with cylindrical gaps are given in Fig. 2.11 b. The graph revealed that electrical characteristics are at the highest level while excitation frequency equal to $105 \mathrm{~Hz}$. The output voltage at this excitation frequency was $28.9 \mathrm{~V}$, current at the resistance load equal to $31 \mu \mathrm{A}$ and as a result average power was $0.95 \mathrm{~mW}$.

It can be noticed that output voltage is higher 1.89 times compare to the conventional piezoelectric cantilever. Output current has higher value more than 1.92 
times and as a result average power has higher value more than 4.31 times. On basis of these results can be concluded that modifications of the cross sections positively affected electrical characteristics of the modified piezoelectric cantilever.
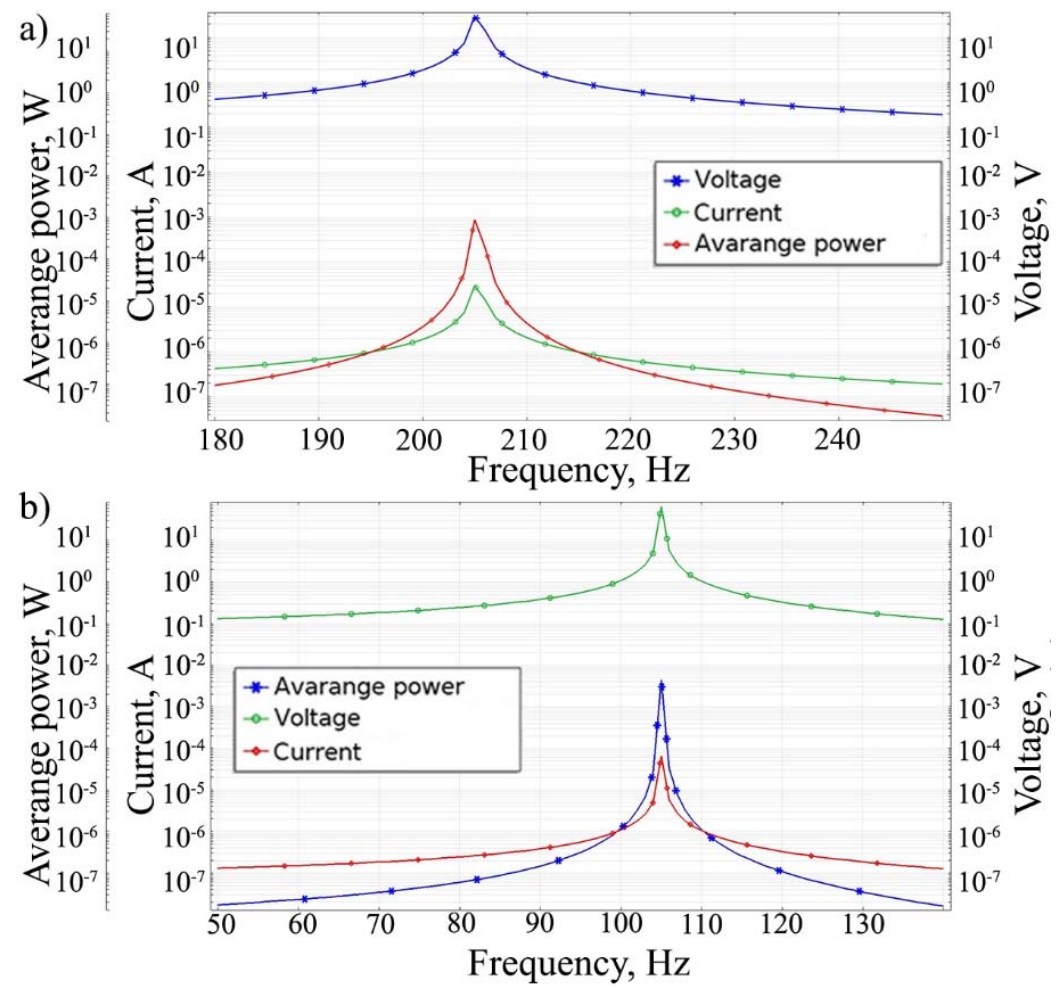

Fig. 2.12. Electrical characteristics of the piezoelectric cantilevers: a) cantilever with rectangular gaps; b) cantilever with trapezoidal gaps

Electrical characteristics of the piezoelectric cantilever with rectangular gaps are given in Fig. 2.12 a. It can be observed that the highest values are obtained at frequency equal to $116 \mathrm{~Hz}$. Coincidence of resonant and base excitation frequencies ensured that output voltage reached $18.2 \mathrm{~V}$, current $17.8 \mu \mathrm{A}$ and average power equal to $0.32 \mathrm{~mW}$. Compare to the conventional piezoelectric cantilever output voltage has 1.17 times higher value, current and average power are 1.10 and 1.45 times higher, respectively. The analysis of results showed that the rectangular gaps have positive influence to the electrical characteristics of the piezoelectric cantilever. However, influence is much lower compare to the case with cylindrical gaps. 
The electrical characteristics of the piezoelectric cantilever with trapezoidal gaps are given in Fig. 2.12 b. The peak electrical characteristics obtained at excitation frequency equal to $124 \mathrm{~Hz}$. At this excitation frequency the output voltage, current and average power reached values $19.6 \mathrm{~V}, 21 \mu \mathrm{A}$ and $0.41 \mathrm{~mW}$ respectively. Compare to the characteristics of the conventional piezoelectric cantilever output voltage was 1.26 times higher, current was 1.3 times higher and average power was 1.86 times higher. However, influence is much lower compare to the case with cylindrical gaps.

In order to compare the electrical characteristics of piezoelectric cantilevers with different resonant frequencies derivative values used. Therefore, voltage, current and average power densities used for the final comparison of the results. The results of comparison given in Fig. 2.13.

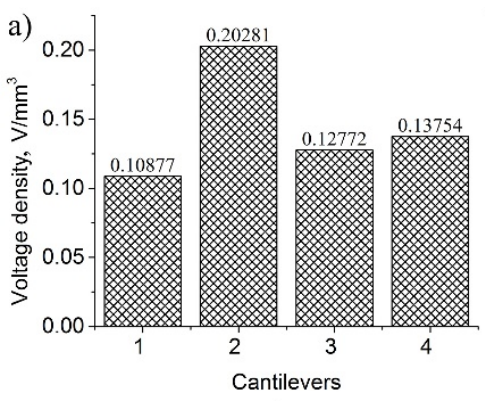

c)
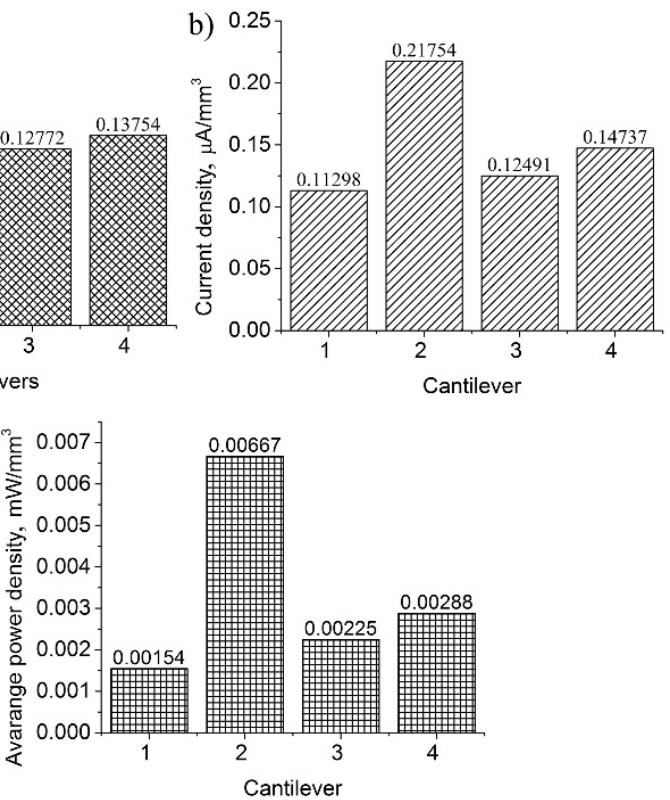

Fig. 2.13. The comparison of the electrical characteristics: a) voltage density; b) current density; c) average power density; 1) conventional cantilever; 2) cantilever with cylindrical gaps; 3) cantilever with rectangular gaps; 4) cantilever with trapezoidal gaps

The comparison of voltage density showed that the best influence to this characteristics have cylindrical gaps. The piezoelectric cantilever with cylindrical gaps has $46.37 \%$ higher voltage density compare to the conventional piezoelectric cantilever and approximately $32.18 \%$ higher compare to the piezoelectric cantilevers with rectangular and trapezoidal gaps. Moreover, analysis of current density revealed that piezoelectric cantilever with cylindrical gaps has also higher value and 
it is higher $48.86 \%$ compare to the conventional piezoelectric cantilever. Moreover, piezoelectric cantilevers with rectangular and trapezoidal gaps has $32.25 \%$ lower current density compare to the piezoelectric cantilever with cylindrical gaps. Finally, comparison of average power densities confirmed results analysed before and showed that cylindrical gaps have the most noticeable influence to the average power. Therefore, compare to the conventional piezoelectric cantilever, cantilever modified by cylindrical gaps has $76.91 \%$ higher average power density. Herewith, piezoelectric cantilevers, with rectangular and trapezoidal gaps have $56.82 \%$ lower average power density compare to the piezoelectric cantilever with cylindrical gaps.

On basis of numerical investigations it can be concluded that modifications of the cross section improved electrical characteristics of the cantilevers. The most noticeable influence to the electrical output characteristics of the cantilever made modifications of cross section by cylindrical gaps. In order to confirm these results the experimental investigation carried out.

\subsubsection{Experimental investigation of rectangular cantilevers with irregular cross-sections}

The experimental investigations of electrical and mechanical characteristics were conducted to in order to confirm the results of numerical investigations. Prototypes of the piezoelectric cantilevers made with respect to the geometrical and physical parameters used in the FEM model (Fig. 2.14).

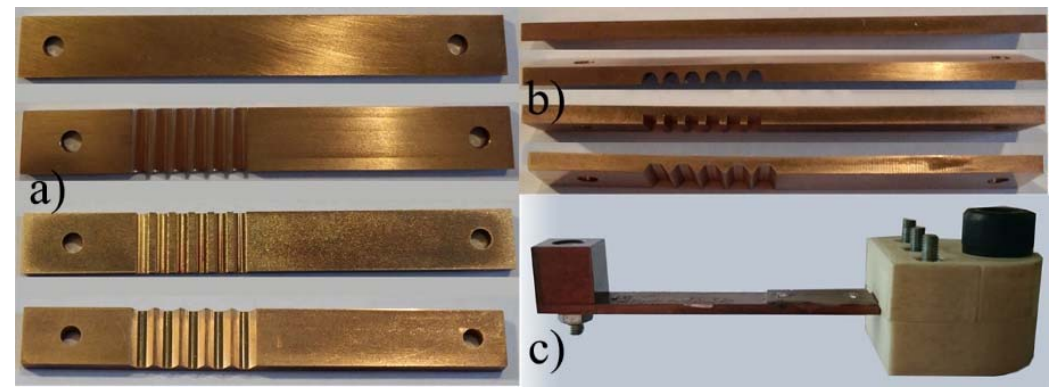

Fig. 2.14. Prototypes of the cantilevers: a) front view; b) side view; c) view of the assembled system

Firstly, operational frequencies and vibration modes of the prototypes measured. The measurements made by 3D vibrometer POLYTEC PSV 500. The goal of this investigation was to confirm the results of the modal analysis and experimentally indicate the first out of plane bending mode for each piezoelectric cantilever. The results given in Fig. 2.15 and Fig. 2.16. 
Fig. 2.15 shows vibration modes of the piezoelectric cantilevers at certain frequency. It revealed that all cantilevers operates at the first out-of plane bending mode. These results confirms results of the modal analysis conducted during numerical investigation.
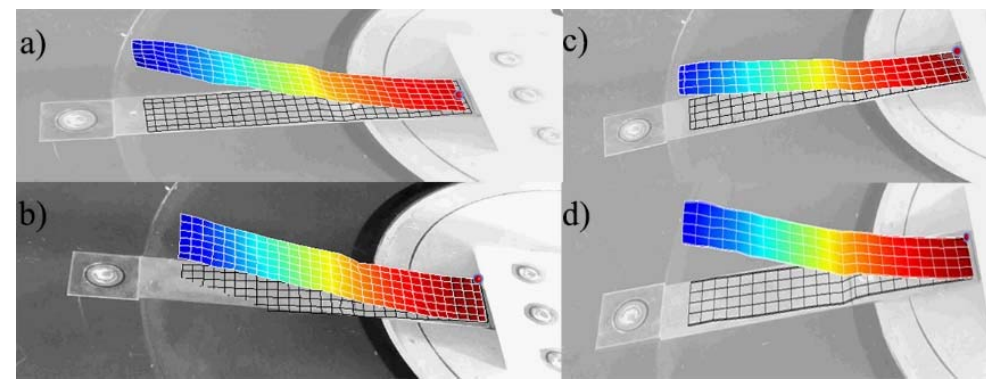

Fig. 2.15. Vibration modes of the piezoelectric cantilevers: a) conventional cantilever, $\omega_{a}-191.5 \mathrm{~Hz}$; b) cantilever with cylindrical gaps, $\omega_{b}-99.4 \mathrm{~Hz}$; c) cantilever with rectangular gaps, $\omega_{c}-108.05 \mathrm{~Hz}$; d) cantilever with trapezoidal gaps, $\omega_{d}-117.3 \mathrm{~Hz}$

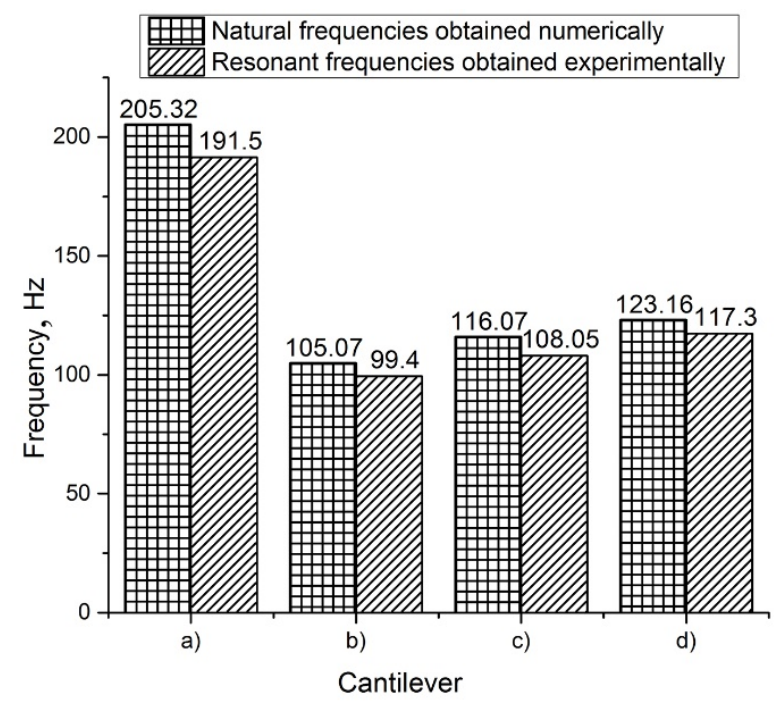

Fig. 2.16. Comparison of operational vibration frequencies: a) conventional cantilever; b) cantilever with cylindrical gaps; c) cantilever with rectangular gaps;

d) cantilever with trapezoidal gaps

Comparison of natural and resonant frequencies (Fig. 2.16) revealed that frequencies obtained numerically are slightly lower compare to the frequencies ob- 
tained by experimental investigation. The highest difference is $6.73 \%$. The differences are mainly caused by tolerances and manufacturing errors. The mismatch between frequencies is acceptable. Based on this it can be concluded that the prototypes are suitable for further investigation.

The next step of experimental investigation was to analyse piezoelectric cantilevers response to different excitations amplitudes and to measure electrical outputs versus resistance load. Experimental setup built for this purpose. The principle scheme of the setup given in Fig. 2.17.

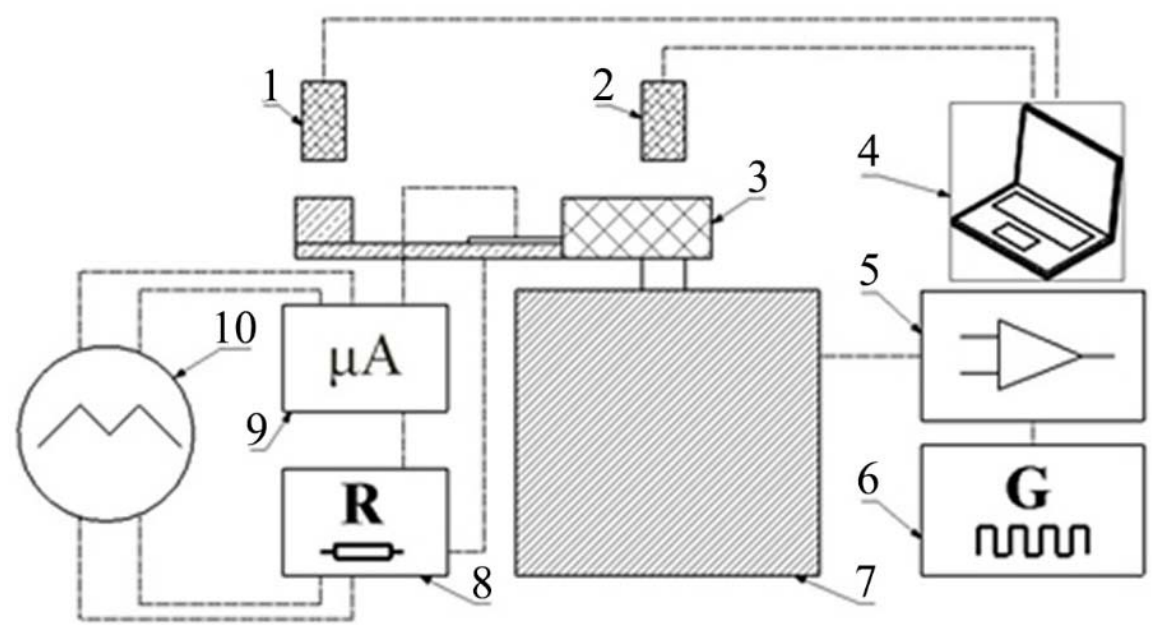

Fig. 2.17. Experimental setup: 1, 2 are optical displacement sensor; 3 is plastic clamping frame; 4 is computer; 5 is power amplifier; 6 is function generator; 7 is electromagnetic shaker; 8 is variable resistive load; 9 is micro current probe; 10 is oscilloscope.

Experimental setup consists of two optical displacement sensors used for displacement control at the base and tip of the cantilever; a special plastic clamping frame was used to attach a cantilever to an electromagnetic shaker; a computer was used for displacement data recording and analysis; a function generator and a power amplifier were employed for driving an electromagnetic shaker; a variable resistive load was used as electrical load of the cantilever; a micro current probe was used for low current measurements; an oscilloscope was used for control and recording of current and voltage values.

Measured excitation response characteristics of the piezoelectric cantilevers shows the influence of base displacement to tip displacement for each cantilever (Fig. 2.18 a). Optical sensors (Fig. 2.17) measured displacements of the base and tip. The resistance load during this stage of investigation was equal to input resistance of the oscilloscope; i. e., $10 \mathrm{M} \Omega$. Hence, the displacement characteristics 
measured in open circuit conditions. The excitation frequencies were set to the resonant frequencies obtained during first stage of the experimental investigation. The characteristics of the open circuit voltage versus tip displacement were investigated at the same conditions. The results are given in Fig. 2.18 b.

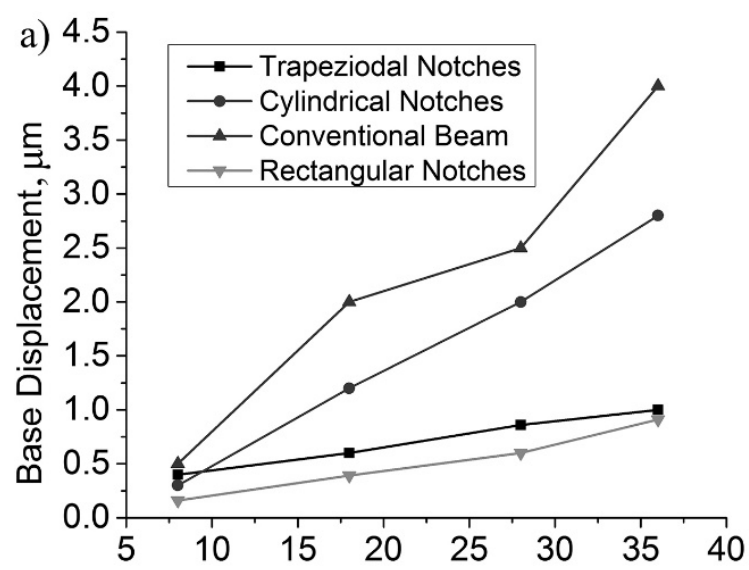

b)

Tip Displacement, $\mu \mathrm{m}$

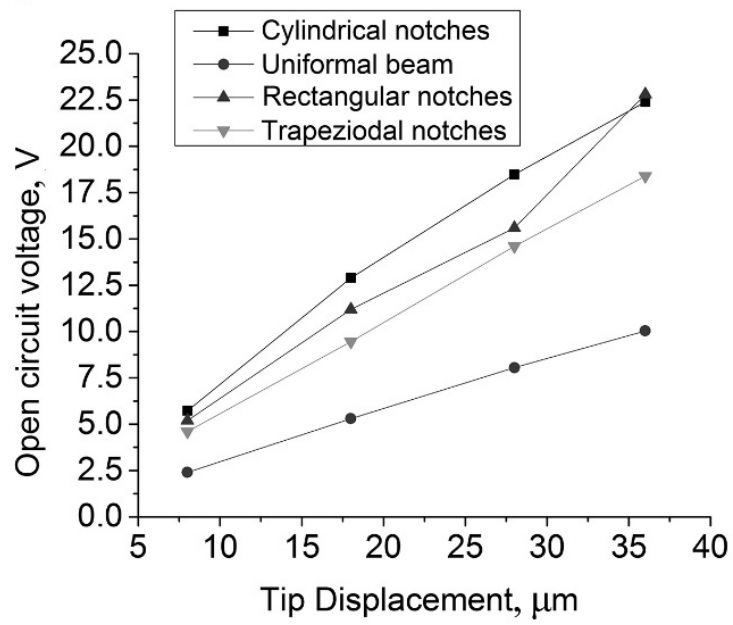

Fig. 2.18. Piezoelectric cantilevers response and open circuit voltage characteristics:

a) mechanical response characteristics; b) open circuit voltage characteristics

In Fig. 2.18 can observed that the highest base-tip displacement characteristics were achieved by the piezoelectric cantilevers modified by rectangular and trapezoidal gaps. Therefore, can be concluded that piezoelectric cantilevers with 
rectangular and trapezoidal gaps are able response to much lower base displacement amplitudes compare to the conventional piezoelectric cantilever. So, could be highlighted that piezoelectric cantilevers with irregular cross-section have much lover potential barrier compare to the conventional piezoelectric cantilevers.

Analysis of Fig. 2.18 showed that the highest open circuit voltage value is $22.4 \mathrm{~V}$. It was generated by the piezoelectric cantilever with cylindrical gaps. The conventional piezoelectric cantilever generated output voltage equal to $10.04 \mathrm{~V}$ i. e. more than 2 times lower compare to the piezoelectric cantilever with cylindrical gaps. Such difference caused by improved bending strain and it distribution in piezo ceramic layer.

The output voltage-tip displacement characteristics measured for each piezoelectric cantilever as well. Voltage measured by oscilloscope as shown in Fig. 2.17. The variable resistance load attached in parallel to piezo ceramic layer. The optical sensor controlled tip displacement. Results of the investigation given in Fig. 2.19.

As can be found in Fig. 2.19, the piezoelectric cantilevers with rectangular and trapezoidal gaps have noticeably higher output voltage compare to the conventional piezoelectric cantilever. The output voltage generated at $38 \mu \mathrm{m}$ tip displacement with $1 \mathrm{M} \Omega$ load was chosen as critical parameter for the comparison of cantilevers. So, output voltage $17.8 \mathrm{~V}, 18.08 \mathrm{~V}, 7.56 \mathrm{~V}$ was generated by the piezoelectric cantilevers with rectangular, trapezoidal and conventional, respectively. Therefore, the conventional piezoelectric cantilever has approximately $55 \%$ lower output voltage compare to the piezoelectric cantilevers with rectangular and trapezoidal gaps. On the other hand, the piezoelectric cantilever with cylindrical gaps generated the highest output voltage. The output voltage was equal to $19.1 \mathrm{~V}$. Generated voltage is higher 5.3\% compare to the piezoelectric cantilevers with rectangular and trapezoidal gaps and $61 \%$ higher compare to the conventional piezoelectric cantilever. Hence, it can be concluded that modifications of the cross section by cylindrical gaps ensures $61 \%$ while modifications by rectangular and trapezoidal gaps ensures 55\% higher output voltage compare to the conventional cross section design.

The output current-tip displacement characteristics were measured for each cantilever as well. As in previous case, same experimental setup was used (Fig. 2.17). Displacement of the tip was controlled by optical displacement sensor, current was measured by the micro current probe. Results of the investigation given in Fig. 2.20.

Analysis of Fig. 2.20 showed that piezoelectric cantilevers with rectangular and trapezoidal gaps have much higher output current compare to the conventional piezoelectric cantilever. The output current generated at $38 \mu \mathrm{m}$ tip displacement with $51 \mathrm{k} \Omega$ load was chosen as critical parameter for the comparison of the piezoelectric cantilevers. 

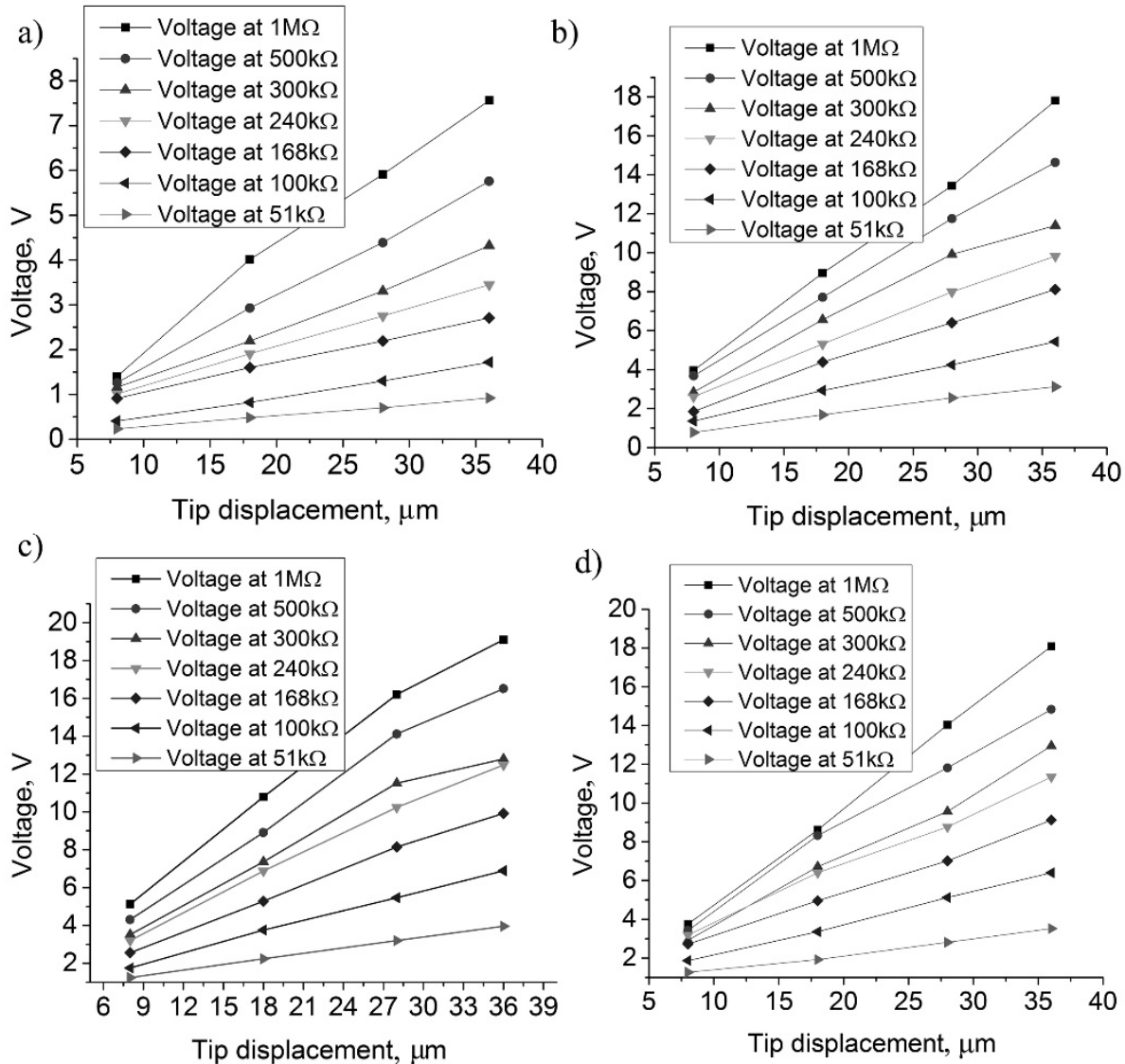

Fig. 2.19. Output voltage versus tip displacement: a) conventional cantilever; b) cantilever with cylindrical gaps; c) cantilever with rectangular gaps; d) cantilever with trapezoidal gaps

The output current of the piezoelectric cantilevers with rectangular and trapezoidal gaps and output current generated by the conventional piezoelectric cantilever are $54.7 \mu \mathrm{A}, 66.3 \mu \mathrm{A}$ and $18.3 \mu \mathrm{A}$, respectively. Therefore, according to the results the conventional piezoelectric cantilever has approximately $72.3 \%$ lower output current compare to the cantilevers with rectangular and trapezoidal gaps. On the other hand, according to this comparison the piezoelectric cantilever with cylindrical gaps has much higher output current. i. e. $74.1 \mu \mathrm{A}$. piezoelectric cantilever with cylindrical gaps has $10.5 \%$ higher output current compare to the piezoelectric cantilevers with rectangular and trapezoidal gaps. 

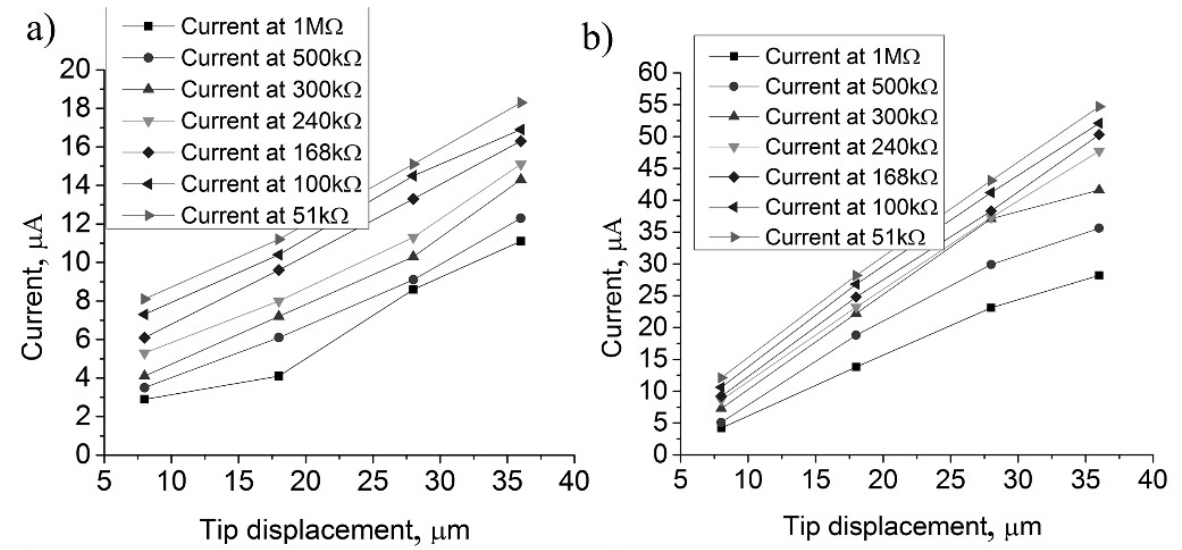

c)
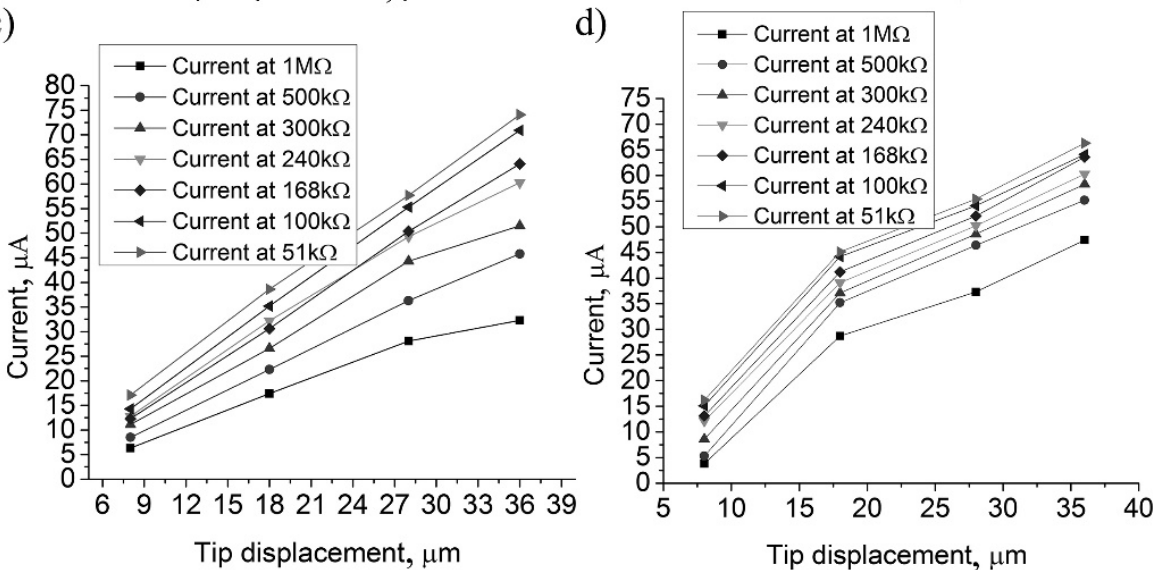

Fig. 2.20. Output current versus tip displacement: a) conventional cantilever; b) cantilever with cylindrical gaps; c) cantilever with rectangular gaps; d) cantilever with trapezoidal gaps

Moreover, conventional piezoelectric cantilever has 75.3\% lower output current compare to the cantilever with cylindrical gaps. Therefore, on basis on this comparison can be concluded that modifications of the cross section by cylindrical gaps ensured $75.3 \%$ higher output current compare to the conventional cross section design. In order to perform accurate comparison of the piezoelectric cantilevers with different resonant frequencies derivative values used. Output voltage, current and power densities were compared. The comparison was made with following conditions $1 \mathrm{M} \Omega$ resistance load and $38 \mu \mathrm{m}$ tip displacement. Results of the comparison given in Fig. 2.21.

As can be noticed in Fig. 2.21 the highest voltage density characteristic has piezoelectric cantilever with cylindrical gaps. It has approximately $5.3 \%$ higher 
voltage density compare to the piezoelectric cantilevers with rectangular and trapezoidal gaps and $61 \%$ higher compare to the conventional piezoelectric cantilever.
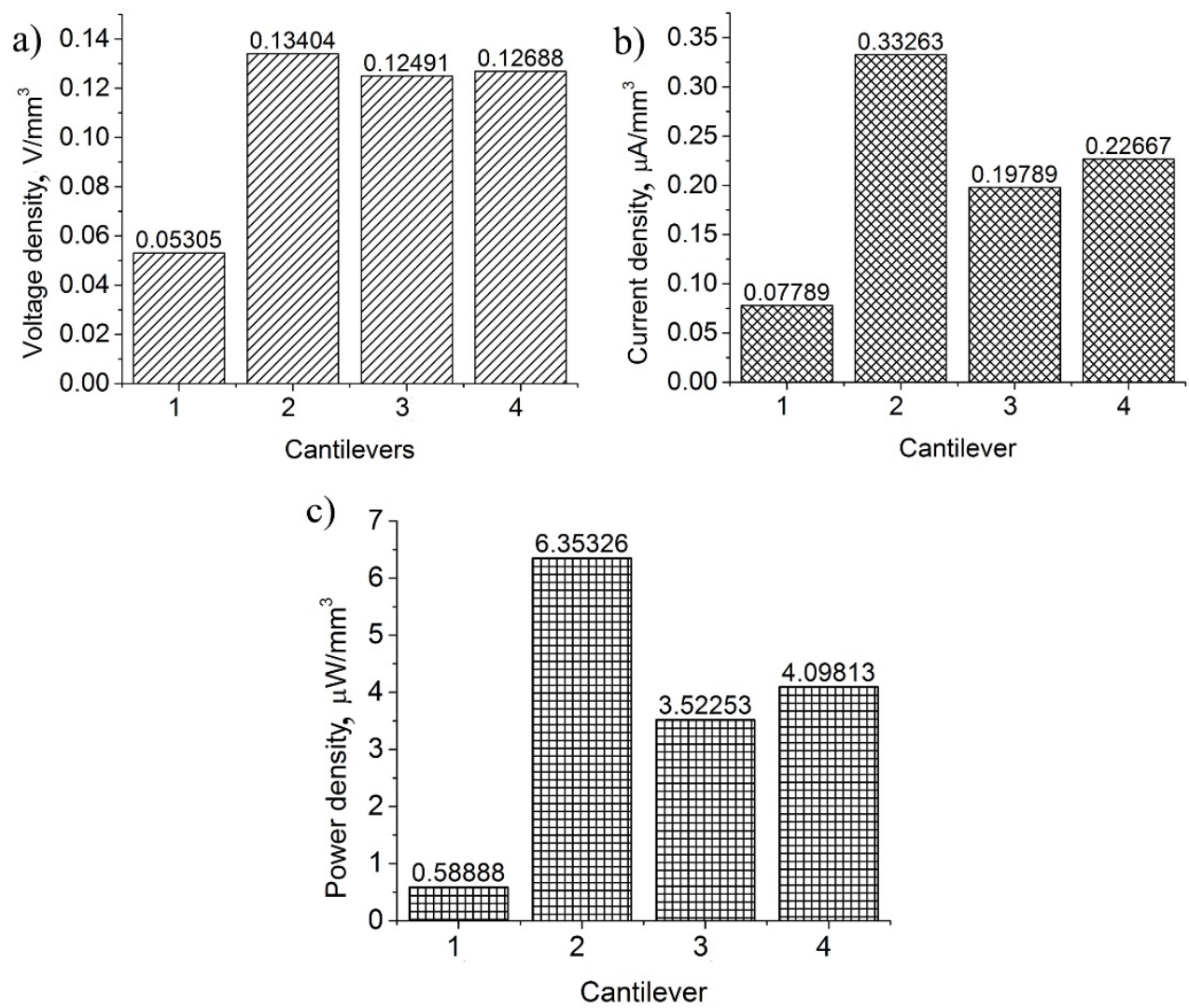

Fig. 2.21. Comparison of the electrical characteristics: a) voltage density; b) current density; c) power density; 1) conventional cantilever; 2) cantilever with cylindrical gaps; 3) cantilever with rectangular gaps; 4) cantilever with trapezoidal gaps

Analysis of the Fig. $2.21 \mathrm{~b}$ revealed that cantilever with cylindrical gaps has $31.8 \%$ higher current density compare to the piezoelectric cantilevers with rectangular and trapezoidal gaps and $76.58 \%$ higher current density compare to the conventional piezoelectric cantilever at the same conditions. In Fig. 2.21 can be found that piezoelectric cantilever with cylindrical gaps has approximately $35.49 \%$ higher power density compare to the piezoelectric cantilevers with rectangular and trapezoidal gaps. Moreover, it has $90 \%$ higher power density compare to the conventional piezoelectric cantilever. 


\subsection{Investigation of trapezoidal piezoelectric cantilevers with irregular cross-sections}

This section represents results of numerical and experimental research on the piezoelectric trapezoidal cantilevers with irregular design of the cross-section. Cylindrical and trapezoidal gaps used for cross-section modifications. The goal of the modifications was to increase bending strain and its distribution at the piezo ceramic layer by combining trapezoidal shape and double sided irregular cross section. Investigate of double-sided cross section influence to power density of energy harvesting system based on trapezoidal cantilevers.

\subsubsection{Designs of trapezoidal piezoelectric cantilevers with irregular cross-sections}

The numerical and experimental investigations of rectangular cantilevers with one-side cross section modifications revealed that bending strain and it distribution function could be improved. However, bending strain distribution at modified part of cantilever still inconstant. Therefore, during comparison of bending strain characteristics at conventional rectangular and trapezoidal cantilevers can be noticed that strain distribution at trapezoidal cantilever is more even. Also, double sided cross section modifications will ensure higher reduce of area moment of inertia and as a result will improve bending strains and it distribution.

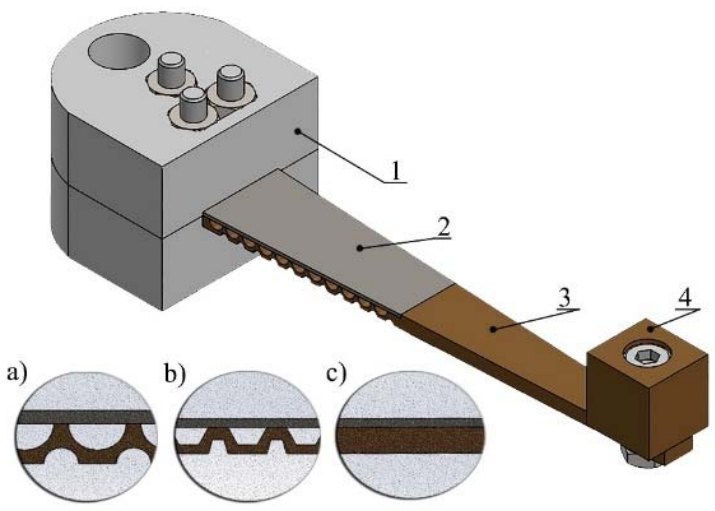

Fig. 2.22. Design of the cantilevers: a) cross-section design with cylindrical gaps;

b) cross-section design with trapezoidal gaps; c) conventional design of the cross-section area; 1) plastic clamping frame; 2) piezo ceramic; 3) cantilever beam; 4) seismic mass. 
Therefore, in order to obtain constant bending strain distribution at energy harvesting systems based on cantilevers, trapezoidal cantilevers with double sided cross section modifications were investigated. Principle scheme of the trapezoidal cantilevers with irregular cross-sections given in Fig. 2.22. It consists of a bronze plate, a piezo ceramic plate and a seismic mass. The piezo ceramic plate has a constant thickness and length of $0.5 \mathrm{~mm}$ and $30 \mathrm{~mm}$, respectively. Furthermore, each cantilever has a constant length equal to $70 \mathrm{~mm}$; therefore, the ratio of the piezo ceramic length and cantilever length is 0.42 . Moreover, each cantilever has a seismic mass, and its weight is $8.71 \mathrm{~g}$. The seismic mass used to reduce the resonant frequency of the cantilever. Cantilevers clamped to host through plastic support structure. The cross-section of two cantilevers were modified (Fig. $2.22 \mathrm{a}$ and $b$ ). The modifications were made by employing cylindrical and trapezoidal gaps. A conventional design of the cross-section (Fig. $2.22 \mathrm{c}$ ) was designed in order to obtain reference data for comparison. The proposed improvements of the cross-section could provide almost a uniform strain distribution along the length of the piezo ceramic plate. Potentially, improvements could have an influence on the electrical characteristics and natural frequencies of the cantilevers.

\subsubsection{Numerical investigation of trapezoidal cantilevers with irregular cross-sections}

Numerical investigation of the cantilevers with conventional and irregular crosssections designs performed. A geometrical optimization problem for each cantilever was set as presented in Eq. (2.3). The geometrical parameters and a side view of each investigated cross-section design are presented in Fig. 2.23 and Table 2.6, respectively. As shown in Fig. 2.22, the cross-section modifications were made only under the piezo ceramic layer. The length of the modified cross-section is equal to the length of the piezo ceramic $L_{\text {Piezo }}$, i. e., $30 \mathrm{~mm}$. It was made in order to obtain a constant strain and its distribution in this part of the cantilever.

Firstly, modal analysis was performed in order to obtain the modal shapes and natural frequencies of each cantilever. After that, a study based on harmonic excitation of the base was performed in order to obtain the electrical and mechanical characteristics of each cantilever. Finite Element Modelling (FEM) software Comsol Multiphysics 5.2 was used for investigation. A FEM model was built, and boundary conditions were set, as well (Fig. 2.24). Mechanical boundary conditions were set as follows: host structure acceleration was set to $0.5 \mathrm{~m} / \mathrm{s}^{2}$; the weight of the seismic mass was equal to $8.71 \mathrm{~g}$; gravity force was included, as well; the resistive load connected in parallel with the piezo ceramic was set as an electrical boundary condition. The value of the resistive load for each cantilever was calculated on basis of Eq. 2.1. 
Finally, material properties were added to the model. Beryllium bronze DIN 2.1247 was used as a base layer of the trapezoidal cantilever and soft modified lead zirconate titanate PIC255 piezo ceramic for active layer modelling. The isotropic loss factor for beryllium bronze was defined. The characteristics of the material properties given in Table 2.3.

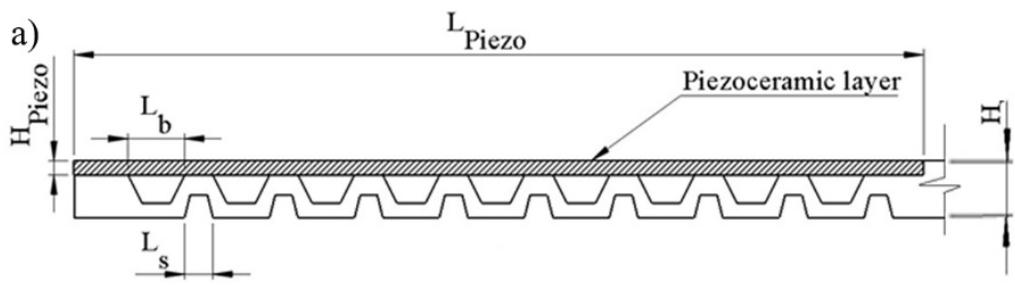

b)

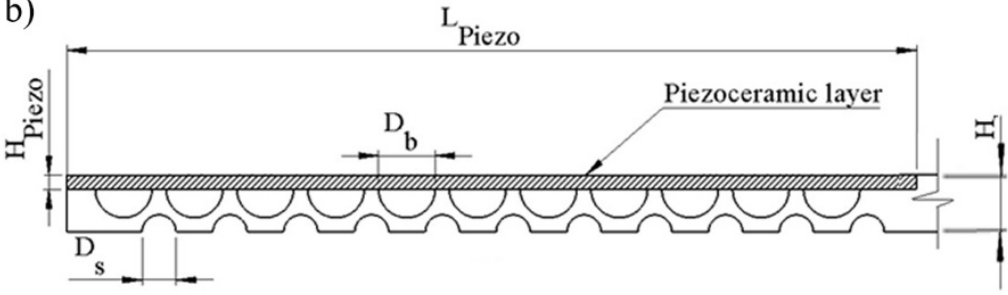

c)

$\mathrm{L}_{\text {Piezo }}$

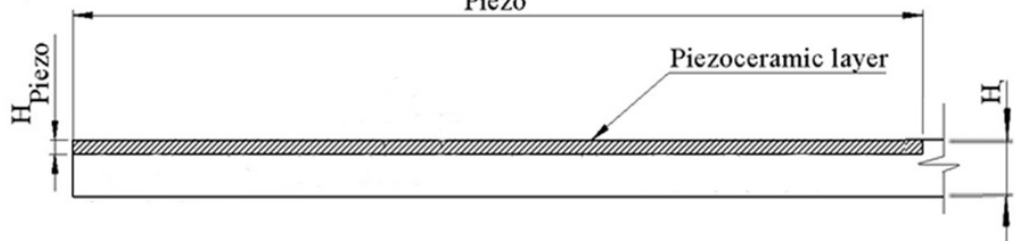

Fig. 2.23. Designs of cross-section: a) cross-section with trapezoidal gaps;

b) cross-section with cylindrical gaps; c) conventional cross-section.

Therefore the results of modal analysis of each cantilever are given in Fig. 2.25. The aim of this investigation was to find the natural frequencies of the first out-of-plane bending mode for each cantilever.

The next step of the numerical investigation was the base harmonic excitation case. The aim of this investigation to obtain output voltage, current, average power and bending strain component $\varepsilon_{Y Y}$ value. The bending strain distribution at the middle line of the trapezoidal cantilever was analysed (Fig. 2.24).

The optimization of cantilever base length $L_{B}$ was performed in order to obtain the highest strains at the middle line of the trapezoidal cantilever. The optimization problem for the cantilevers parameters can be written as given in Eq. (2.3). 
The optimal width of the base will be determined from the viewpoint of the maximum value of bending strain in the piezo ceramic. $L_{T i p}$ is the width of the cantilever's tip; it is constant for all cases. The value of $L_{T i p}$ is given in Table 2.6.

During computation, the following values were used: $\omega_{\min }$ equal to $50 \mathrm{~Hz}$, $\omega_{\max }$ equal to $500 \mathrm{~Hz}, L_{\min }$ equal to $10 \mathrm{~mm}, L_{\max }$ equal to $30 \mathrm{~mm}$. The first optimization was made for $L_{B 1}$. It is the base width of the conventional trapezoidal cantilever. The results of the optimization are given in Fig. 2.26.

Table 2.6. Geometrical parameters of the trapezoidal cantilevers.

\begin{tabular}{|l|l|l|}
\hline Parameter & Value, $\mathrm{mm}$ & Explanation \\
\hline $\mathrm{L}$ & 70 & Length of the trapezoidal cantilever beam. \\
\hline $\mathrm{L}_{\text {Piezo }}$ & 30 & Length of the piezo ceramic layer. \\
\hline $\mathrm{L}_{\text {Tip }}$ & 4.5 & Width of the trapezoidal cantilever tip. \\
\hline $\mathrm{L}_{\mathrm{B} 1}$ & 16 & Width of the trapezoidal cantilever base. \\
\hline $\mathrm{L}_{\mathrm{B} 2}$ & 12 & Width of the trapezoidal cantilever base. \\
\hline $\mathrm{L}_{\mathrm{B} 3}$ & 10 & Width of the trapezoidal cantilever base. \\
\hline $\mathrm{L}_{\mathrm{b}}$ & 2 & Width of the trapezoidal gap base. \\
\hline $\mathrm{L}_{\mathrm{S}}$ & 1.2 & Width of the trapezoidal gap base. \\
\hline $\mathrm{D}_{\mathrm{S}}$ & 2 & Diameter of the cylindrical gap \\
\hline $\mathrm{D}_{\mathrm{b}}$ & 1.2 & Diameter of the cylindrical gap \\
\hline $\mathrm{H}_{\text {Piezo }}$ & 0.5 & Thickness of the piezo ceramic layer \\
\hline $\mathrm{H}$ & 2 & Thickness of the trapezoidal cantilever \\
\hline
\end{tabular}

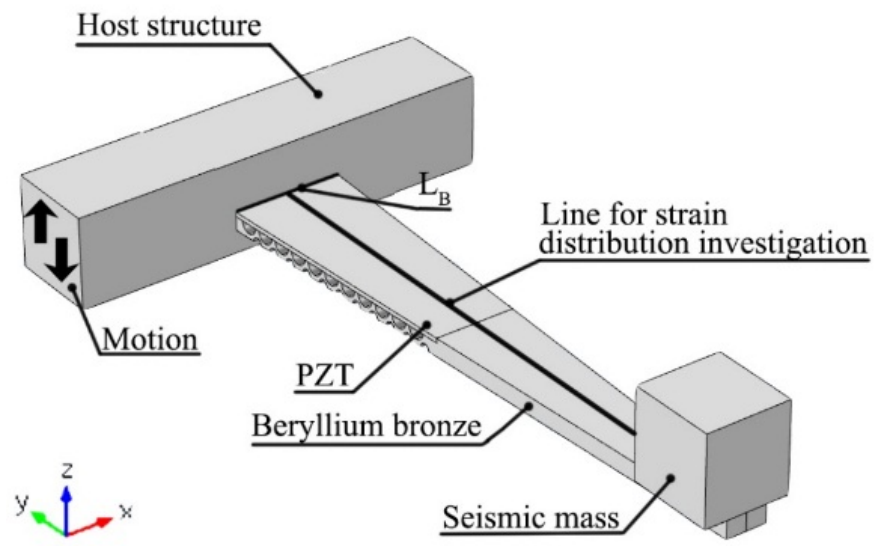

Fig. 2.24. Numerical model of the trapezoidal cantilever; PZT - lead zirconate titanate 
The analysis of the graph (Fig. 2.26) showed that the highest bending strain was achieved when the trapezoidal cantilever base width was $10 \mathrm{~mm}$. This value obtained when the excitation frequency was $85 \mathrm{~Hz}$, and it is almost equal to the natural frequency of the cantilever (Fig. 2.25).

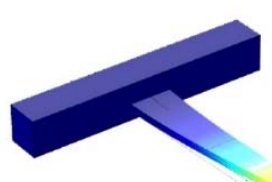

a)

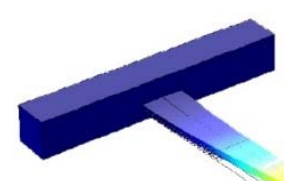

b)

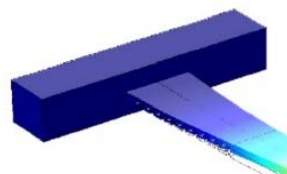

c)

Fig. 2.25. Results of modal analysis: a) conventional trapezoidal cantilever, $\omega_{n}-80.6 \mathrm{~Hz}$; b) trapezoidal cantilever with cylindrical gaps, $\omega_{n}-89.5 \mathrm{~Hz}$;

c) trapezoidal cantilever with trapezoidal gaps, $\omega_{n}-119.1 \mathrm{~Hz}$

$$
\left\{\begin{array}{l}
\int_{0}^{L_{P i e z o}} \varepsilon_{Y Y}^{P Z T} \rightarrow \max \\
\omega_{\min } \leq \omega \leq \omega_{\max } \\
L_{\text {Tip }} \rightarrow \text { const } \\
L_{\min } \leq L_{B 1} \leq L_{\max } \\
L_{\min } \leq L_{B 2} \leq L_{\max } \\
L_{\min } \leq L_{B 3} \leq L_{\max }
\end{array} .\right.
$$

Where $\varepsilon$ is the strain in the piezo ceramic layer; $\omega_{\min }$ is the lowest excitation frequency; $\omega_{\max }$ is the highest excitation frequency; $L_{\min }$ is the minimal width of the base; $L_{\max }$ is maximum width of the base; $L_{B 1}, L_{B 2}$ and $L_{B 3}$ are the optimal base widths of conventional cantilever and cantilevers modified by cylindrical and trapezoidal gaps.

The obtained bending strain value is directly related to cantilevers' stiffness. As can be noticed in Fig. 2.26 a, the highest value of the bending strain was obtained at the lowest base width, when the cross-section design is unmodified. The difference of the bending strain values at the fixed end of the cantilever and at $L_{\text {Piezo }}$ is $25.23 \%$. Constant decreasing of the bending strain shows that the piezo ceramic is strained non-uniformly. Moreover, the standard sample deviation of bending strain values is $7.4 \cdot 10^{-4}$. According to the results of the optimization, it can be concluded that the electrical outputs will be at the highest level when the base width is $10 \mathrm{~mm}$.

Optimization study was conducted for the trapezoidal cantilever base $L_{B 2}$. The cantilever cross-section modified by cylindrical gaps. The frequency range was set according to the optimization problem in Eq. (2.3). The bending strain characteristics presented in Fig. $2.26 \mathrm{~b}$. 
The analysis of the graph given in Fig. 2.26 a revealed that the highest strain value was achieved when $L_{B 2}$ was equal to $12 \mathrm{~mm}$. This value was obtained when the excitation frequency was $90 \mathrm{~Hz}$, and it matches the natural frequency of the cantilever (Fig. 2.25).

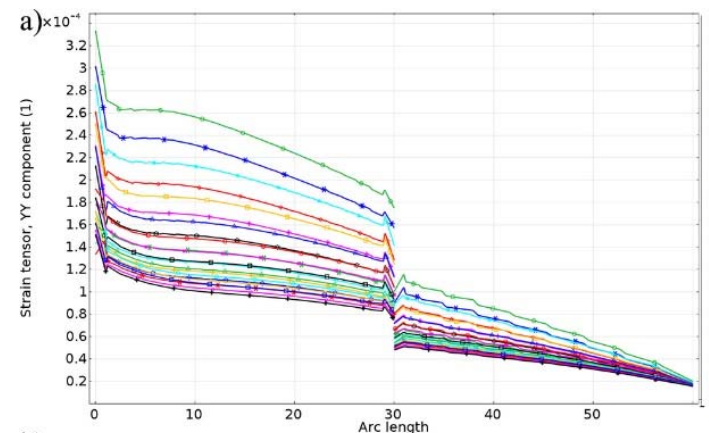

b)

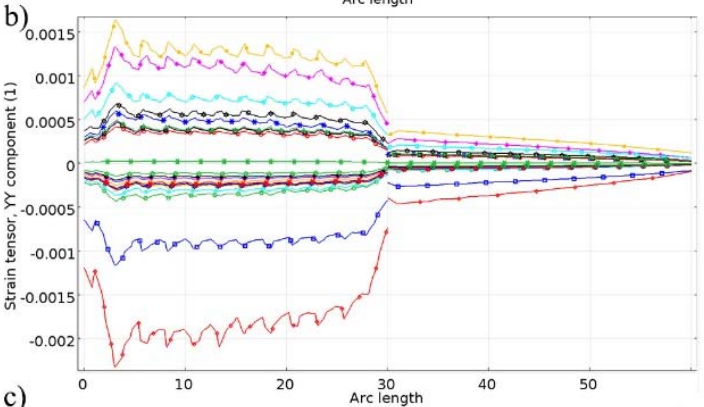

c)

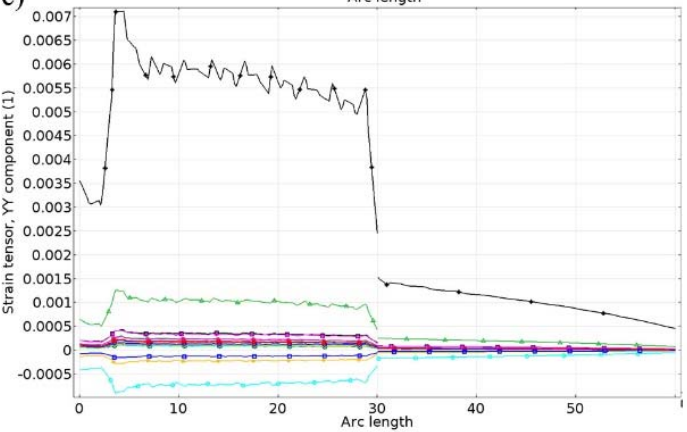

* Base_lenght $=10$, freq $=80$ - Base_lenght $=10$, freq $=85$

- Base_lenght $=12$, freq $=85$

- Base lenght $=12$, freq $=90$

- Base_lenght $=14$, freq $=90$

Base_lenght $=14$, freq $=95$

- Base_lenght $=16$, freq $=95$

- Base lenght $=16$, freq $=100$

* Base_lenght $=18$, freq $=100$

- Base_lenght $=18$, freq $=105$

Base_lenght $=20$, freq $=105$

- Base lenght $=20$, freq $=110$

Base_lenght $=22$, freq $=110$

- Base lenght $=22$, freq $=115$

- Base_lenght $=24$, freq $=115$

*Base_length $=10$, freq $=80$ $\rightarrow$ Base_length $=10$, freq $=85$

$\rightarrow$ Base_length $=12$, freq $=90$

Base_length $=12$, freq $=95$

$\rightarrow$ Base_length $=14$, freq $=95$

Base_length $=14$, freq $=100$

$\rightarrow$ Base_length $=16$, freq $=100$

$\rightarrow$ Base_length $=16$, freq $=105$

$\rightarrow$ Base_length $=18$ freq $=105$

-Base_length $=18$, freq $=110$

- Base_length $=20$, freq $=110$

- Base_length $=20$, freq $=115$

- Base length $=22$, freq $=115$

$\rightarrow$ Base_length $=22$, freq $=120$

- Base_length $=24$, freq $=120$

-Base_length $=10$, freq $=60 \rightarrow$ Base_length $=24$, freq $=100$

$\rightarrow$ Base_length $=10$, freq $=65 *$ Base_length $=26$, freq $=100$

$\rightarrow$ Base_length $=12$ freq $=65-$ Base_length $=26$, freq $=105$

- Base_length $=12$ freq $=70 \rightarrow$ Base_length $=28$, freq $=105$

+ Base_length $=14$, freq $=70$ - Base_length $=28$, freq $=110$

Base_length $=14$, freq $=75 *$ Base_length $=30$, freq $=110$

$\rightarrow$ Base_length $=16$, freq $=75-$ Base_length $=30$, freq $=115$

$\rightarrow$ Base_length $=16$, freq $=80$

* Base_length $=18$, freq $=80$

$\rightarrow$ Base_length $=18$, freq $=85$

$\rightarrow$ Base_length $=20$, freq $=85$

$\rightarrow$ Base_length $=20$, freq $=90$

- Base_length $=22$, freq $=90$

$\rightarrow$ Base_length $=22$, freq $=95$

$\rightarrow$ Base_length $=24$, freq $=95$

Fig. 2.26. Bending strain characteristics: a) at conventional trapezoidal cantilever; b) at cantilever with cylindrical gaps; c) at cantilever with trapezoidal gaps; freq is frequency in hertz.

According to this, it can be concluded that the cantilever stiffness characteristic has the lowest value when the base width is $12 \mathrm{~mm}$; considering this, it can be concluded that modifications decreased the stiffness of the cantilever, and this 
ensured approximately the same bending strain as in the conventional cantilever, but in a larger volume of the piezo ceramic. The graph shows that the bending strain characteristics along the piezo ceramic layer have a non-uniform function and constantly decrease. The difference of the bending strain values at the fixed end of the cantilever and at $L_{\text {Piezo }}$ is $12.16 \%$. This is more than two times lower in comparison with the conventional cantilever, and it shows that the bending strain distribution becomes more, uniform than in the case before. Moreover, the standard sample deviation of the strain is $9.3 \cdot 10^{-4}$. Such results can be explained by the almost constant area moment of inertia in the cantilevers cross-section. Almost constant of the area moment of inertia is caused by cross-section modifications that ensure more effective usage of the piezo ceramic layer. Hence, the electrical characteristics of the cantilever will be improved.

The third optimization study was conducted for the trapezoidal cantilever with trapezoidal gaps. The frequency range was set as in the previous two cases. The obtained strain characteristics given in Fig. $2.26 \mathrm{c}$. The analysis of the graph revealed that higher bending strain and its best distribution in the piezo ceramic were achieved when the width of the base was equal to $16 \mathrm{~mm}$. Moreover, the bending strain increased significantly, and it is almost constantly distributed along $L_{\text {Piezo }}$. The difference of the bending strain values at the fixed end and $L_{\text {Piezo }}$ is $14.16 \%$, and it is 1.5 times lower in comparison with the conventional cantilever. The standard sample deviation of strain is $19.6 \cdot 10^{-4}$. According to these results, can be concluded that modifications of the cross-section improved the bending strain and its distribution characteristics. Considering this, the electrical characteristics will be improved, as well.

Summarizing this part of the numerical investigation, can be concluded that modifications of the cross-sections have improved the bending strain level and its distribution. The analysis of the differences in bending strain values along $L_{\text {Piezo }}$ showed that the strain distribution was increased more than 1.5 times in comparison to the conventional one. Moreover, as shown above in Fig. $2.26 \mathrm{~b}$ and Fig. $2.26 \mathrm{c}$, the strain characteristics' curve became more constant in comparison with Fig. 2.26 a.

Almost constant function of the bending strain was caused by modifications of the cross-sections of the cantilevers. The modifications ensure the decreased area moment of inertia, and thus, bending strain in the modified part of the cantilever is increased. Therefore, the piezo ceramic is employed more efficiently. The highest level of bending strain and its distribution were obtained at the cantilever with trapezoidal gaps. The comparisons of the bending strain distribution functions and average strain values given in Fig. 2.27.

This summary reveals that the bending strain distribution in the modified cantilevers has a more constant function at piezo ceramic layer in comparison with the conventional one. The summary of the bending strain average values shows 
that the strain level at modified cantilevers was increased more than 2.7 times compare to the conventional cantilever. According to this summary, the geometrical parameters of the trapezoidal cantilever were chosen for further investigation; the values are given in Table 2.6.

Numerical investigation related to the electrical characteristics of the trapezoidal cantilevers was performed. Resistance load was included to FEM model. A resistor was connected in parallel to the piezo ceramic layer. The other parameters of the model were set as in the previous cases. The value of optimal resistive load $R_{\text {opt }}$ was chosen according to Eq. (2.2).
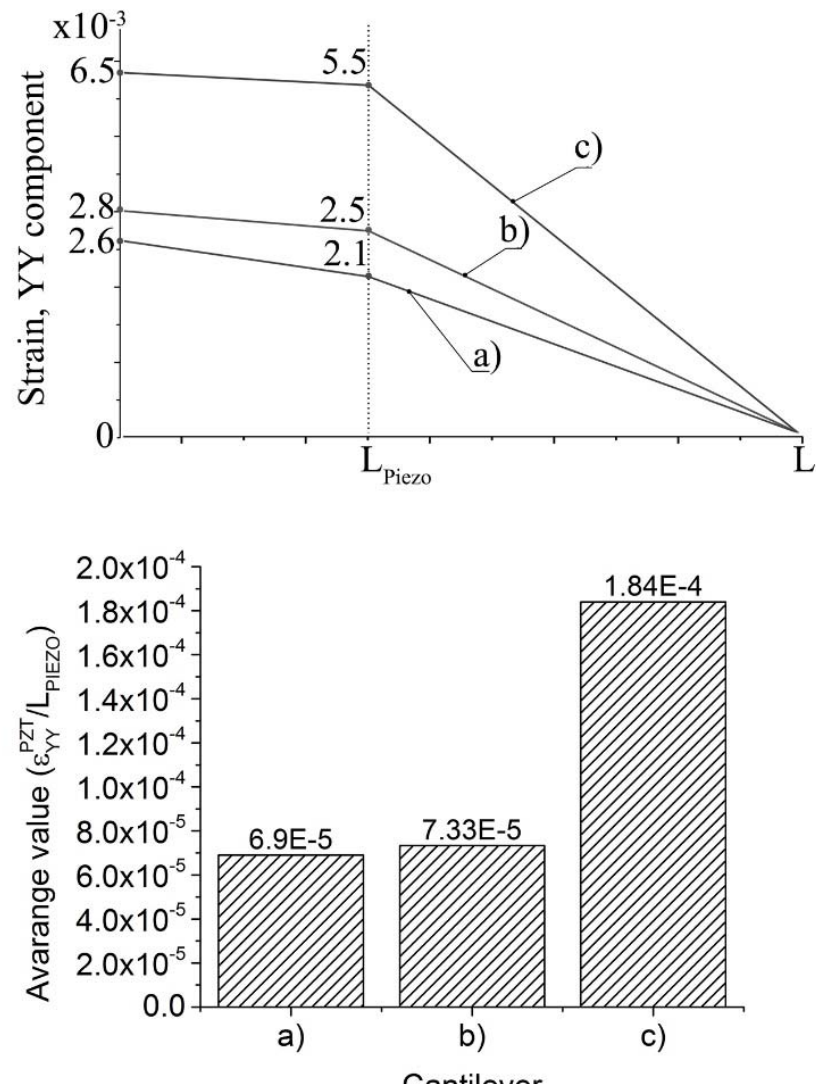

Fig. 2.27. Bending strain functions and average values of bending strain: a) conventional cantilever; b) cantilever with cylindrical gaps; c) cantilever with trapezoidal gaps 
a)

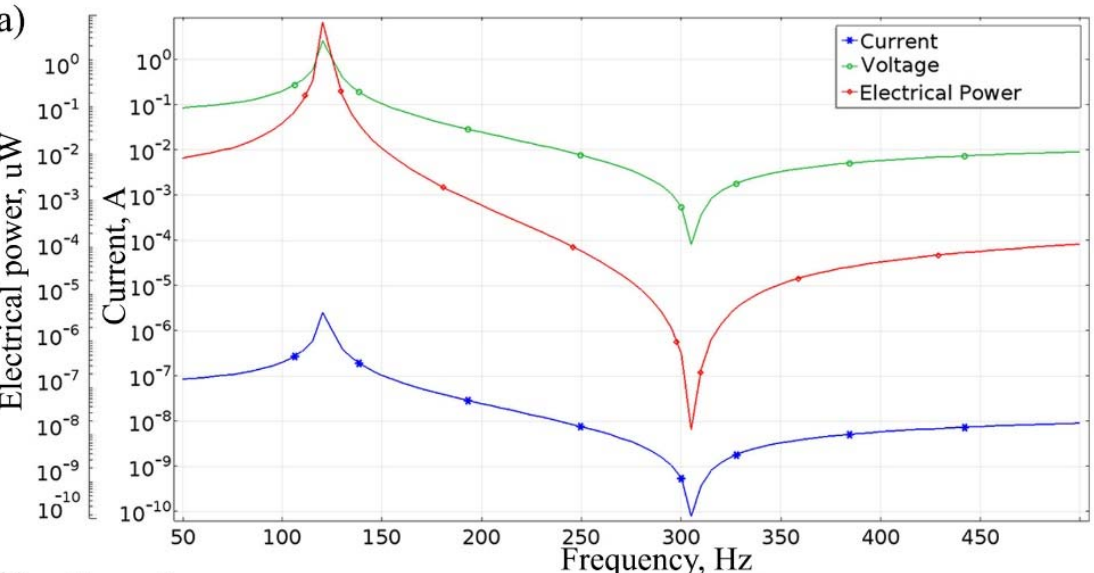

\section{b) $10^{2}$}

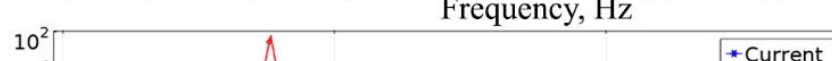

$10^{2}$

$10^{\circ}$

$10^{-1}$

$10^{-3}$

$10^{-4}$

]ี $10^{-5}$

递1 $10^{-6}$

$10^{-8}$

$10^{-9}$
$10^{-10}$
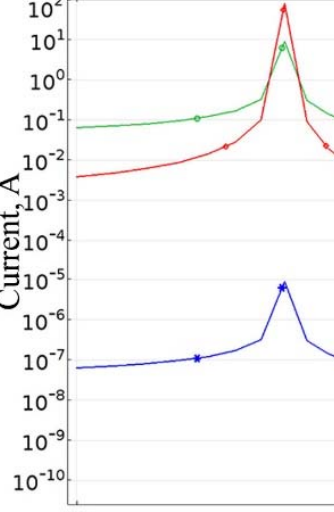

*- Voltage

$10^{1}$

$10^{0}$

$10^{-1}$

$10^{-2}$

$10^{-3}$

$10^{-4}$ i

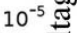

$10^{-6}$ ?

$10^{-7}$

$10^{-8}$

$10^{-10}$

$10^{-10}$.

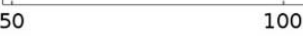

100

Frequency, $\mathrm{Hz}$

c)

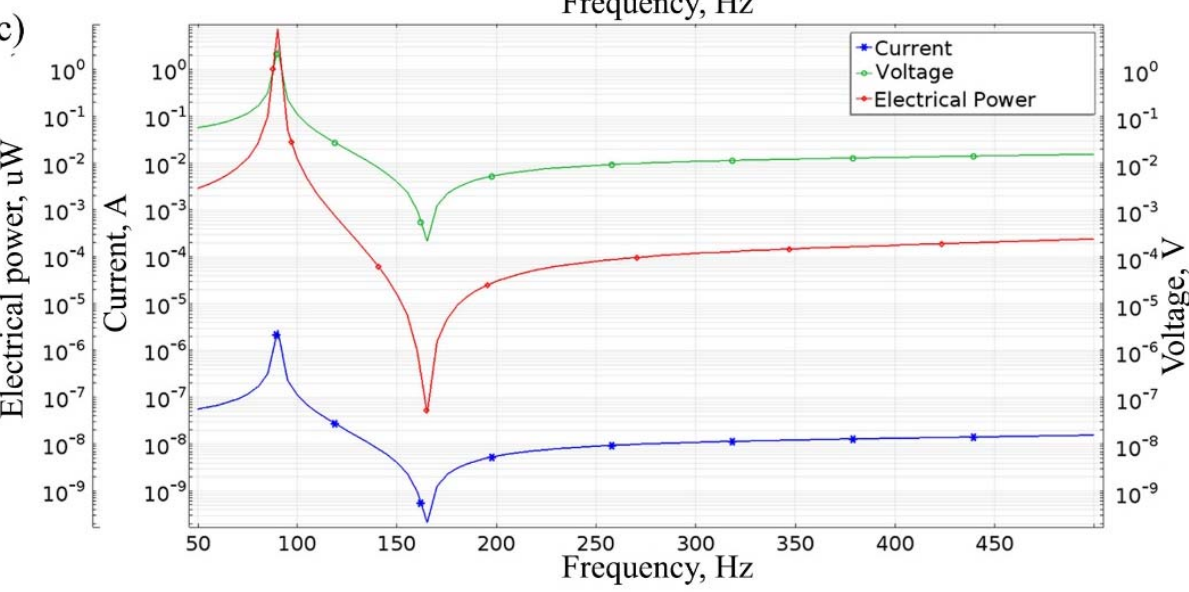

Fig. 2.28. Electrical characteristics of cantilevers: a) conventional cantilever;

b) cantilever with cylindrical gaps; c) cantilever with trapezoidal gaps 
Firstly, the conventional trapezoidal cantilever was analysed. A frequency response study was employed for this investigation. The frequency range from 50 $\mathrm{Hz}$ to $500 \mathrm{~Hz}$ was analyzed. The results of the electric outputs as a function of excitation frequency are presented in Fig. 2.28 a. It can be noticed that the highest values of the electrical outputs were obtained at the resonant frequency of the trapezoidal cantilever. The output voltage on the electrical load is equal to $2.8 \mathrm{~V}$. Moreover, the current is equal to $2.6 \mu \mathrm{A}$, and the average power of the system is $6.6 \mu \mathrm{W}$.

Fig. 2.28 b represents the electrical characteristics of the trapezoidal cantilever with trapezoidal gaps. It can be noticed that the electrical characteristics of the system reach the highest values at the resonant frequency $80.6 \mathrm{~Hz}$. Voltage generated by a modified trapezoidal cantilever is equal to $9 \mathrm{~V}$, and it is 3.2 times larger in comparison to the conventional cantilever. Current generated by a cantilever is equal to $8 \mu \mathrm{A}$ and is 3.1 times higher in comparison with the conventional cantilever. The average output power is equal to $80 \mu \mathrm{W}$, and it is 12.1 times higher in comparison with the conventional beam. Summarizing the results of this investigation, can be concluded that the modification of the cross-section gives a positive impact on the electrical characteristics of the cantilever.
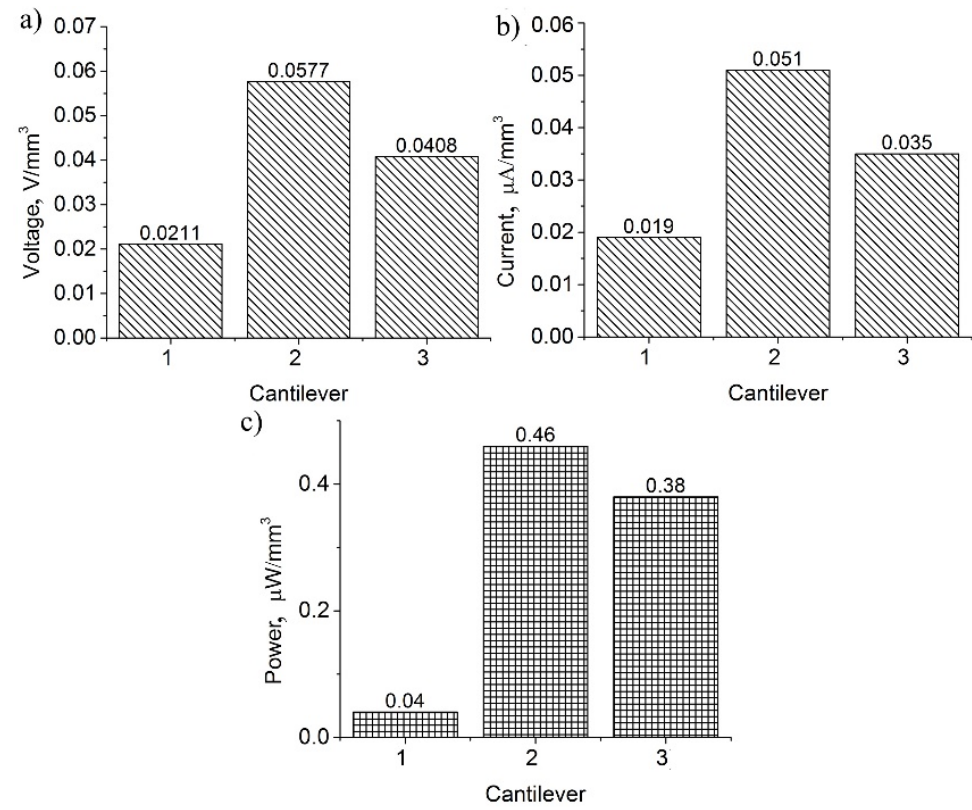

Fig. 2.29. Comparison of the cantilevers: a) voltage density; b) current density; c) power density; 1 - conventional cantilever; 2 - cantilever with cylindrical gaps; 3 - cantilever with trapezoidal gaps 
Fig. $2.28 \mathrm{c}$, represents the electrical characteristics of a trapezoidal cantilever with cylindrical gaps. It can be noticed that the output voltage is equal to $8.3 \mathrm{~V}$ at a resonant frequency of $90 \mathrm{~Hz}$, and it is 2.96 times higher in comparison with the conventional cantilever. The analysis of the output current and average power shows that the highest values are also in the same frequency. Current reached $7.2 \mu \mathrm{A}$, and average power become equal to $59.76 \mu \mathrm{W}$; these are 2.76 and 9.05 times higher in comparison with the conventional cantilever. In summary, it could be said that the modification performed at a trapezoidal cantilever has a notable influence to the electrical characteristics.

In order to accurately compare the electrical characteristics of the cantilevers, the ratios between the used volume of the piezo ceramic and the output voltage, current and power were set as critical. Such a means of comparison was chosen due to the differences in piezo ceramic volumes used in each cantilever. Therefore, parameters like $\mathrm{V} / \mathrm{mm}^{3}, \mu \mathrm{A} / \mathrm{mm}^{3}$ and $\mu \mathrm{W} / \mathrm{mm}^{3}$ were used for comparison. The results of the comparison are given in Fig. 2.29.

According to Fig. 2.29, the voltage generated by modified cantilevers from $1 \mathrm{~mm}^{3}$ is more than 2.2 times higher in comparison with the conventional cantilever. The generated current has more than a 2.5 times higher value, whereas the power is higher by more than 11.5 times. As a result, Fig. 2.29 shows that the best power/piezo ceramic volume ratio is at a cantilever with cylindrical gaps.

\subsubsection{Experimental investigation of trapezoidal cantilevers with irregular cross-sections}

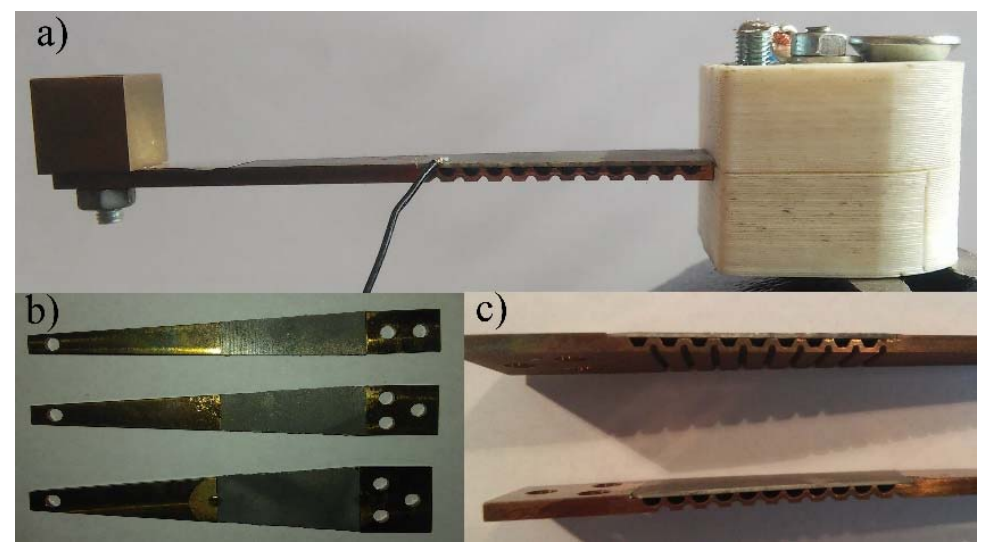

Fig. 2.30. Prototypes of the cantilevers: a) view of the assembled system; b) front view; c) side view 
The experimental investigation was performed in order to validate the results of numerical investigation. Electrical and mechanical characteristics of the prototypes were measured and analysed. Prototypes of cantilevers with the optimal geometrical parameters were made (Fig. 2.30). Moreover, plastic clamping frames designed and manufactured for each cantilever.

The resonant frequency of the first bending mode of the prototypes was measured employing the vibrometer POLYTEC PSV 500. The modes of vibrations are presented in Fig. 2.31.

It can be noticed that the values of measured resonant frequencies and natural frequencies obtained during the numerical investigation are similar; however, the highest difference is up to $17.69 \%$. Furthermore, it can be seen that the measured resonant frequencies have lower values than natural frequencies. The errors mainly occur because of the simplified numerical model and high vibration damping in the plastic clamping frame.

Summarizing this part of the investigation, can be concluded that the calculated natural frequencies and measured resonant frequencies have acceptable differences. The resonant frequencies are lower in comparison with natural ones; therefore, the lowest resonant frequencies could have a positive influence on the electrical characteristics of the cantilevers. Lower resonant frequency ensures greater cantilever tip displacements and results in a higher strain value and better electrical characteristics.

The next task of experimental study was to investigate the cantilever response to the different excitations of the base and measure electrical output densities versus resistance load. An experimental setup was built for this purpose. The principle scheme of the setup given in Fig. 2.17.

The base excitation response characteristics show the dependency of the ratio $z_{\text {Base }} / L_{B}$ to the tip displacement of each cantilever (Fig. 2.36 a).

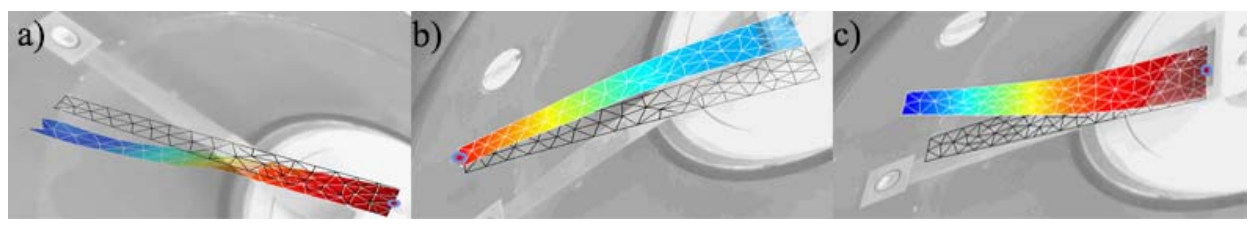

Fig. 2.31. Vibration modes of the cantilevers: a) conventional cantilever $\omega_{a}-70.05 \mathrm{~Hz}$;

b) cantilever with cylindrical gaps, $\omega_{b}-79.68 \mathrm{~Hz}$; c) cantilever with trapezoidal gaps, $\omega_{c}-101.25 \mathrm{~Hz}$

Displacements of the base and tip were measured by optical sensors (Fig. 2.17). The resistance load during this stage of the investigation was equal to the input resistance of the oscilloscope; i. e. $10 \mathrm{M} \Omega$, so displacement characteristics were measured in open circuit conditions. Excitation frequencies were set to 
the resonant frequency for each cantilever. The characteristics of the open circuit voltage density versus tip displacement investigated at the same conditions for each cantilever. The results are given in Fig. 2.32.
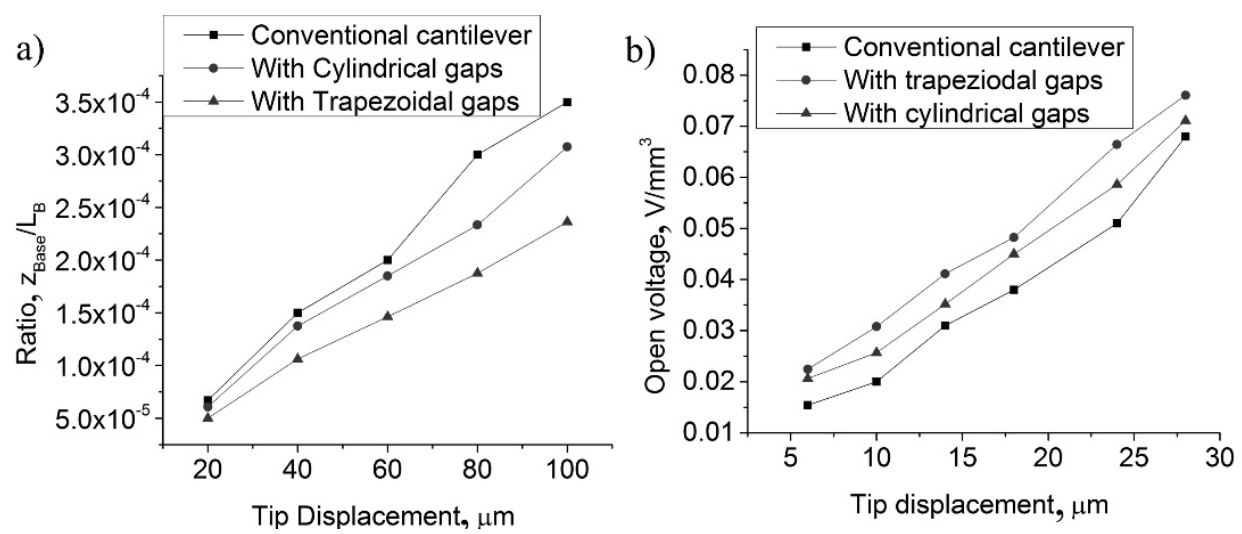

Fig. 2.32. Cantilever response and open circuit voltage density characteristics:

a) displacement characteristics; b) open circuit voltage density characteristics

The ratio between base displacement and the width of the base was chosen as a critical parameter in order to compare cantilevers. The analysis of Fig. 2.32 revealed that a cantilever with trapezoidal gaps has the best response to the base excitation. Considering to cantilever base width, $L_{B 3}$, it could be concluded that trapezoidal gaps have a positive influence to the base excitation. These gaps reduced the stiffness of the cantilever, and thus, the response characteristic was improved.

Furthermore, the generated voltage from the unit of the piezo ceramic volume was chosen as a criterion to compare cantilevers from the viewpoint of open circuit voltage density. Fig. 2.32 reveals that a cantilever with trapezoidal gaps has the best open voltage density characteristic. This caused by gaps that reduced the cantilevers' stiffness and improved strain in the piezo ceramic. The open circuit voltage density of the modified cantilever has a 3\% higher value in comparison with the conventional cantilever.

The output voltage density tip displacement characteristics for each cantilever were measured. The output voltage was measured by the oscilloscope Yokogawa DL2000. Variable resistance load was attached in parallel to the piezo ceramic. The tip displacement was controlled by optical sensor. The results of the investigation are given in Fig. 2.33.

Graphs given in Fig. 2.33 show that modified cantilevers have higher values of output voltage density. Therefore, it can be concluded that modifications of the 
cross-section have a positive influence on the electrical characteristics of the cantilevers. Comparing the maximum values of output voltage density, can be seen that the output voltage density of modified cantilevers was increased up to $9.9 \%$ compare to the conventional cantilever (Fig. 2.34). Considering this, can be concluded that modification of the cross-section can ensure higher output voltage density. Moreover, such modifications ensure more effective piezo ceramic employment.
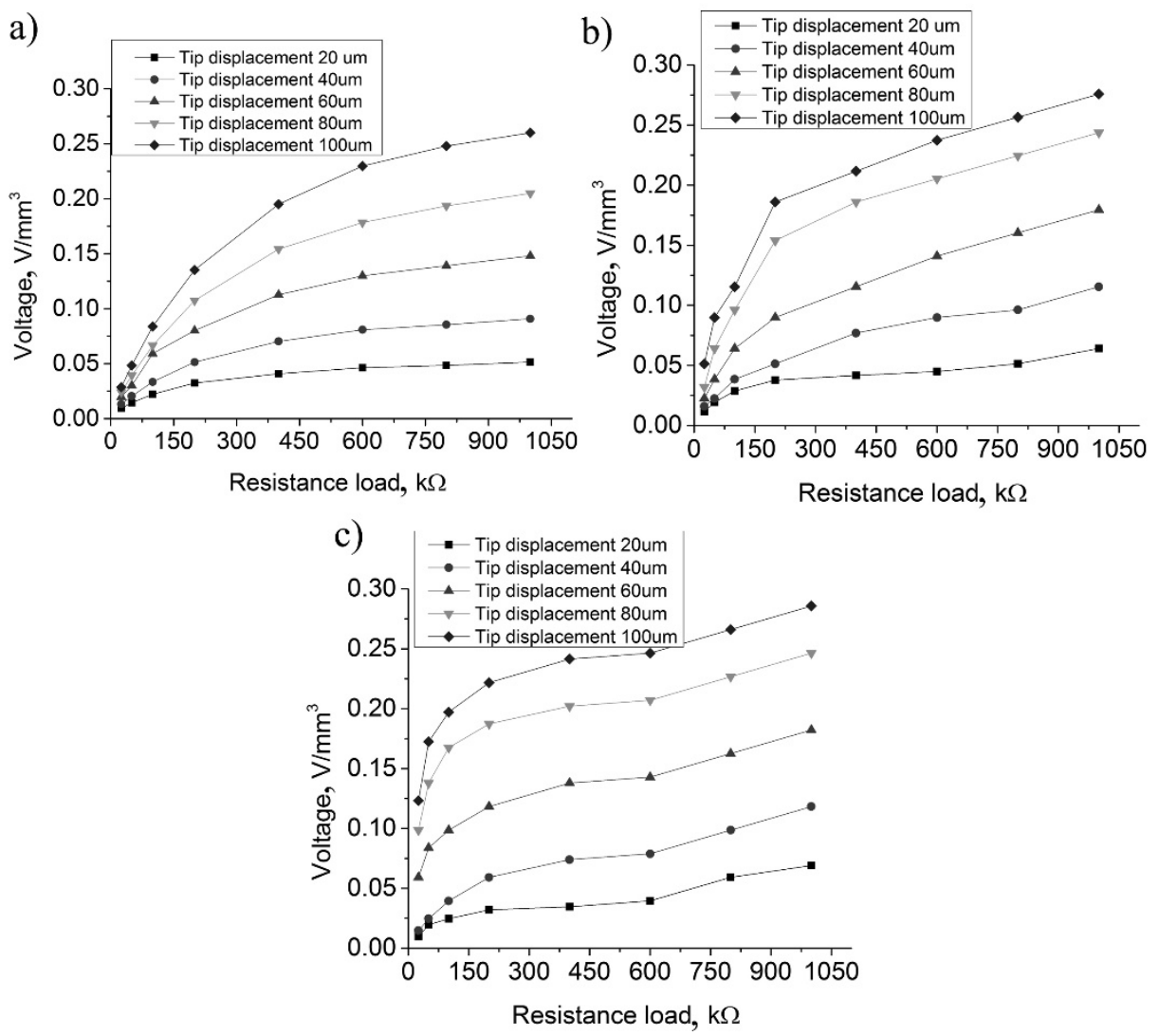

Fig. 2.33. Output voltage density versus tip displacement characteristics: a) conventional cantilever; b) with cylindrical gaps; c) with trapezoidal gaps

The output current density versus tip displacement were measured for each cantilever, as well. Current was measured by a micro current probe. The probe was connected to the oscilloscope, and the values of current were recorded. The results of the investigation given in Fig. 2.35. 


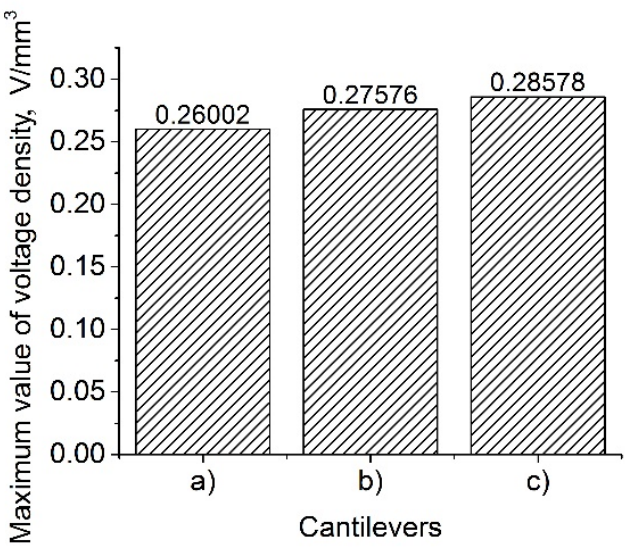

Fig. 2.34. Summary for maximum values of output voltage density: a) conventional cantilever; b) with cylindrical gaps; c) with trapezoidal gaps
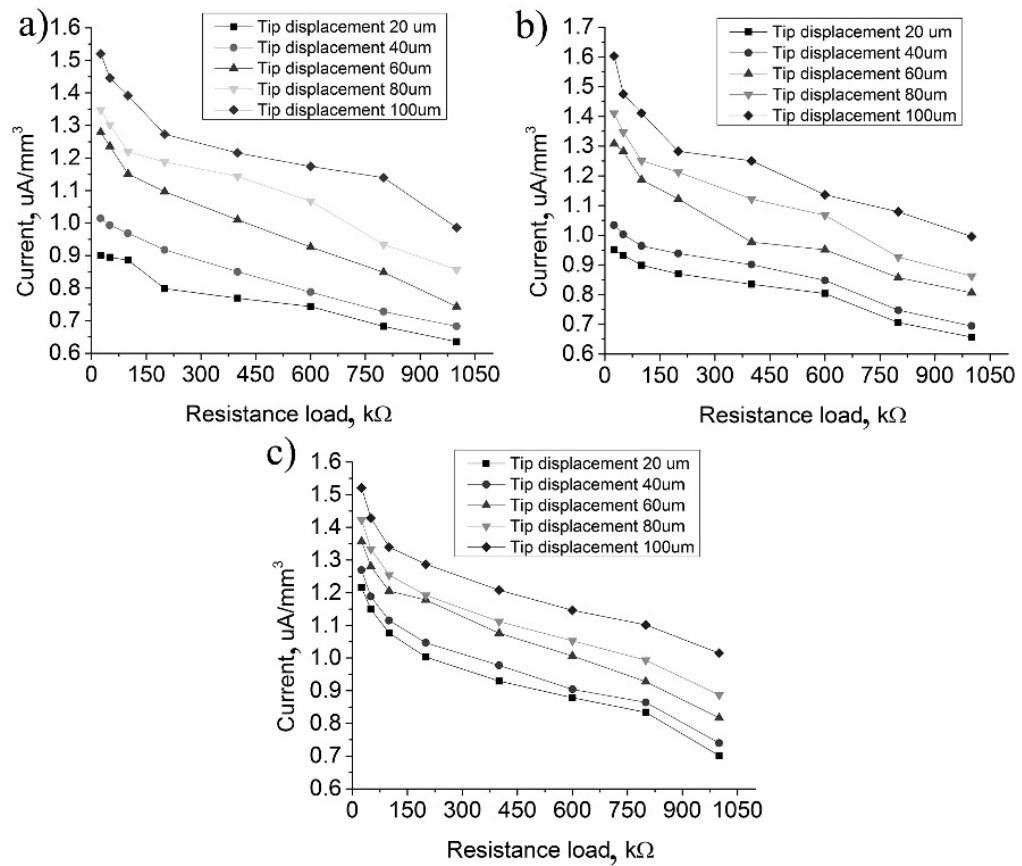

Fig. 2.35. Output current density tip displacement characteristics: a) conventional cantilever; b) with cylindrical gaps; c) with trapezoidal gaps.

The results of the measurements showed that output current density improved for cantilevers with a modified cross-sections. Considering the results, could be 
concluded that modifications of the cross-section have a positive influence to the output current density. Comparing the maximum values for the output current density, it can be noticed that cross-section modifications increased output current density up to $6.9 \%$ in comparison with the conventional cantilever (Fig. 2.36). According to the results of this investigation, it can be concluded that the energy output was improved by modifications of the cross-section.

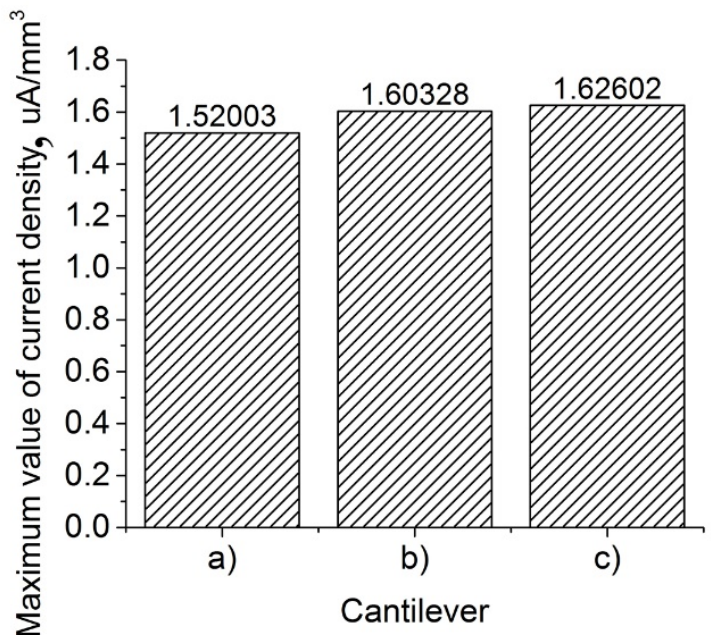

Fig. 2.36. Summary of the maximum values of output current density: a) conventional cantilever; b) with cylindrical gaps; c) with trapezoidal gaps

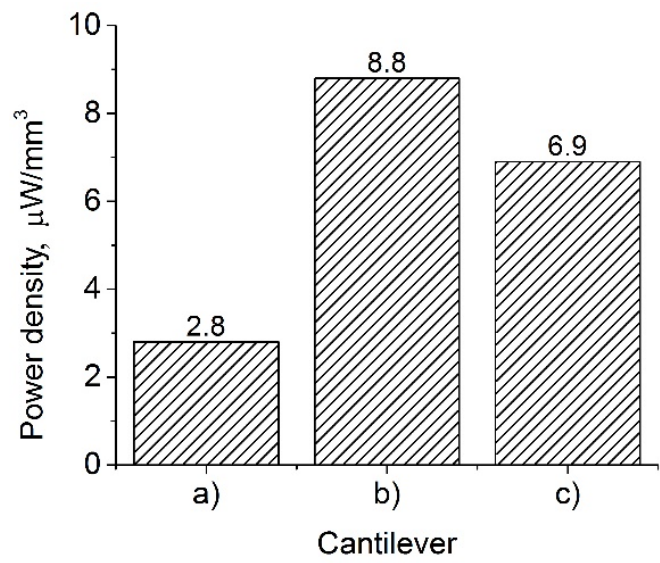

Fig. 2.37. Power density: a) conventional cantilever; b) cantilever with cylindrical gaps; c) cantilever with trapezoidal gaps 
The comparison of the power density was made for each cantilever, as well. Electrical power at $1 \mathrm{M} \Omega$ with the tip displacement of $100 \mu \mathrm{m}$ was chosen as a critical parameter. The results presented in Fig. 2.37. As can be found in the graph the cantilever with cylindrical gaps has the best power density of $8.8 \mu \mathrm{W} / \mathrm{mm}^{3}$. This power density value is 3.14 times higher in comparison with the conventional cantilever.

\subsection{Conclusions of chapter 2}

1. Proposed modifications of cantilevers cross section by various gaps ensures reduce of area moment of inertia. Reduced area moment of inertia leads to increased bending strain and it distribution across the length of cantilever. Moreover, the modified cantilevers have lower stiffness and as a result more sensitive to low excitation amplitudes compare to conventional cantilevers.

2 . The numerical and experimental investigations showed that average bending strain at rectangular cantilever with one side modified cross section is 4.8 times higher compare to conventional cantilever. Therefore, increased bending strain value and improved bending strain characteristics ant rectangular cantilever ensured $90 \%$ higher output power compare to conventional cantilever.

3. Trapezoidal cantilevers with double-sided cross-section modifications have 2.7 times higher bending strain values compare to conventional trapezoidal cantilever. Also, numerical investigations revealed that bending strain distribution across the length of modified part of cantilever is almost constant. Moreover, the investigations showed that improved bending strain and it distribution ensured 3.14 times higher output power compare to conventional cantilever. 


\section{Piezoelectric multi-frequency energy harvesters based on linked cantilever arrays}

This chapter presents results of numerical and experimental investigations of piezoelectric multi-frequency energy harvesters based on rigidly composed cantilever arrays. Rigidly composed cantilevers array configuration ensures frequency response characteristics with several resonant frequencies and narrow frequency range. Moreover, configuration based on rigidly composed cantilevers leads to multi-modal operation principle. Multi-modal operation principle ensures higher deformations and higher total output energy of the energy harvester. The results of numerical and experimental investigations, presented in this chapter, published in three papers (Čeponis, 2017a, 2017b, 2018).

\subsection{A Square type piezoelectric cantilever array for multi-frequency energy harvesting}

This section represents numerical and experimental investigations of multi-frequency square type cantilever array. The goal of investigations is to indicate in- 
fluence of rigidly composed cantilevers to mechanical and electrical characteristics of a square type cantilever array. The cantilever array consist of five piezo electric cantilevers with cross-sections modified by cylindrical gaps. Cantilevers rigidly connected to each other and acts as an indissoluble square type system. On every joint between cantilevers, under specific angle placed seismic masses. The specific angle leads to additional rotation moment for each part of the harvester.

\subsubsection{Design of the square type multi-frequency cantilever array}

In most cases, multi-frequency energy harvesters made as simple cantilever arrays. These arrays consist of several independent cantilevers with different resonant frequencies. Such design of the harvester allows obtain several resonant frequencies located close to each other. However, energy density of the whole system is low. Multi-frequency piezoelectric harvester based on square type cantilever array is able overcome aforementioned disadvantage. The isometric view and schematics of the investigated harvester given in Fig. 3.1.

a)

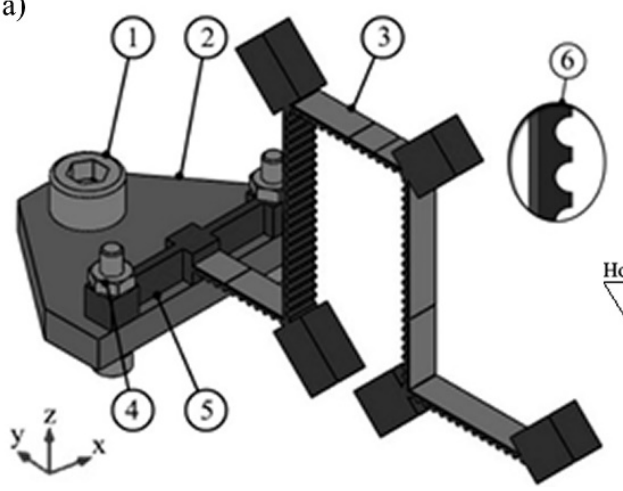

b)

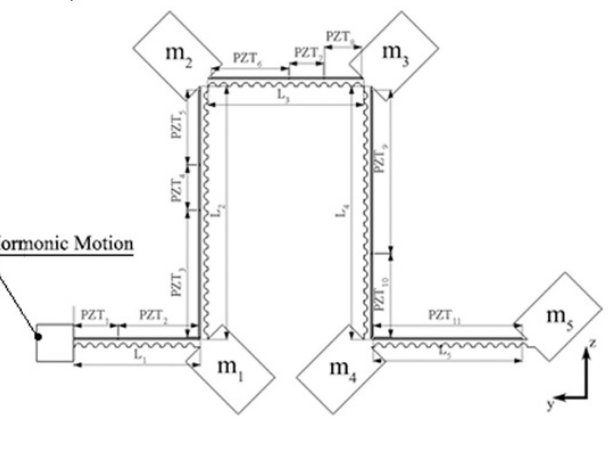

Fig. 3.1. Square type energy harvester: a) isometric view of the harvester; 1 is bolt for clamping to host structure; 2 is housing plate; 3 is body of the harvester made of C17200 beryllium bronze; 4 is bolts for harvester clamping to the housing plate; 5 is supporting beams; 6 is cross-section design of the harvester; b) Principle scheme of the harvester; $\mathrm{PZT}_{1}, \ldots, \mathrm{PZT}_{11}$ soft piezo ceramic made of PIC $255 ; \mathrm{L}_{1}, \ldots, \mathrm{L}_{5}$ is lengths of cantilevers; $\mathrm{m}_{1}, \ldots, \mathrm{m}_{5}$ seismic masses.

Energy harvester has five cantilevers, which connected rigidly to each other and forms square type cantilever array. Five seismic masses placed at every corner of the harvester. All seismic masses are uniform and have weight equal to $2.9 \mathrm{~g}$. Meanwhile, energy harvester clamped to the housing plate by two supporting beams. Finally, M3 bolts fix both ends of the supporting beams. M5 bolts used for 
rigid junction between housing plate and host structure. Principle scheme of the harvester presented in Fig. 3.1 b, while geometrical parameters are given in Table 3.1 .

Table 3.1. Geometrical parameters of the harvester

\begin{tabular}{|l|l|l|l|}
\hline Parameter & Value, $\mathrm{mm}$ & Parameter & Value, $\mathrm{mm}$ \\
\hline $\mathrm{L}_{1}$ & 17 & $\mathrm{PZT}_{4}$ & 6 \\
\hline $\mathrm{L}_{2}$ & 34 & $\mathrm{PZT}_{5}$ & 10 \\
\hline $\mathrm{L}_{3}$ & 21 & $\mathrm{PZT}_{6}$ & 10.4 \\
\hline $\mathrm{L}_{4}$ & 34 & $\mathrm{PZT}_{7}$ & 4.6 \\
\hline $\mathrm{L}_{5}$ & 21 & $\mathrm{PZT}_{8}$ & 5 \\
\hline $\mathrm{PZT}_{1}$ & 5.9 & $\mathrm{PZT}_{9}$ & 22 \\
\hline $\mathrm{PZT}_{2}$ & 10.8 & $\mathrm{PZT}_{10}$ & 11.3 \\
\hline $\mathrm{PZT}_{3}$ & 17 & $\mathrm{PZT}_{11}$ & 20 \\
\hline
\end{tabular}

Thickness of all cantilevers is $1 \mathrm{~mm}$, moreover cross sections of the cantilevers are modified by periodical cylindrical gaps with radius $0.5 \mathrm{~mm}$. So, thickness of the cantilevers become uneven. Therefore, modifications of the cross section leads to improvements in bending strain and it distribution at piezo ceramic layer. Modifications of the cross sections reduce structural damping of the system and decrease potential barrier of the harvester. Width of all cantilevers is $5 \mathrm{~mm}$ as well as width of the seismic masses. Upper surfaces of the cantilevers are covered by piezo ceramic layers, which are divided into eleven sections. Such scheme of the piezo ceramic layers prevents charge cancelation during harvester operation at the second out of plane bending mode as well as compounds of the first and second bending modes. Partition of the piezo ceramic layers based on the results of numerical investigation. Explanation of the piezo ceramic partition principle given in next the section.

In most cases, clamping of energy harvesters is rigid. Such clamping is suitable for systems, which operates at one fixed resonant frequency. The cantilevers of proposed energy harvester vibrates at the first and the second out of plane bending modes. Moreover, compounds of these modes used for the harvesters operation as well. So, during operation at compounded mode, longitudinal motion of the base generated. Therefore, rigid clamping of the base will damp energy harvester and usage of compounds of the modes will be ineffective. In order to reduce this disadvantage of rigid base clamping, two supporting beams used. Scheme of the clamping given in Fig. 3.2.

Supporting beams designed to reduce damping of the energy harvester while the harvester base generates longitudinal displacement. Such operation of the 
clamping ensures possibility to obtain more resonance frequencies at same frequency range.

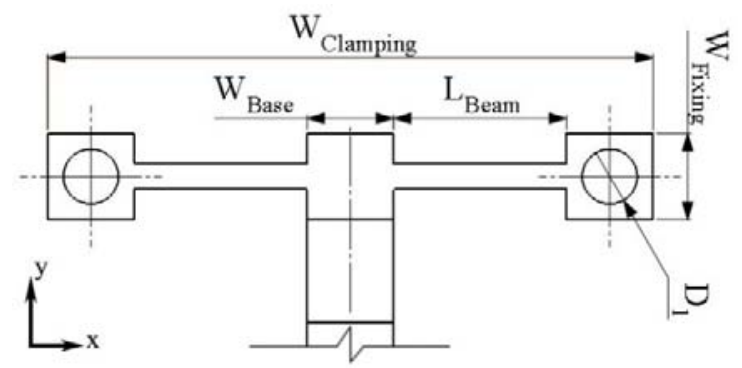

Fig. 3.2. Scheme of the harvester clamping

So, width of the all clamping system, $\mathrm{W}_{\text {Clamping, }}$ is equal to $35 \mathrm{~mm}$. Width of the base, $\mathrm{W}_{\text {Base, }}$ is same as width of the cantilevers i. e. $5 \mathrm{~mm}$. Lengths of the supporting beams were obtained by numerical investigation and are equal to $10 \mathrm{~mm}$. Width of the fixing sites, $\mathrm{W}_{\text {Fixing, }}$ is $5 \mathrm{~mm}$ and finally diameter of the fixing holes, $\mathrm{D}_{1}$ is $3.2 \mathrm{~mm}$.

\subsubsection{Numerical investigation of the square type multi-frequency cantilever array}

Numerical investigation of piezoelectric multi-frequency square type cantilever array performed in order to investigate operation principle and to investigate mechanical and electrical output characteristics. Finite element model (FEM) built by Comsol 5.2 software. Properties of the materials used in FEM model given in Table 2.3. Therefore, boundary conditions were set as follows i. e. ends of the supporting beams rigidly fixed. Harmonic motion of the harvester base in $\mathrm{Z}$ direction used to excite host structure. Acceleration amplitude was set to $1 \mathrm{~m} / \mathrm{s}^{2}$. Probe lines for bending strain and it distribution investigations were set at the centre of each piezo ceramic layer.

Firstly, modal analysis of the harvester performed in order to obtain natural frequencies and modal shapes of the system. Modal shapes of the harvester in frequency range from $15 \mathrm{~Hz}$ to $300 \mathrm{~Hz}$ given in Fig. 3.3.

Analysis of the results revealed that dominant modal shapes of the cantilevers are $1^{\text {st }}$ and $2^{\text {nd }}$ out of plane vibration modes. Moreover, modal analysis showed that system operation at the higher frequencies based on compounds of two dominant modes. Hence, summation of the modal bending strains gives possibility to increase bending strain values and make bending strain distribution more uniform at the piezo ceramic layers. 
a)

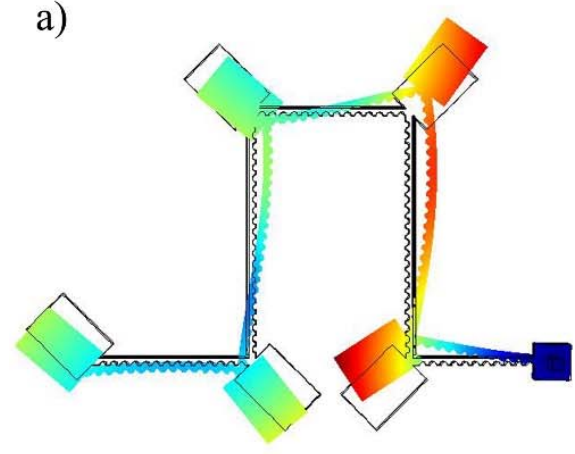

c)

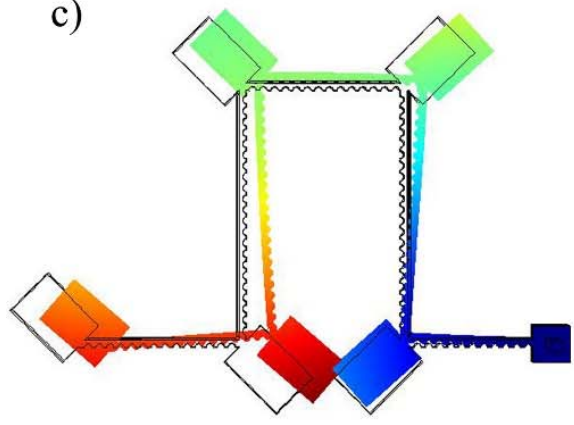

b)

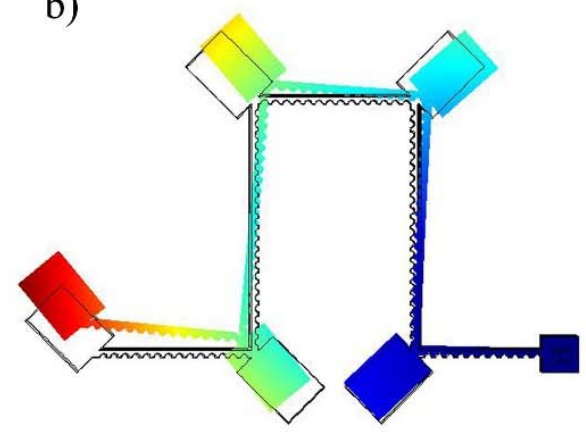

d)

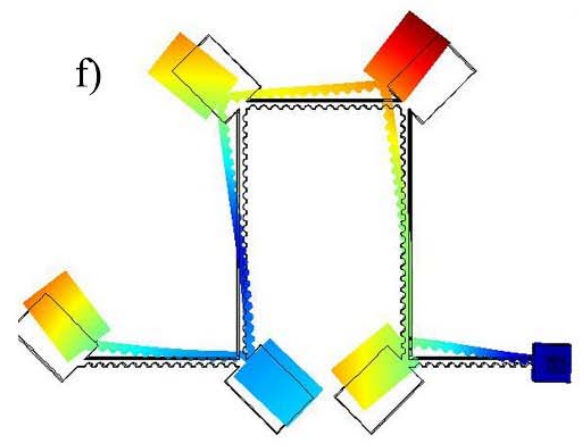

Fig. 3.3. Modal shapes of the harvester: a) $w_{n 1}=24.95 \mathrm{~Hz}$; b) $w_{n 2}=47.49 \mathrm{~Hz}$; c) $w_{n 3}=170.9 \mathrm{~Hz}$; ) $\mathrm{w}_{\mathrm{n} 4}=229.3 \mathrm{~Hz}$;) $w_{n 5}=298.15 \mathrm{~Hz}$

In order to harvest energy of mechanical vibrations by all vibration modes, a complex partition of piezo ceramic layers must be implemented. Differences between adjacent frequencies calculated in order to assess distribution of the natural 
frequencies. It can be noticed that the first and the second natural frequencies have difference in 1.90 times, second and third have 3.59 times difference, third and fourth have 1.12 times and finally fourth and fifth have difference in frequency values in 1.34 times.

According to the results of the modal analysis, it can be concluded that five natural frequencies are adequately close to each other and ensures principle of multi-frequency operation. Therefore, proposed design of the multi-frequency energy harvester can provide energy feed at five resonant frequencies which are located and range from $15 \mathrm{~Hz}$ to $300 \mathrm{~Hz}$.

Frequency domain study used in order to investigate frequency response, bending strain and it distribution characteristics. Moreover, on basis of bending strain distribution along the length of the cantilevers, segmentation of the piezo ceramic layers was made. It is done in order to avoid charge cancelation during systems operation at the second out of plane bending mode. Frequency response characteristic given in Fig. 3.4.

The frequency response characteristics confirmed results obtained during modal analysis. Exact coincidence of the resonant and natural frequencies shows high systems stability at different resonant frequencies. So, the highest acceleration of the harvesters tip achieved at the lowest resonant frequency with the first, out of plane, bending mode. On basis of this can be highlighted that harvested energy density and generated voltage density at this resonant frequency will be at the highest level.

Therefore, the lowest acceleration, in $Z$ direction, obtained at resonant frequency is $50 \mathrm{~Hz}$. Such low acceleration level, in $Z$ direction, caused by compound of two vibration modes. Therefore, at Fig. $3.3 \mathrm{~b}$, can be observed that cantilever $\mathrm{L}_{4}$ operates at the first, out of plane, bending mode and as a result $L_{5}$ displacement behaviour becomes longitudinal in $X$ direction. Moreover, due to specific angle of the seismic masses additional rotation moment created in whole body of the harvester.

Also, frequency response characteristics given in Fig. 3.4 shows that three resonant frequencies are close to each other and provides multi-frequency energy harvesting. In general, the resonant frequencies at that frequency range operates at compounded vibration modes. Such, operation principle and seismic masses placed under specific angle leads to an additional rotation moment in whole system and as result, all cantilevers will be strained. Hence, all cantilevers employed during systems operation and this leads to higher energy density of the whole system. Therefore, results of the frequency response analysis showed that proposed design of the energy harvester is able to operate at multi-frequency operation principle. Moreover, compounds of vibration modes leads to modal strain summation and herewith ensures real multi-frequency operation principle. 


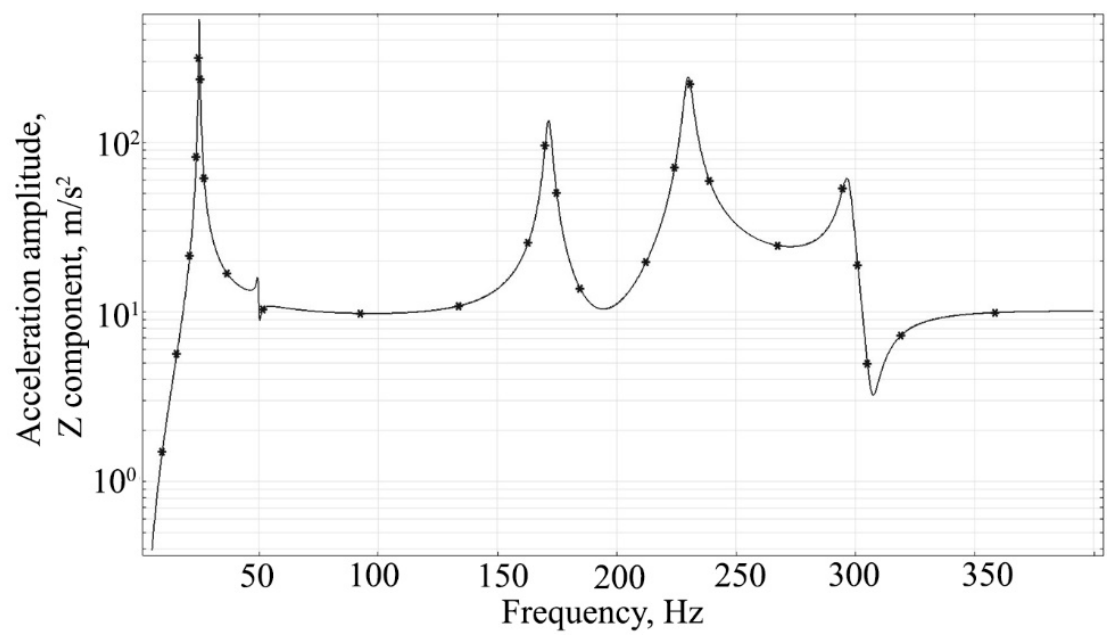

Fig. 3.4. Frequency response characteristics of the harvester

Investigation and analysis of bending strain and it distribution characteristics at each cantilever performed. The goal of investigation was to obtain partition scheme of piezo ceramic layers based on bending strain distribution at each cantilever (Fig. 3.5). The following algorithm was used i. e. piezo ceramic layers were divided at the nodes of the higher out of plane bending modes. Totally 11 piezo ceramic sections were obtained after numerical calculations. Such complex partition was made in order to avoid charge cancelation during systems operation at second bending mode. Calculated dimensions of the piezo ceramic sections given in Table 3.1 .

During analysis of bending strain distribution at the first resonance frequency can be noticed that distribution is almost uniform (Fig. 3.5). This achieved by modifying cross section with periodical gaps, modal strain summation and seismic masses as well. Seismic masses creates an additional rotation moment at whole body of the harvester. Moreover, bending strain at the first resonance frequency has the highest value compare to other frequencies. So, based on this can be assumed that electrical characteristics at this resonant frequency will be the highest. On the other hand, bending strain characteristics at the higher resonance frequencies also have almost uniform distribution. However, bending strain values are much lower compare to the bending strain values at the first resonance frequency. Summary of the maximum bending strain values was made in order to assess strain level at every resonance frequency. Results given in Table 3.2. 

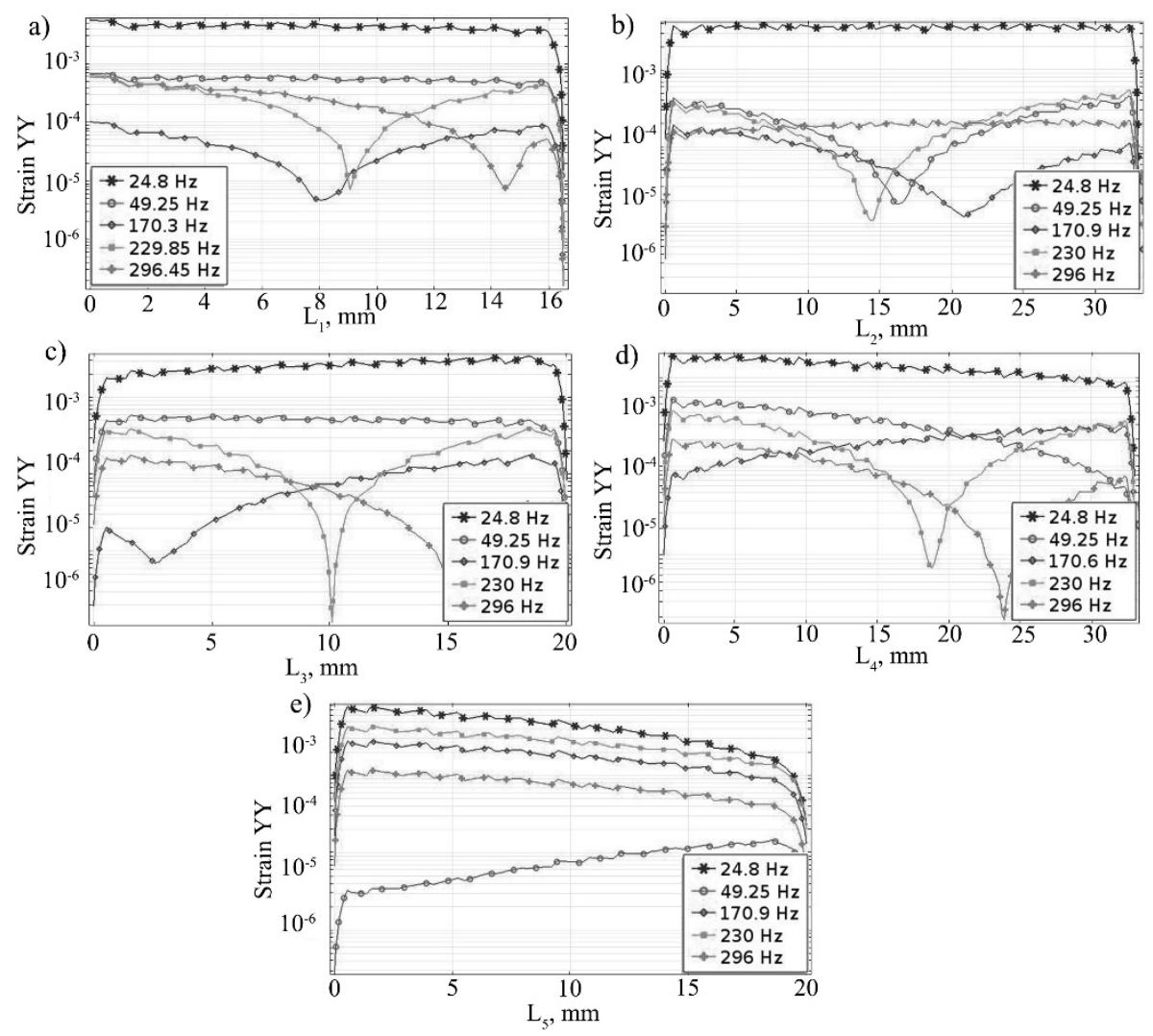

Fig. 3.5. Strain characteristics: a) strain characteristics at $L_{l}$; b) strain characteristics at $L_{2} ;$ c) strain characteristics at $L_{3} ;$ d) strain characteristics at $L_{4}$; f) strain characteristics at $L_{5}$

Table 3.2 Summary of the maximum strain values

\begin{tabular}{|c|c|c|c|c|c|}
\hline $\begin{array}{c}\text { Cantilever } \\
\text { Resonance }\end{array}$ & $24.8 \mathrm{~Hz}$ & $49.25 \mathrm{~Hz}$ & $170.9 \mathrm{~Hz}$ & $230 \mathrm{~Hz}$ & $296 \mathrm{~Hz}$ \\
\hline Strain at $\mathrm{L}_{1}$ & $5.59 \cdot 10^{-3}$ & $7.43 \cdot 10^{-4}$ & $10.2 \cdot 10^{-5}$ & $4.15 \cdot 10^{-4}$ & $6.42 \cdot 10^{-4}$ \\
\hline Strain at $\mathrm{L}_{2}$ & $3.88 \cdot 10^{-3}$ & $4.48 \cdot 10^{-4}$ & $2.37 \cdot 10^{-4}$ & $4.5 \cdot 10^{-4}$ & $1.81 \cdot 10^{-4}$ \\
\hline Strain at $\mathrm{L}_{3}$ & $3.41 \cdot 10^{-3}$ & $5.22 \cdot 10^{-4}$ & $1.63 \cdot 10^{-4}$ & $3.72 \cdot 10^{-4}$ & $1.76 \cdot 10^{-4}$ \\
\hline Strain at $\mathrm{L}_{4}$ & $1.85 \cdot 10^{-3}$ & $6.21 \cdot 10^{-4}$ & $2.84 \cdot 10^{-4}$ & $3.11 \cdot 10^{-4}$ & $1.54 \cdot 10^{-4}$ \\
\hline Strain at $\mathrm{L}_{5}$ & $8.15 \cdot 10^{-4}$ & $3.42 \cdot 10^{-6}$ & $2.99 \cdot 10^{-4}$ & $4.25 \cdot 10^{-4}$ & $1.18 \cdot 10^{-4}$ \\
\hline
\end{tabular}

It can be noticed that strain maximum values at cantilevers are similar at every resonance frequency. The difference between the first and higher resonance 
frequencies is approximately 10 times. On the other hand, bending strain at the higher resonance frequencies are also roughly similar.

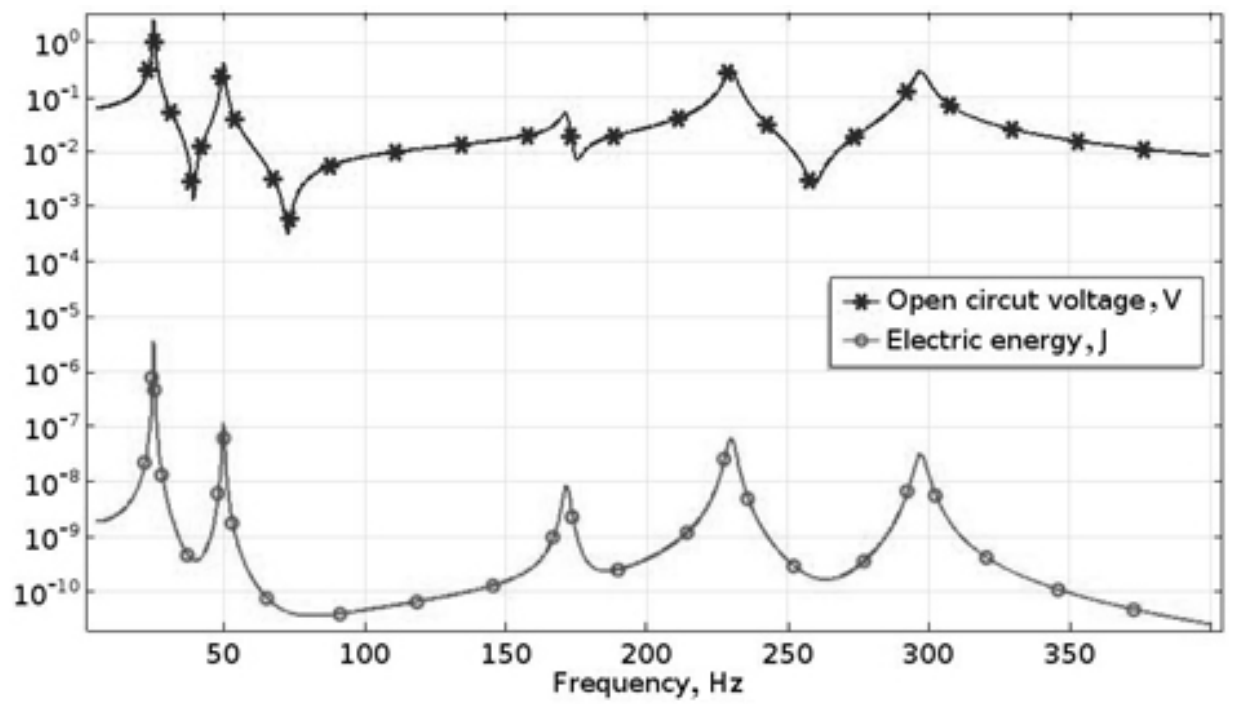

Fig. 3.6. Electrical characteristics of the harvester

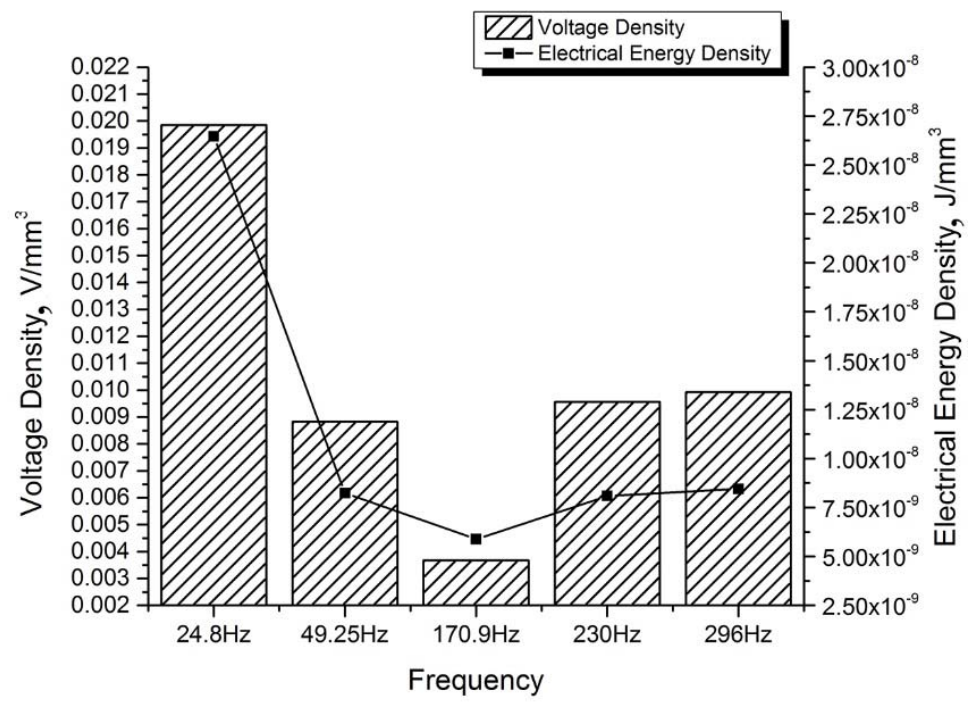

Fig. 3.7. Comparison of electrical characteristics 
It shows that electrical characteristics at the higher resonance frequencies could have the same values and harvester will be able to provide lower, but stable energy feed to the load.

Open circuit voltage and electrical energy investigated as electrical characteristics of the energy harvester. Frequency domain study used for this investigation. The results given in Fig. 3.6.

Analysis of the electrical characteristics showed that maximum open circuit and electrical energy densities achieved at the lowest resonant frequency and it is equal to $19.85 \mathrm{mV} / \mathrm{mm}^{3}$ and $26.4 \mathrm{~nJ} / \mathrm{mm}^{3}$, respectively. Such electrical characteristic obtained because of the dominant first out of plane bending mode and almost uniform bending strain distribution at piezo ceramic layers. However, electrical characteristics at the higher resonant frequencies are lower.

On the other hand, it can be noticed that electrical characteristics obtained at higher frequencies have similar values. So, it shows that energy harvester is able provide adequately stable energy feed at different resonant frequencies. Comparison of electrical characteristics given in Fig. 3.7.

\subsubsection{Experimental investigation of the square type multi-frequency cantilever array}

Experimental investigation of the multi-frequency energy harvester was performed in order to validate results obtained during numerical investigation. Prototype was made with strict respect to geometrical and physical parameters used for the numerical model. View of the prototype given in Fig. 3.8.

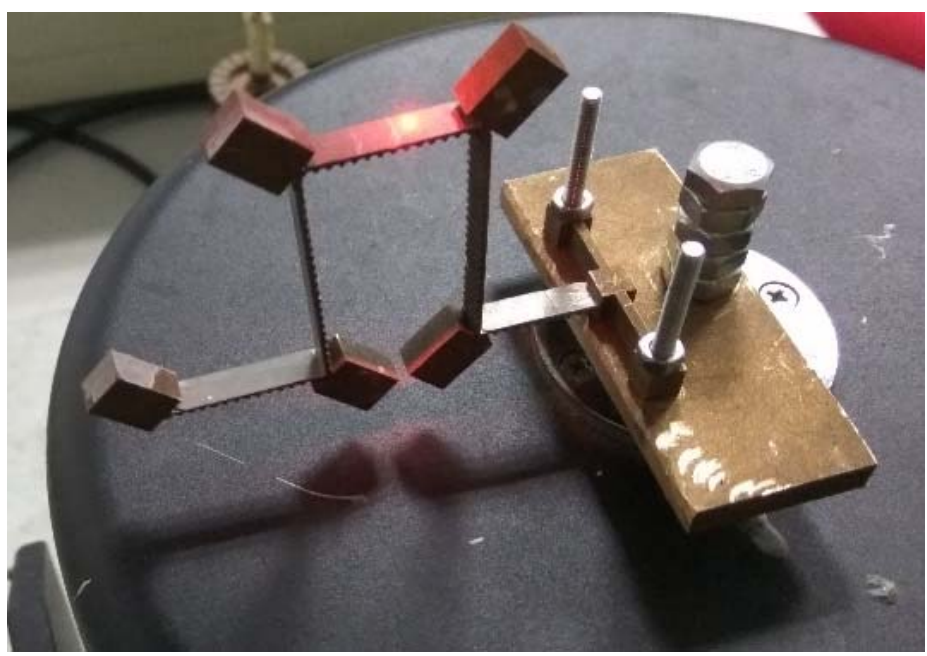

Fig. 3.8. Prototype of the energy harvester 
Firstly, experimental study of frequency response characteristics was performed with the aim to validate results of numerical investigation. OFV 056 scanning vibrometer was employed for this purpose. Result of the tip vibration measurement in frequency domain given in Fig. 3.9.

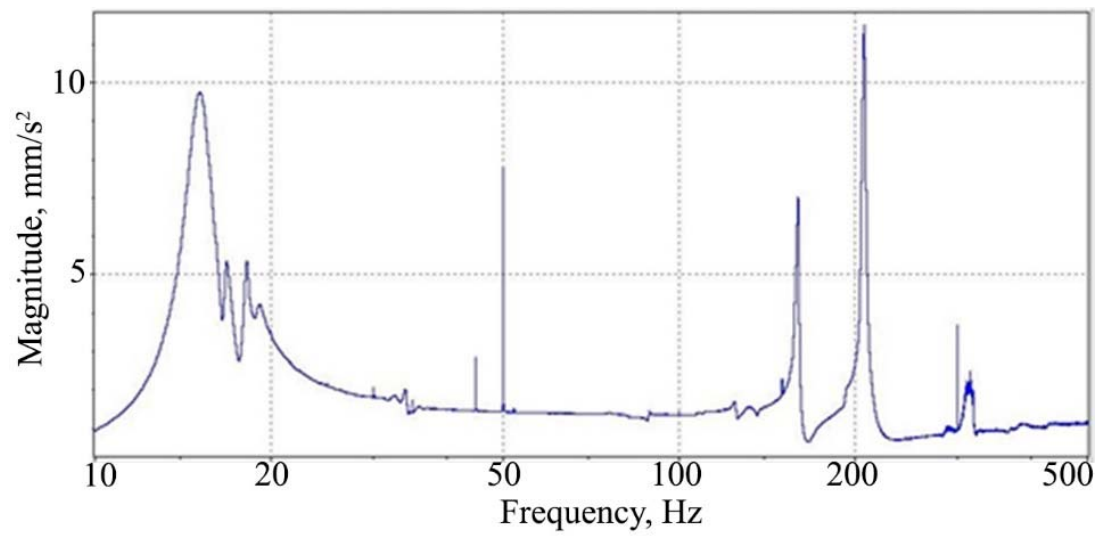

Fig. 3.9. Frequency response characteristics of the harvester.

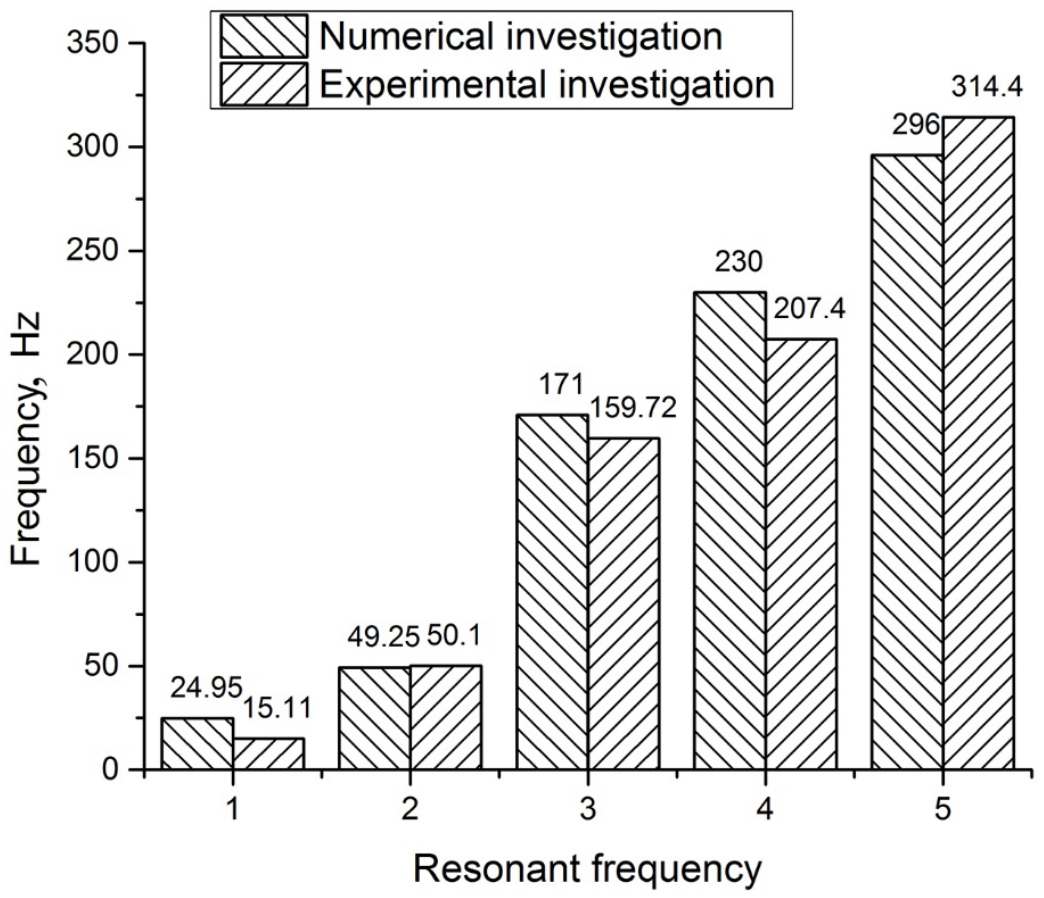

Fig. 3.10. Comparison of the resonance frequencies 
It can be seen that frequency response characteristic obtained experimentally has good coincidence with the results of numerical simulation. The difference between natural frequencies obtained numerically and resonant frequencies obtained experimentally is $22.6 \mathrm{~Hz}$. Also, analysis of the results revealed that mechanical quality factor of the system at the first resonant frequency is much lower compere to the other resonant frequencies. So, it can be said that harvester operation at the first resonant frequency will be more stable during fluctuations in excitation frequency. In order to assess differences in frequency response characteristics, comparison of the resonant frequencies made. The results given in Fig. 3.10.

Comparison of the frequencies showed, that resonant frequencies obtained experimentally are lower compare to the frequencies obtained numerically except the fifth resonant frequency.

Differences are caused by errors which occurred during the prototype manufacturing, mismatches in material properties and glue layer, which was neglected in the numerical model. However, differences are in adequate range. On basis of this can be concluded that the results of numerical investigation have good agreement with experimental investigation.

Experimental investigations of the electrical characteristics performed as well. The aim of investigation was to obtain electrical output characteristics of the harvester from view point of open circuit voltage and generated energy densities. For this purpose experimental setup and electronic interface were build. Neat diagram of the experimental setup given in Fig. 3.11.

The experimental setup consist of function generator and amplifier, which used for electromagnetic shaker driving. The displacement sensor and data logging multimeter used to measure base displacement and output voltage amplitudes during whole investigation. In order to record and manage data, the displacement sensor and multimeter connected to the computer with special software. Electronic interface specially designed and manufactured for experimental setup (Fig. 3.12).

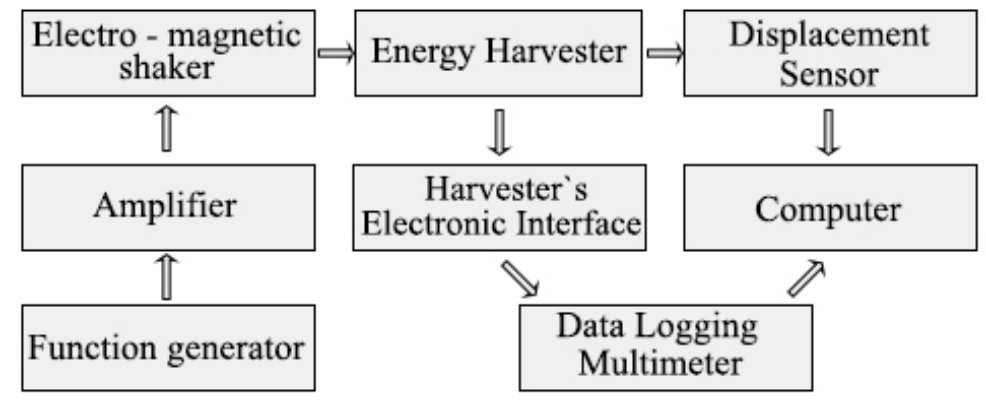

Fig. 3.11. Neat diagram of the experimental setup 
The electrical interface represent classical AC/DC converter with single output and multi-channel output operation modes. Therefore, it consist of five full wave diode bridges which are made of BAT46 low loss Schottky diodes $\left(\mathrm{D}_{1}, .\right.$. , $\mathrm{D}_{20}$ ). During multi-channel operation mode, the diode bridges are in parallel and forms five channel AC/DC voltage converter with $47 \mu \mathrm{F}$ electrolytic capacitors $\left(\mathrm{C}_{1}, \ldots, \mathrm{C}_{5}\right)$ as energy storage buffers. Multi-channel operation mode gives possibility separately convert and store energy generated by different piezo ceramic layers. Moreover, the electrical interface could be switched to one channel mode. It means that DC outputs of each channel will be connected to common $220 \mu \mathrm{F}$ $\left(\mathrm{C}_{\mathrm{Com}}\right)$ electrolytic energy storage capacitor. Single channel operation mode gives possibility convert and store energy from all piezo ceramic layers which operates at different deformation modes. Moreover, designed AC/DC voltage converter can be connected in cascades to increase number of the channels.

Investigation of open circuit voltage at resonant frequencies was performed. Voltage measured separately at each piezo ceramic layer. For this investigation, the experimental setup, without electronic interface, was used. Voltage measured and recorded by the data logging voltmeter and computer. Base displacement, during this stage of the investigation, was $100 \mu \mathrm{m}$ and the displacement sensor measured it. Results of the investigation given in Fig. 3.13.

Analysis of open circuit voltage characteristics showed that voltage distribution at the energy harvester during it excitation at the first resonance frequency has uniform behaviour (Fig. 3.13 a).

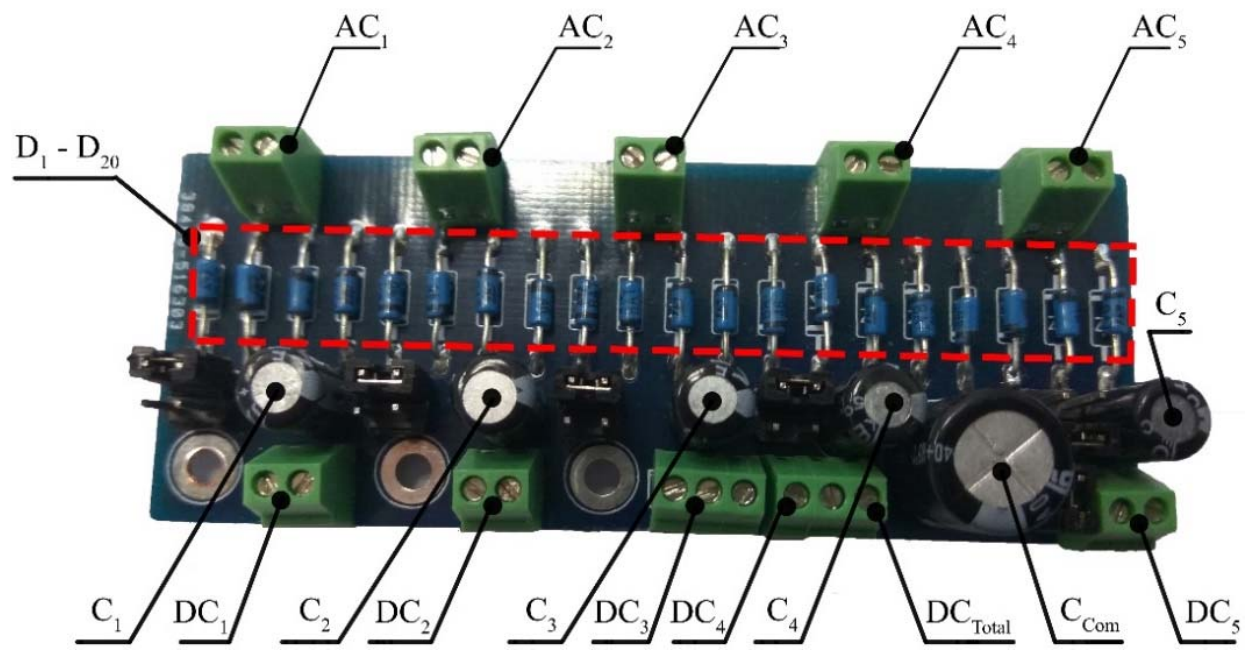

Fig. 3.12. Electronic interface for the energy harvester 

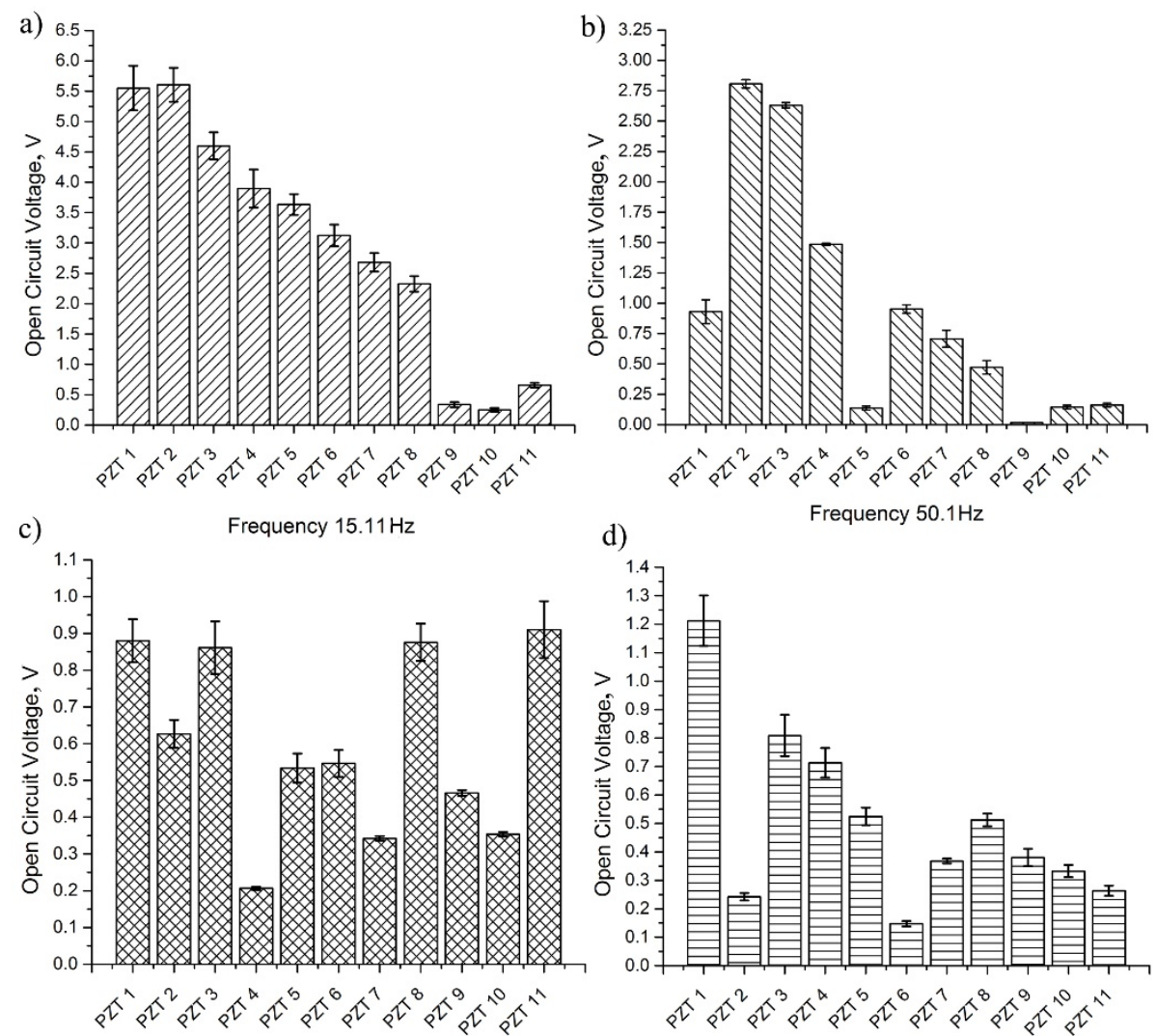

d)

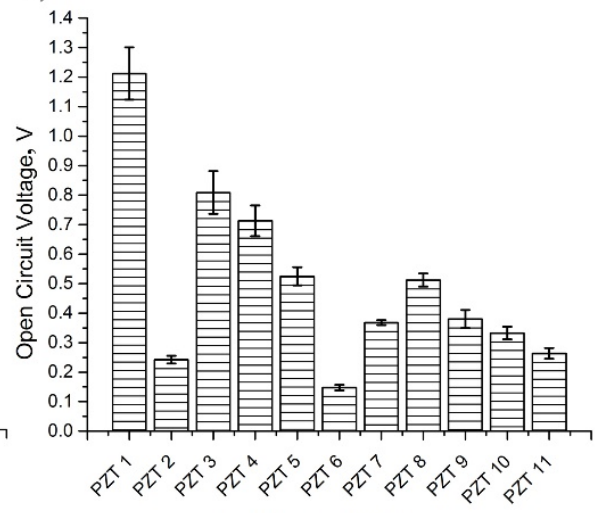

Frequency $159.72 \mathrm{~Hz}$

Frequency $207.4 \mathrm{~Hz}$

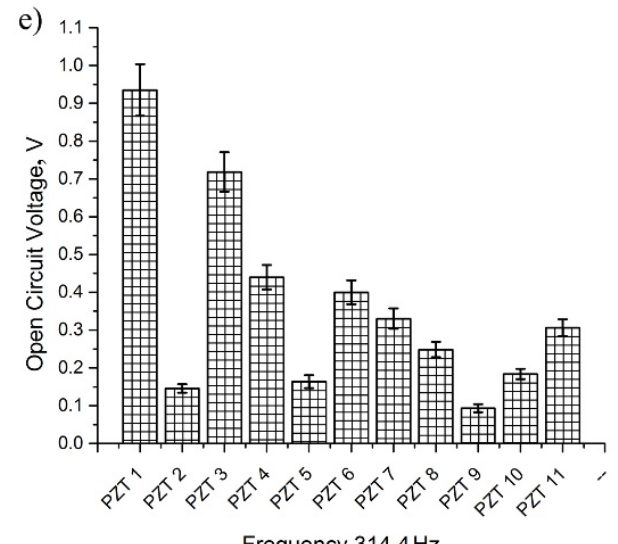

Frequency $314.4 \mathrm{~Hz}$

Fig. 3.13. Open circuit voltage characteristics at the resonant frequencies: a) at $15.11 \mathrm{~Hz}$; b) at $50.1 \mathrm{~Hz}$; c) at $159.72 \mathrm{~Hz}$; d) at $207.4 \mathrm{~Hz}$; e) at $314.4 \mathrm{~Hz}$ 
Such voltage characteristic shows that whole harvester operates at the first, out of plane, bending mode (Fig. 3.5). Therefore, open circuit voltage characteristics confirms the results of frequency response and modal analysis. Moreover, the highest open circuit voltages obtained at the first resonant frequency are $5.4 \mathrm{~V}$ and 5.6 V. It achieved at $\mathrm{PZT}_{1}$ and $\mathrm{PZT}_{2}$ piezo ceramic layers.

Fig. 3.13 b, represents open circuit voltage characteristics of the energy harvester at second resonance frequency. The highest open circuit voltage levels were achieved at $\mathrm{PZT}_{2}$ and $\mathrm{PZT}_{3}, 2.8 \mathrm{~V}$ and $2.63 \mathrm{~V}$, respectively. It shows that the highest bending strain is at junction between cantilevers $\mathrm{L}_{1}$ and $\mathrm{L}_{2}$. On basis of this can be concluded that displacement of the harvester's body has longitudinal behaviour and operates at compound of the first and second bending modes.

Open circuit voltage characteristics of the energy harvester at the third resonance frequency is given in Fig. $3.13 \mathrm{c}$ Analysis of the characteristics revealed that the highest open circuit voltage levels were achieved at $\mathrm{PZT}_{1}, \mathrm{PZT}_{3}, \mathrm{PZT}_{8}$ and $\mathrm{PZT}_{11}$, with values $0.88 \mathrm{~V}, 0.86 \mathrm{~V}, 0.87 \mathrm{~V}, 0.91 \mathrm{~V}$ respectively. On basis of the open circuit voltage peaks can be concluded that harvesters operation at the third resonance frequency is based on the second, out of plane bending mode and compounds of it.

Fig. $3.13 \mathrm{~d}$ represents open circuit voltage characteristics of the harvester at fourth resonance frequency. Analysis of the characteristics showed that the highest voltage values were achieved at $\mathrm{PZT}_{1}$ and $\mathrm{PZT}_{3}$ layers. Open circuit voltage values reached $1.21 \mathrm{~V}$ and $0.8 \mathrm{~V}$, respectively. At this resonance frequency, voltage levels are lower compere to before mentioned cases. On the other hand, the harvester at the first three resonance frequencies operates at the first, out of plane, mode or compounds of the first and second mode. On basis of the modal analysis and the results of experimental investigation can be said that dominant mode at that frequencies is the first. However, at the fourth and fifth resonance frequencies dominant mode is the second. So, such modes distribution at the cantilevers in higher resonance frequencies leads to lower voltage levels.

Finally, analysis of the open circuit characteristics at the fifth resonance frequency showed that the highest voltage values were achieved at $\mathrm{PZT}_{1}$ and $\mathrm{PZT}_{3}$ (Fig. 3.13 e). Open circuit values reached $0.93 \mathrm{~V}$ and $0.71 \mathrm{~V}$, respectively. Moreover, analysis revealed that characteristics of the fourth and fifth characteristics have coincidence in behaviour and voltage levels. So, it confirms that energy harvester operation at higher resonance frequencies is based on the second, out of plane, bending mode or compounds of the second and first modes.

Open circuit voltage characteristics represents values generated by different piezo ceramic layers, in order to accurately assess harvester's open circuit voltage at different resonance frequencies comparison from view point of open circuit voltage density was performed. Results of the comparison given in Fig. 3.14. 
Comparison revealed that the highest open circuit voltage density is at the first resonance frequency. Voltage density at the first resonant frequency at least 3.12 times higher compare to other frequencies. On the other hand, voltage densities at higher frequencies are not in such extreme difference. Therefore, can be concluded that the highest open circuit voltage density will be achieved at the lowest excitation frequencies. On the other hand, energy harvester is able provide lower, but stable open circuit voltage density at the higher resonant frequencies.

Next stage of the investigation dedicated to output energy density at the resonance frequencies. For this purpose, the experimental setup with electronic interface switched to multi-channel mode. Energy generated by each piezo ceramic layer was stored and measured on $47 \mu \mathrm{F}$ capacitor. Measurements were performed at each channel by the data logging voltmeter.

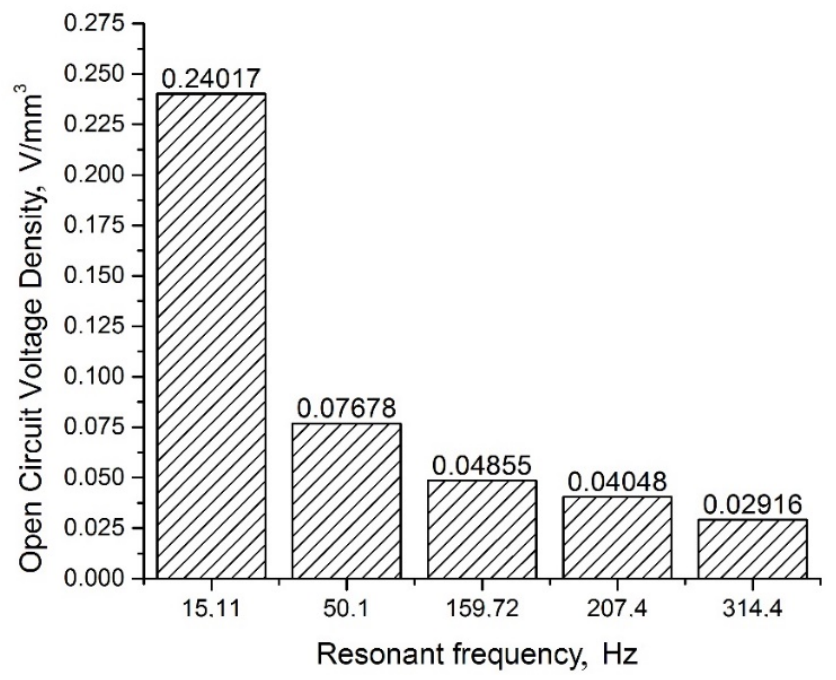

Fig. 3.14. Open circuit voltage density characteristics

Energy harvester's base displacement, during whole experimental investigation, was $100 \mu \mathrm{m}$. Results of the investigation given in Fig. 3.15.

Analysis of the results showed that highest energy density at the first resonant frequency reached $84 \mu \mathrm{J} / \mathrm{mm}^{3}$ and it was generated by $\mathrm{PZT}_{1}$ piezo ceramic layer.

Also, the results revealed that the highest energy densities at the first resonance frequency were achieved near fixed end of the harvester. So, on basis of the experimental investigation could be concluded that the highest output energy density concentration is near fixed end of the harvester when the first bending mode is dominant. 

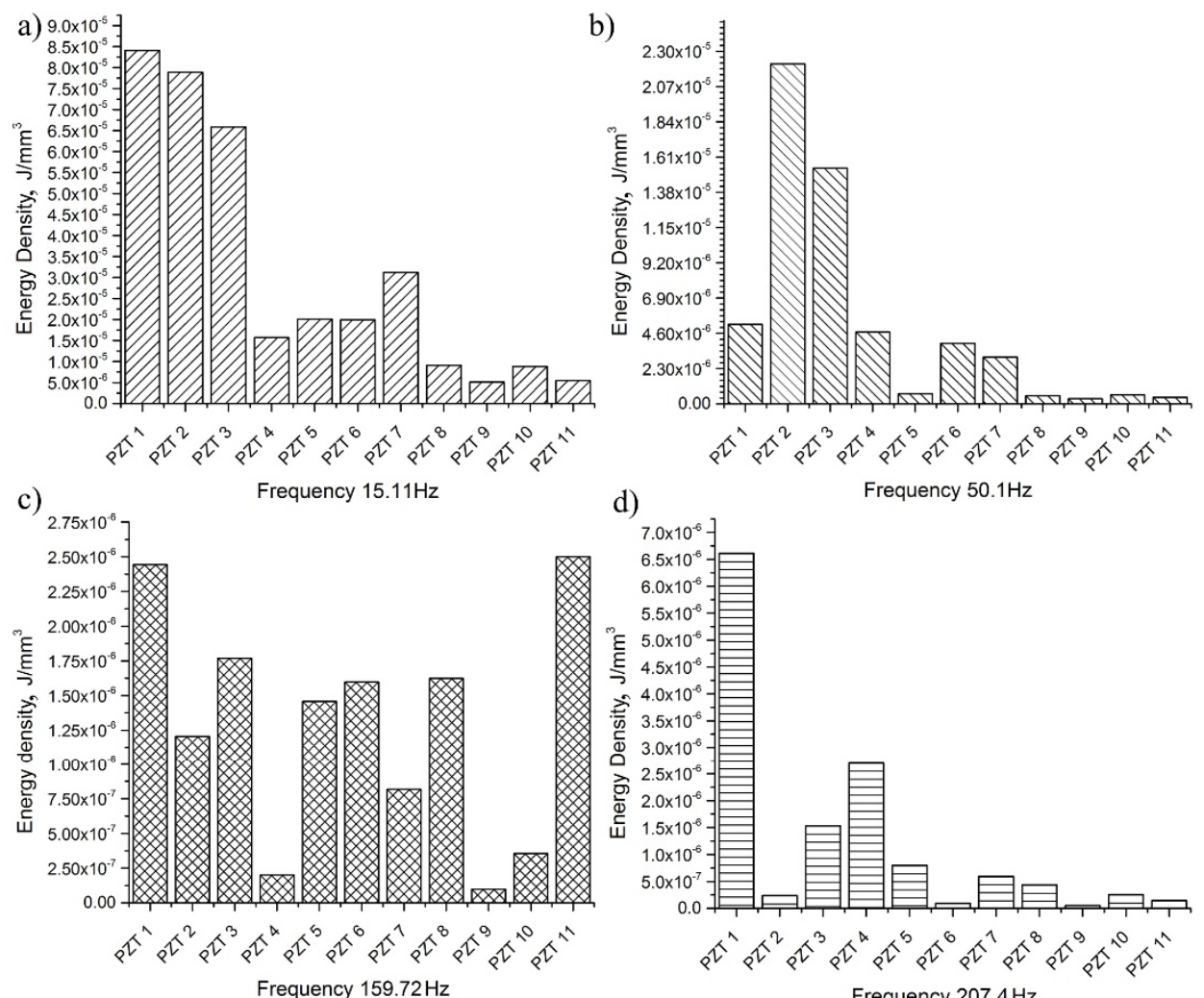

d)

Frequency $50.1 \mathrm{~Hz}$
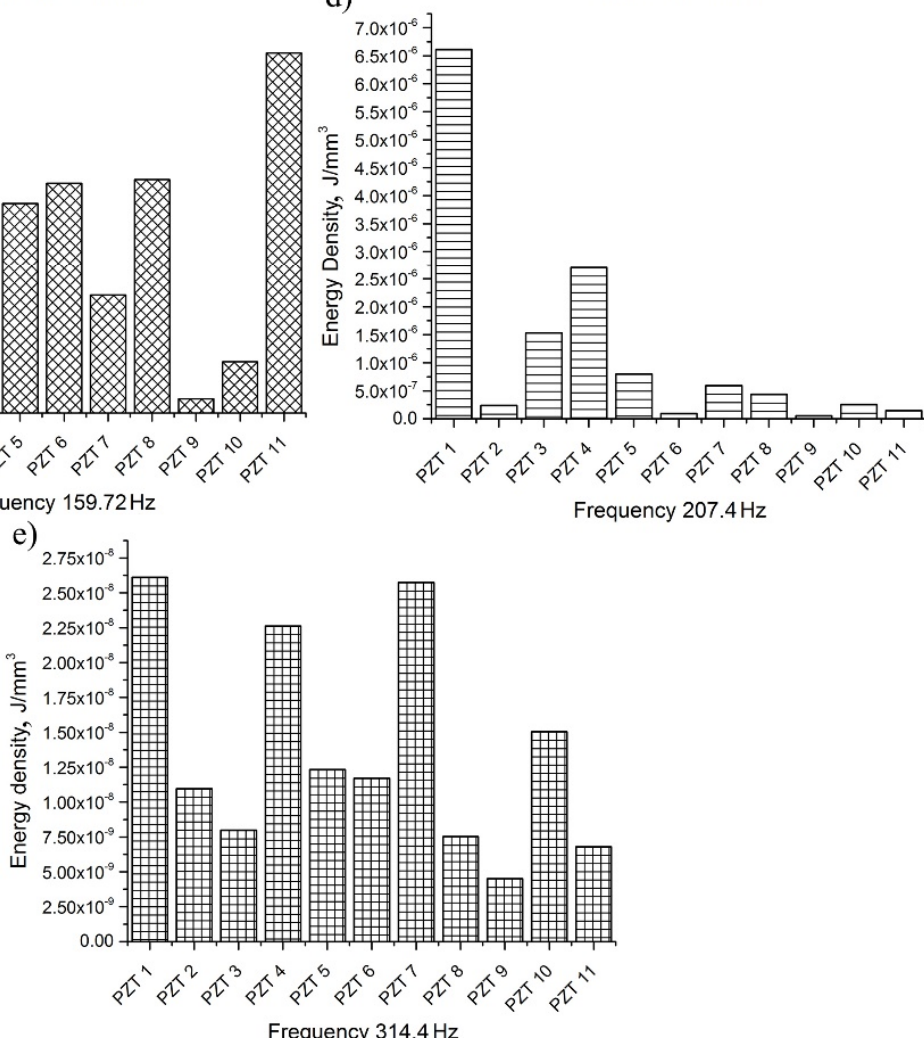

Fig. 3.15. Energy density characteristics of the harvester at resonant frequencies:

a) at $15.11 \mathrm{~Hz}$; b) at $50.1 \mathrm{~Hz}$; c) at $159.72 \mathrm{~Hz}$;

d) at $207.4 \mathrm{~Hz} ; \mathrm{e}$ ) at $314.4 \mathrm{~Hz}$ 
Analysis of the energy densities at the second resonant frequency showed that highest values reached $22.17 \mu \mathrm{J} / \mathrm{mm}^{3}$ and $15.37 \mu \mathrm{J} / \mathrm{mm}^{3}$ at $\mathrm{PZT}_{2}$ and $\mathrm{PZT}_{3}$ respectively. However, maximum energy density at the first resonant frequency is 3.78 times higher. On the other hand, the first resonant frequency represents pure first, out of plane, bending mode while the second resonance frequency stands for compound of the first and second bending modes.

Results of the experimental investigation related to the third resonance frequency showed that the highest energy densities achieved at piezo ceramic layers $\mathrm{PZT}_{1}$ and $\mathrm{PZT}_{11}$ with values $2.44 \mu \mathrm{J} / \mathrm{mm}^{3}$ and $2.5 \mu \mathrm{J} / \mathrm{mm}^{3}$, respectively.

However, energy densities levels are much lower compare to the first two resonance frequencies, but on the other hand it distribution is more uniform. Therefore, at this resonance frequency the energy harvester is able provide stable energy feed to the energy storage device.

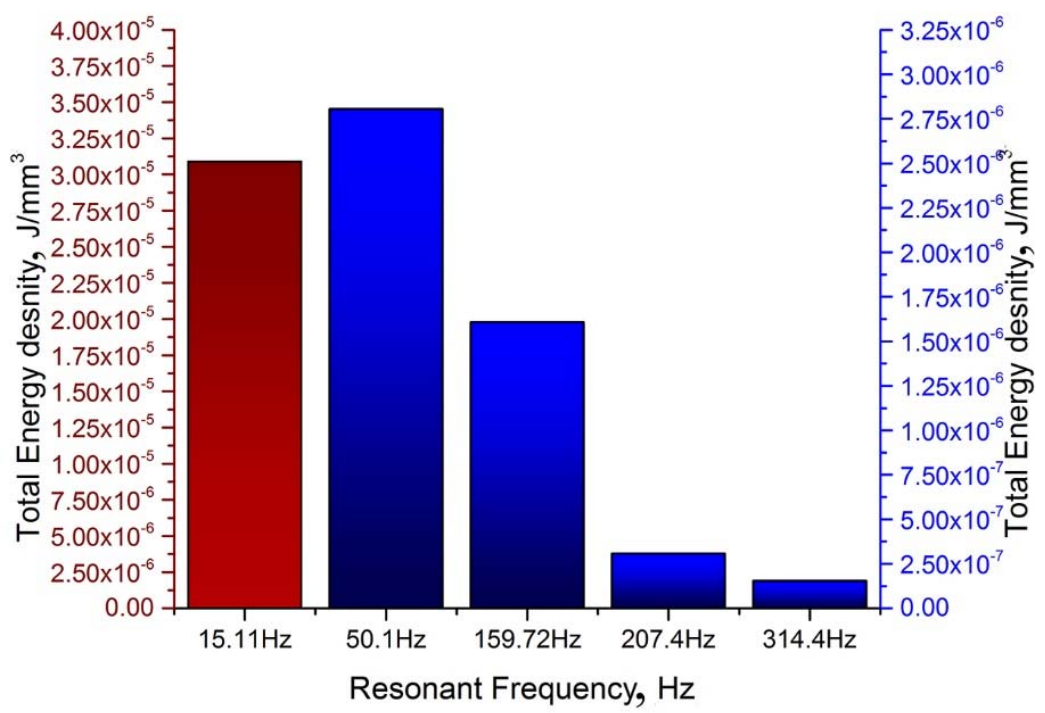

Fig. 3.16. Total energy densities at the resonance frequencies

Fig. $3.15 \mathrm{~d}$, e revealed that energy harvester has much lower energy densities at the fourth resonant frequency. Only $\mathrm{PZT}_{1}$ generated suitable energy density i. e. $6.61 \mu \mathrm{J} / \mathrm{mm}^{3}$. On the other hand, distribution of the energy densities at the fifth resonance frequency showed more stable characteristics with maximum values generated by $\mathrm{PZT}_{1}$ and $\mathrm{PZT}_{7}$. Energy densities at these piezo ceramic layers reached $26.11 \mathrm{~nJ} / \mathrm{mm}^{3}$ and $25.75 \mathrm{~nJ} / \mathrm{mm}^{3}$ respectively. Considering to much lower 
values, energy density characteristics at the fifth resonance frequency are more stable compare the fourth resonance frequency.

In order to assess total energy densities at the resonance frequencies, electronic interface was switched to one channel mode with one common $220 \mu \mathrm{F}$ energy storage capacitor. Energy harvester's base displacement during this investigation was $100 \mu \mathrm{m}$. Results of the investigation given in Fig. 3.16.

\subsection{A piezoelectric saw-tooth cantilever array for multi-frequency energy harvesting}

This section presents results of numerical and experimental investigations of a piezoelectric energy harvester based on a saw-tooth shape cantilever array. Proposed design of the energy harvester operates in multi-frequency regime. Moreover, vibration modes of the rigidly composed cantilevers ensure bending strain summation of several composing cantilevers and allow improving output power of the harvester. Energy harvester consist of four cantilevers that composed rigidly to each other. The cross-sections of the cantilevers are modified by cylindrical gaps in order to increase bending strain and to improve bending strain distribution characteristic along length of the cantilever as well as reduce potential barrier of whole energy harvesting system.

\subsubsection{Design of the piezoelectric saw-tooth multi-frequency cantilever array}

Multi-frequency energy harvester consists of four cantilevers with cross-sections modified by cylindrical gaps. Also, the harvester has seismic masses (Fig. 3.17). Cantilevers are rigidly composed to each other and forms a saw-tooth shaped system. Piezo ceramic layers glued on the top surface of the cantilevers. The seismic masses are placed at the end of each cantilever and at the tip of the harvester as well. Purpose of the seismic masses is to reduce natural frequencies and to increase bending strain at the system. Moreover, seismic masses have different weights in order to make imbalance in the system and as a result obtain additional rotation moment.

Must be highlighted that the energy harvester operates not only at fundamental mode of vibrations. Higher vibration modes are employed for energy harvesting as well. It must be mentioned that longitudinal vibrations of the base are generated when harvester operates at the higher vibration modes. Rigid clamping of the harvesters base damps these modes therefore a special support was designed (Fig. 3.2). 


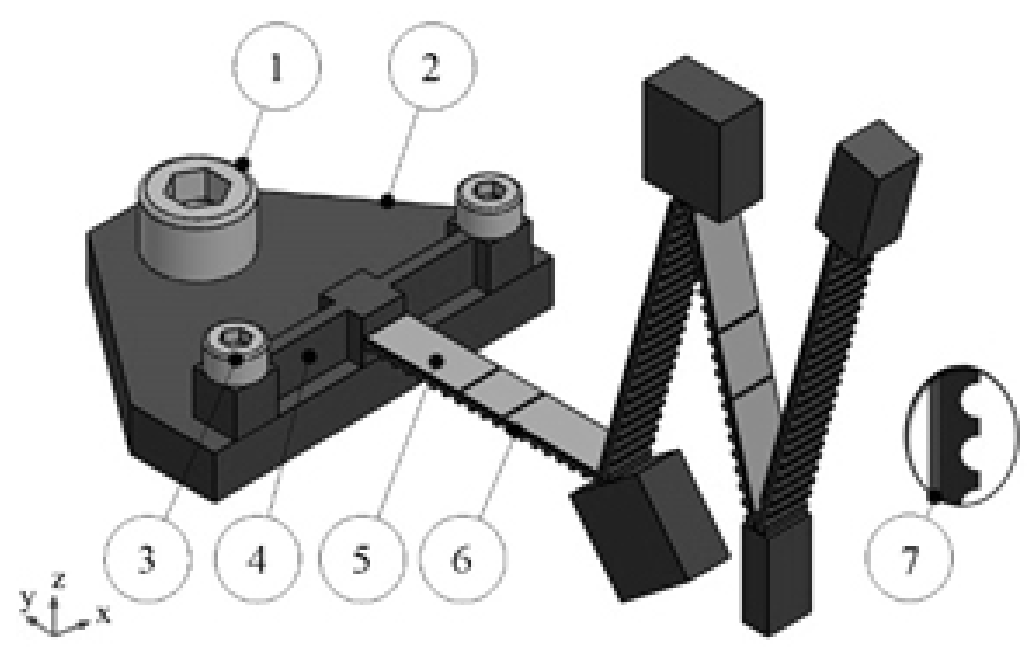

Fig. 3.17. Isometric view of the energy harvester: 1 is bolt for the clamping to host structure; 2 is housing plate; 3 is bolts for clamping harvester to clamping plate; 4 is supporting beams; 5 is piezo ceramic layer; 6 is body of the harvester; 7 is design of the cross-section

Such clamping structure reduces damping of the harvester and ensures possibility to obtain high-density multi-frequency operation of the harvester. The width of the full clamping system $\mathrm{W}_{\text {Clamping }}$ is equal to $40 \mathrm{~mm}$; the width of the base $\mathrm{W}_{\text {Base }}$ is the same as the width of the cantilevers or $5 \mathrm{~mm}$. The lengths of the supporting beams $\mathrm{L}_{\text {Beam }}$ were obtained by solving an optimization problem by frequency domain study. Boundary conditions for optimization problem were stated as follows: Height of the supporting cantilevers was $10 \mathrm{~mm}$, and it was fixed. Upper and lower limits, for the supporting cantilevers lengths were stated to $8 \mathrm{~mm}$ and $20 \mathrm{~mm}$, respectively. Frequency domain study was stated to range from $10 \mathrm{~Hz}$ to $200 \mathrm{~Hz}$. The width of the fixing sites $\mathrm{W}_{\text {Fixing }}$ was $5 \mathrm{~mm}$ and, finally, the diameter of the fixing holes $\mathrm{D}_{1}$ was $3.2 \mathrm{~mm}$. In the result, of the optimization $\mathrm{L}_{\text {Beam }}$ become equal to $12.5 \mathrm{~mm}$.

\subsubsection{Numerical investigation of the piezoelectric saw-tooth multi-frequency cantilever array}

Numerical investigation was performed in order to identify optimal geometrical parameters of the body and to analyse mechanical and electrical output characteristics of the harvester. Finite element modelling (FEM) was performed by Comsol 5.2. Principle scheme of the harvester used to build the FEM model is given in Fig. 3.18. Boundary conditions of the FEM model were set as follows: clamping 
nodes of the supporting beams were fixed rigidly. Acceleration of the harvester base in the $Z$ direction was applied to excite vibrations of the harvester. Properties of the materials used in FEM model given in Table 2.3.

Two optimization problems solved sequentially in order to obtain optimal design of the harvester. Goal of the first optimization problem was to find optimal length of the cantilevers when sum of the square differences of the neighbouring resonant frequencies of the harvester minimized. The resonant frequencies dominated by the first and the second out of plane vibration mode of any cantilever were analysed. Length of the four cantilevers were chosen as the design variables and optimization problem was formulated as given in Eq. (3.1).

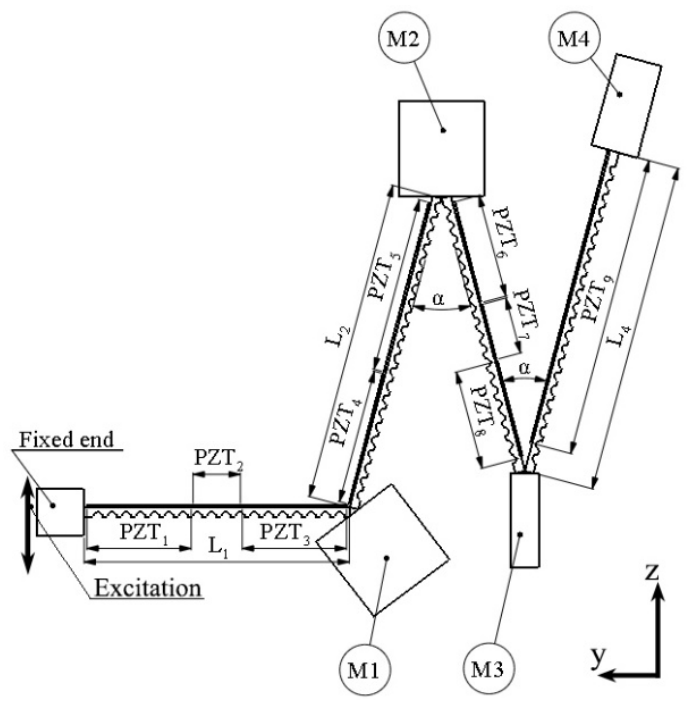

Fig. 3.18. Principle scheme of piezoelectric multi-frequency harvester: $\mathrm{L}_{1}-\mathrm{L}_{4}$ cantilevers ( $\mathrm{C} 17200$ beryllium bronze); $\mathrm{M}_{1}-\mathrm{M}_{4}$ seismic masses (C17200 beryllium bronze); $\mathrm{PZT}_{1}-\mathrm{PZT}_{9}$ sections of soft piezo ceramic (PIC255)

$$
\begin{gathered}
\min _{L} \sum_{i=1}^{n-1}\left(w_{i+1}(L)-w_{i}(L)\right)^{2}, \\
\text { subject to } \\
l_{\text {min }} \leq l_{i} \leq l_{\text {max }}, \quad w_{\text {min }} \leq w_{i} \leq w_{\text {max }}, \quad i=1, \ldots, \quad 4 .
\end{gathered}
$$

Here $L=\left(l_{1}, \ldots l_{4}\right)$ is a vector of cantilever lengths; $w_{i}$ is a resonant frequency of the harvester dominated by the first vibration mode of any cantilever; $l_{\min }$ and $l_{\max }$ 
is the minimal and the maximum values of the cantilever length, $n$ is the number of cantilevers and it is equal to 4 .

Target of the second optimization problem was to obtain optimal mass values of the seismic masses in order to maximize tip displacement of the harvester in $\mathrm{z}$ direction. Optimization problem was formulated as follows:

$$
\begin{gathered}
\max _{M}\left(u_{z}(M)\right), \\
\text { subject to } \\
m_{\text {min }} \leq m_{i} \leq m_{\max }, \quad i=1, \ldots, 4 .
\end{gathered}
$$

Here $M=\left(m_{1}, \ldots, m_{7}\right)$ is a vector of seismic mass weights; $u_{z}$ is harvester tip displacement in $\mathrm{Z}$ direction; $m_{\min }$ and $m_{\max }$ is the minimal and the maximal mass values of the seismic masses.

Both optimization problems were solved by frequency domain studies. Acceleration of the base was set to $1 \mathrm{~m} / \mathrm{s}^{2} . L_{\min }$ and $L_{\max }$ were set to $25 \mathrm{~mm}$ and 35 $\mathrm{mm}$, respectively. The values of $m_{\min }$ and $m_{\max }$ were set to $1 \mathrm{~g}$ and $5 \mathrm{~g}$, respectively. Frequency range was set from $10 \mathrm{~Hz}$ to $200 \mathrm{~Hz}$. Geometrical and physical parameters of the harvester obtained by optimization listed in Table 3.3.

Table 3.3. Optimal geometrical parameters of the harvester

\begin{tabular}{|l|l|l|l|}
\hline Parameter & Value, $\mathrm{mm}$ & Parameter & Value, g \\
\hline $\mathrm{L}_{1}$ & 28 & $\mathrm{M}_{1}$ & 4.22 \\
\hline $\mathrm{L}_{2}$ & 34 & $\mathrm{M}_{2}$ & 3.81 \\
\hline $\mathrm{L}_{3}$ & 30 & $\mathrm{M}_{3}$ & 1.26 \\
\hline $\mathrm{L}_{4}$ & 35 & $\mathrm{M}_{4}$ & 2.11 \\
\hline
\end{tabular}

The second part of the numerical investigation was to analyse mechanical and electrical characteristics of the harvester. Geometrical parameters of the harvester stated with respect to the values obtained during optimization. Modal analysis of the harvester performed in order to indicate natural frequencies and modal shapes. The results given in Fig. 3.19.

Mechanical and electrical output characteristics of the harvester investigated at the frequency range from $20 \mathrm{~Hz}$ to $135 \mathrm{~Hz}$. Acceleration of the base was set to $1 \mathrm{~m} / \mathrm{s}^{2}$. Calculated displacement of the tip in the $\mathrm{z}$ direction shown in Fig. 3.20.

Analysis of the frequency response characteristic showed that resonant and natural frequencies are in good agreement. Resonant frequencies are almost uniformly distributed along the frequency range $20 \mathrm{~Hz}$ to $135 \mathrm{~Hz}$. Also, it must be 
noticed that tip displacement has different vibration amplitudes at different resonant frequencies.

Numerical investigation of bending strain distribution along each cantilever performed. Results given in Fig. 3.21. It can be seen that bending strain distribution characteristics in most cases are almost linear, except the cases when higher vibration modes are excited. Such strain characteristic achieved by modifications made to cross sections and by additional rotation moment created by seismic masses. These results leads to conclusion that sufficient high output voltage can be achieved by investigated multi-frequency energy harvester.

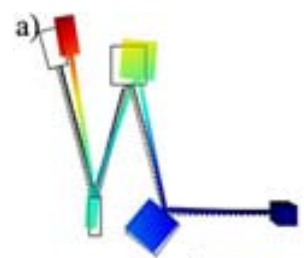

d) b)

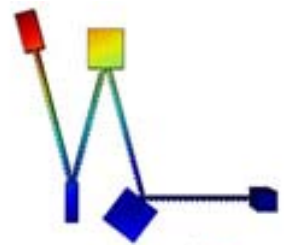

e) c)
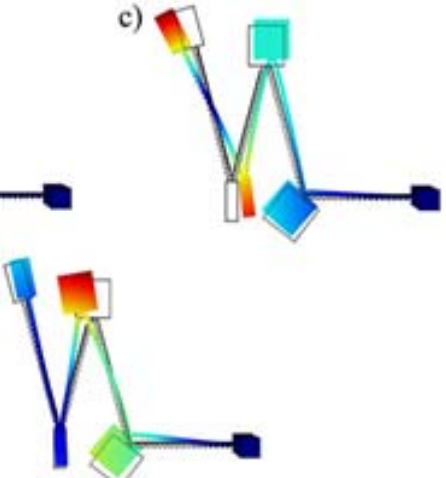

Fig. 3.19. Modal shapes of the harvester: a) $21.198 \mathrm{~Hz}$; b) $42.006 \mathrm{~Hz}$; c) $67.089 \mathrm{~Hz}$; d) $96.307 \mathrm{~Hz}$; e) $123.428 \mathrm{~Hz}$

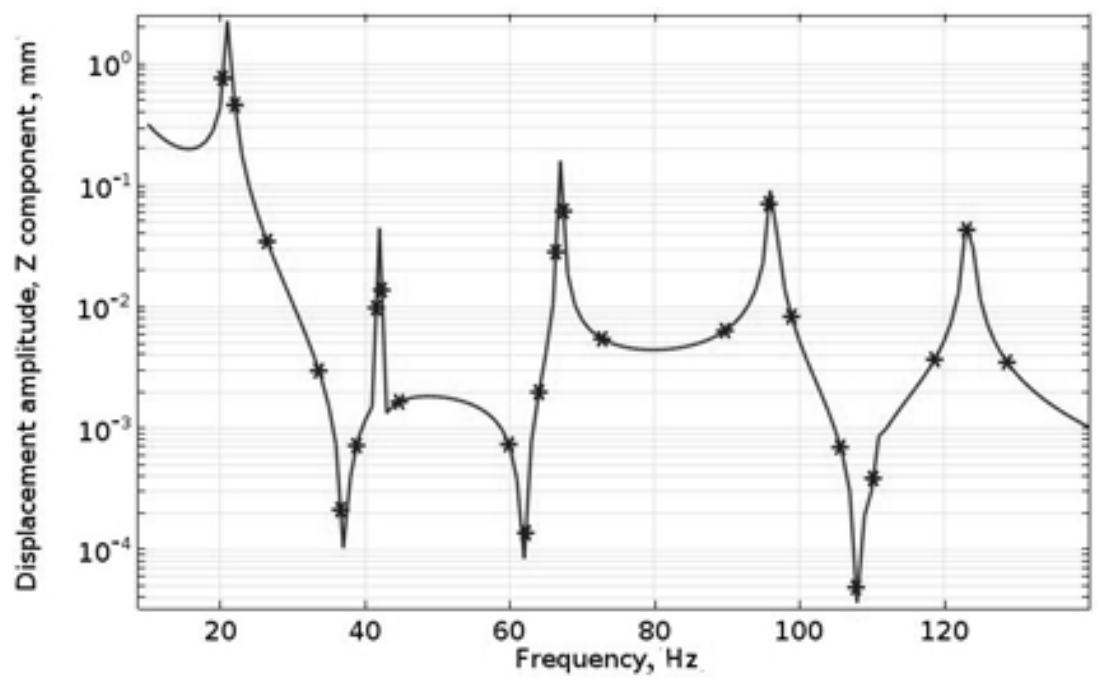

Fig. 3.20. Displacement amplitude versus frequency 

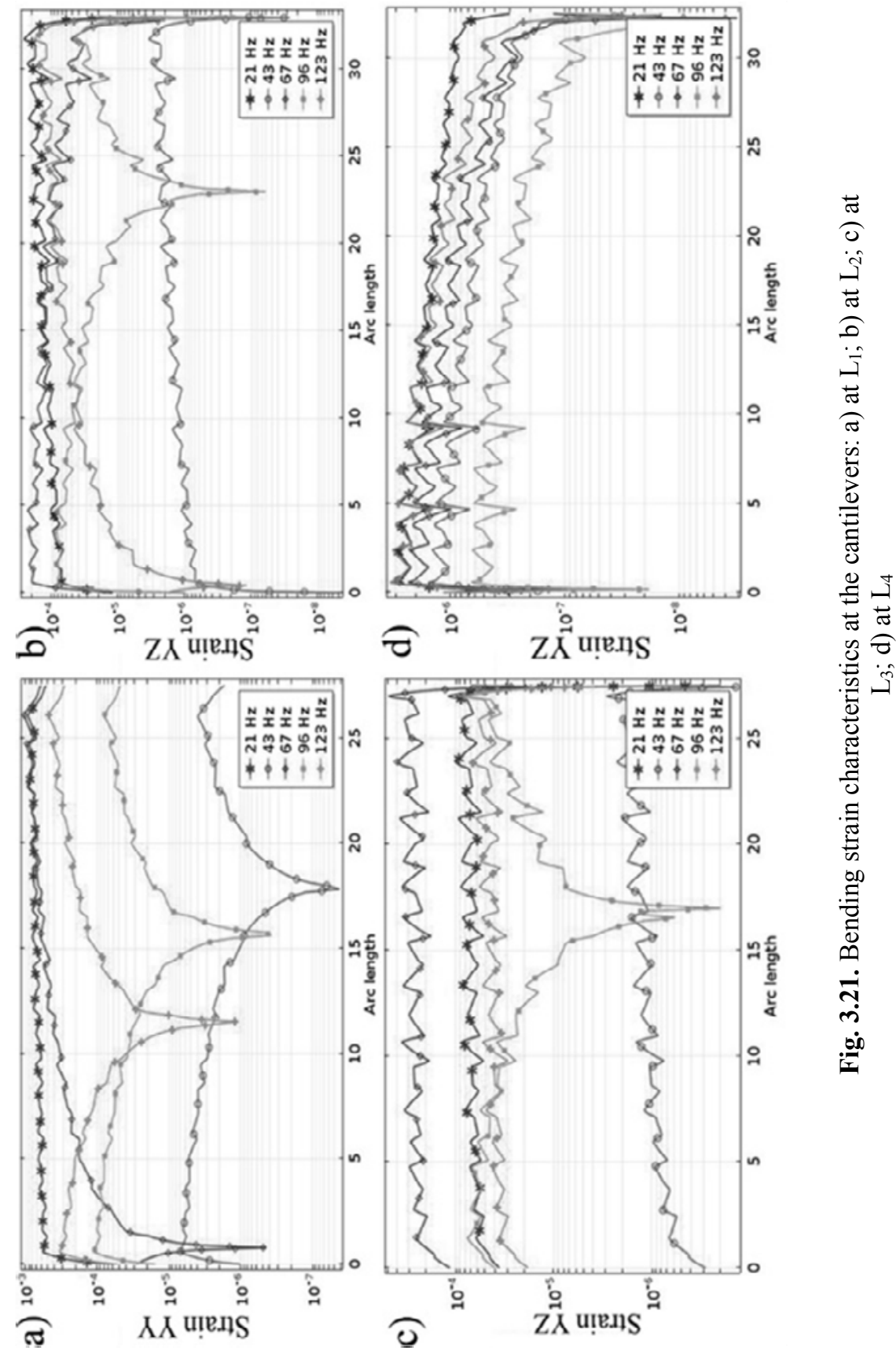
Electrode configuration of piezo ceramic layers made on basis of the bending strain distribution along the length of the cantilever. Proper electrode configuration ensures the separation of positive and negative charges when the harvester operates at higher vibration modes. It is important in order to increase efficiency of a multi-frequency energy harvesting system.

Algorithm of electrode configuration was formulated as follows: partitioning of the electrodes was made in the places where the value of bending stain tensor component is close to zero.

Therefore, the five vibration nodes of the harvester were analysed and partitioning of the electrodes was made at indicated nodes.

As a result, the nine different electrodes formed of the top surfaces of the piezo ceramic layers. The geometrical parameters of the electrodes are given in Table 3.4

Table 3.4. Geometrical parameters of the electrodes

\begin{tabular}{|l|l|l|l|}
\hline Parameter & Value, $\mathrm{mm}$ & Parameter & Value, $\mathrm{mm}$ \\
\hline $\mathrm{PZT}_{1}$ & 11 & $\mathrm{PZT}_{6}$ & 11 \\
\hline $\mathrm{PZT}_{2}$ & 5 & $\mathrm{PZT}_{7}$ & 6 \\
\hline $\mathrm{PZT}_{3}$ & 10 & $\mathrm{PZT}_{8}$ & 9 \\
\hline $\mathrm{PZT}_{4}$ & 14 & $\mathrm{PZT}_{9}$ & 31 \\
\hline $\mathrm{PZT}_{5}$ & 18 & $\mathrm{PZT}_{\text {widh }}$ & 5 \\
\hline
\end{tabular}

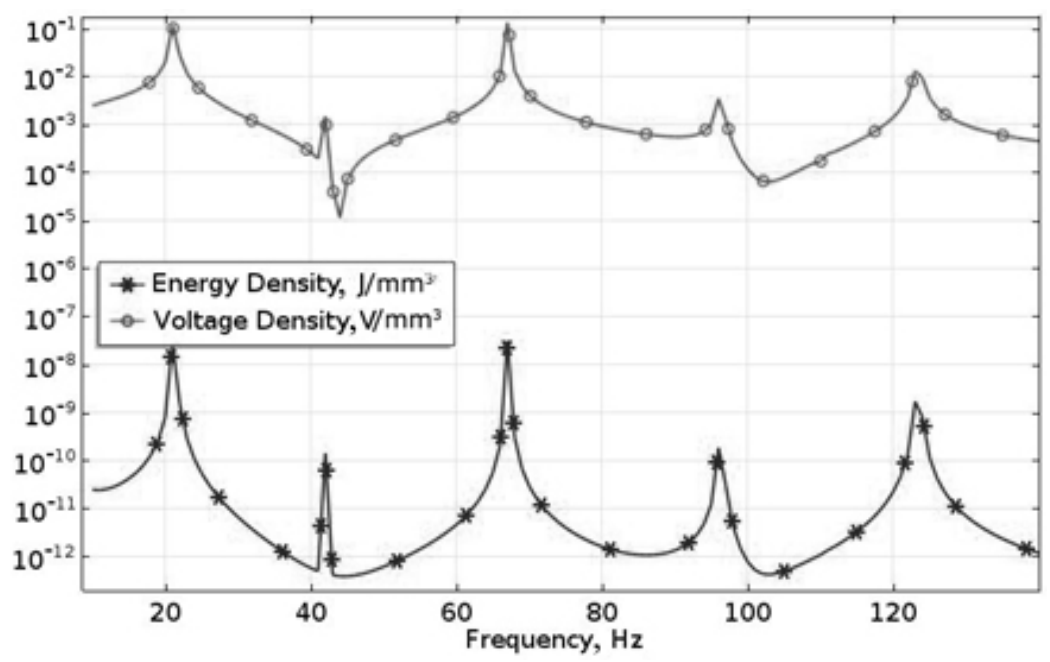

Fig. 3.22. Electrical output characteristics of the harvester versus frequency 
The numerical study of electrical characteristics was performed as well. Boundary conditions were set the same as in the previous investigation. The electrodes connected in parallel in order to increase a charge during systems operation at higher vibration modes. The aim of this investigation was to calculate output voltage density and energy density versus frequency. In addition, it must be noted that the voltage density characteristic was obtained at open circuit conditions. Results of the study given in Fig. 3.22.

Analysis of the Fig. 3.22 showed that peaks of the both voltage and energy densities obtained at the same frequencies as at the frequency response characteristic. It confirms the results of modal analysis and shows that the first five vibration modes of the harvester are suitable for energy harvesting. Also, analysis showed that the maximum output voltage density equal to $48.39 \mathrm{mV} / \mathrm{mm}^{3}$ and was obtained at the $5^{\text {th }}$ resonant frequency.

The second highest voltage density of $26.91 \mathrm{mV} / \mathrm{mm}^{3}$ was obtained at the $1^{\text {st }}$ resonance frequency while other values are significant lower. Such differences caused by a higher strain values obtained at $5^{\text {th }}$ resonance by the strain summation of different cantilevers.

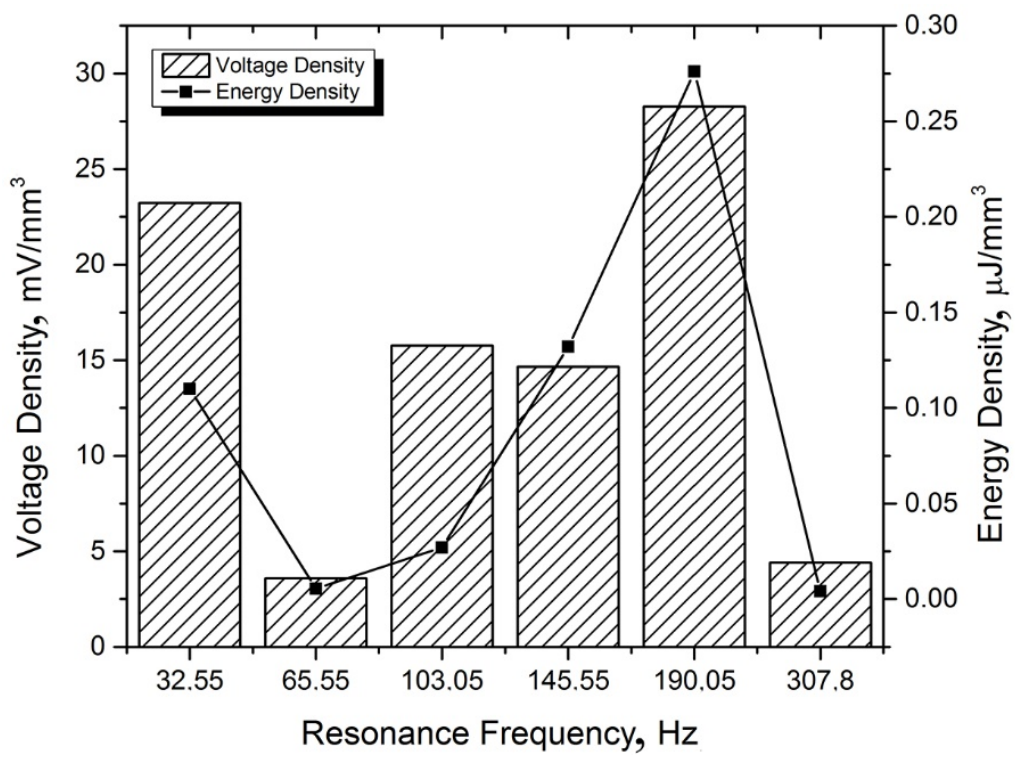

Fig. 3.23. Comparison of the electrical output characteristics of the harvester

Analysing energy density characteristic it can be noticed that the peaks are obtained at the same frequencies as in previous case. The highest energy density was obtained at the $5^{\text {th }}$ resonant frequency and it reached $61.25 \mathrm{uJ} / \mathrm{mm}^{3}$. Energy 
density reached $25.13 \mathrm{uJ} / \mathrm{mm}^{3}$ at the $1^{\text {st }}$ resonant frequency while at the other frequencies has much lower values. It can be concluded that the energy harvester is able to provide a stable, but much lower energy feed at the first four resonant frequencies and generate energy feed with the overcapacity at the $5^{\text {th }}$ resonant frequency.

Comparison of both voltage and electrical energy densities at different resonance frequencies was made (Fig. 3.23). It can be noticed that voltage density and energy density values vary from $11.53 \mathrm{mV} / \mathrm{mm}^{3}$ to $48.39 \mathrm{mV} / \mathrm{mm}^{3}$ and from $1.86 \mu \mathrm{J} / \mathrm{mm}^{3}$ to $61.25 \mu \mathrm{J} / \mathrm{mm}^{3}$, respectively. It shows that voltage and energy density values distributed at wide range and the harvester is not able to provide highly stable voltage and energy output in frequency domain.

\subsubsection{Experimental investigation of the piezoelectric saw-tooth multi-frequency cantilever array}

Experimental investigations of the saw-tooth shaped piezoelectric harvester performed to confirm results obtained during the numerical investigation. A prototype of the harvester made strictly corresponding to the geometrical and physical parameters used during numerical investigation (Fig. 3.24).

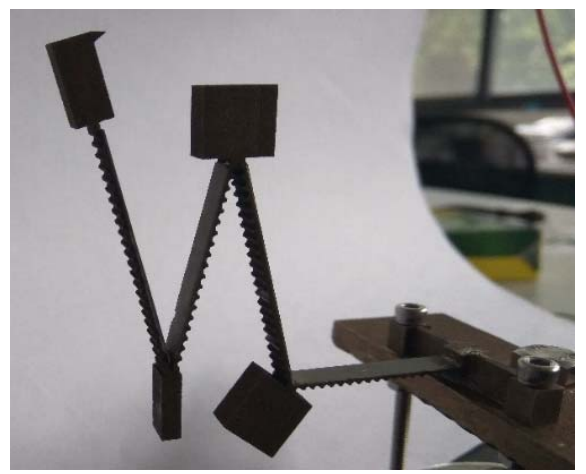

Fig. 3.24. A prototype of the piezoelectric energy harvester.

Firstly, experimental investigation of the frequency response characteristic performed with the aim to validate results of the numerical investigation. Scanning vibrometer Polytec OFV 056 used to measure tip vibrations. Excitation of the harvester base performed by an electromagnetic shaker Thermotron DSX4000. A controller of Polytec vibrometer was used to generate frequency sweep function for the shaker. Results of the measurements shown in Fig. 3.25. 
It can be seen that the harvester has five resonant frequencies at the frequency range from $20 \mathrm{~Hz}$ to $135 \mathrm{~Hz}$. Measured results are in adequate agreement with the results of the numerical investigation.

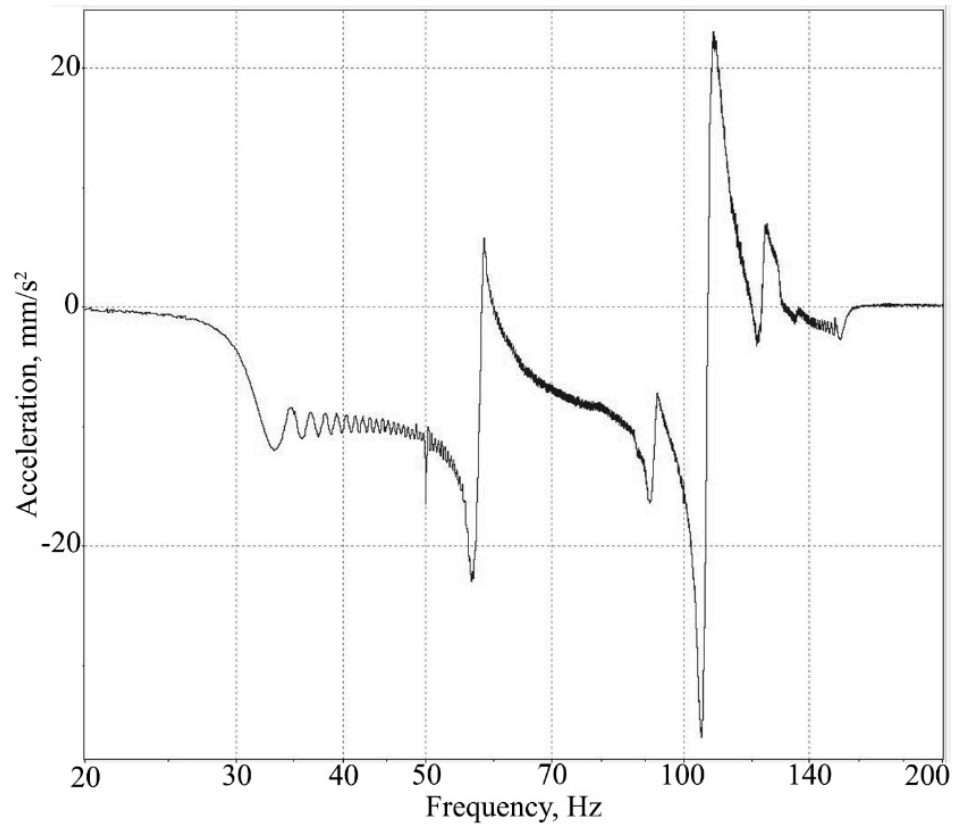

Fig. 3.25. Frequency response characteristic of the energy harvester

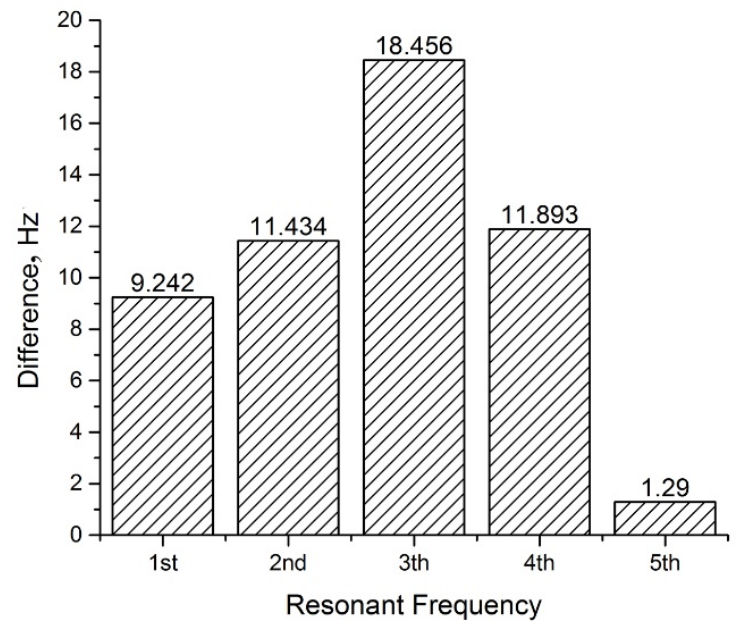

Fig. 3.26. Differences between measured and calculated resonant frequencies 
Difference between measured and calculated resonant frequencies does not exceed $19.69 \%$ (Fig. 3.26). The highest difference is obtained at the $3^{\text {th }}$ resonant frequency and it reached $18.456 \mathrm{~Hz}$. The differences are caused by manufacturing errors and possible differences in the clamping.

An experimental investigation of electrical characteristics performed as well. Output voltage and energy densities measured in the frequency range 20-140 Hz. A special experimental setup was built for this purpose (Fig. 3.27). It consisted of function generator Tectronix AFG1062 and linear amplifier that used for electromagnetic shaker driving. Laser displacement sensor Keyence LK-G155 and data logging multimeter Fluke 289 were used to measure base displacement and output voltage amplitudes. Laser sensor and voltmeter connected to the computer with data acquisition software in order to record and manage data. Electronic interface based on thirteen rectifiers used as well. It made from low-loss Shottky diodes BAT46 and low ESR electrolytic capacitors (Fig. 3.12).

Voltage density at the frequency range from $20 \mathrm{~Hz}$ to $140 \mathrm{~Hz}$ measured. Acceleration amplitude was set the same as during numerical investigation. Electronic interface switched to open-circuit condition i. e. the electrical load was more than $10 \mathrm{M} \Omega$. The results of measurements shown in Fig. 3.28.

Fig. 3.28 shows that voltage density peaks are at the same frequencies as it was obtained during numerical modelling. Also, it must be noticed that minimum voltage density is $3.98 \mathrm{mV} / \mathrm{mm}^{3}$.

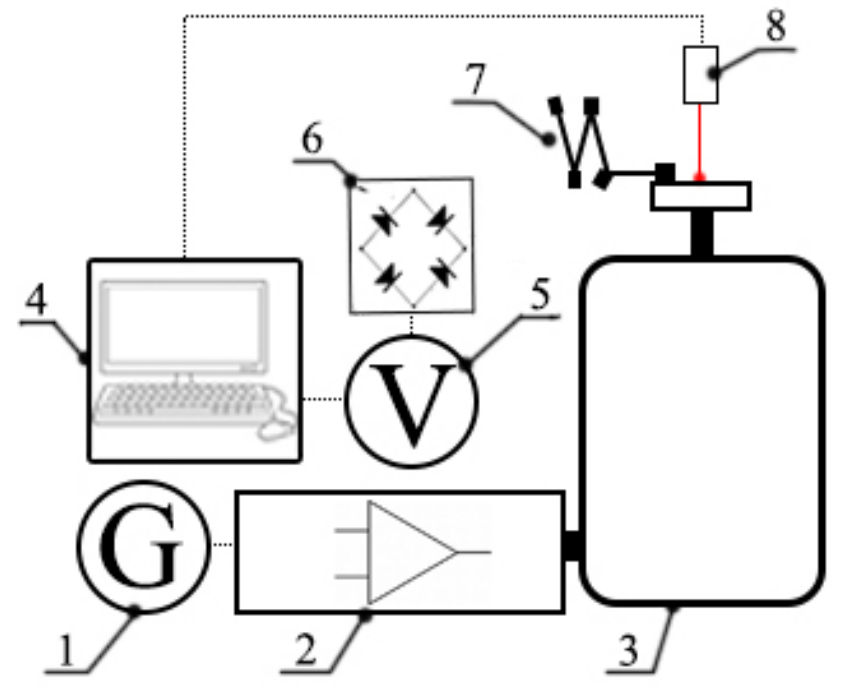

Fig. 3.27. The experimental setup: 1 is function generator; 2 is amplifier; 3 is electromagnetic shaker; 4 is computer; 5 is data logging multimeter; 6 is electronic interface;

7 is prototype harvester; 8 is displacement sensor 
It means that energy harvester is able to provide a sufficient voltage while it operates at the resonant mode. The highest voltage density was obtained at the $5^{\text {th }}$ resonant frequency and it has value equal to $55.65 \mathrm{mV} / \mathrm{mm}^{3}$. Voltage density has much lower values at the other resonant frequencies.

Energy density was measured in the same frequency range as well. Electrical interface was switched from open-circuit condition to loaded condition for this case. An electrolytic low ESR capacitor with the capacitance of $220 \mu \mathrm{F}$ was connected as a common load. Results of measurements given in Fig. 3.29.

It can be noticed that the measured energy density characteristic has five peaks. However, the peaks are slightly shifted down compared to the frequency response characteristics.

Such mismatch can be explained by the influence of a capacitive load that was connected to the energy harvester thru the voltage rectifiers. On the other hand, a shift of the resonance frequencies is relatively small and does not exceed $16 \mathrm{~Hz}$. The highest energy density was obtained at the $4^{\text {th }}$ resonant frequency and reached value of $52.56 \mu \mathrm{J} / \mathrm{mm}^{3}$.

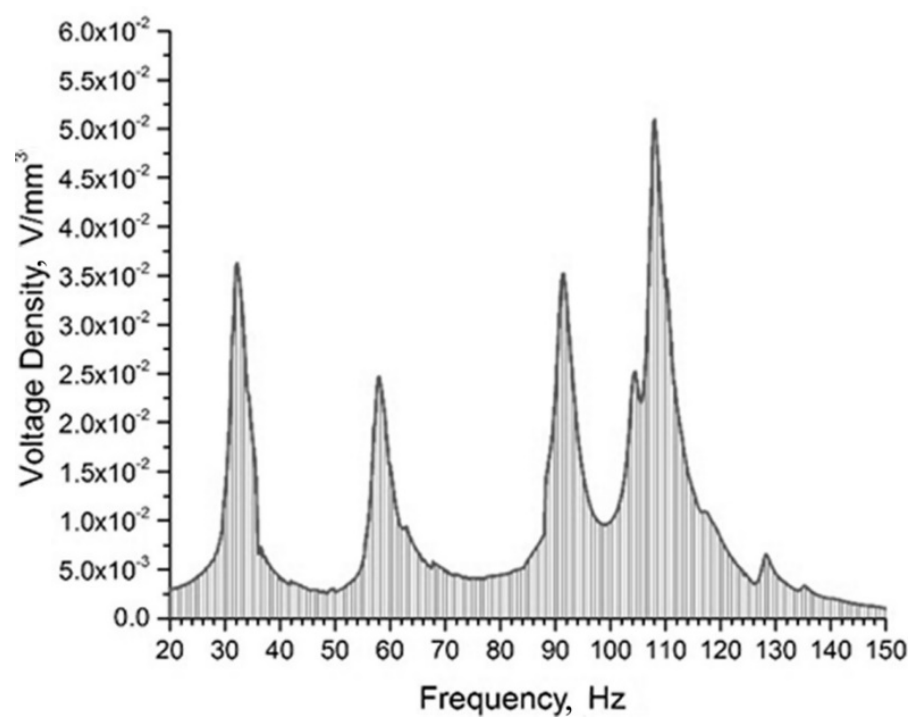

Fig. 3.28. Measured voltage density versus frequency

However, the maximum value of energy density was obtained at the $5^{\text {th }}$ resonant frequency during numerical modelling. It means that capacitive load shifted up the $4^{\text {th }}$ vibration mode. The connected capacitive load increased stiffness of the harvester and caused this mismatch. 


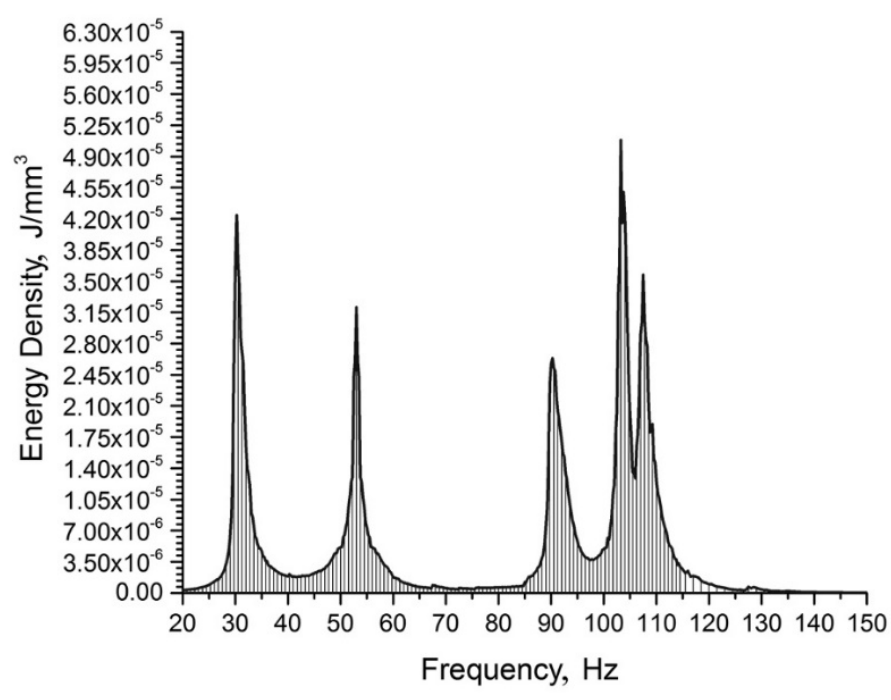

Fig. 3.29. Measured energy density versus frequency characteristic

On the other hand, the frequency values of the other resonance frequencies are almost same. It means that the operation of the harvester at higher vibration modes is not stable and depends on electrical load. The second highest energy density was obtained at the $1^{\text {st }}$ resonance frequency and it reached $42.86 \mu \mathrm{J} / \mathrm{mm}^{3}$. Energy density values at the other resonant frequencies are lower. Comparison of the both measured voltage and electrical energy densities at the different resonance frequencies given in Fig. 3.30.

It can be seen that energy harvesting system at the first and fourth resonance frequencies is able to provide high energy feed to the energy storage device and even to ensure overcapacity. However, energy harvesting system provides much lower energy feed at other resonant frequencies.

Therefore, in the end of this section can be concluded that numerical and experimental investigations confirmed assumption that the proposed piezoelectric saw-tooth energy harvester can operate in multi-frequency operation principle. Modal analysis of the harvester revealed that the proposed structure has five resonant frequencies in the range from $20 \mathrm{~Hz}$ to $140 \mathrm{~Hz}$.

The dominant vibration modes of the structure are the $1^{\text {st }}$ and $2^{\text {nd }}$ out of plane bending modes of the cantilever. Numerical investigation of bending strain distribution showed that the strain distribution along the length of the cantilevers is almost constant. Such distribution obtained by a modification made to the cross section and special design of the clamping. 


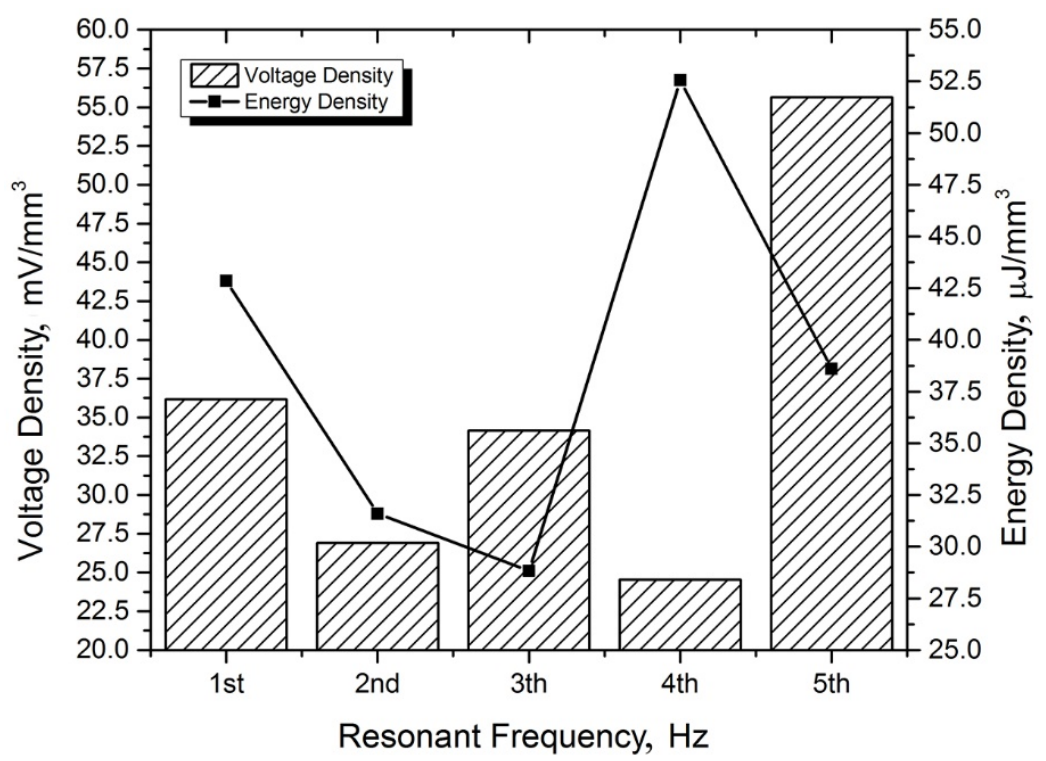

Fig. 3.30. Comparison of electrical characteristics

Numerical investigation of the both voltage and energy densities showed that maximum values reached $48.39 \mathrm{mV} / \mathrm{mm}^{3}$ and $61.25 \mathrm{uJ} / \mathrm{mm}^{3}$, respectively. The maximum values were obtained at the $5^{\text {th }}$ resonant frequency. An experimental investigation of the mechanical characteristics confirmed the results of numerical study. The highest difference between resonant frequencies values obtained numerically and experimentally is $18.456 \mathrm{~Hz}$ or $19.69 \%$. Measurements of the electrical characteristics showed that the maximum voltage density was obtained at the $5^{\text {th }}$ resonant frequency and it reached $55.65 \mathrm{mV} / \mathrm{mm}^{3}$. On the other hand, the maximum energy density was obtained at the $4^{\text {th }}$ resonant frequency. The mismatch was caused by the connected capacitive load that increased stiffness of the harvester and shifted up the $4^{\text {th }}$ vibration mode. The highest energy density obtained at the same vibration mode and it reached $52.56 \mu \mathrm{J} / \mathrm{mm}^{3}$.

\subsection{A piezoelectric polygon shape multi-frequency cantilever array}

This section represents the results of numerical and experimental investigation related to polygon shape multi-frequency piezoelectric energy harvester. Special design of the harvester ensures modal strain summation and multi-frequency energy harvesting. Irregular design of the cross section of the cantilevers and special 
design of the seismic masses improve bending strain distribution characteristic along the cantilevers length. Bending strain summation and advanced design of the proposed piezoelectric harvester allows obtain increased electrical characteristics of cantilever array.

\subsubsection{Design of the piezoelectric polygon shaped multi-frequency cantilever array}

The design of polygon shape cantilever array consists of eight piezoelectric cantilevers with irregular cross section design, seven seismic masses and a clamping system (Fig. 3.31). Number of the cantilevers was influenced by demand to create two polygon shape systems with different stiffness within the same indissoluble energy harvesting device and to increase number of natural frequencies in specific frequency range. Such solution gives an opportunity to obtain modal strain summation at different vibration frequencies. Irregular design of cross-section of the cantilevers was caused by two goals i.e to increase bending strain characteristics and to improve bending strain distribution characteristics along the cantilevers.

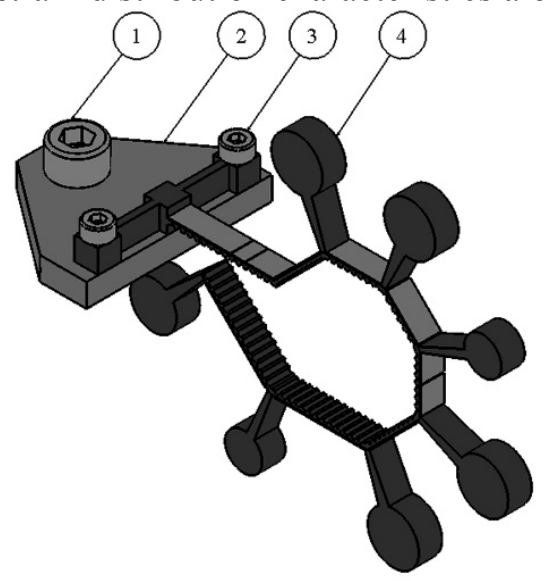

Fig. 3.31. Isometric view of the energy harvester: 1 is clamping bolt; 2 is clamping frame; 3 is M3 bolts for junction between the clamping frame and the harvester; 4 is body of the polygon shape harvester

The polygon shape energy harvester has seven seismic masses placed at every corner of the harvester's body. A junction between seismic masses and the harvester was made by additional beams. The design of seismic masses introduced in order to create an additional rotation moment and to increase bending strain in the piezo ceramic layers. Hence, an additional rotation moment and irregular design of cross sections allow obtaining almost liner function of the bending strain distribution along the length of the cantilevers. 
The clamping frame serves as the coupling between the body of harvester and the host (Fig. 3.2). Two bolts used to clamp frame. Two supporting beams connect harvester and clamping bracket.

Dimensions of the supporting beams designed so that damping of energy harvester is lowest while displacement of the harvester base in Y direction is generated. Such design of the supporting beams allows avoiding structural damping of the harvester vibrations.

\subsubsection{Numerical investigation of the piezoelectric polygon shaped multi-frequency cantilever array}

Numerical investigation of the polygon shaped energy harvester divided into two parts. At the beginning, numerical investigation performed to calculate optimal geometrical parameters of the cantilevers. Mechanical and electrical characteristics of the harvester investigated as well. Modal analysis and harmonic response analysis used for this purpose.

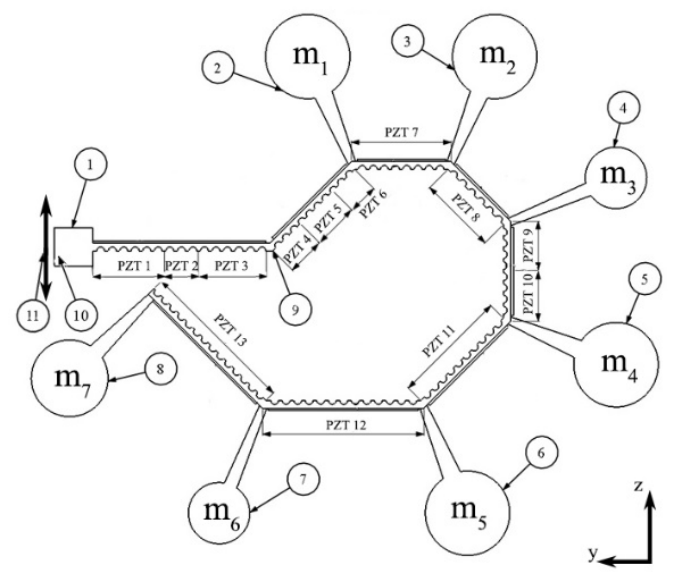

Fig. 3.32. Principle scheme of the piezoelectric polygon shape energy harvester: 1 is base of harvester; $\mathrm{m}_{1}, \ldots, \mathrm{m}_{7}$ are seismic masses (C17200 beryllium bronze);

$\mathrm{PZT}_{1}, \ldots, \mathrm{PZT}_{13}$ are piezo ceramic layers (PIC255); 9 is body of harvester (C17200 beryllium bronze); 10 is fixed constrain; 11 is direction of excitation

Finite element model (FEM) built using Comsol 5.2 software. Boundary conditions were set as follows: ends of the supporting beams were fixed rigidly, motion of the host structure was modelled as acceleration of the harvester base in Z direction. Material properties used to build FEM model given in Table 2.3. Principle scheme of the harvester shown in Fig. 3.32. 
Two optimization problems were solved sequentially in order to obtain optimal design of the harvester. Goal of the first optimization problem was to find optimal length of the cantilevers when sum of the square differences of the neighbouring resonant frequencies of the harvester is minimized. The resonant frequencies dominated by the first and the second out of plane vibration mode of any cantilever were used. Length of the eight cantilevers chosen as the design variables and optimization problem was formulated as given in Eq. (3.5)

$$
\begin{gathered}
\min _{L} \sum_{i=1}^{n-1}\left(w_{i+1}(L)-w_{i}(L)\right)^{2}, \\
\text { subject to } \\
l_{\text {min }} \leq l_{i} \leq l_{\max }, \quad w_{\min } \leq w_{i} \leq w_{\max }, \quad i=1, \ldots, 8 .
\end{gathered}
$$

Here $L=\left(l_{1}, \ldots, l_{8}\right)$ is a vector of cantilever lengths; $w_{i}$ is resonant frequency of the harvester dominated by the first vibration mode of any cantilever; $l_{\min }$ and $l_{\max }$ is the minimal and the maximal values of the cantilever length, $n$-is the number of cantilevers and is equal to 8 .

Goal of the second optimization problem was to obtain optimal mass values of the seismic masses in order to maximize tip displacement of the harvester in $\mathrm{Z}$ direction. It solved after the optimal length of the cantilevers was obtained. Optimization problem formulated as given in Eq. (3.7).

$$
\begin{gathered}
\max _{M}\left(u_{z}(M)\right), \\
\text { subject to } \\
m_{\min } \leq m_{i} \leq m_{\max }, \quad i=1, \ldots, 7 .
\end{gathered}
$$

Here $M=\left(m_{1}, \ldots, m_{7}\right)$ is a vector of seismic mass weights; $u_{z}$ is harvester tip displacement in $\mathrm{Z}$ direction; $m_{\min }$ and $m_{\max }$ is the minimal and the maximal mass values of the seismic masses.

Both optimization problems were solved by frequency domain studies using linear search method. Acceleration of the base was set to $0.5 \mathrm{~m} / \mathrm{s}^{2}$. Values of $l_{\min }$ and $l_{\max }$ were set to $10 \mathrm{~mm}$ and $25 \mathrm{~mm}$, respectively while length iteration step was $1 \mathrm{~mm}$. Values of $m_{\min }$ and $m_{\max }$ were set to 2.5 grams and 5 grams respectively while step was 0.1 gram. The frequency range for both optimization problems was stated from $w_{\min }$ equal $10 \mathrm{~Hz}$ to $w_{\max }$ equal $450 \mathrm{~Hz}$. Obtained optimized parameters of the harvester are listed in Table 3.5.

The second part of numerical investigation dedicated to analyse mechanical and electrical characteristics of the harvester. Geometrical parameters of the harvester stated with respect to the values obtained during optimization study. Modal 
analysis of the harvester performed in order to indicate natural frequencies and modal shapes of the harvester (Fig. 3.33).

Table 3.5 Optimized parameters of the harvester

\begin{tabular}{|l|l|l|l|}
\hline Parameter & Value, $\mathrm{mm}$ & Parameter & Value, $\mathrm{g}$ \\
\hline 11 & 23 & $\mathrm{~m}_{1}$ & 4.6 \\
\hline 12 & 15 & $\mathrm{~m}_{2}$ & 4.6 \\
\hline 13 & 13 & $\mathrm{~m}_{3}$ & 2.7 \\
\hline 14 & 11 & $\mathrm{~m}_{4}$ & 4.6 \\
\hline 15 & 13 & $\mathrm{~m}_{5}$ & 4.6 \\
\hline 16 & 16 & $\mathrm{~m}_{6}$ & 2.7 \\
\hline 17 & 2 & $\mathrm{~m}_{7}$ & 3.9 \\
\hline 18 & 21 & & \\
\hline
\end{tabular}

Analysis of the results revealed that energy harvester has five natural frequencies at the range from $10 \mathrm{~Hz}$ to $240 \mathrm{~Hz}$. It can be noticed that the first and the second out of plane bending modes of the cantilevers are dominating in the obtained modal shapes of the harvester. This study showed that number of the natural frequencies in the analysed frequency range is sufficient for the multi-frequency energy harvesting.

Mechanical and electrical characteristics of the harvester investigated at the frequency range $10 \mathrm{~Hz}$ to $240 \mathrm{~Hz}$. Base acceleration amplitude was set to $0.5 \mathrm{~m} / \mathrm{s}^{2}$. Graph of harvester tip acceleration in $\mathrm{Z}$ direction versus frequency is shown in Fig. 3.34.

Analysis of the frequency response characteristic confirmed results of the modal analysis. Resonant frequencies have good coincidence with the natural frequencies obtained during modal analysis. Obtained characteristic showed that the first three resonance frequencies are located at the narrow frequency range and are close to each other. It shows that energy harvester will be able to operate efficiently at this frequency range. On the other hand, $4^{\text {th }}$ and $5^{\text {th }}$ resonant frequencies are located at slightly higher frequencies.

However, these resonance frequencies are adequately close to each other and provides multi-frequency energy harvesting at that frequency range. Moreover, high acceleration amplitude of the energy harvester tip at the resonance frequencies have positive influence to the electrical characteristics of harvester. 

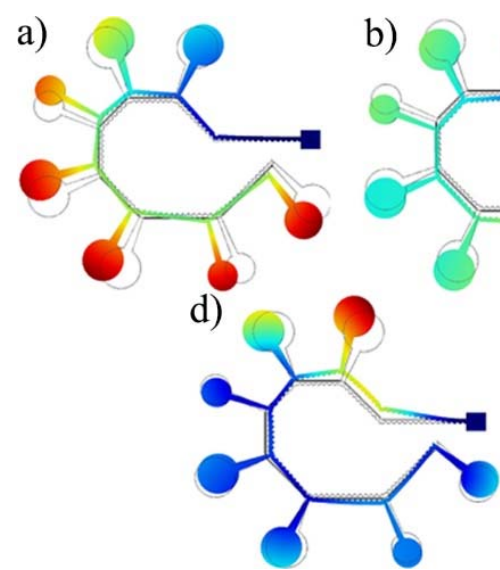

b)

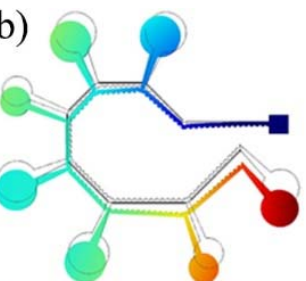

c)

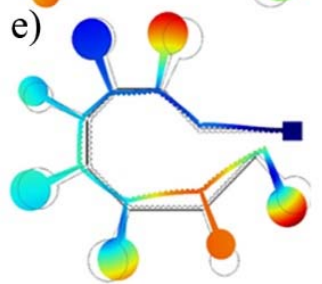

Fig. 3.33. Modal shapes of the harvester: a) $14.41 \mathrm{~Hz}$; b) $25.926 \mathrm{~Hz}$; c) $73.981 \mathrm{~Hz}$; d) $199.53 \mathrm{~Hz}$; e) $214.56 \mathrm{~Hz}$

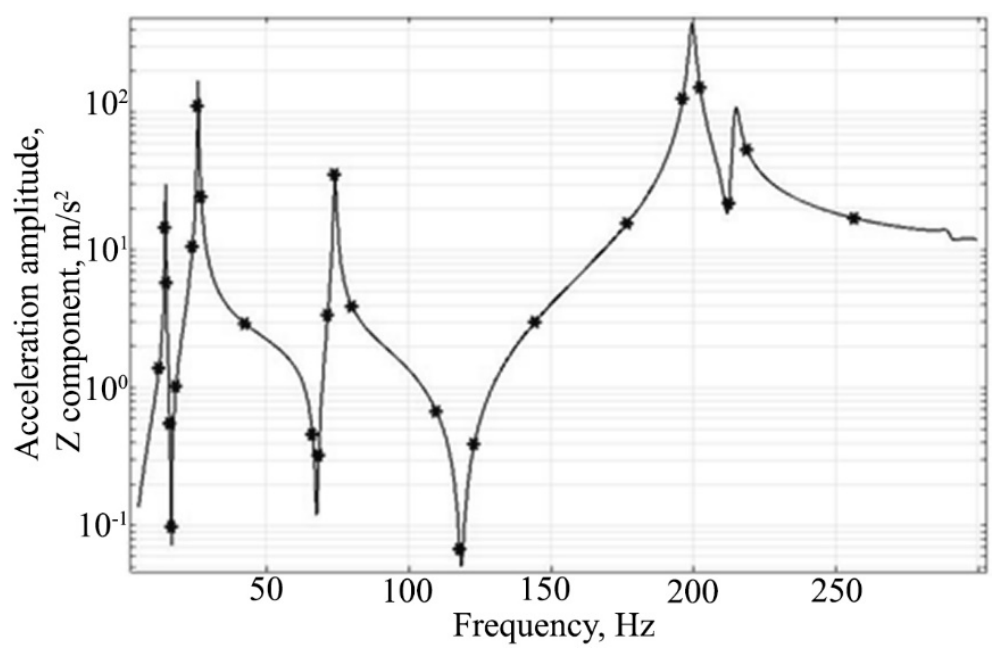

Fig. 3.34. Acceleration amplitude versus excitation frequency

Investigation of bending strain distribution along each cantilever performed as well. Results of the calculations given in Fig. 3.35. It can be seen that bending strain distribution characteristics are almost liner and constant along the length of the cantilever except the cases when the second or higher vibration are excited. Almost uniform bending strain characteristic was achieved by modifications made to the cross sections and special design of the seismic masses. Modifications of the cross sections improved bending strain distribution while special design of the seismic masses ensured higher values of the bending strain. 
Electrode configuration of piezo ceramic layers based on the bending strain distribution along the length of the beam. Electrode configuration allowed proper separation of positive and negative charges obtained when cantilevers of the harvester vibrate at the second vibration mode. Proper electrode configuration influences electrical output characteristics of multi-frequency energy harvester. Algorithm of electrode configuration formulated as follows: partitioning of the electrodes made in the places where the value of bending stain tensor component is close to zero. Therefore, five vibration nodes of the harvester analysed and partitioning of the electrodes made at indicated nodes. As a result, thirteen different electrodes $\left(\mathrm{PZT}_{1}-\mathrm{PZT}_{13}\right)$ composed on the top surfaces of the piezo ceramic layers of the harvester (Fig. 3.32).

Investigation of electrical characteristics performed as well. Boundary conditions for the harvester were the same as in the previous numerical investigation. The electrodes connected in parallel. The aims of investigation were to obtain output voltage density and energy density characteristics in frequency domain. Voltage density and energy density introduced in order to compare electrical characteristics of the harvester at the different resonant frequencies. Voltage density can be expressed as given in Eq. (3.9).

$$
U_{\sigma}=\frac{U_{\text {output }}}{W_{P Z T} \cdot h_{P Z T} \cdot \sum_{i=1}^{i=j-1} P Z T_{i}} .
$$

Here $U_{\sigma}$ is total voltage density of the harvester; $U_{\text {output }}$ is output voltage of the harvester; $P Z T_{i}$ is length of piezo ceramic layer; $W_{P Z T}$ is width of piezo ceramic layer; $h_{P Z T}$ is height of piezo ceramic layer; $j$ is number of piezo ceramic layer (Fig. 3.32).

Energy density of the harvester calculated as given in Eq. (3.10):

$$
E_{\sigma}=\frac{E_{\text {output }}}{W_{P Z T} \cdot h_{P Z T} \cdot \sum_{i=1}^{i-1} P Z T_{i}} .
$$

Here $E_{\sigma}$ is total energy density of the harvester; $E_{\text {ouput }}$ is output energy of the harvester; $P Z T_{i}$ is length of piezo ceramic layer; $W_{P Z T}$ is width of piezo ceramic layer; $h_{P Z T}$ is height of piezo ceramic layer; $j$ is number of piezo ceramic layer (Fig. 3.32).

Numerical investigation of the voltage density performed with open circuit boundary conditions. The results of calculations given in Fig. 3.36.

It can be seen that peaks of voltage density and energy density were obtained at the resonant frequencies. 

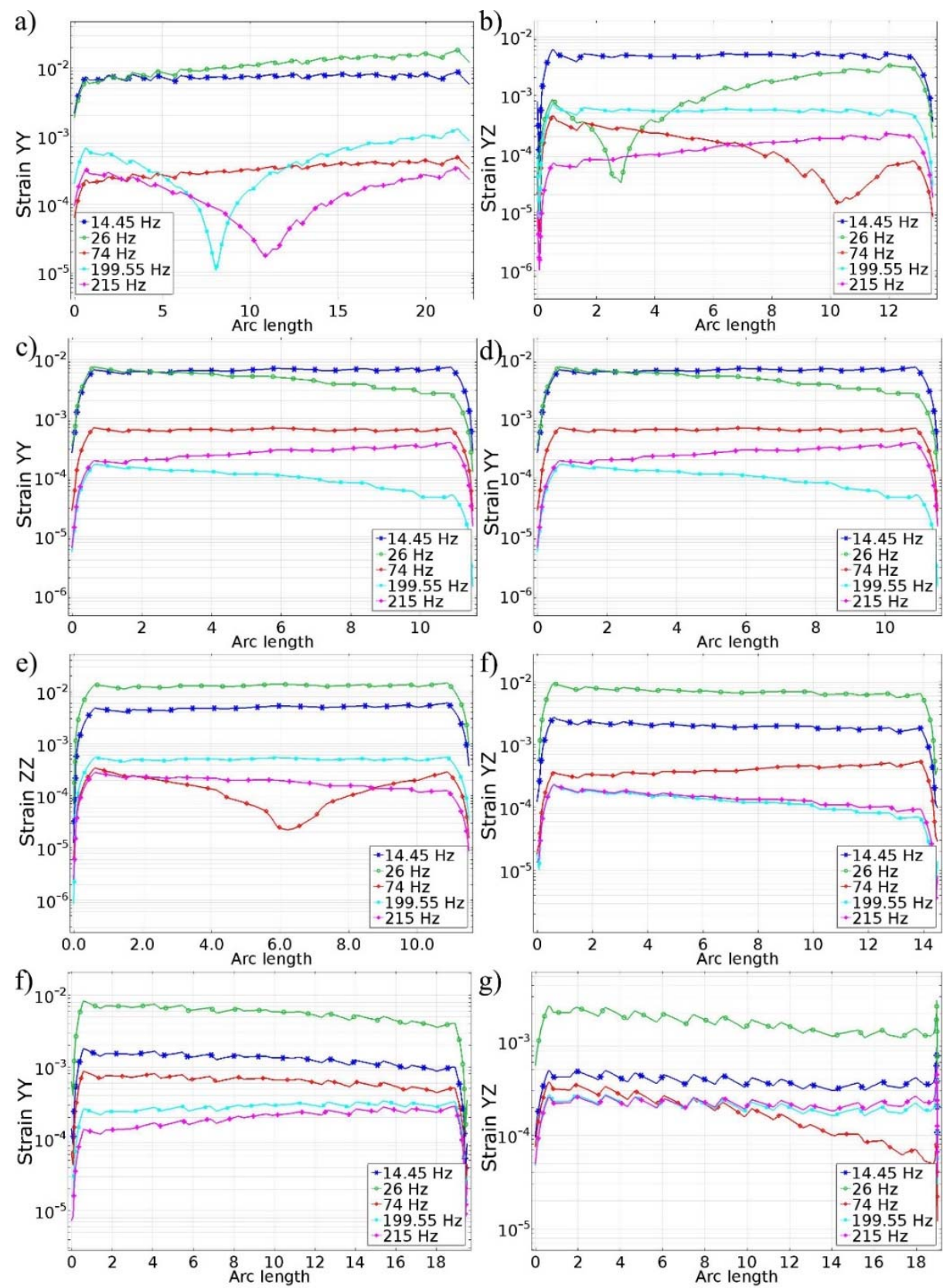

Fig. 3.35. Strain characteristics at the cantilevers; a) at $\mathrm{L}_{1} ;$ b) at $\mathrm{L}_{2} ; \mathrm{c}$ ) at $\mathrm{L}_{3} ; \mathrm{d}$ ) at $\mathrm{L}_{4}$; e) at $\mathrm{L}_{5} ;$ f) at $\mathrm{L}_{6} ; \mathrm{g}$ ) at $\mathrm{L}_{7} ; \mathrm{h}$ ) at $\mathrm{L}_{8}$ 
The highest voltage density was obtained at the $2^{\text {nd }}$ resonant frequency and it reached $50.03 \mathrm{mV} / \mathrm{mm}^{3}$. Other values of voltage density are lower. However, it shows high electrical potential of the energy harvester. Ratio between the highest and the lowest voltage density is 6.78 . It shows that voltage density is sensitive to the resonant frequency mode. However, several voltage density peaks at narrow frequency range gives an opportunity to obtain multi-frequency energy harvesting.

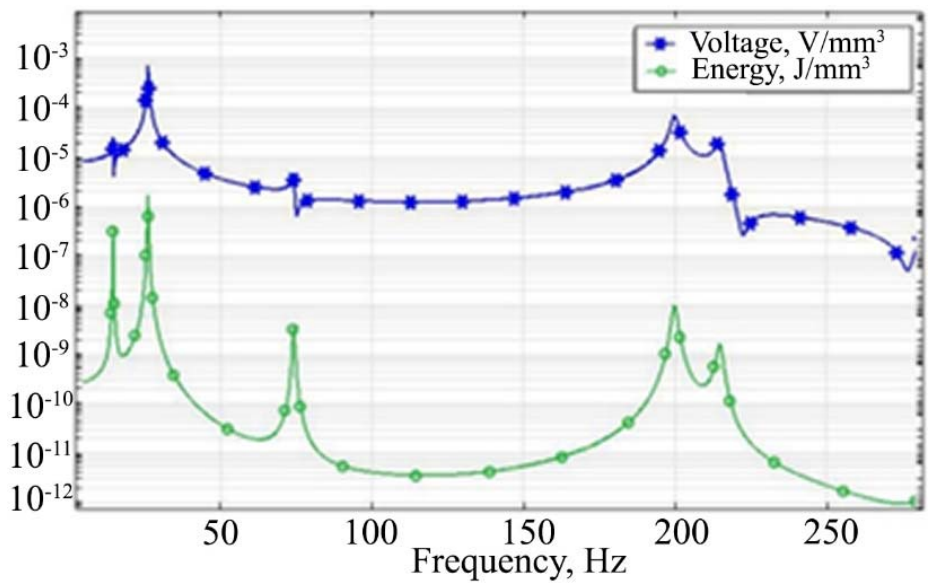

Fig. 3.36. Electrical characteristics of the harvester

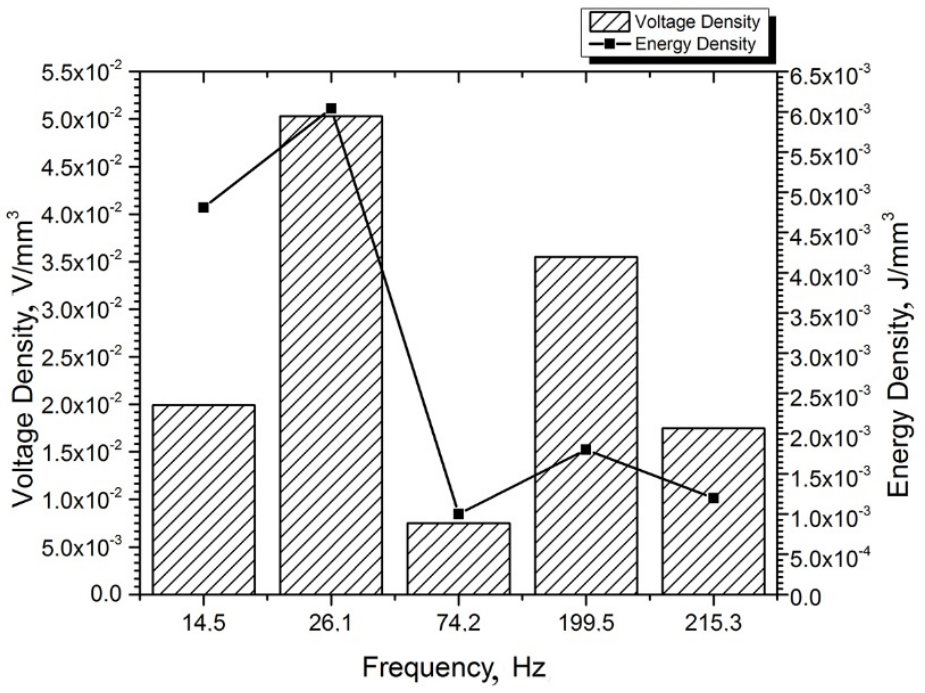

Fig. 3.37. Summary of electrical characteristics of the harvester 
Analysis of energy density characteristic showed that energy harvester is able to provide acceptable energy feed at the different resonant frequencies. The highest energy density was obtained at the $2^{\text {nd }}$ resonant frequency as well. Maximum value of the energy density reached $604 \mu \mathrm{J} / \mathrm{mm}^{3}$. In addition, it must be mentioned, that energy density reached high value $481 \mu \mathrm{J} / \mathrm{mm}^{3}$ at the $1^{\text {st }}$ resonant frequency as well. Therefore, it can be concluded that energy harvester is able to provide high-energy feed with overcapacity at the two different resonant frequencies. On the other hand, energy feed at the other resonant frequencies is much lower.

It can be concluded that the highest efficiency of energy harvester will be achieved at the lower frequency while operation at the higher frequency is less effective, but energy feed is appreciable.

Comparison of voltage density and energy density values made in order to assess electrical characteristics of the energy harvester at different resonant frequencies (Fig. 3.37). On basis of obtained results, it can be concluded that voltage and energy densities varies from $7.5 \mathrm{mV} / \mathrm{mm}^{3}$ to $50.03 \mathrm{mV} / \mathrm{mm}^{3}$ and from $120 \mu \mathrm{J} / \mathrm{mm}^{3}$ to $604 \mu \mathrm{J} / \mathrm{mm}^{3}$, respectively. It shows that values of voltage and energy densities obtained at wide range, but harvester is not capable to provide constant voltage and energy at the different excitation frequencies. On the other hand, if comparing minimum values of the conventional cantilever array with the proposed multi-frequency harvester, it can be noticed that the higher output values were obtained. In addition, stability of electrical characteristics significantly improved using the proposed design of piezoelectric harvester.

\subsubsection{Experimental investigation of the piezoelectric polygon shaped multi-frequency cantilever array}

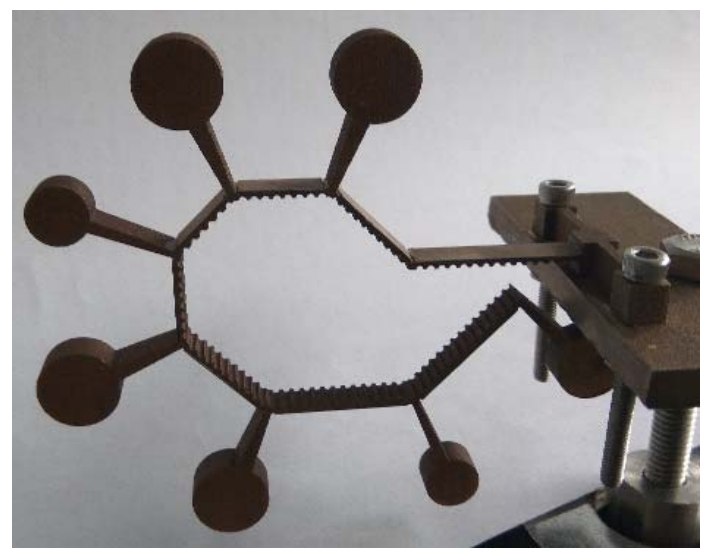

Fig. 3.38. Prototype of piezoelectric energy harvester 
Experimental investigations of mechanical and electrical characteristics performed in order to confirm results of numerical investigation. Prototype of the energy harvester was made with strict respect to the geometrical and physical parameters used during FEM modelling (Fig. 3.38).

Firstly, experimental investigation of frequency response characteristic performed with the aim to validate results of numerical investigation. Polytec OFV 056 scanning vibrometer used for tip velocity measurements. Excitation of the energy harvester performed by electromagnetic shaker Thermotron DSX-4000. A controller of Polytec vibrometer used to generate frequency sweep function for the shaker. The results of harvester tip velocity measurement are shown in Fig. 3.39.

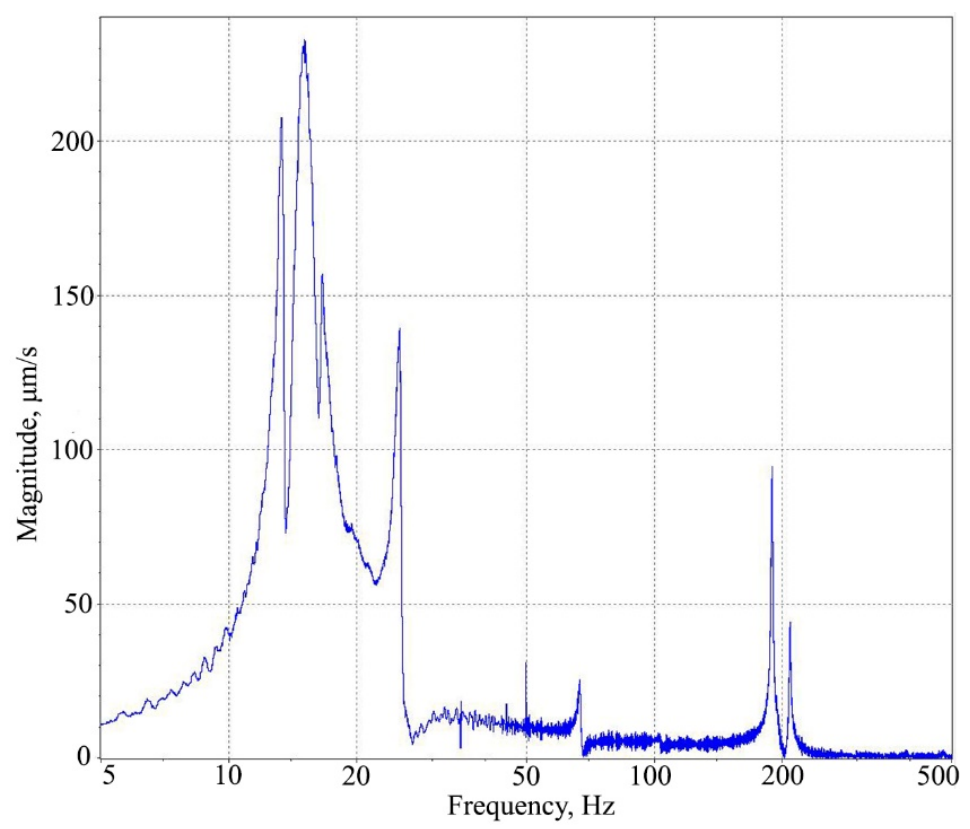

Fig. 3.39. Frequency response characteristic of the energy harvester

Results of the measurement shows that the energy harvester has five resonances in frequency range from $10 \mathrm{~Hz}$ to $240 \mathrm{~Hz}$. Also, it can be seen that two additional peaks appears close to the $1^{\text {st }}$ resonant frequency. It was caused by specific characteristic of the function of excitation signal. However, performed measurements confirmed results of modal analysis. Differences between measured and calculated frequencies does not exceed $5.02 \%$. Summary of the differences between measured and calculated frequencies made to compare obtained results (Fig. 3.40). It can be seen that the highest difference comes at the $4^{\text {th }}$ frequency 
and it reached $10.125 \mathrm{~Hz}$. Differences caused by mismatch in materials characteristics, manufacturing errors and slight differences in clamping.

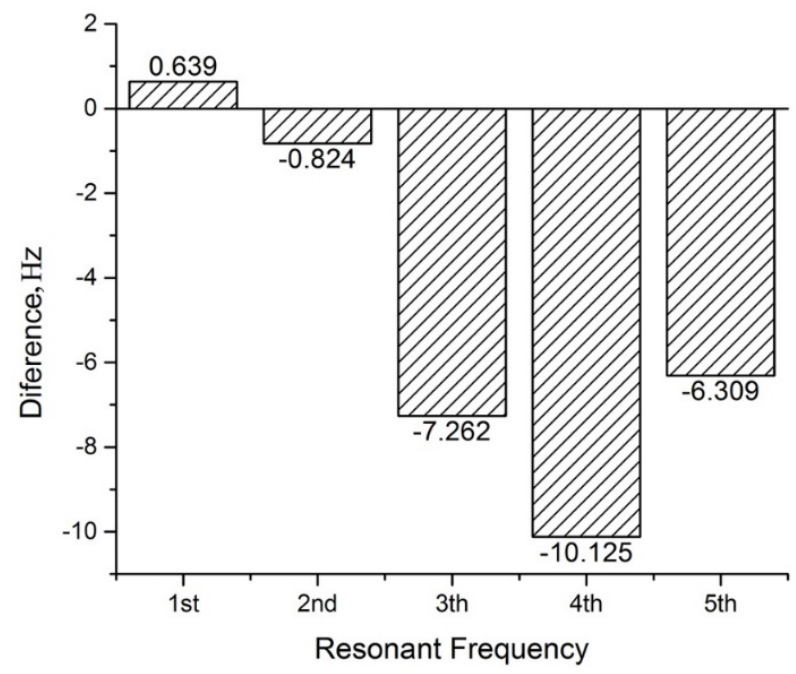

Fig. 3.40. Differences between measured and calculated resonant frequencies

Experimental investigation of electrical characteristics was performed as well. Output voltage density and energy density were measured in frequency range from $10 \mathrm{~Hz}$ to $240 \mathrm{~Hz}$. Special experimental setup was used for this purpose (Fig. 3.27).

Firstly, characteristic of unrectified open circuit voltage measured versus excitation frequency for each piezo ceramic layer. Voltmeter connected directly to the each piezo ceramic layer. Base acceleration of the harvester was set to 0.475 $\mathrm{m} / \mathrm{s}^{2}$. The goal of this investigation was to indicate characteristics of unrectified open circuit voltage for each piezo ceramic layer and to assess electrical performance of the harvester. Results of measurements given in Fig. 3.41.

The results of measurements confirmed that all piezo ceramic layers generate voltage while harvester operates at resonant frequencies. The highest output voltages obtained at the low resonant frequencies. The highest output voltage was $10.61 \mathrm{~V}$ and it was generated by $\mathrm{PZT}_{1}$ layer at $25 \mathrm{~Hz}$ excitation frequency. $\mathrm{PZT}_{1}$ layer is located close to the clamped end of the harvester (Fig. 3.32). Analysis of the results revealed that all piezo ceramic layers provides output voltage at five resonance frequencies.

It confirms an assumption of modal strain summation phenomena obtained by special design of the harvester. Hence, it can be noticed that all cantilevers are employed when harvester operate at resonance frequencies and it can be claimed 
that proposed piezoelectric harvester is more advanced compare to the conventional array of the cantilevers.

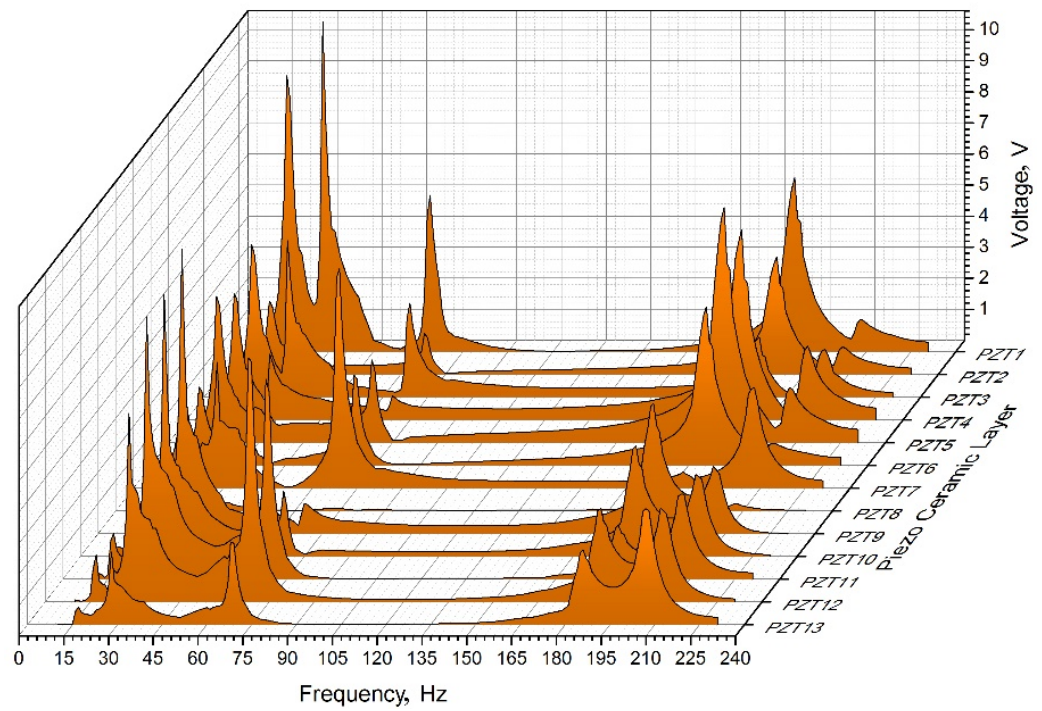

Fig. 3.41. Measured output voltage of all piezo ceramic layers versus frequency.

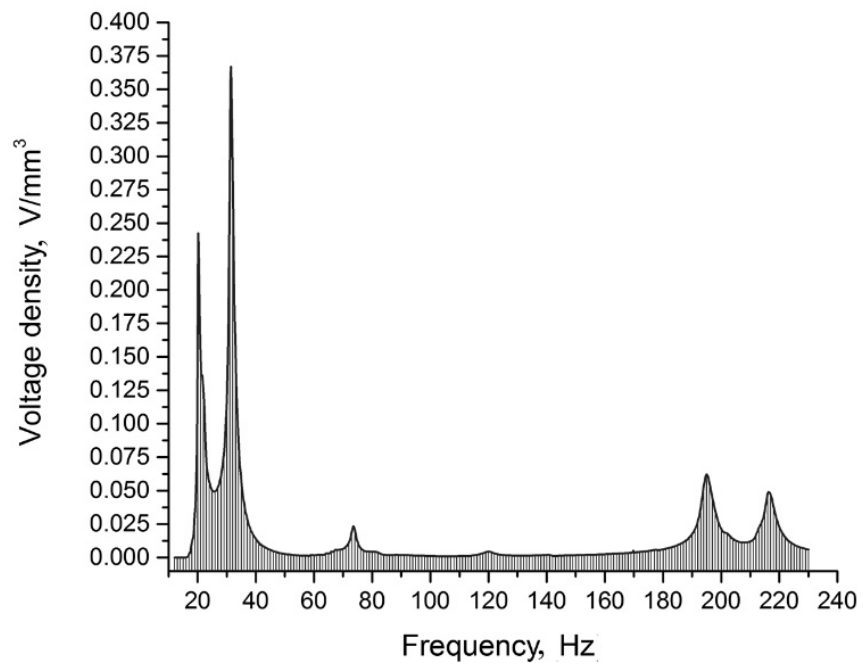

Fig. 3.42. Measured voltage density in frequency domain.

Next step of experimental investigation dedicated for measurements of total rectified output voltage density. Electronic interface designed and connected to 
the energy harvester for this purpose. It consisted of thirteen full diode rectifiers. The rectifiers made from low loss Shottky diodes BAT46 and low equivalent series resistance electrolytic capacitor (Fig. 3.12). Voltage density at the frequency range from $10 \mathrm{~Hz}$ to $240 \mathrm{~Hz}$ measured. Electronic interface was switched to the open circuit condition i. e. electrical load was approximately equal to $10 \mathrm{M} \Omega$. Results of the measurement shown in Fig. 3.42.

Analysis of the voltage density graph showed that voltage density peaks obtained at the same frequencies as in the previous measurements. It confirmed good agreement between numerical calculations and experimental measurements. Moreover, measurement shows that voltage density level is not falling lower than $5.25 \mathrm{mV} / \mathrm{mm}^{3}$. It means that energy harvester is able to provide sufficient voltage output at non-resonant frequency as well. The highest voltage density was obtained at the $2^{\text {nd }}$ resonance frequency and it reached $37.5 \mathrm{mV} / \mathrm{mm}^{3}$. It is 7.14 times higher than lowest voltage density level. Also, it can be noticed that voltage densities at the remaining four resonance frequencies are much lower than at the $2^{\text {nd }}$ resonance frequency.

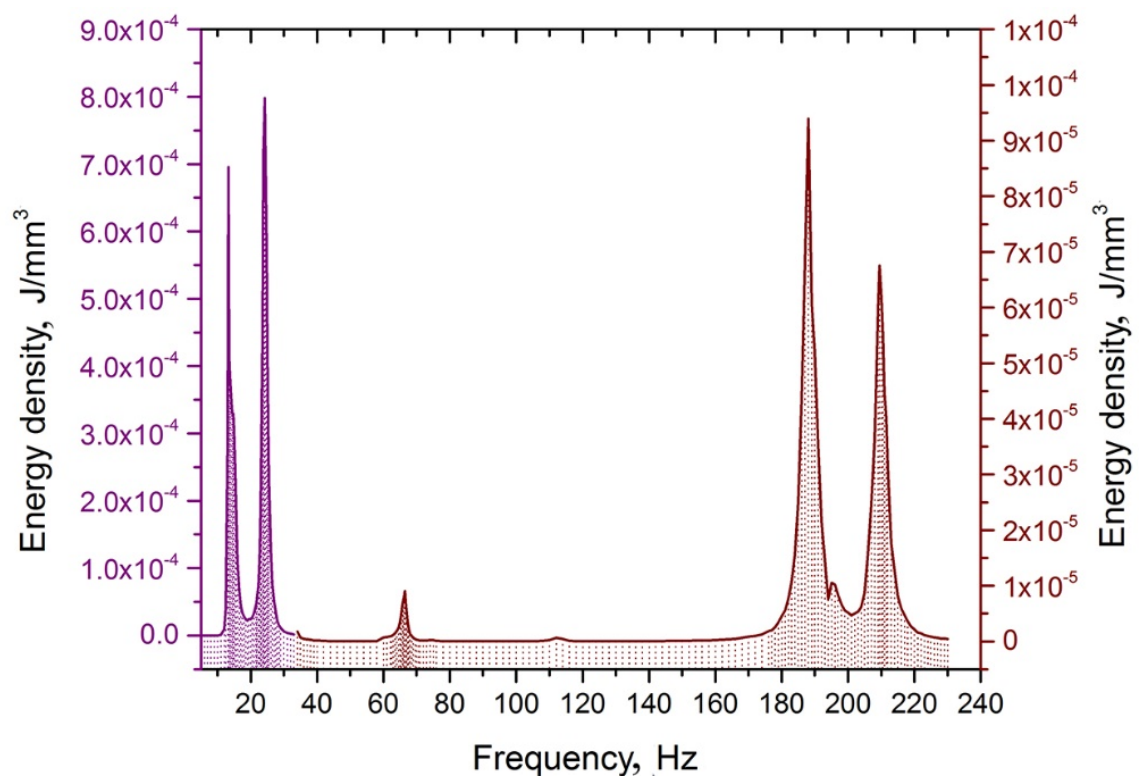

Fig. 3.43. Energy density versus frequency characteristic

Experimental investigation of energy density at the same frequency range performed as well. The same experimental setup is used (Fig. 3.12). The electrical interface switched from open circuit condition to the loaded condition. Electrolytic low ESR capacitor with capacitance $220 \mu \mathrm{F}$ connected as the common load. 
Results of the measurements given in Fig. 3.43. It can be seen that energy density graph has five peaks as in the case discussed before. However, peaks are slightly lower compare to the frequency response characteristic. Such mismatch can be explained by influence of capacitive load, which was connected to the energy harvester thru voltage rectifiers. On the other hand, shift of the resonance frequencies is relatively small i. e. 3-5 Hz. Hence, it shows that energy harvester operates sufficiently stable when capacitive load is applied.

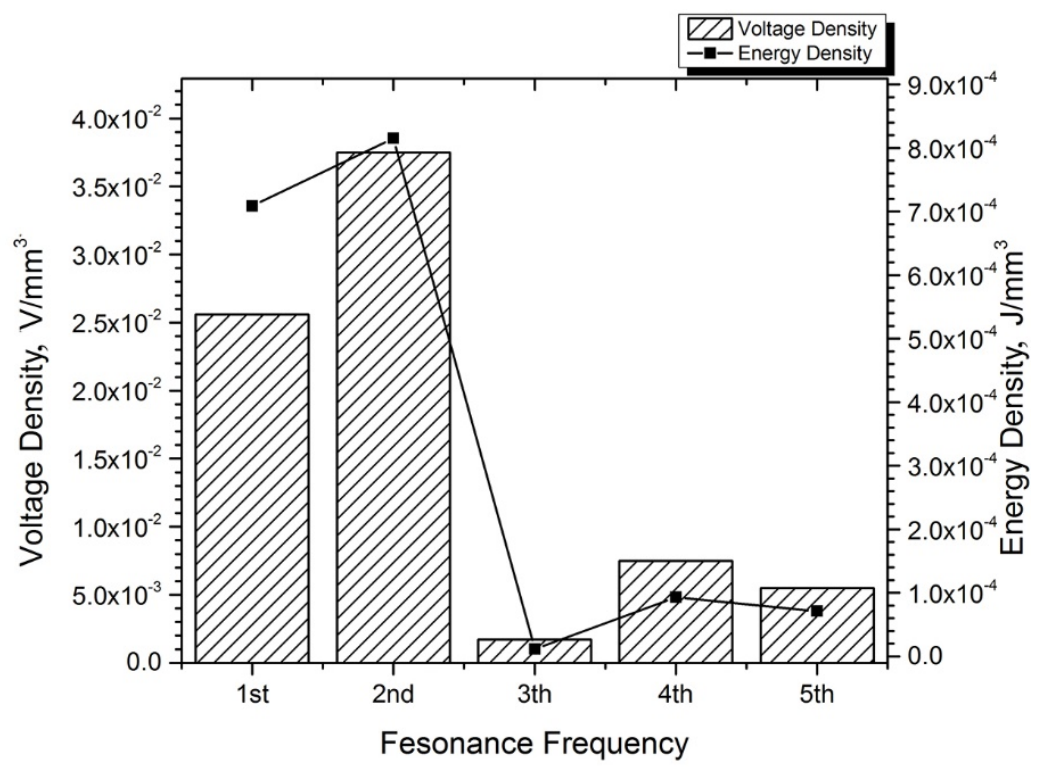

Fig. 3.44. Voltage density and energy density of the harvester at different resonant frequencies

Also it can be noticed that the highest energy density was obtained at the $2^{\text {nd }}$ resonance frequency. Energy density at this frequency reached $815.16 \mu \mathrm{J} / \mathrm{mm}^{3}$. It shows that maximum output power of the proposed harvester is $65.24 \mu \mathrm{W}$ when it operates at the $2^{\text {nd }}$ resonant frequency and it is $12.68 \%$ higher value compare to the maximum output power of the conventional multi-frequency cantilever array. However, energy density value at the $1^{\text {st }}$ resonant frequency is lower and is equal to $708.71 \mu \mathrm{J} / \mathrm{mm}^{3}$. Also, it can be seen that energy density values are much lower at the higher resonant frequencies. Energy density value reached $93.23 \mu \mathrm{J} / \mathrm{mm}^{3}$ at the $4^{\text {th }}$ resonance frequency and $11.5 \mu \mathrm{J} / \mathrm{mm}^{3}$ at the $3^{\text {rd }}$ resonant frequency. Comparison of the both voltage and energy densities at the different resonant frequencies is given in Fig. 3.44. 
It can be seen that energy harvesting system at the first two resonance frequencies is able to provide high energy feed to the energy storage device and even to ensure overcapacity. However, energy harvesting system provides much lower energy feed at the higher resonance frequencies.

Therefore, in the end of this section can be concluded that numerical and experimental investigation showed that energy harvester has five resonance frequencies in the range from $10 \mathrm{~Hz}$ to $240 \mathrm{~Hz}$. The first and the second out of plane bending mode of the cantilevers are dominating in aforementioned frequency range. Moreover, numerical investigation of the bending strain and bending strain distribution showed that bending strain function along the piezo ceramic layers is almost constant. Such bending strain function was achieved by modification of cross sections of the cantilevers. Numerical investigation of electrical characteristics showed that maximum voltage and energy densities were obtained at the $2^{\text {nd }}$ resonant frequency and reached $50.03 \mathrm{mV} / \mathrm{mm}^{3}$ and $604 \mu \mathrm{J} / \mathrm{mm}^{3}$, respectively.

Experimental investigation confirmed results of the numerical modelling. The highest difference between resonant frequencies is 5.02\%. Moreover, experimental investigation of electrical characteristics showed that the highest voltage density and energy density were obtained at the $2^{\text {nd }}$ resonant frequency. Both voltage and energy densities reached $37.5 \mathrm{mV} / \mathrm{mm}^{3}$ and $815.16 \mu \mathrm{J} / \mathrm{mm}^{3}$, respectively. Maximum output power of the harvester is $65.24 \mu \mathrm{W}$. Finally, it can be concluded that proposed piezoelectric energy harvester is able to provide suitable energy feed thru multi-frequency operation principle.

\subsection{Conclusions of chapter 3}

1. On basis of the numerical and experimental investigations can be concluded that usage of rigidly composed cantilevers at multi-frequency piezoelectric arrays ensures bending strain summation and as a results improves electrical potential of cantilever arrays.

2. Numerical investigations revealed that cantilever arrays based on rigidly composed cantilevers with modified cross-sections have almost uniform bending strain distributions. Therefore, it can be concluded that usage of piezoelectric layers at these cantilever arrays is notably better compare to conventional design of energy harvesters based on cantilever arrays.

3. Experimental investigations showed that arrays based on rigidly composed cantilevers provides sufficiently high voltage and energy densities i. e. polygon shaped multi-frequency energy harvester reached 37.5 $\mathrm{mV} / \mathrm{mm}^{3}$ and $815.16 \mu \mathrm{J} / \mathrm{mm}^{3}$, respectively. It is equal to $65.24 \mu \mathrm{W}$ as total output power. Therefore, it shows that proposed design method of multifrequency energy harvesters has good potential for father investigations. 



\section{General conclusions}

1. The review of mechanical vibrations energy harvesting technologies has shown that piezoelectric energy harvesters are able provide the highest power and energy densities. However, bending strain distribution along the piezoelectric cantilever lacks more detail research. Also, most of multi -frequency energy harvesters based on cantilever arrays are low power devices, therefore, new developments of design and construction must be proposed.

2. The proposed configuration of single sided irregular cross section for piezoelectric cantilever allows increasing bending strain up 4.8 times and output power density up to $90 \%$ for rectangular cantilever. Moreover, bending strains of trapezoidal cantilever was increased by 2.7 times and output power density up to 3.14 times using double-sided modified cross sections. Also, it was found, that cross section modifications by cylindrical and trapezoidal gaps allow to achieving the highest bending strain of the cantilevers.

3. The cross-section modifications by gaps causes additional deformations of the cantilever, which varies according to gaps configuration. The single-sided and double-sided cross sections modifications ensured almost constant bending strain distribution along length of the cantilevers. 
4. Investigations of a novel cantilever arrays based on linked cantilevers with modified cross-sections revealed that during variation in excitation frequencies bending strains are inducted in whole array. Also, it was found that bending strains at the cantilever arrays are almost constant. Therefore, almost constant bending strains distribution leads to increased output energy and power densities of the system. 


\section{References}

Aboulfotoh, N., Twiefel, J., Krack, M., Wallaschek, J. 2017. Experimental Study on Performance Enhancement of a Piezoelectric Vibration Energy Harvester by applying SelfResonating Behaviour. Energy Harvesting and Systems.

Ahmed, B.; Despesse, G.; Boisseau, S.; Defay, E. 2012. Small-Scale Energy Harvesting: Chapter 10. Strategies for Wideband Mechanical Energy Harvester; 1122-1127. InTech, London

Amirtharajah, R., Chandrakasan, A.P. 1998. Self-powered signal processing using vibration-based power generation. IEEE Journal of Solid-State Circuits. 33(5): 687-695.

ANSI/IEEE Std. 176-1987. IEEE Standard on Piezoelectricity. The Institute of Electrical and Electronics Engineers, Inc. New York. 1987.

Anton, S.; Sodano, H. 2007. A review of power harvesting using piezoelectric materials (2003-2006). Smart Materials \& Structures 16(3): 1-21.

Asai, T., Araki, Y., Ikago, K., Hoof, C. 2017. Energy harvesting potential of tuned inertial mass electromagnetic transducers. Mechanical Systems and Signal Processing. 84:659672.

Bai, Y., Tofel, P., Hadas, Z., Smilek, J., Losak, P., Skarvada, P., Macku, R. 2018. Investigation of a cantilever structured piezoelectric energy harvester used for wearable devices with random vibration input. Mechanical Systems and Signal Processing. 106: 303318. 
Beeby, S. P., Torah, R. N., Tudor, M. J., Glynne-Jones, P., O'Donnell, T., Saha, C. R., Roy, S. A. 2007. A micro electromagnetic generator for vibration energy harvesting. Journal of Micromechanics and Microengineering. 17(7): 1257-1265.

Bradai, S., Naifar, S., Viehweger, C., Kanoun, O., Litak, G. 2015. Nonlinear analysis of an electrodynamic broadband energy harvester. European Physical Journal: Special Topics. 224(14-15): 2919-2927.

Cammarano, A., Burrow, S. G., Barton, D.A.W. 2011. Modelling and experimental characterization of an energy harvester with bi-stable compliance characteristics. Proceedings of the Institution of Mechanical Engineers. Part I: Journal of Systems and Control Engineering. 225(4):475-484.

Castagnetti, D.2016. Experimental modal analysis of fractal-inspired multi-frequency structures for piezoelectric energy converters. Smart Materials and Structures. 21(094009)

Chae, S. H., Ju, S., Choi, Y., Chi, Y. E., Ji, C. H. 2017. Electromagnetic linear vibration energy harvester using sliding permanent magnet array and ferrofluid as a lubricant. Micromachines. 8(10): 1-14.

Challa, V.R., MG Prasad, M.G., Shi, Y., Fisher, F.T. 2008. A vibration energy harvesting device with bidirectional resonance frequency tunability. Smartmaterials and Structures. 17(015035)

Chen, S., Du, S., Arroyo, E., Jia, Y. 2017. Shock reliability enhancement for MEMS vibration energy harvesters with nonlinear air damping as a soft stopper. Journal of Micromechanics and Microengineering. 27(104003)

Cheng, Y., Wu, N., Wang, Q. 2017. An efficient piezoelectric energy harvester with frequency. Journal of Sound and Vibration. 396: 69-82.

Chiu, Y., Hong, H., Hsu, W. 2016. Wideband vibrational electromagnetic energy harvesters with nonlinear polyimide springs based on rigid-flex printed circuit boards technology. Smart Materials and Structures. 25(12):125014.

Cottone, F., Basset, P., Vocca, H., Gammaitoni, L., Bourouina, T. 2014. Bistable electromagnetic generator based on buckled beams for vibration energy harvesting. Journal of Intelligent Material Systems and Structures. 25(12): 1484-1495.

Curie, J., Curie, P. C. R. 1880 . Acad Sei 91. Bull. soc. min. de France 3.90

Daqaq, M. F. 2012. On intentional introduction of stiffness nonlinearities for energy harvesting under white Gaussian excitations. Nonlinear Dynamics. 69:1063-1079.

Dietl, J.M., Wickenheiser, A.M., Garcia, E. 2010. A Timoshenko beam model for cantilevered piezoelectric energy harvesters. Smart materials and structures. 19(055018).

Ding, W., Song, B., Mao, Z., Wang, K. 2016. Experimental investigations on a low frequency horizontal pendulum ocean kinetic energy harvester for underwater mooring platforms. Journal of Marine Science and Technology (Japan). 21(2):359-367. 
El-hami, M., Glynne-Jones, P., White, N. M. Hill, M., Beeby, S., James, E., Brown, A. D., Ross, J. N. 2001. Design and fabrication of a new vibration-based electromechanical power generator. Sensors and Actuators, A: Physical. 92 (1-3): 335-342.

Elvin, N.; Erturk, A. 2013. Advances in energy harvesting methods. Springer Sience+Business Media, New York.

Erturk, A. Inman, D.J. 2008. On Mechanical Modeling of Cantilevered Piezoelectric Vibration Energy Harvesters. Journal of Intelligent Material Systems and Structures. 19(11): 1311-1325.

Erturk, A., Hoffmann, J., Inman, D. J. 2009. A piezomagnetoelastic structure for broadband vibration energy harvesting. Applied physics letters. 94(254102).

Erturk, A., Inman, D.J. 2008. A distributed parameter electromechanical model for cantilevered piezoelectric energy harvesters electromechanical model for cantilevered piezoelectric energy. 130:041002-1.

Erturk, A., Inman, D.J. 2009b. An experimentally validated bimorph cantilever model for piezoelectric energy harvesting from base excitations. 18(025009).

Feng, Y., Zhang, X., Han, Y., Yu, Z., Lou, W., 2017. Airflow-driven rotary electret energy harvester. 2017 IEEE 12th International Conference on Nano/Micro Engineered and Molecular Systems (NEMS).

Ferrari, M., Ferrari, V., Guizzetti, M., Marioli, D., Taroni, A. 2008. Piezoelectric multifrequency energy converter for power harvesting in autonomous microsystems. Sensors and Actuators, A: Physical. 142(1): 329-335.

Goldschmidtboeing, F., Woias, P. 2008. Characterization of different beam shapes for piezoelectric energy harvesting. Journal of Micromechanics and Microengineering. 18(104013).

Gonzalez-Buelga, A., Clare, L.R., Neild, S.A., Burrow, S.G., Inman, D.J. 2015. An electromagnetic vibration absorber with harvesting and tuning capabilities. Structural Control and Health Monitoring. 22: 1359-1372.

Gu, L., Livermore, C. 2012. Compact passively self-tuning energy harvesting for rotating applications. Smart materials and Structures. 21(015002).

Han, M., Li, Z., Sun, X., Zhang, H. 2014b. Analysis of an in-plane electromagnetic energy harvester with integrated magnet array. Sensors and Actuators A: Physical. 219: 38-46.

Han, M., Yuan, Q., Sun, X., Zhang, H. 2014a. Design and fabrication of integrated magnetic MEMS energy harvester for low frequency applications. Journal of Microelectromechanical Systems. 23(1):204-212.

Harb, A. 2011. Energy harvesting: State-of-the-art. 2011. Renewable Energy. 36(10): 2641-2654

Harne, R. L., Thota, M., Wang, K. W. 2013. Bistable energy harvesting enhancement with an auxiliary linear oscillator. Smart Materials and Structures. 22(12): 1-12. 
Harris, P., Arafa, M., Litak, G., Bowen, C. R., Iwaniec, J. 2017. Output response identification in a multistable system for piezoelectric energy harvesting. The European Physical Journal B. 90(20).

Hehn, T.; Manoli, Y.; 2015. CMOS Circuits for Piezoelectric Energy Harvesters. Springer, New York.

Hosseini, R., Hamedi, M. 2015. Improvements in energy harvesting capabilities by using different shapes of piezoelectric bimorphs. Journal of Micromechanics and Microengineering. 25 (125008)

Jeong, B., Kim, M. O., Lee, J. I., Eun, Y., Choi, J., Kim, J. 2017. Development of MEMS multi-mode electrostatic energy harvester based on the SOI process. Micromachines. $8(2): 1-12$.

Jia, Y., Yan, J., Soga, K., Seshia, A. A. 2013. Multi-frequency operation of a mems vibration energy harvester by accessing five orders of parametric resonance. Journal of Physics: Conference Series. 476(1): 1-5.

Jiang, Y., Masaoka, S., Fujita, T., Uehara, M., Toyonaga, T., Fujii, K., Higuchi, K., Maenaka, K. 2011. Fabrication of a vibration-driven electromagnetic energy harvester with integrated $\mathrm{NdFeB/Ta}$ multilayered micro-magnets. Journal of Micromechanics and Microengineering. 21(9): 1-6.

Jin, L., Gao, S., Zhou, X., Zhang, G. 2017. The effect of different shapes of cantilever beam in piezoelectric energy harvesters on their electrical output. Microsystem Technologies. 23(10):4805-4814.

Kaur, S., Halvorsen, E., Søråsen, O., Yeatman, E. M. 2015. Characterization and Modelling of Nonlinearities in In-Plane Gap Closing Electrostatic Energy Harvester. Journal of Microelectromechanical Systems. 24(6):2071-2082.

Kazmierski, T.J.; Beeby, S. 2011. Energy Harvesting Systems. Springer, New York.

Khan, F., Sassani, F., Stoeber, B. 2014. Nonlinear behaviour of membrane type electromagnetic energy harvester under harmonic and random vibrations. Microsystem Technologies. 20(7):1323-1335.

Koga, H., Mitsuya, H., Honma, H., Fujita, H., Toshiyoshi, H., Hashiguchi, G., 2017. Development of a Cantilever-Type Electrostatic Energy Harvester and Its Charging Characteristics on a Highway Viaduct. Micromachines. 8(10):293

Kok, S., Mohamad, N., Yap D.F.W., Chen,S.K., Dee, C.F. 2011. Multi-Frequency Energy Harvesting Using Thick- Film Piezoelectric Cantilever. International Conference on Electrical, Control and Computer Engineering. 2: 420-423.

Lee, B., Chung, G. 2016. Design and analysis of a pendulum-based electromagnetic energy harvester using anti-phase motion. IET Renewable Power Generation. 10(10): 16251630.

Lee, H., Sharpes, N., Abdelmoula, H., Abdelke, A., Priya, S. 2018. Higher power generation from torsion-dominant mode in a zigzag shaped two-dimensional energy harvester. Applied Energy. 2016(January): 494-503. 
Leng, Y., Tan, D., Liu, J., Zhang, Y., Fan, S. 2017. Magnetic force analysis and performance of a tri-stable piezoelectric energy harvester under random excitation. Journal of Sound and Vibration. 406:146-160.

Lippmann, M.G. 1881. Ann. Chirnie et Phys. 24(145)

Liu, H., Qian, Y., Lee, C. 2013. A multi-frequency vibration-based MEMS electromagnetic energy harvesting device. Sensors and Actuators, A: Physical. 204: 37-43.

Liu, S., Cheng, Q., Zhao, D., Feng, L. 2016. Theoretical modeling and analysis of twodegree-of-freedom piezoelectric energy harvester with stopper. Sensors \& Actuators: A. Physical. 245: 97-105.

Ma, X., Zhang, X. 2017. Low cost electrostatic vibration energy harvesters based on negatively-charged polypropylene cellular films with a folded structure. Smart Materials and Structures. 26: 085001.

Mahmoud, M. A. E., Abdel-Rahman, E. M., Mansour, R. R., El-Saadany, E. F. 2017. Outof-plane continuous electrostatic micro-power generators. Sensors (Switzerland). 17(4):1-21.

Mallick, D., Constantinou, P., Podder, P., Roy, S. 2017. Multi-frequency MEMS electromagnetic energy harvesting. Sensors and Actuators, A: Physical. 264:247-259.

Matsumoto, K., Saruwatari, K., Suzuki, Y. 2011. Vibration-powered Battery-less Sensor Node Using MEMS Electret Generator. Digest Tech. PowerMEMS 2011.

Mohamed, R., Sarker, M. R., Mohamed, A. 2016. An optimization of rectangular shape piezoelectric energy harvesting cantilever beam for micro devices. 50: 537-548.

Morris, D. J., Youngsman, J. M., Anderson, M. J., Bahr, D. F. 2008. A resonant frequency tunable, extensional mode piezoelectric vibration harvesting mechanism. Smartmaterials and Structures. 17(065021)

Muthalif, A. G. A., Nordin, N. H. 2015. Optimal piezoelectric beam shape for single and broadband vibration energy harvesting: Modeling, simulation and experimental results. Mechanical Systems and Signal Processing. 54:417-426.

Ostaševičius, V., Janušas, G., Milašauskaitè, I., Žilys, M., Kižauskienė, L. 2015b. Peculiarities of the Third Natural Frequency Vibrations of a Cantilever for the Improvement of Energy Harvesting. Sensors. 15: 12594-12612.

Ostaševičius, V., Markevičius, V., Jurenas, V., Žilys, M., 2015a. Physical Cutting tool vibration energy harvesting for wireless sensors applications. Sensors \& Actuators: A. Physical. 233: 310-318.

Ou, Q., Chen, X., Gutschmidt, S., Wood, A., Leigh, N., Arrieta, A. F. 2011. An experimentally validated double- mass piezoelectric cantilever model for broadband vibrationbased energy harvesting. Journal of Intelligent Material Systems and Structures. 23(2): $117-126$

Park, C.H. 2001. On the Circuit Model of Piezoceramics. Journal of Intelligent Materials Systems and Structures. 12(7): 515-522. 
Paula, A. S. D., Inman, D. J., Savi, M. A. 2015. Energy harvesting in a nonlinear piezomagnetoelastic beam subjected to random excitation. Mechanical Systems and Signal Processing. 54-55: 405-416.

Podder, P., Constantinou, P., Mallick, D., Amann, A., Roy, S. 2017. Magnetic Tuning of Nonlinear MEMS Electromagnetic Vibration Energy Harvester. Journal of Microelectromechanical Systems. 26(3): 539-549.

Priya, S.;Inman, D.J. 2009. Energy Harvesting Technologies. Sience+Business Media, New York.

Ramlan, R., Brennan, M.J., Mace, B.R., Kovacic. 2010. Potential benefits of a non-linear stiffness in an energy harvesting device. Nonlinear Dynamics 59: 545-558.

Roundy, S., Zhang, Y. 2005. Toward self-tuning adaptive vibration based micro-generators. Proceedings of SPIE, Smart Structures, Devices, and Systems. 5649: 373-384.

Roundy, S.; Wright, P.K.; Rabaey, J.M. 2004. Energy scavenging for wireless sensor networks with special focus on vibrations. Springer Sience+Business Media, New York.

Saleem, M. M., Danish, A. M., Iqbal, J., Bazaz, S. A. 2017. Wide bandwidth 2-DoF electromagnetic MEMS energy harvester for low g applications. Microsystem Technologies. 23(12): 5477-5489.

Sari, I., Balkan, T., Kulah, H., 2008. An electromagnetic micro power generator for wideband environmental vibrations. Sensors and Actuators, A: Physical. 145-146(1-2) 405413.

Satpute, N.V., Satpute, S. N., Jugulkar, L. M. 2017. Hybrid electromagnetic shock absorber for energy harvesting in a vehicle suspension. Proceedings of the Institution of Mechanical Engineers, Part C: Journal of Mechanical Engineering Science. 231(8): 15001517.

Seo, M. H., Choi, D. H., Han, C. H., Yoo, J. Y., Yoon, J. B. 2015. An electrostatic energy harvester exploiting variable-area water electrode by respiration. Proceedings of the IEEE International Conference on Micro Electro Mechanical Systems (MEMS). 2015Febru(Februrary): 126-129.

Serre, C., Pérez-Rodríguez, A., Fondevilla, N., Morante, J.R., Montserrat, J., Esteve, J. 2006. Vibrational energy scavenging with si technology electromagnetic inertial microgenerators. Technology. April: 26-28.

Siang, J., Lim, M.H., Salman Leong, M. 2018. Review of vibration-based energy harvesting technology: Mechanism and architectural approach. International Journal of Energy Research. 1-28.

Sirohi, J., Chopra, I. 2000. Fundamental Understanding of Piezoelectric Strain Sensors. Journal of Intelligent Materials Systems and Structures. 11(4): 246-257.

Stephen, N. G. 2006. On energy harvesting from ambient vibration. Journal of Sound and Vibration. 293(1-2): 409-425 
Tadesse, Y., Zhang, S., Priya, S. 2009. Multimodal Energy Harvesting System: Piezoelectric and Electromagnetic. Journal of Intelligent Material Systems and Structures. 20(March): 625-632.

Tan, Y. 2012. Energy Harvesting Autonomous Sensor Systems: Design, Analysis and Practical Implementation. Taylor and Francis Group, New York.

Tang, L., Yang, Y. 2012. A nonlinear piezoelectric energy harvester with magnetic oscillator. Applied physics letters. 101(094102)

Tao, H., Wei, L., Qin, Y., Zu, J., 2018. Modeling and experimental validation of a buckled compressive-mode piezoelectric energy harvester. Nonlinear Dynamics

Tao, K., Liu, S., Lye, S. W., Miao, J., Hu, X. 2014. A three-dimensional electret-based micro power generator for low-level ambient vibrational energy harvesting. Journal of Micromechanics and Microengineering. 24(6): 1-11.

Tao, K., Lye, S. W., Miao, J., Tang, L., Hu, X. 2015. Out-of-plane electret-based MEMS energy harvester with the combined nonlinear effect from electrostatic force and a mechanical elastic stopper. Journal of Micromechanics and Microengineering. 25(10):104014.

Thein,C.K., Ooi, B.L. Liu, J.S., Gilbert J.M. 2016. Modelling and optimization of a bimorph piezoelectric cantilever beam in an energy harvesting application. Journal of Engineering Science and Technology. 11(2): 212-227.

Thomas, T.;Qidwai, M.; Kellogg, J. 2006. Energy scavenging for small-scale unmanned systems. Journal of Power Sources 159(2): 1494-1509.

Trigona, C., Ando, B., Baglio, S., Nouet, P., Latorre, L. 2011. Nonlinear mechanism in MEMS devices for energy harvesting applications. Journal of Micromechanics and Microengineering. 20(12): 1-12.

Truong, B.D., Le, C.P., Halvorsen, E., 2017. Analysis of MEMS electrostatic energy harvesters electrically configured as voltage multipliers.

Twiefel, J., Westermann, H. 2013. Survey on broadband techniques for vibration energy harvesting. Journal of Intelligent Material Systems and Structures 24(11): 1291-1302.

von Buren, T., Troster, G. 2007. Design and optimization of a linear vibration-driven electromagnetic micro-power generator. Sensors and Actuators, A: Physical. 135(2): 765-775.

Vullers, R., Schaijk, R., Visser, H., Penders, J., 2010. Energy harvesting for autonomous wireless sensor networks. IEEE Solid-State Circuits Magazine. 2(2): 29-38.

Wang, G., Liao, W. 2016. A bistable piezoelectric oscillator with an elastic magnifier for energy harvesting enhancement. Journal of Intelligent Material Systems and Structures. 28(3): 392-407.

Wang, J., Wang, Z. 2017. A Double Bi-stable Energy Harvester for Enhanced Ability of Bi-stable Energy Harvesting from Random Vibration. Journal of Applied Science and Engineering. 20(3): 387-392. 
Wang, P., Tanaka, K., Sugiyama, S., Dai, X., Zhao, X., Liu, J. 2009. A micro electromagnetic low level vibration energy harvester based on MEMS technology. Microsystem Technologies. 15(6):941-951

Wang, X., Chen, C., Wang, N., San, H., Yu, Y., Halvorsen, E., Chen, X. 2017. A frequency and bandwidth tunable piezoelectric vibration energy harvester using multiple nonlinear techniques. Applied Energy. 190: 368-375.

Wei, C., Jing, X., 2017. A comprehensive review on vibration energy harvesting: Modelling and realization. 74(December 2016): 1-18.

Wischke, M., Masur, M., Goldschmidtboeing, F., Woias, P., 2010. Piezoelectrically tunable electromagnetic vibration harvester. Proceedings of the IEEE International Conference on Micro Electro Mechanical Systems (MEMS). 1199-1202.

Wu, H., Tang, L., Yang, Y., Soh, C.K. 2012. A novel two-degrees-of-freedom piezoelectric energy harvester. Journal of Intelligent Material Systems and Structures 24(3): 357-368

Xiao, H., Wang, X., John, S. 2016. A multi-degree of freedom piezoelectric vibration energy harvester with piezoelectric elements inserted between two nearby oscillators. Mechanical Systems and Signal Processing. 68-69: 138-154.

Yan, Z., Abdelkefi, A., Hajj, R.H. 2014. Piezoelectric energy harvesting from hybrid vibrations. Smart Mater. Struct. 23:025026

Yang, J., Wen, Y., Li, P., 2011. Magnetoelectric energy harvesting from vibrations of multiple frequencies. Journal of Intelligent Material Systems and Structures. 22(14): 1631-1639.

Yang, W., Towfighian, S., 2017. A hybrid nonlinear vibration energy harvester. Mechanical Systems and Signal Processing. 90: 317-333.

Yurchenko, D., Alevras, P. 2018. Parametric pendulum based wave energy converter. Mechanical Systems and Signal Processing. 99: 504-515.

Zhao, L., Yang, Y., 2018. An impact-based broadband aeroelastic energy harvester for concurrent wind and base vibration energy harvesting. Applied Energy. 212(December 2017): 233-243.

Zhou, S., Hobeck, J. D., Cao, J., Inman, D. J. 2017b. Analytical and experimental investigation of flexible longitudinal zigzag structures for enhanced multi-directional energy harvesting. Smart Materials and Structures. 26(035008)

Zhou, W., Penamalli, G.R., Zuo, L. 2012a. An efficient vibration energy harvester with a multi-mode dynamic magnifier. Smart Materials and Structures. 21(015014).

Zhu, D., Beeby, S. P. 2013. A broadband electromagnetic energy harvester with a coupled bistable structure. Journal of Physics: Conference Series. 476(1): 1-5.

Zhu, D., Tudor, M. J., Beeby, S. 2010. Strategies for increasing the operating frequency range of vibration energy harvesters: a review. Measurement science and technology. 21(022001). 
Zhu, P., Ren, X., Qin, W., Zhou, Z. 2017. Improving energy harvesting in a tri-stable piezomagnetoelastic beam with two attractive external. Archive of Applied Mechanics. 87(1): 45-57.

Žižys, D., Gaidys, R., Daukševičius, R., Ostaševičius, V. 2015. Segmentation of a VibroShock Cantilever-Type Piezoelectric Energy Harvester Operating in Higher Transverse Vibration Modes. Sensors 16(11): 1-14.

Zuo, L., Scully, B., Shestani, J., Zhou, Y. 2010. Design and characterization of an electromagnetic energy harvester for vehicle suspensions. Smart Materials and Structures. 19(4): 1-6. 



\section{List of scientific publications by the author on the topic of the dissertation}

\section{Papers in the reviewed scientific journals}

Čeponis, A., Mažeika, D., 2017a. Investigation of multi-frequency piezoelectric energy harvester, Shock and Vibration 2017: 1-13, Art.nr. 5037187, DOI:10.1155/2017/8703680

Čeponis, A., Mažeika, D., Bakanauskas, V. 2017b. Trapezoidal cantilevers with irregular cross-sections for energy harvesting systems, Applied sciences 7(2): 1-16, DOI: 10.3390/app7020134

Čeponis, A., Mažeika, D., Kulvietis, G., Yang, Y. 2018a. Piezoelectric cantilevers for energy harvesting with irregular design of the cross sections, Mechanika 24(2): 221-231, DOI: $10.21595 /$ jve.2016.16632

Mažeika, D., Čeponis, A., Yang, Y. 2018b. Multi-frequency piezoelectric energy harvester based on polygon shaped cantilever array, Shock and Vibration 2018: 1-11, Art.nr. 5037187, DOI: $10.1155 / 2018 / 5037187$ 


\section{Other Papers}

Čeponis, A., Mažeika, D. 2016. Investigation of the cantilever beam for piezoelectric energy harvesting, Mechanika'2016: proceedings of the 21th international scientific conference 2016:52-61. ISSN 1822-2951.

Čeponis, A., Mažeika, D., 2014. Piezoelectric systems as an alternative energy source, Science-future of Lithuania: Mechanics, material science, industrial engineering and management 6(6): 676-681, DOI:10.3846/mla.2015.775

Čeponis, A., Mažeika, D., 2017c. Multi-frequency piezoelectric energy harvester based on the square type cantilever array, Mechanika 2017: proceedings of the 22nd international scientific conference 2017: 81-87, ISSN 1822-2951. 


\section{Summary in Lithuanian}

\section{Ivadas}

\section{Problemos formulavimas}

Šiai dienai, bevieliai jutikliai, autonominès elektronikos sistemos ir žmogaus sveikatos stebėjimo ịrenginiai užima didelę dalį kasdieninio gyvenimo. Dažniausiai, šie įrenginiai yra taikomi stebèti, kontroliuoti ir kaupti duomenis bei esant poreikiui juos perduoti bevieliu būdu. Taigi, galime rasti daugelị šiu sistemų pritaikymo sričių.

Kita vertus, šios sistemos pasižymi tokiu trūkumu: dažniausiai energija joms yra tiekiama pasitelkiant ịprastas elektrochemines baterijas. Iprastos elektro-chemines pasižymi sekančiais trūkumais: trumpas tarnavimo laikas, brangus techninis aptarnavimas ir aplinkos tarša. Taigi, siekiant išvengti šiu trūkumų turi būti taikomos alternatyvios energijos tiekimo sistemos. Mechaninių vibracijų energijos surinkimas pagrịstas pjezoelektrinèmis medžiagomis yra viena iš daugiausiai žadančių technologijų. Dažniausiai pjezoelektriniai mechaninių vibracijų energijos keitikliai yra paremti pjezoelektrinėmis gembèmis. Efektyvus pjezoelektrinio sluoksnio išnaudojimas šiuose energijos keitikliuose yra viena iš svarbiausių charakteristikų apibrěžiančių išèjimo galios ir energijos tankius. Lenkimo deformacijos ir jų pasiskirstymas pjezoelektriniame gembiniame keitiklyje turi būti didinamos siekiant gauti geresnes elektrines charakteristikas. Gembès su ịprastu skerspjūviu pasižymi tolygiu lenkimo deformacijų mažèjimu išilgai gembès t. y. maksimalios deformacijos gaunamos ties ịtvirtintu gembès galu, o mažiausios ties laisvu gembès galu. 
Toks lenkimo deformacijų pasiskirstymas išilgai pjezoelektrinės gembės ịtakoja žemus sistemos galios ir energijos tankius.

Taip pat, mechaninių vibracijų energijos surinkimo sistema pagrịsta viena pjezoelektrine gembe gali užtikrinti tinkamą energijos tiekimą tik žadinant ją vienu dažniu. Taigi, siekiant gauti energijos tiekimą plačiame žadinimo dažnių diapazone gembès yra sujungiamos ị gembių masyvus. Kita vertus, dažniausiai šie pjezoelektrinių gembių masyvai pasižymi žemu galios ir energijos tankiu dẻl neefektyvaus jos veikimo kintant žadinimo dažniams.

Disertacijoje didžiausias dėmesys skiriamas tyrimams susijusiems su efektyvesniu pjezoelektrinio sluoksnio išnaudojimu energijos surinkimo sistemose pagrịstose viena pjezoelektrine gembe arba šių gembių masyvais.

\section{Darbo aktualumas}

Energijos tiekimo sistemų, kuriose naudojamos pjezoelektrinès medžiagos, kūrimas gali išplèsti mažos galios elektronikos sistemų ir bevielių jutiklių taikymo galimybès. Pjezoelektriniai mechaninių vibracijų energijos keitikliai gali užtikrinti nenutrūkstamą energijos tiekimą ịvairiems šiems įtaisams. Atsižvelgiant ị atliktą literatūros analizę galime teigti, kad viena iš svarbiausių tyrimų sričių yra susijusi su efektyvesniu pjezoelektrinio sluoksnio išnaudojimu.

Gembėmis paremtos energijos surinkimo sistemos yra pačios populiariausios. Kita vertus, šios sistemos pasižymi neefektyviu pjezoelektrinio sluoksnio išnaudojimu. Neefektyvus yra įtakojamas netolygiu lenkimo deformacijų pasiskirstymu pjezoelektrinèje medžiagoje. Taigi, tyrimai susiję su lenkimo deformacijų pasiskirstymu pjezoelektrinèse gembėse turi pastebimą mokslinę reikšmę. Platesni šios srities tyrimai gali turèti teigiamą poveikị pjezoelektrinių energijos keitiklių elektrinėms charakteristikoms ir mechaninių vibracijų energijos surinkimo technologijos taikymui.

\section{Tyrimo objektas}

Tyrimo objektas yra pjezoelektrinès energijos surinkimo sistemos.

\section{Darbo tikslas}

Darbo tikslas yra pasiūlyti pjezoelektrinių gembių ir pjezoelektrinių daugiakampių energijos surinkimo sistemų struktūrinius patobulinamus siekiant padidinti šių sistemų išèjimo galios ir energijos tankius, atlikti skaitinius ir eksperimentinius tyrimus.

\section{Darbo uždaviniai}

Siekiant pasiekti keliamą tikslą, sekantys uždaviniai turi būti išspręsti:

1. Atlikti naujausios mokslinès literatūros, susijusios su mechaninių vibracijų surinkimo sistemomis didžiausią dèmesị skiriant pjezoelektrinėmis sistemoms, apžvalgą. 
2. Pasiūlyti pjezoelektrinių gembių ir pjezoelektrinių gembių masyvų išèjimo galios ir energijos tankių didinimo metodus taikant netaisyklingus skerspjūvius ir daugiakampes struktūras pagrịstas susijusiomis gembèmis.

3. Ištirti pjezoelektrinius energijos surinkèjus pagrịstus pjezoelektrinèmis gembèmis su netaisyklingos formos skerspjūviais, atlikti skaitinius ir eksperimentinius tyrimus ir ịvertinti šių sistemų elektrines charakteristikas.

4. Skaitiškai ir eksperimentiškai ištirti pjezoelektrinių, pagrịstų susijusiomis gembẻmis, daugiakampių energijos surinkëjų mechanines ir elektrines charakteristikas.

\section{Tyrimų metodika}

Siekiant ištirti tiriamaji objektą ir atlikti literatūros analizę buvo taikoma lyginamoji ir literatūros analizès metodikos.

Teoriniai pjezoelektrinių gembių ir gembių masyvų tyrimai atlikti taikant teorinę mechaniką ir statistinius metodus. Skaitiniai tyrimų modeliai sukurti taikant Comsol Multiphysics, LTspice, Origin, ir SolidWorks programines ịrangas.

Eksperimentinių tyrimų metodai buvo taikomi siekiant patvirtinti rezultatus gautus skaitinais metodais. Mechaniniu ir elektrinių charakteristikų matavimai atlikti taikant Polytec OFV 056 skanuojantị vibrometrą, Polytec PSV 500 3D skanuojantị vibrometrą, Keyence LK-G155 lazerini poslinkio jutikli, Yokogawa DLM2000 daugiakanali osciloskopą.

\section{Mokslinis naujumas}

Šio darbo mokslinis naujumas gali būti apibrěžtas kaip:

1. Siekiant padidinti pjezoelektrinių energijos surinkimo sistemų išèjimo galios ir energijos tankius, pasiūlytas netaisyklingos formos skerspjūvių taikymas gembėse. Pasiūlyti netaisyklingos formos skerspjūviai užtikrina padidintas lenkimo deformacijas ir pagerintas lenkimo deformacijų pasiskirstymo charakteristikas gembèse.

2. Standžiai sujungtos ị daugiakampę sistemą gembes pasiūlytos siekiant padidinti rezonansinių dažnių tankị siaurame dažnių diapazone, padidinti lenkimo deformacijas gembèse ir gauti didesnius elektrinès galios ir energijos tankius.

\section{Darbo rezultatų praktinė reikšmė}

Pasiūlyti netaisyklingos formos skerspjūviai gali būti plačiai naudojami siekiant patobulinti pjezoelektrines energijos surinkimo sistemas pagrịstas viena gembe arba gembių masyvais. Daugiakampiai gembių masyvai, tai pat gali būti taikomi kuriant naujo tipo pjezoelektrines daugiadažnes energijos surinkimo sistemas arba tobulinant esamus energijos keitiklius. 


\section{Ginamieji teiginiai}

1. Pjezoelektrinès gembès pasyvaus sluoksnio netaisyklingos formos skerspjūvis užtikrina pastebimai tolygesnị lenkimo deformacijų pasiskirstymą išilgai gembès ir padidina išèjimo galios ir energijos tankius daugiau kaip 3,14 karto, lyginant su ịprastomis pjezoelektrinèmis gembèmis.

2. Gembių masyvai sudaryti kaip neišardomos daugiakampès struktūros pasižymi didesniu savujų dažnių tankiu siaurame dažnių diapazone ir užtikrina didesnes lenkimo deformacijas visoje sistemoje.

\section{Darbo rezultaty aprobavimas}

Disertacijos tema paskelbti septyni mokslinai straipsniai: 4 straipsniai paskelbti žurnaluose turinčiuose citavimo rodiklį ir ịtrauktuose ị Clarivate Analytics Web of Science duomenų bazes (Čeponis 2017a, 2017b, 2018a, 2018b). 1 straipsnis paskelbtas konferencijos medžiagoje ịtrauktoje i Clarivate Analytics Web of Science "Conference Proceedings" duomenų bazę (Čeponis, 2016), 2 straipsniai paskelbti žurnaluose įtrauktuose ị kitas duomenų bazes (Č́eponis, 2015, 2017c).

Disertacijos tema buvo perskaityti pranešimai penkiose tarptautinėse konferencijose:

1. Tarptautine konferencija "Mechanika-2016", Investigation of cantilever beam for piezoelectric energy harvesting. Kaunas, Lithuania.

2. Dvylikta tarptautinè konferencija „Mechatronic Systems and Materials“, Investigation of trapezoidal cantilever beam for piezoelectric energy. Balstogè, Lenkija.

3. Ketvirta tarptautine jaunujų mokslininku konferencija „The $4^{\text {th }}$ IACG“, Investigation of piezoelectric cantilevers with improved energy harvesting efficiency. Nankinas, Kinija.

4. Trylikta tarptautinè konferencija „Mechatronic Systems and Materials“, Multifrequency piezoelectric energy harvester based on rhomb type cantilever array. Vilnius, Lietuva. Penkta tarptautinè jaunųų mokslininkų konferencija

5. „The $5^{\text {th }} I_{A C G}$ “ Multi-frequency piezoelectric energy harvester based on sawtooth shape cantilever array. Nankinas, Kinija.

\section{Disertacijos struktūra}

Disertaciją sudaro įvadas, trys skyriai ir bendrosios išvados. Disertacijos apimtis 132 puslapiai, disertacijos tekste pateikiami 102 paveikslai ir 47 sunumeruotos formulès, 10 lentelių. Rengiant disertaciją panaudoti 109 literatūros šaltiniai.

\section{Padèka}

Noréčiau nuoširdžiai padèkoti moksliniam savo vadovui prof. dr. Daliui Mažeikai už pagalbą ir paramą studijuojant doktorantūroje, atliekant mokslinius tyrimus ir rengiant šią disertaciją, už kantrybę, motyvavimą ir suteiktas žinias. Visų studijų metu prof. dr. Daliaus Mažeikos patarimai ir mentorystè motyvavo judèti ị priekị ir nesustoti ties jau pasiektais rezultatais. Negalęčiau ịsivaizduoti geresnio patarèjo ir mentoriaus. 


\section{Mechaninių vibracijụ energijos surinkimo apžvalga}

Bevielių, dèvimų ir mažos galios elektronikos sistemų tobulèjimas ịgavo didžiulị pagreitị. Šių sistemų pritaikymas galimas ịvairiose, mokslo, inžinerijos ir kasdieninio gyvenimo srityse. Platesnis šių sistemų pritaikymas apribojamas pagrindiniu trūkumu: ịprastų elektrocheminių baterijų taikymu (Elvin and Erturk, 2013).

Taigi, šiai dienai, viena iš svarbiausių tyrimų sričių yra be baterinis energijos tiekimas bevielèms elektronikos sistemoms. Šių tyrimų svarba įtakota baterijomis grịsto energijos tiekimo metodo trūkumais. Kaip pagrindiniai, baterijų kaip energijos šaltinio, trūkumai gali būti įvardinti: trumpas tarnavimo laikas, brangus aptarnavimas, aplinkos tarša ir kita (Anton and Sodano, 2007). Šie trūkumai motyvuoja pakeisti baterijomis pagrịstus energijos šaltinius mažos galios elektronikos sistemose taikant alternatyvius energijos tiekimo metodus, kurie suteiktų galimybę taikyti energiją maitinimui, sutinkamą sistemų montavimo ir taikymo aplinkose (Priya and Inman, 2009). Šiam tikslui tinkamos energijos rūšys pateikiamos S.1.1 paveikslas.

Saulès, vandens tėkmès, vèjo, radijo bangų ir kitos energijos rūšys tinkami pasirinkimai energijos surinkimui. Kita vertus, šių energijos rūšių pritaikymas mažos galios elektronikos sistemų maitinimui sudaro specialias sąlygas šių sistemų montavimui ir taikymui. Taigi, energijos šaltiniai pagrịsti šiomis energijos formomis sudaro apribojimus maitinamų sistemų taikyme ir naudojime. Žvelgiant iš kitos pusès, daugiausiai žadanti energijos forma yra mechaninès vibracijos. Platus šios energijos paplitimas, didelis jos tankis aplinkoje suteikia galimybę ją surinkti ir paversti ị elektros energiją be papildomų reikalavimų maitinamos sistemos taikymo aplinkai (Ahmed and et al. 2012).

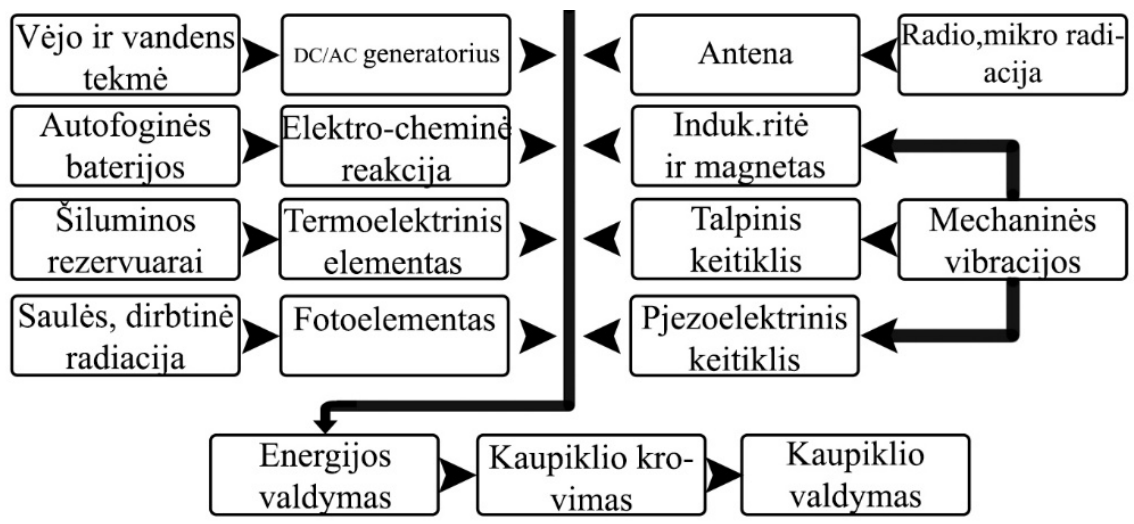

S.1.1 pav. Itvairios energijos rūšys tinkamos surinkimui (Thomas and et al. 2006)

Energijos šaltiniai pagrịsti mechaninių vibracijų energijos surinkimu gali užtikrinti nenutrūkstamą ir pigių energijos tiekimą mažos galios elektronikos imtuvams atsisakant ịprastų elektro-cheminių baterijų. Taip pat, energijos šaltiniai pagrịsti šiomis technologijomis yra draugiški aplinkai (Priya and Inman, 2009). Mechaninių vibracijų energijos surinkimas gali būti išpildytas remiantis trimis pagrindinèmis technologijomis pagrịstomis skirtingais fizikiniais dėsniais t. y. elektromagnetiniu, elektro-statiniu ir pjezoelektriniu 
(Roundy and et al. 2004). Atsižvelgiant ị tai kad mechaninių vibracijų energijos surinkimo technologijos paremtos skirtingais fizikiniais dèsniais, bendra energijos surinkimo koncepcija išlieka vienoda. Blokinè, mechaninių vibracijų energijos surinkimo schema pateikiama S.1.2 paveikslas.

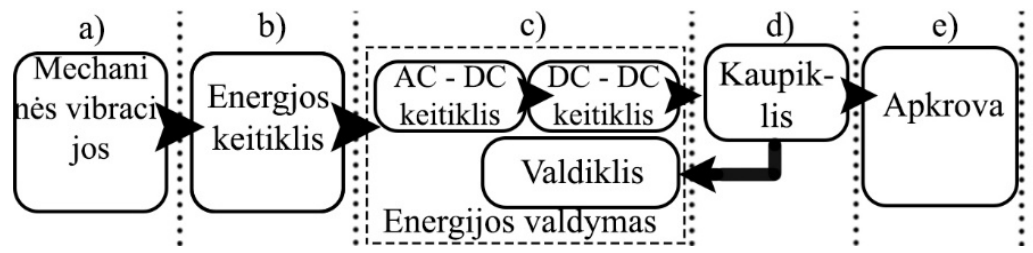

S.1.2 pav. Bendra, mechaninių vibracijų energijos surinkimo sistemos, blokinè schema

(Tan, 2012)

Mechaninių vibracijų energijos surinkimas susidaro iš keturių pagrindinių etapų. Mechaninių vibracijų energija ir energijos keitiklis pagrịstas tam tikru veikimo principu ir fizikiniu reiškiniu (S.1.1 pav., S.1.3 pav.), energijos valdymo grandinè (S.1.2 pav. c), elektrinès energijos kaupimo įrenginiai (S.1.2 pav. d) ir elektros energijos imtuvai (S.1.2 pav. e). Dažniausi elektros energijos imtuvai yra bevielių jutiklių sistemos, mažos galios elektronikos sistemos, mažos galios duomenų perdavimo sistemos ir kita.

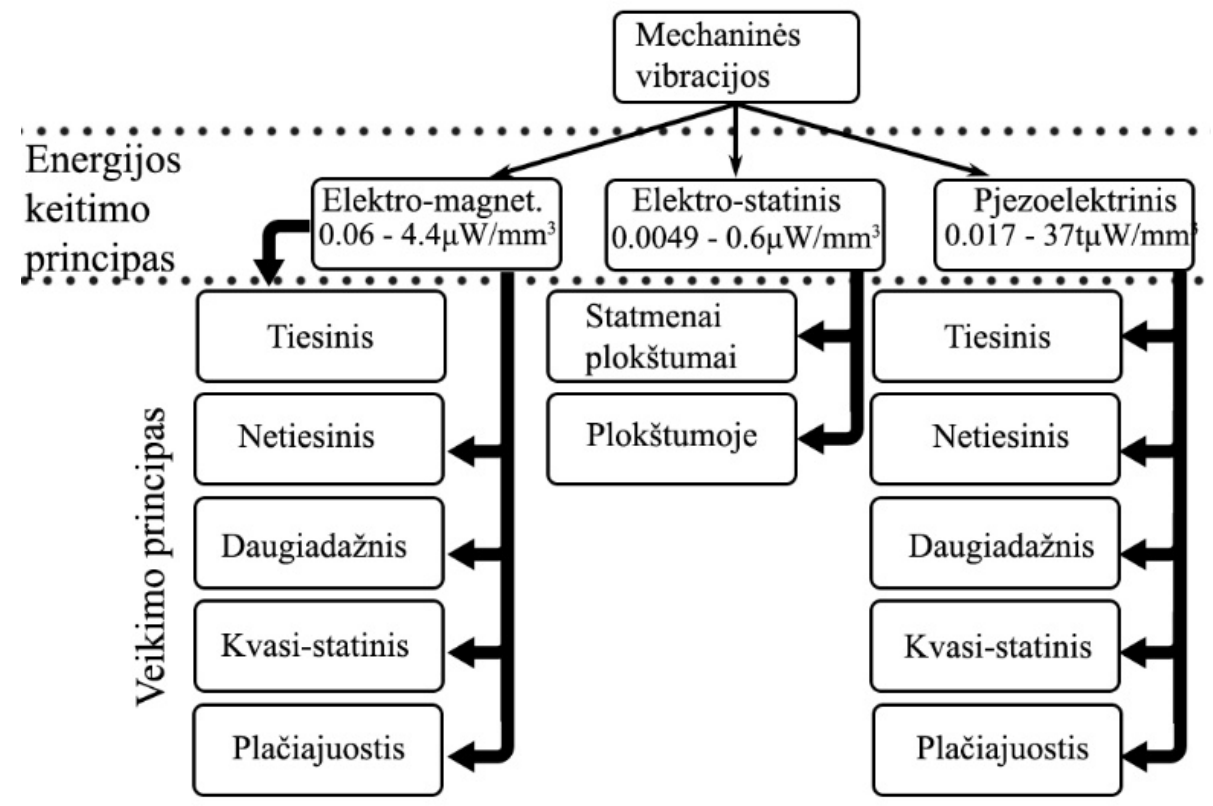

S.1.3 pav. Mechaninių vibracijų energijos keitiklių ir jų veikimo principų klasifikavimas

(Kazmierski and Beeby, 2011; Priya and Inman, 2009; Elvin and Erturk, 2013) 
Pagrindinis mechaninių vibracijų energijos keitiklių vertinimo metodas yra sukuriamos elektrinès galios ar energijos vienetas iš paviršiaus ploto ar tūrio (t. y. elektrinès galios/energijos tankis)( Roundy and et al. 2004). Kiekviena mechaninių vibracijų energijos surinkimo technologija pasižymi tipiniais galimais elektrinės galios ar energijos tankiais. Šių tankių reikšmès yra pateikiamos paveiksle S.1.3 paveikslas.

Taigi, surinkta energija turi būti pakeista ị tinkamą elektros energiją tam ir sudaryti sąlygas ją kaupti baterijose ar tiesiogiai tiekti šios energijos imtuvams. Energijos šaltinio išèjimo varža ir energijos imtuvo iejejimo varža turi būti suderinta siekiant išgauti maksimalų mechaninių vibracijų energijos keitiklio efektyvumą (Hehm and Manoli, 2015). Sukuriamos energijos kaupimui, valdymui ir tiekimui turi būti taikomos tinkamos standartinès elektronikos sistemos arba sukuriamos konkrečiai mechaninių vibracijų energijos surinkimo sistemai.

Apibendrinant galima teigti, kad mechaninių vibracijų energijos surinkimo strategijų ịdeja apima skirtingų tipų mechaninių vibracijų energijos vertimą į elektros energiją taikant skirtingus fizikinius dėsnius. Šios įdejos taikymas, užtikrina savarankišką ir nenutrūkstamą mažos galios elektronikos ir bevielių sistemų veikimą îvairiose aplinkose užpildytose skirtingo pobūdžio mechaninių vibracijų energija.

\section{Gembiniai, pjezoelektriniai energijos keitikliai su netaisyklingos formos skerspjūviais}

Šiame skyriuje pateikiami stačiakampių ir trapecinių gembių su netaisyklingais skerspjūviais, skaitinių ir eksperimentinių tyrimų rezultatai. Tiriami trys skirtingi netaisyklingų skerspjūvių tipai. Netaisyklingų skerspjūvių taikymas užtikrina geresnes, pjezoelektrinių stačiakampių ir trapecinių gembių, elektrines charakteristikas.

a)

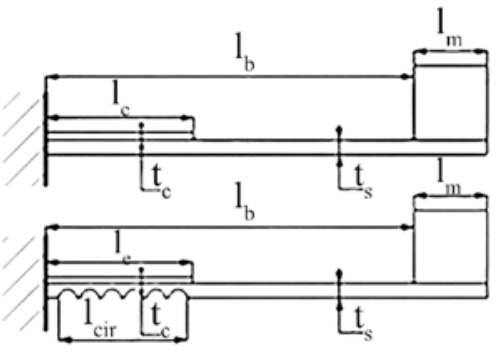

c)

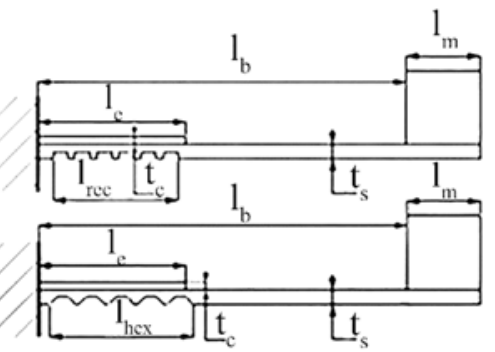

S.2.1 pav. Stačiakampès gembès su netaisyklingais skerspjūviais: a) ịprasta gembė; b) gembè su cilindrinėmis išpjovomis; c) gembẻ su stačiakampèmis išpjovomis; d) gembè su trapecinėmis išpjovomis

Siekiant gauti padidintas lenkimo deformacijas ir jų pasiskirstymą pjezoelektriniame, stačiakampių ir trapecinių gembių, sluoksnyje inercijos momentas gembejje turi būti sumažintas. Atsižvelgiant ị tai, kad lenkimo deformacijos gembẻje yra atvirkščiai proporcingos inercijos momentui, o pjezoelektrinès gembès sukuriama ịtampa yra tiesiogiai proporcinga lenkimo deformacijoms, galima teigti kad netaisyklingi skerspjūviai gali užtikrinti geresnes gembių elektrines charakteristikas. Siekiant tai ịrodyti buvo sudarytos 
ir ištirtos stačiakampès ir trapecinès pjezoelektrinès gembès su netaisyklingais skerspjūviais. Gembių skerspjūviai buvo modifikuojami cilindrinèmis, stačiakampemis ir trapecinėmis išpjovomis. Gembių skerspjūviai pateikiami S.2.1 paveiksle. ir S.2.2 paveiksle.
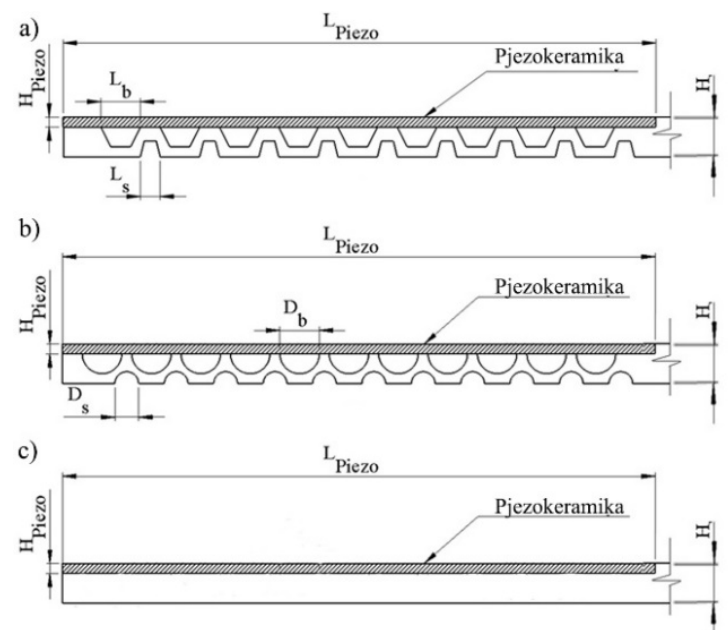

S.2.2 pav. Trapecinių gembių netaisyklingi skerspjūviai: a) su trapecinėmis išpjovomis;

b) su cilindrinèmis išpjovomis; c) gembė su ịprastu skerspjūviu

Tyrimų tikslas - nustatyti ir ịvertinti modifikuotų gembių mechanines ir elektrines charakteristikas ir jas palyginti su ịprastos, to pačio tipo, gembès charakteristikomis. Buvo nustatytos deformacijų modos ir savujjų svyravimų dažniai taikant modalinę analizę. Taip pat atliekant dažnį žadinimą buvo nustatytos mechaninès ir elektrinès gembių charakteristikos.

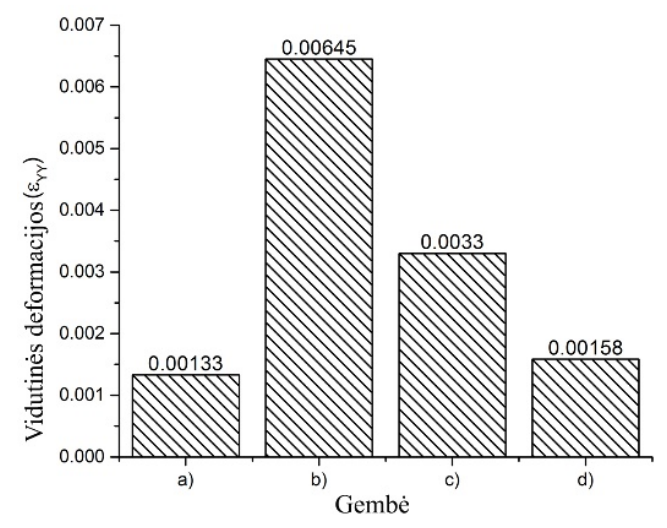

S.2.3 pav. Vidutinių deformacijų stačiakampèse gembėse palyginimas: a) ịprasta gembė; b) gembẻ su cilindrinèmis išpjovomis; c) gembè su stačiakampèmis išpjovomis; d) gembe su trapecinėmis išpjovomis 

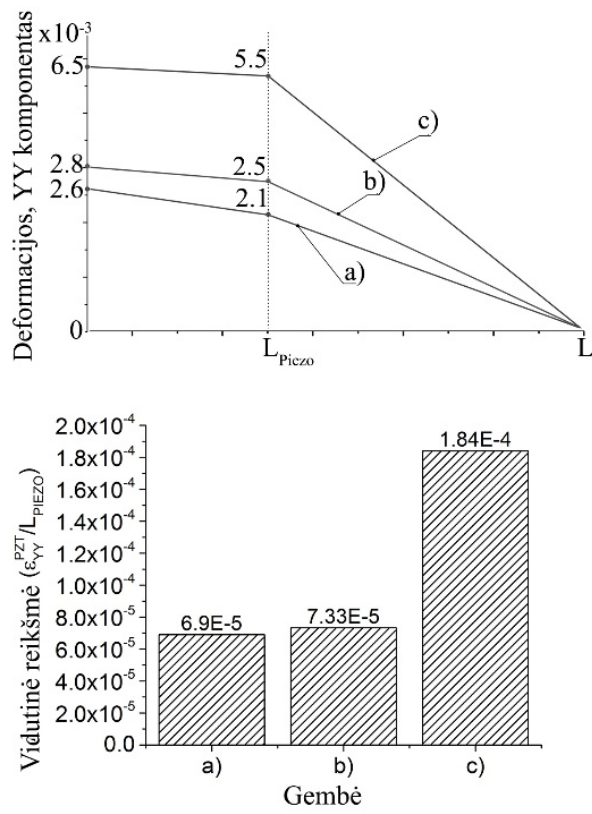

S.2.4 pav. Deformacijų funkcijos ir vidutinès jų reikšmės trapecinėse gembėse: a) ịprasta gembė;

b) gembè su cilindrinèmis išpjovomis; c) gembè su trapecinėmis išpjovomis

Siekiant palyginti stačiakampių gembių mechanines charakteristikas, vidutinès lenkimo deformacijų reikšmės buvo paskaičiuotos. Palyginimo rezultatai pateikti S.2.5 paveiksle.

Remiantis palyginimo rezultatais, galima teigti kad geriausią lenkimo deformacijų charakteristiką turi gembè su cilindrinèmis išpjovomis.

Vidutinè deformacijų reikšmè šioje gembèje yra 4,8 karto didesnès lyginant su ịprastos gembès charakteristika. Atsižvelgiant ị šiuos rezultatus galime daryti išvadą, kad netaisyklingas skerspjūvis su cilindrinèmis išpjovomis turi pastebimą įtaką lenkimo deformacijoms ir jų pasiskirstymui.

Taip pat buvo ištirtos lenkimo deformacijos ir jų pasiskirstymas trapecinèse gembèse su netaisyklingais skerspjūviais. Buvo atliktas trapecinių gembių palyginimas (S.2.4 pav.)

Lenkimo deformacijų charakteristikų palyginimas atskleidè, kad lenkimo deformacijų pasiskirstymas gembèse su netaisyklingais skerspjūviais ịgavo tolygesnị deformacijų pasiskirstymą ir didesnes vidutines deformacijų reikšmes lyginant su ịprastine gembe. Vidutinè deformacijų reikšmè gembèse su netaisyklingais skerspjūviais yra 2,7 karto didesné lyginant su įprasta gembe.

Buvo atlikti eksperimentiniai gembių elektriniu charakteristikų tyrimai. Gautų rezultatų palyginimas buvo atliktas siekiant nustatyti stačiakampę ir trapecinę gembę su geriausiomis elektrinèmis charakteristikomis. Stačiakampių gembiu palyginimo rezultatai pateikiami S.2.5 paveiksle. 

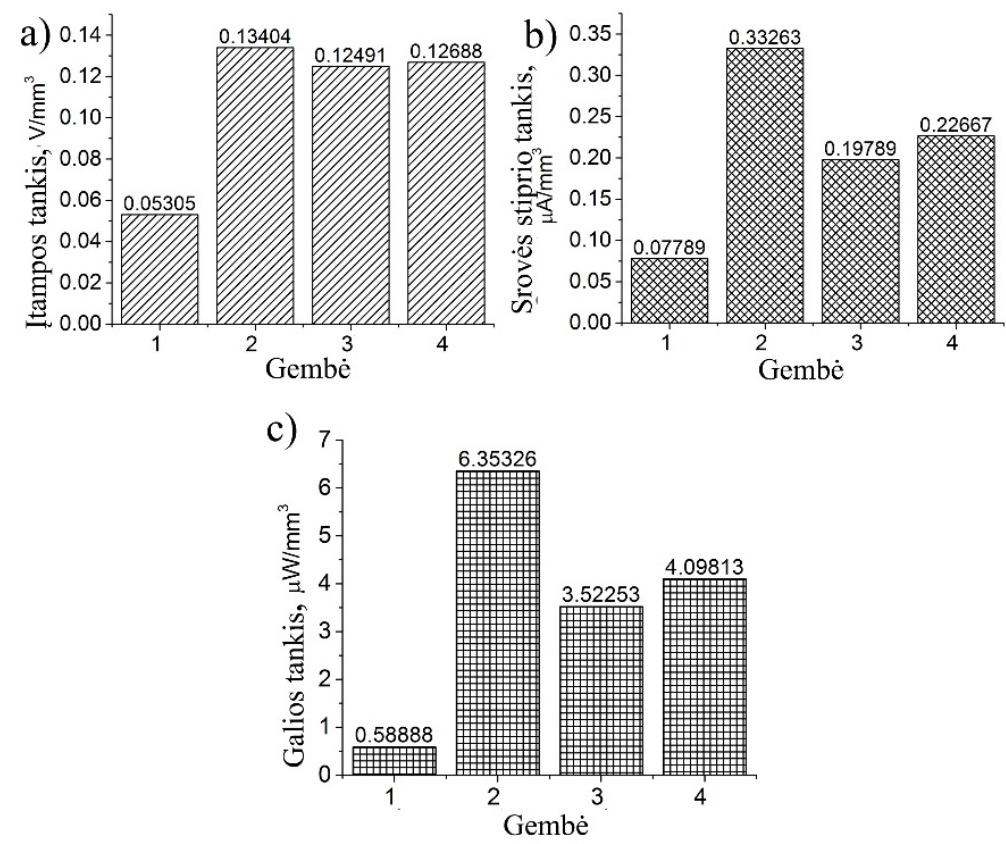

S.2.5 pav. Stačiakampių gembių elektrinių charakteristikų palyginimas: a) įtampos tankis; b) srovès stiprio tankis; c) vidutinès galios tankis; 1 ịprasta gembè; 2 gembè su cilindrinèmis išpjovomis; 3 gembè su stačiakampemis išpjovomis; 3 gembè su trapecinėmis išpjovomis

Atlikus stačiakampių gembių elektrinių charakteristikų palyginimą buvo nustatyta, kad gembè su cilindrinèmis išpjovomis pasižymi 46,37\% aukštesniu įtampos tankiu, $48.86 \%$ aukštesniu srovès stiprio tankiu ir 76,91\% didesniu galios tankiu.

Buvo nustatyta, kad stačiakampė gembė su cilindrinėmis išpjovomis pasižymi $61 \%$ aukštesniu įtampos tankiu, 76,58\% aukštesniu srovès stiprio tankiu ir 90\% aukštesniu galios tankiu lyginant su ịprasta stačiakampe gembe.

Trapecinių gembių palyginimo rezultatų pagrindu galime daryti išvadą, kad trapecinès gembès su netaisyklingais skerspjūviais pasižymi 9,9\% aukštesniu įtampos tankiu, $6,9 \%$ didesniu srovès stiprio tankiu ir 3,14 karto aukštesniu galios tankiu.

Taigi, remiantis atliktais skaitiniais ir eksperimentiniais tyrimais galime teigti kad:

1. Pasiūlytos pjezoelektrinių gembių skerspjūvių modifikacijos taikant įvairios formos išpjovas sumažina inercijos momentus gembèse. Sumažintas gembių inercijos momentas įtakoja padidejusias lenkimo deformacijas ir jų pasiskirstymą išilgai gembès. Taipogi, gembès su netaisyklingais skerspjūviais pasižymi didesniu jautrumu žemoms žadinimo amplitudėms.

2. Skaitiniai ir eksperimentiniai tyrimai atskleidè, kad stačiakampès gembès su viepusiu netaisyklingu skerspjūviu pasižymi iki 4,8 karto didesnèmis lenkimo deformacijomis lyginant su ịprasta stačiakampe gembe. Padidejusios lenkimo deformacijos stačiakampèse gembèse su netaisyklingais skerspjūviais užtikrino iki 
90\% aukštesnę modifikuotų gembių elektrinę galią lyginant su ịprasta stačiakampe gembe.

3. Trapecinès gembès su dvipusiu netaisyklingu skerspjūviu pasižymi 2,7 karto didesnemis lenkimo deformacijomis lyginant su nemodifikuota trapecine gembe. Skaitiniai tyrimai taip pat atskleidè, kad lenkimo deformacijų pasiskirstymas modifikuotoje gembeje yra beveik tolygus. Be to, gembių tyrimai atskleidè, kad padidintos lenkimo deformacijos ir jų pasiskirstymas trapecinèse gembėse užtikrino iki 3,14 karto aukštesnes trapecinių gembių elektrinès galios charakteristikas lyginant su nemodifikuota trapecine gembe.

\section{Daugiadažniai pjezoelektriniai mechaninės energijos sunkimo masyvai paremti susietomis gembẻmis}

Šiame skyriuje pateikiami skaitinių ir eksperimentinių, daugiadažnių pjezoelektrinių masyvų paremtų susietomis gembėmis, tyrimų rezultatai. Susietų gembių taikymas daugiadažniuose masyvuose užtikrina dažnines keitiklių charakteristikas su keliais rezonansiniais dažniais siaurame dažnių diapazone. Taip pat, susietų gembių taikymas daugiadažniuose masyvuose užtikrina jų multi-modalinị veikimo principą ir modalinių deformacijų sumavimo reiškinị. Taikant šio tipo konstrukcijas užtikrinamas pastebimai efektyvesnis daugiadažnių masyvų veikimas rezonansiniame ir nerezonansiniame režime.

a)

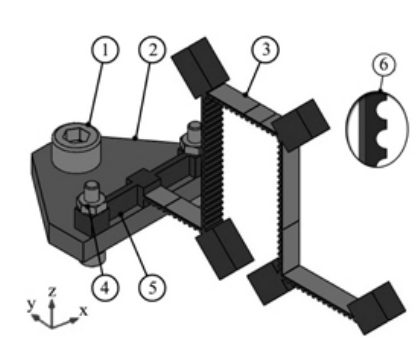

b)

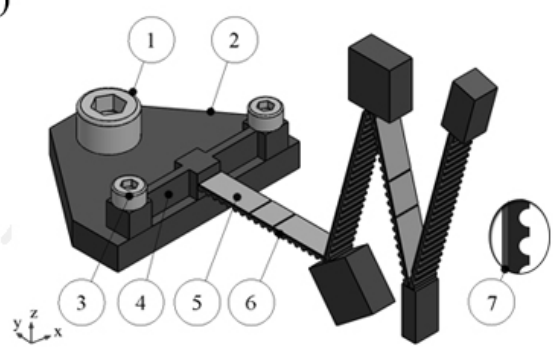

c)

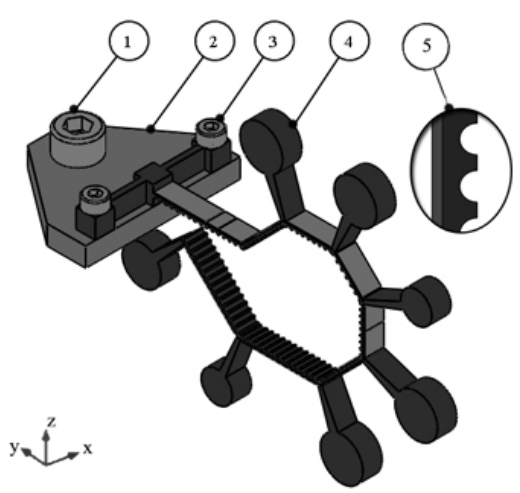

S.3.1 pav. Masyvų trimačiai vaizdai: a) stačiakampio formos masyvas; b) pjūklo formos masyvas;

c) daugiakampio formos masyvas 
Dažniausiai pjezoelektriniai masyvai sudaromi iš atskirų gembių sujungiant jas ị bendrą masyvą. Toks sudarymo principas suteikia galimybę sukurti pjezoelektrinę mechaninių vibracijų energijos surinkimo sistemą su keliais rezonansiniais dažniais. Kita vertus, tokia sistemos konfigūracija sąlygoja tik vienos masyvo gembės efektyvų veikimą esant konkrečiam žadinimo dažniui kol kitos gembès nesukuria pastebimos energijos.

Siekiant išspręsti, ankščiau minètą problemą, yra siūlomas susietų gembių taikymas daugiadažniuose masyvuose. Siūlomo sprendimo pagrindu buvo sudaryti trys pjezoelektrinių gembių masyvai pagrissti susietomis gembèmis. Masyvų trimačiai vaizdai yra pateikiami S.3.1 paveiksle.

Paveiksle S.3.1 pav. a) pavaizduotas stačiakampio formos masyvas kurị sudaro: 1 sistemos tvirtinimo varžtas; 2 - tvirtinimo plokšté; 3 - stačiakampio formos masyvas; 4 masyvo tvirtinimo varžtas; 5 - tvirtinimo gembès.

Paveiksle S.3.1 pav. b) pavaizduotas pjūklo formos masyvas kurị sudaro: 1 - sistemos tvirtinimo varžtas; 2 - tvirtinimo plokšté; 3 - masyvo tvirtinimo varžtas; 4 - tvirtinimo gembès; 5 - pjezoelektrinès keramikos sluoksnis; 6 - pjūklo formos masyvas; 7 gembių skerspjūvis.

Paveiksle S.3.1 pav. c) pavaizduotas daugiakampio formos masyvas kurị sudaro: 1 sistemos tvirtinimo varžtas; 2 - tvirtinimo plokštė; 3 - masyvo tvirtinimo varžtas; 4 daugiakampio formos masyvas; 5 - gembių skerspjūvis.

Žadinant masyvus sugeneruojamas išilginis bazès poslinkis, siekiant sumažinti viso masyvo slopinimą tvirtinimo gembės operuoja kaip vieno laisvès laipsnio sistema, ko pasèkoje sumažinamas visos sistemos slopinimas. Taip pat, sumažintas masyvo slopinimas užtikrina papildomas deformacijų modas kurios gali būti išnaudojamos mechaniniu vibracijų energijos surinkimui.

Skaitiniai masyvų tyrimai buvo atlikti modelius sudarant Comsol 5,2 programine ịranga. Skaitinių tyrimų tikslas nustatyti masyvų elektrines ir mechanines charakteristikas.

Dažninis gembių masyvų tyrimas buvo atliktas siekiant nustatyti lenkimo deformacijas ir jų pasiskirstymą gembèse bei gembių elektrines charakteristikas. Be to, remiantis lenkimo deformacijų pasiskirstymo charakteristikomis, atliekamas pjezoelektrinių sluoksnių dalijimas gembių masyvuose.

Analizuojant lenkimo deformacijų pasiskirstymą gembių masyvuose buvo pastebėta, kad lenkimo deformaciju pasiskirstymas visose gembèse yra beveik tolygus. Toks lenkimo deformacijų pasiskirstymas pasiektas dèka gembių skerspjūvio modifikacijų cilindrinèmis išpjovomis, modalinių deformacijų sumavimo ir masyvuose taikytų seisminių masių. Seisminès masès užtikrino papildomą sukimo momentą gembių masyvuose, dèl sukurtų papildomų pečių ir dèl nevienodo seisminių masių sukurto disbalanso. Taip pat galime pastebèti, kad lenkimo deformacijų reikšmès žemuose rezonansiniuose dažniuose yra aukštesnès lyginant su aukštais dažniais.

Pjezoelektrinių sluoksniu dalijimas pagrịstas deformacijų pasiskirstymu gembėse. Aukštesniuose dažniuose gembès operuoja antroje arba aukštesnèje lenkimo deformacijų modoje. Taigi, remiantis modalinių mazgų pozicijomis, pjezoelektriniai masyvų sluoksniai, buvo padalinti. Padalijimo tikslas išvengti skirtingų ženklų krūvių sumavimosi masyvams operuojant antroje arba aukštesnèje deformacijų modoje. 
Visų masyvų atviros grandines išęjimo ịtampos tankio ir išèjimo energijos tankio charakteristikų skaitiniai tyrimai atlikti taikant dažnini žadinimą. Žadinimo diapazonas kiekvienam masyvui buvo parenkamas remiantis modalinès analizès rezultatais.

Remiantis gautomis stačiakampio masyvo elektrinėmis charakteristikomis, buvo nustatyta, kad didžiausias atviros grandinès išejimo ịtampos tankis pasieké $19,85 \mathrm{mV} / \mathrm{mm}^{3}$. Tokia įtampos reikšmè gauta žemiausiame rezonansiniame dažnyje atskleidžia, kad energijos keitiklis užtikrins tinkamą įtampos lygị esant žemiems žadinimo dažniams. Kita vertus, įtampos tankiai aukštesniuose žadinimo dažniuose yra pastebimai žemesni, bet taip pat gali užtikrinti adekvatų išejimo ịtampos lygị.

Stačiakampio keitiklio išèjimo energijos tankio skaitiniai tyrimai atskleidè, kad aukščiausias energijos tankis taip pat pasiekiamas žemiausiuose dažniuose. Energijos tankio reikšmė pasiekė $26,4 \mathrm{~nJ} / \mathrm{mm}^{3}$. Tai įrodo, kad stačiakampis keitiklis generuos tinkamą energijos lygị esant žemiems žadinimo dažniams. Kita vertus, esant aukštesniems žadinimo dažniams keitiklis generuos pastebimai žemesnius energijos tankius, bet šių tankių reikšmès gali užtikrinti žemesnio lygio bet stabilų energijos tiekimą.

Pjūklo formos masyvo elektrinių charakteristikų skaitinis tyrimas patvirtino modalinès analizès rezultatus ir atskleidè kad visos nustatytos deformacijų modos tinkamos mechaninių vibracijų energijos surinkimui. Išejimo atviros grandinès ịtampos ir išẻjimo energijos tankiai gauti esant dažniams atitinkantiems modalinės analizės rezultatus. Maksimalus išèjimo atviros grandinès ịtampos tankis $48,39 \mathrm{mV} / \mathrm{mm}^{3}$ gautas esant penktam rezonansiniam dažniui. Antra aukščiausia reikšmė $26,91 \mathrm{mV} / \mathrm{mm}^{3}$ gauta esant pirmam rezonansiniam dažniui. Akivaizdus ịtampos tankių skirtumas tarp penkto ir pirmo rezonanso ịtakotas kelių gembių lenkimo deformacijų sumavimu penktame rezonanse.

Analizuojant energijos tankius buvo nustatyta kad didžiausia tankio reikšmè 61,25 $\mathrm{uJ} / \mathrm{mm}^{3}$ gauta esant sistemai penktame rezonanse. Tai patvirtina rezultatus gautus tiriant įtampos tankius ir ịrodo kad kelių gembių lenkimo deformacijų sumavimas gali užtikrinti geresnes sistemos elektrines charakteristikas.

Daugiakampio masyvo elektrinių charakteristikų, gautų skaitiniu metodu, analizè atskleidè kad aukščiausias atviros grandinès išèjimo įtampos tankis $50,03 \mathrm{mV} / \mathrm{mm}^{3}$ gautas esant antram rezonansiniam dažniui, kol kitos reikšmės yra pastebimai žemesnès. Santykis tarp aukščiausios ir žemiausios reikšmės yra 6,78 karto. Tai atskleidžia kad esant antram rezonansiniam dažniui ịtampos tankis bus pastebimai aukštesnis lyginant su kitais dažniais. Kita vertus, esant kitiems žadinimo dažniams ịtampos tankiai bus žemesnis bet stabilūs.

Daugiakampio energijos tankių charakteristikų analizè atskleide, kad energijos keitiklis sugeneruoja priimtinus energijos tankius esant skirtingiems žadinimo dažniams. Aukščiausią energijos tankị $604 \mu \mathrm{J} / \mathrm{mm}^{3}$ keitiklis pasiekia esant antram rezonansui. Taip pat, galime pastebèti kad keitiklis sugeneruoja $481 \mu \mathrm{J} / \mathrm{mm}^{3}$ energijos tankị esant pirmam rezonansui. Tai įrodo, kad daugiakampis masyvas aukštus energijos tankius esant žemiems žadinimo dažniams. Kita vertus, esant aukštesniems žadinimo dažniams keitiklis sugeneruoja žemesnius bet stabilius energijos tankius.

Gembių masyvų eksperimentiniai, mechaninių ir elektrinių charakteristikų, tyrimai buvo atlikti siekiant patvirtinti rezultatus gautus atliekant skaitinius skaičiavimus. Šiam tikslui pasiekti buvo pagaminti gembių masyvų prototipai kurių geometriniai ir fizikiniai parametrai atitiko taikytus skaitiniuose modeliuose. 
Pirmiausiai atlikti gembių masyvų dažninių charakteristikų matavimai. Matavimų tikslas nustatyti rezonansinių dažnių atitikimą skaitiniams rezultatams. Šiam tikslui pasiekti buvo taikomas Polytec OFV 056 skanuojantis vibrometras. Matavimų rezultatai ir rezultatų palyginimai pateikiami žemiau šiame skyriuje.

Atlikus dažninès stačiakampio gembių masyvo charakteristikos analizę galima teigti, kad eksperimentinių ir skaitinių tyrimų rezultatai sutampa. Didžiausias skirtumas tarp rezonansų pasiekia 22,6 Hz. Taigi, prototipas tinkamas tolimesniems eksperimentiniams tyrimams. Taip pat buvo atliktas visų rezonansinių dažnių palyginimas. Atliktas visų rezonansinių dažnių palyginimas atskleide, kad prototipo rezonansiniai dažniai yra žemesni lyginant su skaitiniu modeliu. Skirtumai tarp rezonansinių dažnių iškyla dèl nedidelių neatitikimų medžiagų savybėse, gamybos netikslumo, supaprastinto modelio ir neatitikimo masyvo tvirtinime.

Atlikus pjūklo formos masyvo dažninès charakteristikos analizę buvo pastebėta, kad sistema turi penkis rezonansinius dažnius dažnių juostoje nuo $20 \mathrm{~Hz}$ iki $135 \mathrm{~Hz}$. Taip pat, buvo nustatyta kad išmatuotos rezonansinių dažnių reikšmės yra adekvačiai artimos gautoms atliekant skaitinius tyrimus.

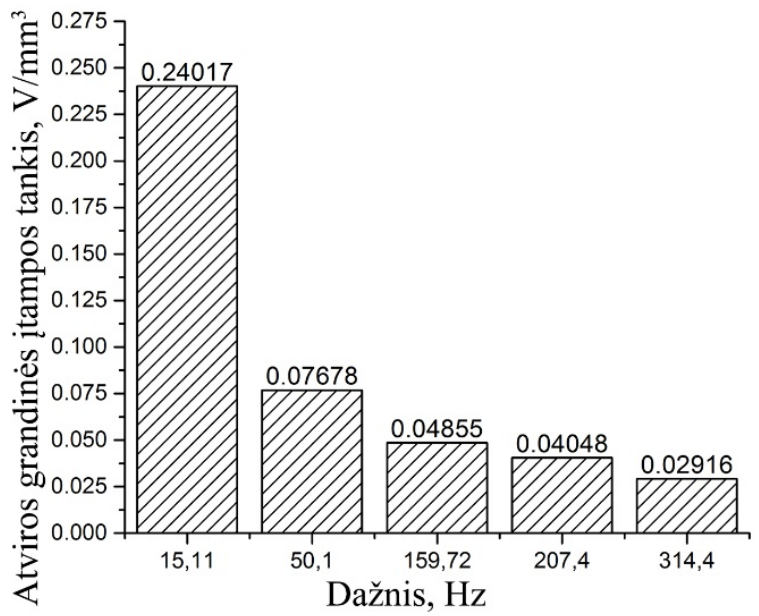

S.3.2 pav. Stačiakampio formos gembių masyvo įtampų tankių suvestinė

Atlikus rezonansinių dažnių palyginimą buvo pastebèta kad didžiausias skirtumas siekia 19,69\%. Šis skirtumas gautas lyginant trečiųų rezonansų reikšmes ir pasiekia $18,456 \mathrm{~Hz}$ reikšmę. Kaip ir stačiakampio formos gembių masyvų tyrimuose, skirtumai gauti dèl gamybos netikslumo, tvirtinimo ir medžiagų neatitikimo. Taigi, remiantis atliktu palyginimu galime teigti kad prototipas yra tinkamas tolimesniems tyrimams.

Taip pat, buvo atliktas daugiakampio gembių masyvo dažninės charakteristikos eksperimentinis tyrimas. Tyrimo tikslas, taip pat, patvirtinti rezonansų reikšmes gautas atliekant skaitinius daugiakampio masyvo tyrimus

Gautų rezultatų analizė atskleidè kad daugiakampio formos gembių masyvas turi penkis rezonansinius dažnius pasiskirsčiusius dažnių juostoje nuo $10 \mathrm{~Hz}$ iki $240 \mathrm{~Hz}$. 
Atlikus skaitinių ir eksperimentinių rezultatų palyginimą buvo nustatyta kad skirtumai tarp rezonansinių dažnių gautų atliekant skaitinius tyrimus ir eksperimentiškai nustatytų neviršija 5,02\%. Taigi galime teigti kad prototipas tinkamas tolimesniems eksperimentiniams tyrimams.

Taigi, atlikti stačiakampio formos gembių masyvo elektrinių charakteristikų tyrimai atskleide kad didžiausią ịtampos tankị sistema generuoja esant pirmam rezonansui. Ittampos tankio reikšmé pasiekia $0,24017 \mathrm{~V} / \mathrm{mm}^{3}$.

Remiantis gautais galime teigti kad energijos keitiklis generuoja aukščiausią įtampos tankį esant žemiausiam rezonansiniam dažniui. Aukštesniuose rezonansiniuose dažniuose išèjimo įtampos tankiai pastebimai žemesni. Kita vertus, tokios išèjimo įtampos charakteristikos atskleidžia kad energijos keitiklis generuos aukštą ịtampos reikšmę esant žemam žadinimo dažniui, o didejjant generuos žemesnę bet stabilią įtampos reikšmę.

Taip pat buvo atliktas, stačiakampio formos gembių masyvo išejjimo visos sistemos energijos tankio eksperimentinis tyrimas. Gautų rezultatų suvestinė pateikiama S.3.3 paveiksle.

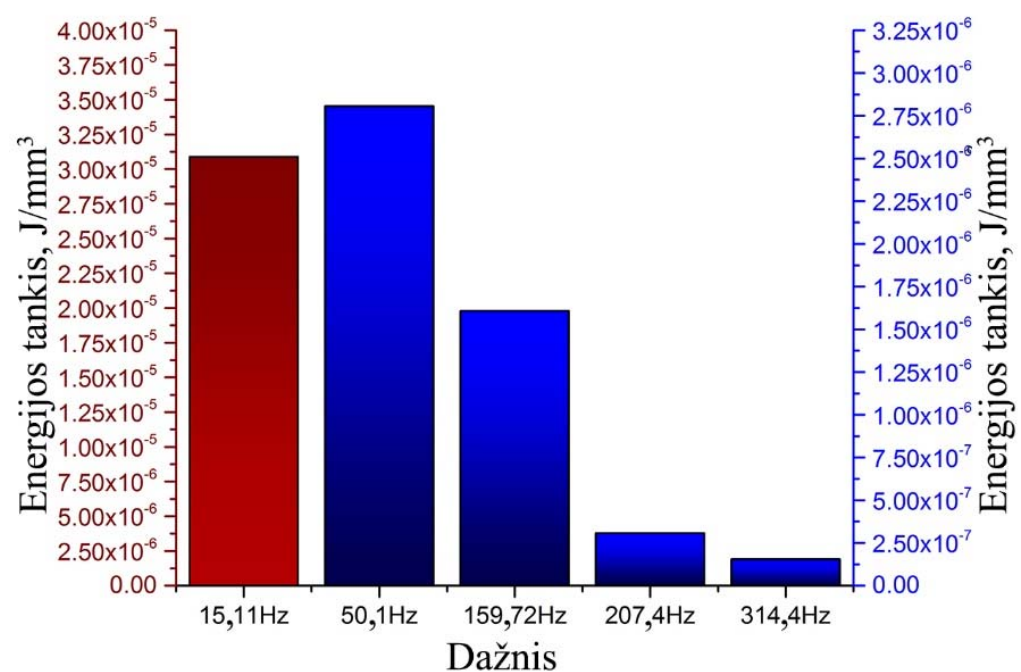

S.3.3 pav. Stačiakampio formos masyvo energijos tankių suvestinė

Analizuojant energijos tankių suvestinę galime pastebėti kad didžiausias energijos tankis pasiekiamas sistemai esant pirmame rezonanse. Energijos tankio reikšmė pasiekia $32,16 \mu \mathrm{J} / \mathrm{mm}^{3}$. Kaip galime pastebėti, stačiakampio formos energijos keitiklis aukščiausią energijos tankị pasiekia pirmame rezonansiniame dažnyje. Kita vertus, aukštesniuose dažniuose bendras energijos tankis pastebimai žemesnis ir tolygiai žemėja kylant žadinimo dažniui. 


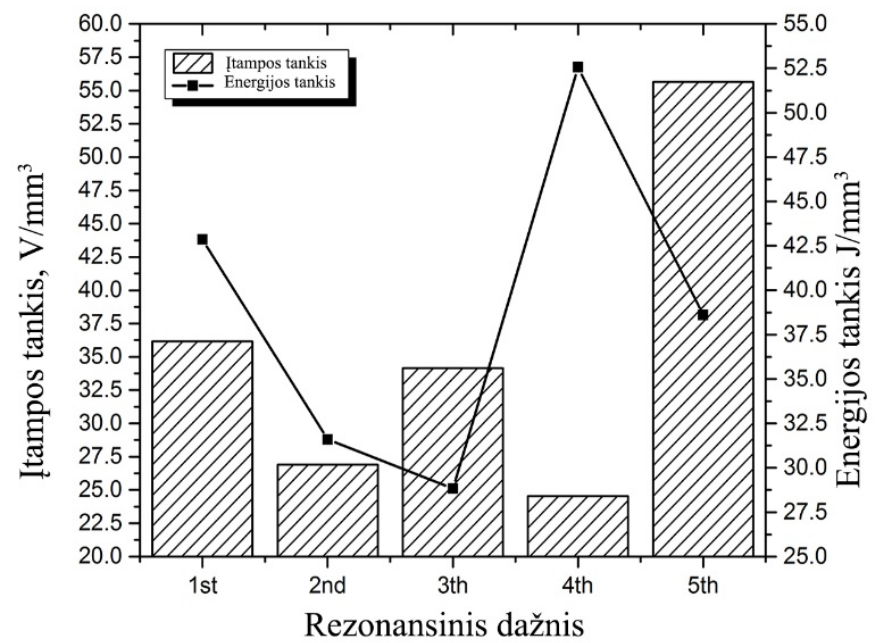

S.3.4 pav. Pjūklo formos gembių masyvo elektrinių charakteristikų suvestinè

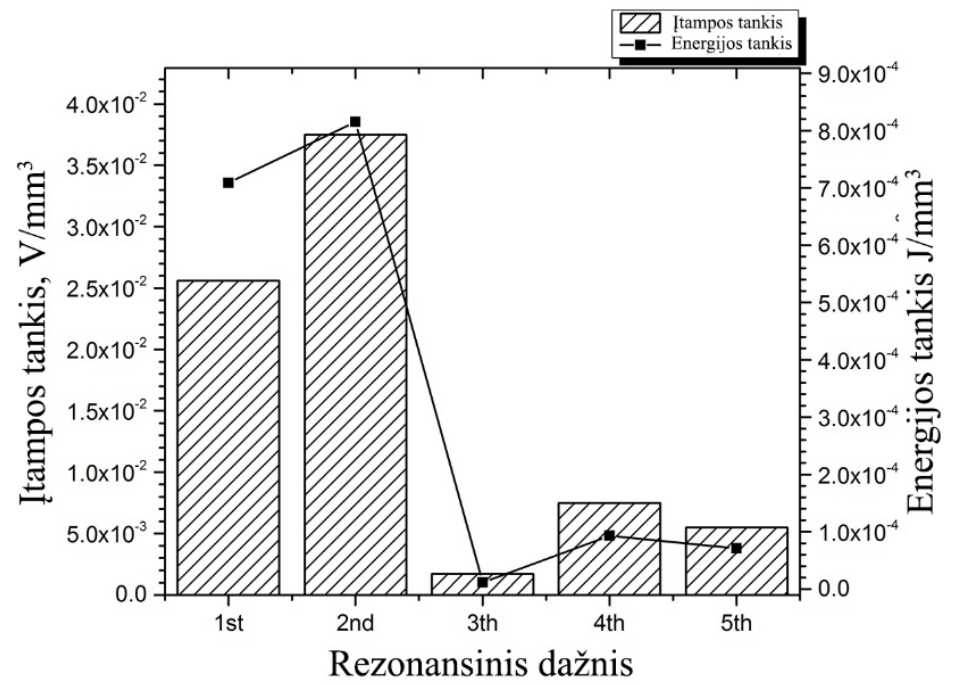

S.3.5 pav. Daugiakampio formos gembių masyvo elektrinių charakteristikų suvestinè.

Atlikti pjūklo formos gembių masyvo elektrinių charakteristikų eksperimentiniai tyrimai atskleide, kad maksimalus energijos tankis $55,65 \mathrm{mV} / \mathrm{mm}^{3}$ pasiektas energijos keitikliui esant penktame rezonansiniame dažnyje, o maksimalus energijos tankis $52,56 \mu \mathrm{J} / \mathrm{mm}^{3}$ pasiektas esant energijos keitikliui ketvirtame rezonansiniame dažnyje. Neatitikimas tarp rezonansinių dažnių ir maksimalių reikšmių buvo įtakotas lygiagrečiai visai 
sistemai pajungtos talpinès apkrovos. Bendra, energijos keitiklio elektrinių charakteristikų gautu eksperimentiškai, suvestinè pateikiama S.3.4 paveiksle.

Remiantis daugiakampio gembių masyvo elektrinių charakteristikų eksperimentiniais tyrimais galime teigti, kad maksimalus ittampos tankis buvo pasiektas esant sistemai antrame rezonanse. Itampos tankis pasiekè $37,5 \mathrm{mV} / \mathrm{mm}^{3}$. Maksimalus energijos tankis taip pat pasiekė aukščiausią reikšmè keitikliui esant antrame rezonansiniame dažnyje. Energijos tankis pasiekè $815,16 \mu \mathrm{J} / \mathrm{mm}^{3}$. Taigi, remiantis šiais rezultatais galime teigti, energijos keitiklis gali suteikti tinkamą energijos kieki operuodamas daugiadažniame režime. Taigi, remiantis atliktų skaitinių eksperimentų rezultatais, galime teigti kad standžiai sujungtų gembių taikymas daugiadažniuose masyvuose užtikrina modalinių deformacijų sumavimą ir ko pasėkoje pagerina gembinių masyvų elektrini potencialą. Taip pat, buvo nustatyta kad masyvuose pagrịstuose standžiai sujungtomis gembėmis dominuojančios deformacijų modos yra pirma ir antra. Taigi, daugiadažniai gembių masyvai gali veikti pirmoje arba antroje deformacijų modoje bei šių modų junginiuose. Eksperimentiniai daugiadažnių keitiklių tyrimai atskleidẻ kad standžiai sujungtų gembių taikymas masyvuose užtikrina didesnị sistemos potencialo išnaudojimą esant skirtingiems žadinimo dažniams.

\section{Bendrosios išvados}

1. Mechaninių vibracijų energijos surinkimo technologijų analizė atskleidé, kad pjezoelektriniai energijos keitikliai pasižymi aukščiausiu galios ir energijos tankiais. Kita vertus, lenkimo deformacijų pasiskirstymas išilgai pjezoelektrinès gembès turi būti tyrinèjamas plačiau. Taip pat, daugiadažniai energijos keitikliai pagrịsti gembių masyvais gali būti ịvardijami kaip mažos galios įtaisai. Taigi, naujo tipo daugiadažnių sistemų konstrukcijos turi būti vystomos.

2. Vienpusio netaisyklingos formos skerspjūvio taikymas stačiakampèse pjezoelektrinèse gembèse užtikrina iki 4,8 karto didesnes lenkimo deformacijas ir iki $90 \%$ didesni galios tankị. Be to, lenkimo deformacijos trapecinèse gembėse padidèja iki 2,7 karto, o galios tankis iki 3,14 karto taikant dvipusi netaisyklingos formos skerspjūvị. Taip pat, buvo nustatyta, kad cilindrinių ir trapecinių išpjovų taikymas gembių skerspjūvio modifikacijoms užtikrina didžiausias lenkimo deformacijas.

3. Skerspjūvių modifikacijos išpjovomis ittakoja papildomas deformacijas kurios kinta priklausomai nuo išpjovų formos ir pasiskirstymo. Vienpusis ir dvipusis skerspjūvio modifikavimas užtikrina beveik tolygų lenkimo deformacijų pasiskirstymą išilgai gembès.

4. Naujo tipo gembių masyvų paremtų susietomis gembemis tyrimai atskleidè, kad kintant žadinimo dažniui lenkimo deformacijos yra sukuriamos visose masyvo gembėse. Taip pat, buvo atskleista kad šio tipo gembių masyvuose lenkimo deformacijų pasiskirstymas gembėse yra beveik tolygus. Taigi, beveik tolygus lenkimo deformacijų pasiskirstymas gembėse užtikrina didesnius išèjimo energijos ir galios tankius. 



\section{Annexes $^{2}$}

Annex A. The author's declaration of conscientiousness

Annex B. Agreements of co-authors to provide published materials in the dissertation

Annex C. Copies of scientific publications published by the author on the topic of the dissertation

${ }^{2}$ The annexes are supplied in the enclosed compact disc 


\section{Andrius ČEPONIS}

RESEARCH OF PIEZOELECTRIC ENERGY

HARVESTING SYSTEMS BASED ON CANTILEVERS

WITH IRREGULAR CROSS-SECTIONS

Doctoral Dissertation

Technological Sciences,

Mechanical Engineering (09T)

Andrius ČEPONIS

GEMBINIŲ PJEZOELEKTRINIŲ ENERGIJOS SURINKIMO

SISTEMŲ SU NETAISYKLINGAIS SKERSPJÜVIAIS TYRIMAS

Daktaro disertacija

Technologijos mokslai, Mechanikos inžinerija (09T)

201810 12. 15,0 sp. I. Tiražas 20 egz.

Vilniaus Gedimino technikos universiteto

leidykla „Technika“,

Saulètekio al. 11, 10223 Vilnius,

http://leidykla.vgtu.lt

Spausdino UAB „BMK leidykla“,

A. Mickevičiaus g. 5, LT-08119 Vilnius 